SLRVIÇO DE PÓS-GRADUAÇÃO DO ICMC-USP

Data de Depósito: 15 de Janeiro de 2004

Assinatura $\mathcal{L}+\mathrm{n}$ lar

\title{
Recuperação de informação por similaridade utilizando técnicas inteligentes'
}

\author{
Ernesto Cuadros Vargas
}

Orientador: Profa. Dra. Roseli Aparecida Francelin Romero

Tese apresentada ao Instituto de Ciências Matemáticas e de Computação ICMC/USP - como parte dos requisitos necessários para a obtenção do título de Doutor em Ciências -... Ciências da Computação e Matemática Computacional.

\section{USP - São Carlos \\ Janeiro/ 2004}

\footnotetext{
${ }^{I}$ Trabalho realizado com anxílio financeivo da FAPESP 99/11835-7.
} 


\section{A Comissão Julgadora:}

Profa. Dra. Roseli Aparecida Francelin Romero

Prof. Dr. André Carlos Ponce de L. F. de Carvalho

Profa. Dra. Agma Juci Machado Traina
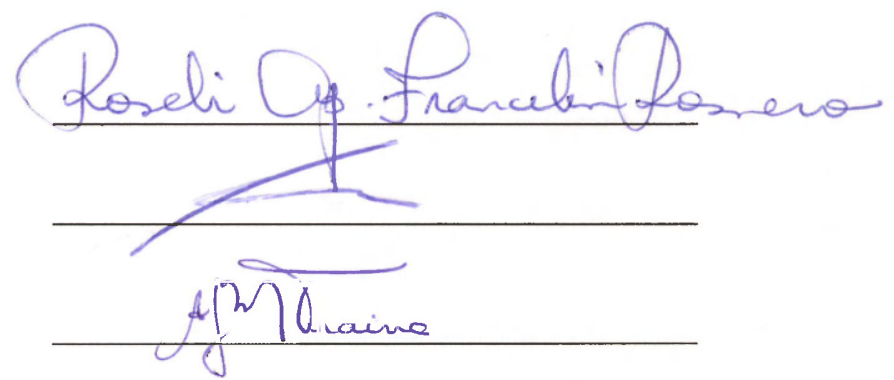

Prof. Dr. Fernando José Von Zuben

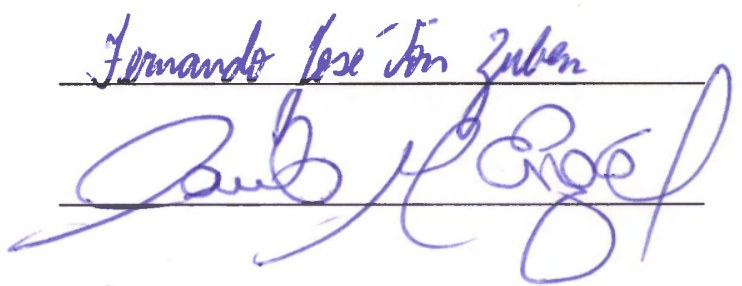

Prof. Dr. Paulo Martins Engel 
A Giovanna, minha esposa e Ana Flávia, minhlá filha, com anor admiração o gratidão por sua compreensão, carinho, presença e incansável apoio ao longo período de claboração doste trabalho. 


\section{Agradecimentos}

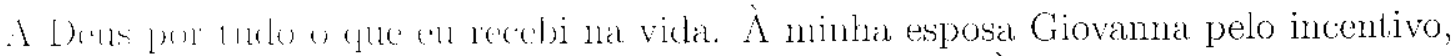
apoio compreensa nos períodos que estive fora do país. À minha orientadora Profa. Dra. Roseli Aparecida Francelin Romero que esteve sempre presente e atenciosa. Amradeço-lhe a paciencial. o apoio e os múltiplos conselhos recebidos ao longo desses gluatro anom de trat)allow.

A FAPJ'SP pela contiança depositada neste trabalho e pela atenção dispensada ('m toclas as oportmidades que os consultei por diversas dúvidas.

Aos men pais. Julio Ernesto e Yolanda. pela educação, amor e carinho, apesar de marem muito longe. Aos mens irmãos Alex Jesús c Chepi pelo incentivo, pelo exemplo cor estarem sempre do men lado.

Ao Prol'. Dr. ('hristos Faloutsos, meu supervisor durante o programa de estágio na Cumegte Mellon lmmersity. com quem aprendi muitas coisas que contribuíram para a minha formaca acalemica è minta vida.

Ao Prof. Dr. Klans Obermayer. meu supervisor durante o estágio na Technischen Untersilü Bethe pela ajuda dispensada nesse período.

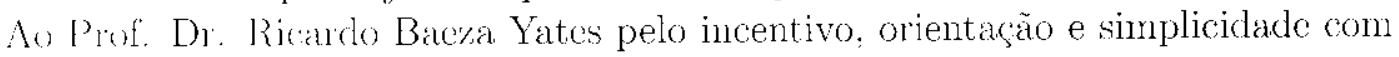
a cual sompre atendeu às minhas dúvidas.

Ao Bruce a Gail Camplell que me recoberam na sua casa em Pitusburgh sem ne conherer. Conhecer o conviver com eles foi a melhor parte da minha experiência $120 \% 1 \% 1$.

Aos docentes do ICMC especialmente aos Profs. Drs. Agma Traina, Caetano Trailia. Cristina Ferreira, Edson dos Santos Moreira, Rosane Minghirn, Custavo Vonato. Andre de Gurvalho. Zhao Liang, com os quais aprendi muitas coisas úteis

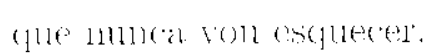

Aos meus amigos do ICMC, TU-Berlin, o peruanos Alex, Jorge Félix (Yorch), Milıska Félix, Adenilso, Tatiana, Luciana, Cabelinha (Andrea), Rudinei, Waldo, Cosar (titi). Fduardo Tejada, Eduardo Llapa, Patricia, Guillemo (Web), Percy, (O)irer Burk. Banbang. IIendrik Purwins, Anca Dinna, Susanne Schönknecht, Sepp Ilocherter "Raul Antríne de Mayolo pelo aprendizado nos países que visitei, pela amizade a chance do ter compartilhado um ponco da minha vida com oles.

Aon mens colcgas P’an ricia Rufino, Tatiana Sugeta, Rudinci Coulart, Adenilso da Silva Sintion "Janquetink Bigladori pelas dicas para melhorar a redação do texto.

Ao pessoal de seguranga do ICMC que me ajudaram naquele 31 de dezembro em que cheguei em São Carlos sem conhecer nem falar quase nada de português. 


\section{Sumário}

Lista de Abreviaturas

XVII

Resumo

XIX

Abstract

XXI

1 Introdução 1

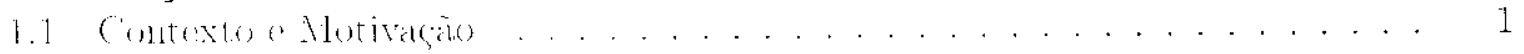

1.2 Definiçio do problena . . . . . . . . . . . . . . . . . 2

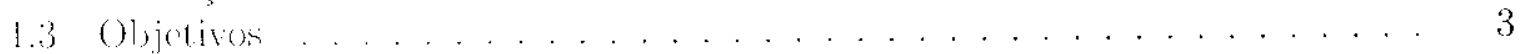

$1 . t$ Organizacio do Trabalho e Esclarecimentos ............. 4

2 Redes Neurais Auto-Organizáveis 5

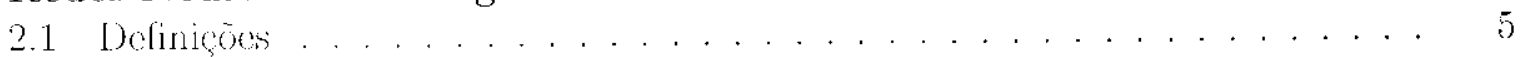

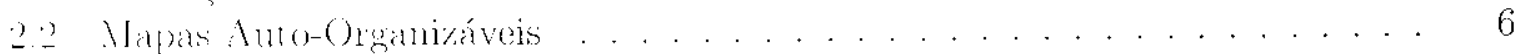

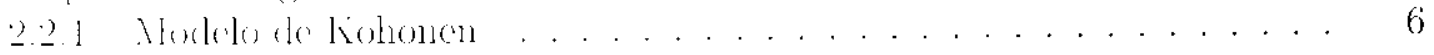

2.3 Mapas Auto-Organizáveis Construtivos . . . . . . . . . . . . . 9

2.3 .1 Aprendirado Hebbiano Competitivo . . . . . . . . . . . . . 10

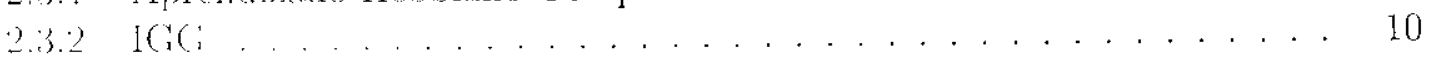

2.3 .3 virat Gas con CHI . . . . . . . . . . . . 10

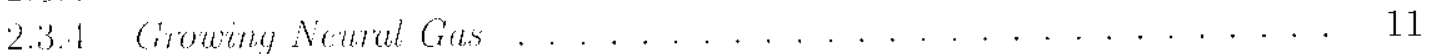

2.3 .5 GCS . . . . . . . . . . . . . . . . . 14

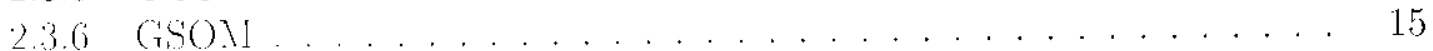

2.3 .7 . Napal Alto-Organizáveis Esféricos . . . . . . . . . . . . . 16

2.4 Majad Auto-Organizáveis Ilierárquicos . . . . . . . . . . . . . . . . . . 17

2.4.1 Mapa Ilierárquico . . . . . . . . . . . . . . . . . . . . . . . . 17

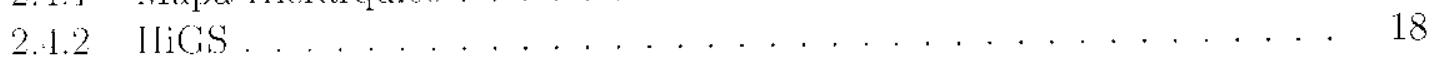

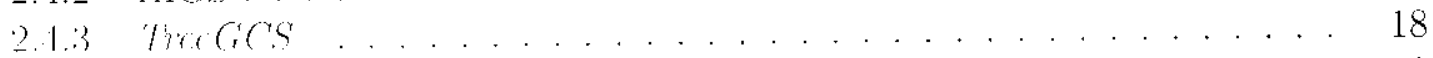

2.1 ( $\mathrm{HHSO}_{2} \ldots \ldots \ldots \ldots \ldots$

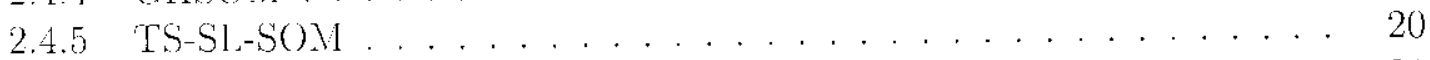

$21.6 \mathrm{AHIGC} \ldots \ldots \ldots \ldots . \ldots \ldots . \ldots \ldots 21$

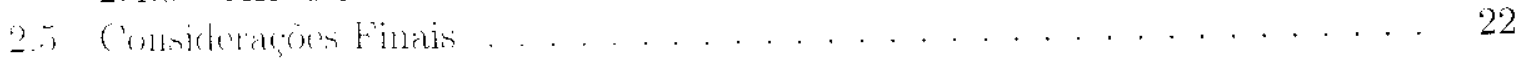


3.1 Definiçôes . . . . . . . . . . . . . . . . . . . . . . . . . . .

3.1 .1 Grafos e seus clementos . . . . . . . . . . . . . . . . . . . . . . . . .

3.1 .2 Árvores e seus dementos . . . . . . . . . . . . . . . . . . 26

3.1 .3 Espaço Mćtrico . . . . . . . . . . . . . . . . . . . . . . . . 27

3.1 .4 Espaço Vetorial . . . . . . . . . . . . . . . . . . . 2 .

3.2 Métodos de Acesso para Dados unidimensionais . . . . . . . . . . 30

3.3 Métodos de Acesso Espacial . . . . . . . . . . . . . . . . . . . . 32

3.3 .1 Mćtodos de Accsso para Dados Pontuais . . . . . . . . . . . . . 32

3.3 .2 Métodos de Indexação para Dados Não-Pontuais . . . . . . . . . . . 36

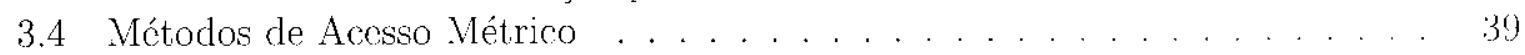

3.4 .1 Método Burkhard \& Keller . . . . . . . . . . . . . . . . . . . 39

3.4 .2 AESA . . . . . . . . . . . . . . . . . . . . . 41

3.4 .3 VPT . . . . . . . . . . . . . . . . . . . . 12

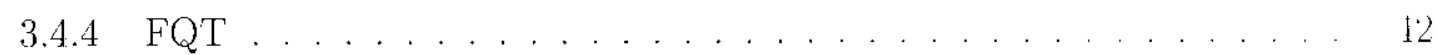

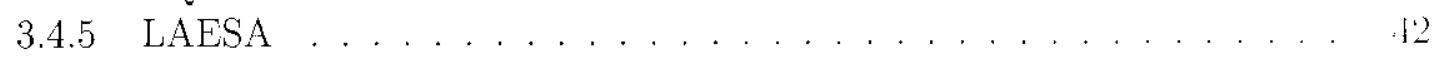

3.1 .6 FHQT . . . . . . . . . . . . . . . . . . . . . . . . 43

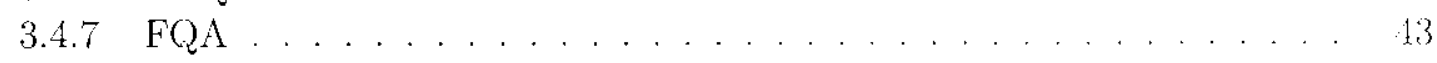

3.4 MVPT . . . . . . . . . . . . . . . . . . . . . . . 43

3.4 .9 VPF . . . . . . . . . . . . . . . . . . . . . . . 44

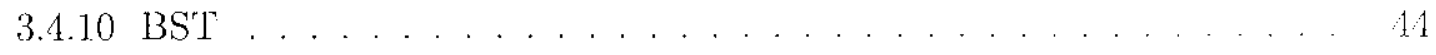

3.4 .11 GHT . . . . . . . . . . . . . . . . . . . . 11

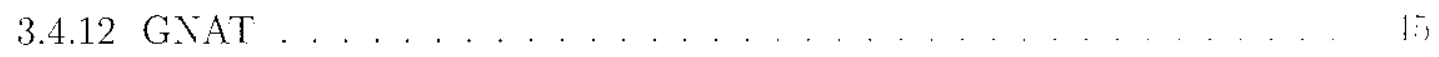

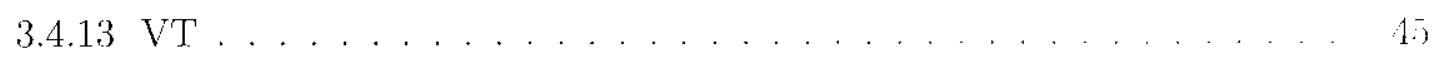

3.4 .14 M-Tree . . . . . . . . . . . . . . . . . . . . . 15

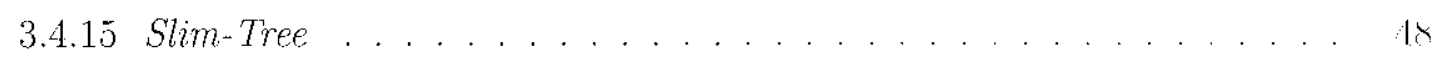

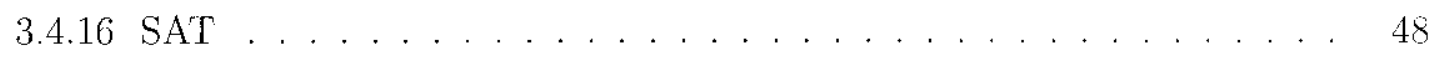

3.4 .17 A família OMNI . . . . . . . . . . . . . . . . . . . . 49

3.5 Considerações Finais . . . . . . . . . . . . . . . . . . . . . .

4 Potencial de RNA, MAE e MAM no processo de RIS 53

4.1 RNA na Recuperação de Informação . . . . . . . . . . . . . . . . . . .

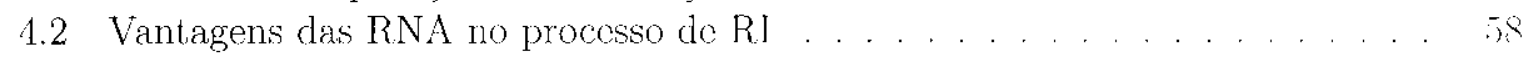

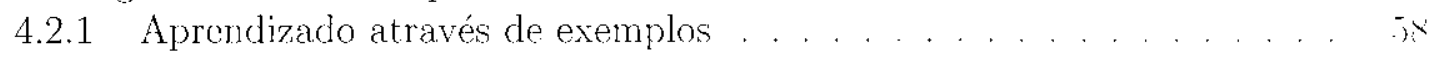

4.2 .2 Capacidade de generalização . . . . . . . . . . . . . . . 58

4.2 .3 Pouco espaço necessário para armazenar a estrutura. . . . . . . . . 59

4.2 .4 Capacidade de reduzir a dimensão dos dados . . . . . . . . . . . . . . 59

4.2 .5 Capacidade para detectar agrupamentos . . . . . . . . . . . . . . . . . . . . . .

4.2 .6 Capacidade para provisão do sćries tomporais . . . . . . . . . . is

4.3 Limitaçôes das RNA no processo de RI . . . . . . . . . . . . . . . (il)

4.3.1 Definição da quantidade de ciclos de treinamento . . . . . . . . (i)

4.3.2 Definição da arquitet.ura apropriada da redt . . . . . . . . . (ii)

4.3 .3 Reinicializaçào do treinamento . . . . . . . . . . . . . (i)

4.3 .4 Instabilidade . . . . . . . . . . . . . . . . . . . 6.2

4.3.5 Projetadas para trabalhar em menória principal . . . . . . . . 63

4.3.6 Falta de organizaçäo para responder consultas fo tijon ti-viriulum mais

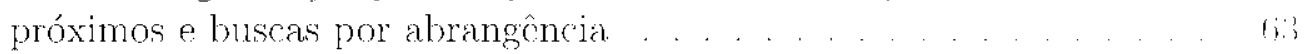




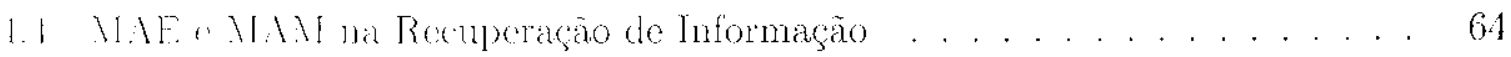

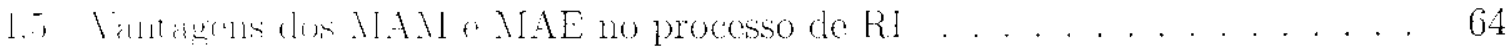

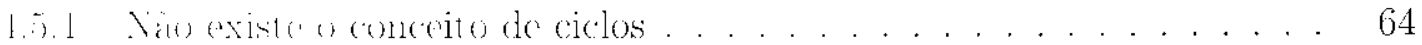

4.5.2 A incorporagà de un novo padrão pode ser realizada a qualquer montente . . . . . . . . . . . . . . . . 65 65

1.5.3 Existe nun pento na estrutura para cada pardrão . . . . . . . . 65

4.5 .4 Mniton deles foram projetados também para memória secundária. . . 65

1.;.; Mator facilitade para a execugâo de consultas do tipo $k$-vizinhos mais próxinus o buscas por abrangencia . . . . . . . . . . 66

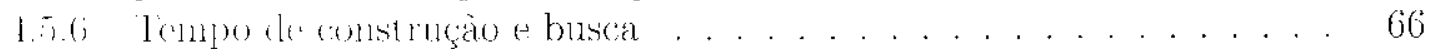

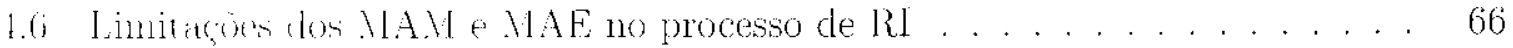

1.ti.1 Van almonden dos exemplos anteriores . . . . . . . . . . 60

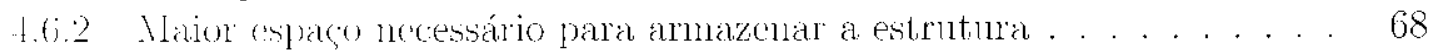

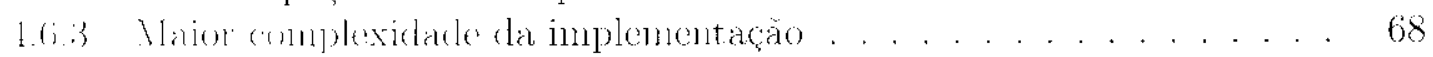

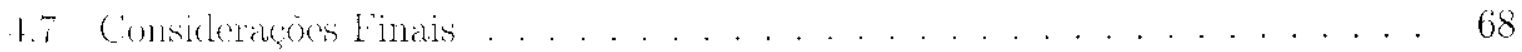

5 As técnicas SAM-SOM e MAM-SOM $\quad 71$

5.1 Análine du (nsto computacional do treinamento de redes do tipo SOM . . . 71

52 Incorporaça do WAF o MAM em SOM . . . . . . . . . 75

5 . Experinentos . . . . . . . . . . . . . . . . . . . . . 79

5.3 .1 Aplicando a técnica SAM-SOM híbrida . . . . . . . . . 80

5.3 .2 Aplicande an tónieas SAM-SOM* c MAM-SOM* . . . . . . . 85

5.1 Propriedades das técnicas SA.M-SOM o MAM-SOM . . . . . . . . . . 87

5.5 Consideragoes finais . . . . . . . . . . . . . . . . . . . . 89

6 Métodos de Acesso bascados no comportamento do usuário 91

(j.1 Análise do problenta . . . . . . . . . . . . . . . . . . . . . 91

6.2 Algunas soluçoes existentos . . . . . . . . . . . . . . . . . . 92

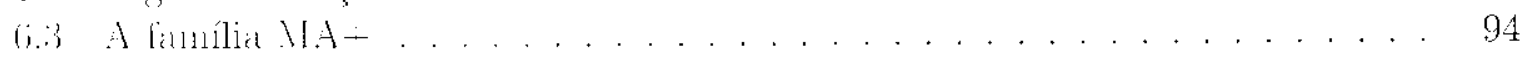

(j.t Inplenentacão do PMAM através de árvores $3^{*} \ldots \ldots \ldots \ldots . \ldots . \ldots 9$

6.5 Experimentos . . . . . . . . . . . . . . . . . . . . . . . . . . . . . . . . .

6.6 Propriedades da técnica proposta . . . . . . . . . . . . . . . . 99

6.7 Consideraçós Finais . . . . . . . . . . . . . . . . . . 101

7 Conclusões e Trabalhos Futuros 103

7.1 Principais Contribuiçoes . . . . . . . . . . . . . . . . . 105

i.2 Prepestas do Trabalhos Futurus . . . . . . . . . . . . . 106

$\begin{array}{ll}\text { Bibliografia } & 108\end{array}$ 


\section{Lista de Figuras}

2.1 Areputetmra Básica de um Mapa Auto-Organizávol.

2.2 Duas runtignaraces de mapa de Kohonen e de níveis de vizinhança do neurônio vencerlort.

2.3 Corrospondéncia cintre a distância física dos neurônios de una rede de Kohonen a grau de semelhança dos padróes por eles reconliecidos. . . . . . . . .

2.1 lsitade inicial de wna rede do tipo Growing Self-Organizing Maps (Alahakoon (1) al. 20000).

2.5 Estarto final de man rete do tipo GSOM (Alahakoon ot al, 2000) . . . . . 16

2.6 Recunstruca de objetos a partir de nuvens de pontos através de Spherical-Map Bomijenall a al. 2003). . . . . . . . . . . . . . . . . . 16

2.7 Arquiter ma dos Maparis Hierárquieos (Hierarchical Maps) (Koikkalainen e Oja,

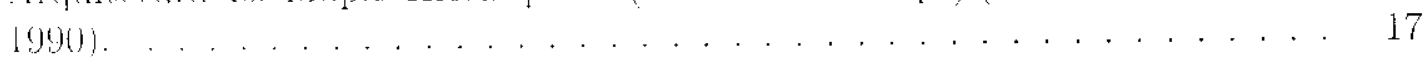

2. Henthical GCS (IIGS) (Burzevski e Mohan, 1996) . . . . . . . . . . 18

20 Divisato hiorárquica segundo o algoritmo Tree CCS (Hodge e Austin, 2001a). 19

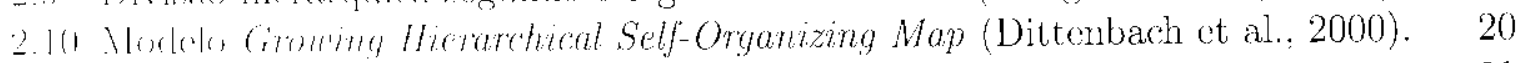

2.11 Tiec-Strutured Self-Labelled Self-Organizing Map. . . . . . . . . . 21

2.12 Arquitetura de uma rede $\mathrm{AHIGG}$ (Merkl et al., 2003). . . . . . . . . . . 22

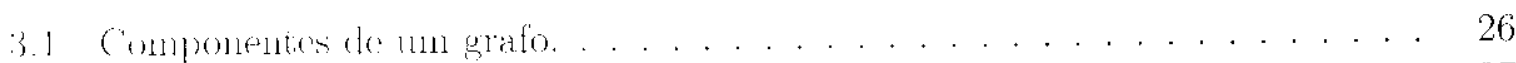

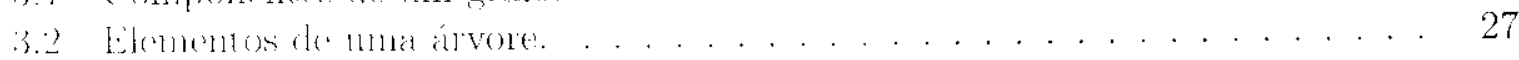

3.3 Representaçáo dos pontos situados à distância $r_{q}$ a partir do objeto $o_{q}$, con-

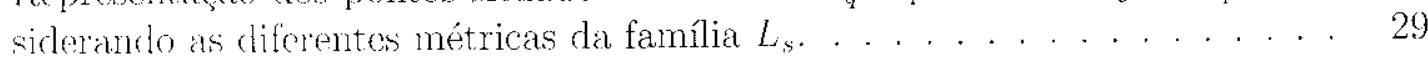

3. Crírio dr insercà ('n uma árvore binária simples. . . . . . . . . . . 30

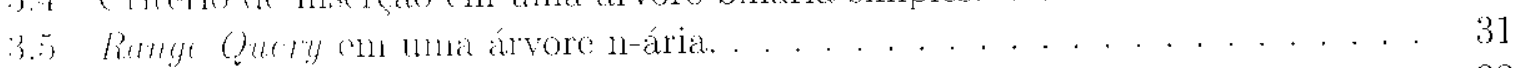

3.6 Divisano do espaco em quadrantes utilizando PointQuad-Tree. . . . . . . . . 33

3.7 Fstrutura de una árvore PointQuad-Tree. . . . . . . . . . . . 33

3.8 Fistrutura de una árvore $2-d$-Tree . . . . . . . . . . . . . 34

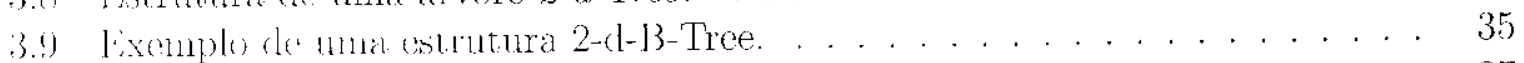

3.10 MBR representada por una árvore $R$-Tree. . . . . . . . . . . . 37

3.11 Representaçăo escuenática dos elementos armazonados em uma $R$-Tree, se-

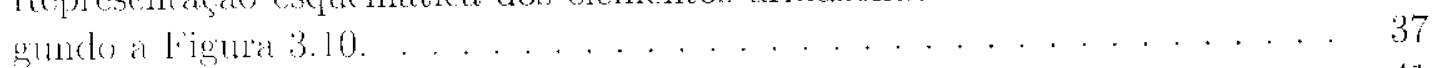

3.12 Propricalide da desigualdade triangular. . . . . . . . . . . . . . 41

3.13 Estrutura de una árvore $M$-'tree . . . . . . . . . . . . . 47 
3.14 Efcito da aplicação do processo de Slim-Doun. . . . . . . . . 48

3.15 Excmplo de um SAT construído considerando a5 como riziz . . . . . . . .

3.16 Proccsso de indexação de um novo objeto. . . . . . . . . . . . 19)

3.17 Utilização dos Foci para realizar consultas cm estruturas da Familia (OMNI. 50

3.18 Utilização das MBOR para recuperar informação em uma OmniRTree. . . 5]

4.1 Diagrama de Voronoi para uma distribuição arbitrária do poulos. . . . . . (i)

4.2 Efeito do treinamento em um SOM derivado do modelo de Kolionen. . . . . 62

5.1 Efcito da diminuição de $\lambda$ utilizando uma rede do tipo GNG. . . . . . . it

5.2 Consulta por abrangência em uma R-Tree. . . . . . . . . . . . T T

5.3 Áreas atingidas, no primciro nível da estrutura, pela consulta por alrangencia da Figura 5.2. . . . . . . . . . . . . . . . . . . 77

5.4 Áreas atingidas, no segundo nível da estrutura. pela consulta por abrangencia

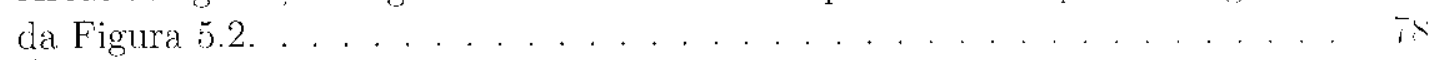

5.5 Áreas atingidas, no terceiro nível da estrutura, pola consulta por abrangen ia

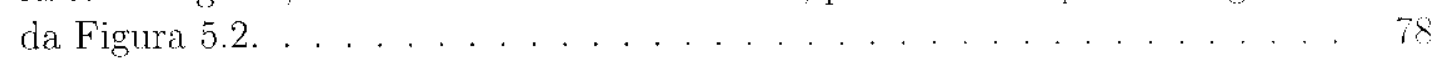

5.6 Número de cálculos de distância por ciclo em função do núnero de agrupamentos no treinamento on-line de $k$-Médias no conjunto de dadon $\triangle B A \mathrm{~L}$ ()NF. 81

5.7 Número de cálculos de distância por ciclo cm funçào do número de agrupamentos no treinamento cm lotes de $k$-Médias no conjunto de dados ABALONL. 81

5.8 Número de cálculos de distâucia por ciclo en funçăo do numeres (lo agrupa-

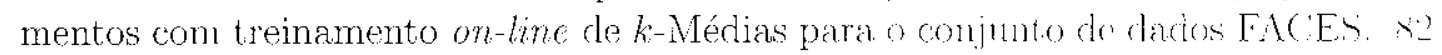

5.9 Número de cálculos de distância por ciclo em funçào do numoro de agrupamentos com treinamento em lotes de k-Médias para o conjunto do dados FACES. . . . . . . . . . . . . . . . . . . . . . . . . .

5.10 Número de cálculos de distância por ciclo em fumção do múmero de agrupamentos com treinamento on-line de k-Médias para o conjunto de dados LEITERS.

5.11 Número de cáleulos de distância por ciclo em funceño do número de agm pamentos com treinamento con lotes de k-Médias para o comjunto de dados LETTERS.

5.12 Número de cáleulos de distância em função do número de padrōes apresentados utilizando um SOM do dimensão $10 \times 10$ con treinamento on-line como conjunto de dados IMAGES. . . . . . . . . . . . . . . . . . . . .

5.13 Número de cálculos de distância para uma rede Grouning Neural Gas utilizando o conjunto de dados IMAGES. Os parametros utilizados para osta simmlaçán

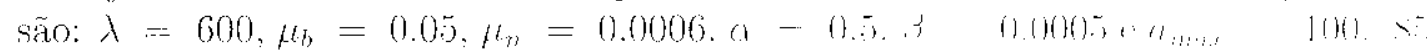

5.14 Redes GNG tradicionais tremadas com $\lambda=1 \ldots \ldots \ldots$. . . . . . . . .

5.15 Rode $R$-Tree $+C N G$ com 5000 padrocs $0 \phi=3 \ldots \ldots \ldots$. . . . . . . . .

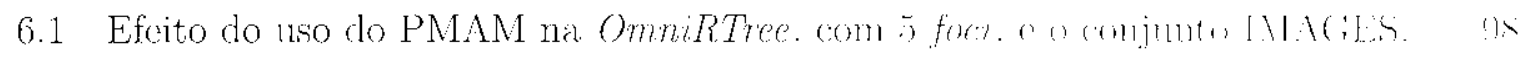

6.2 Efcito do uso do PMAM em OmniRTree. com 3-foct no anjunto forlish $(54-D)$.

6.3 Efeito do uso do PMAM com uma função de clistància com baixo custo computacional utilizando OmniRTree com 7-foct o o conjunto de dades I.F.T.

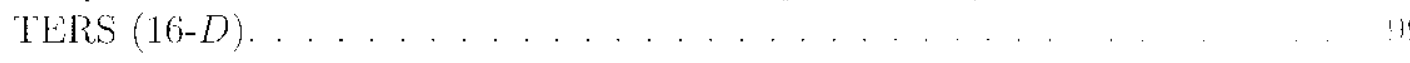




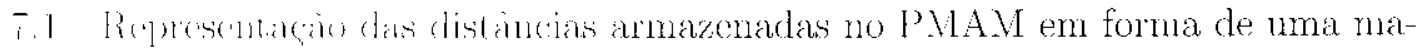

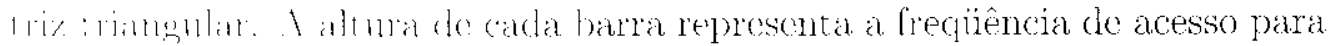
nunta distanciat . . . . . . . . . . . . . . . . . . . 107 


\section{Lista de Tabelas}

1.1 ('man onnputancionais de construção e busca en MAM. . . . . . . . . 67

5.1 Compararace (mu tormos de cálenlos de distância entre R-Tree+GNG e GNG

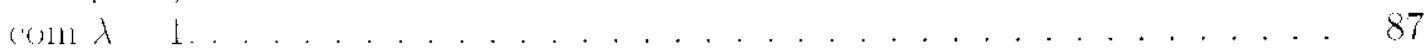




\section{Lista de Algoritmos}

2.1 Treinantento de man rede GNG . . . . . . . . . . . . . . . . . 12

5.1 lieinanente de $14 n$ SOM visto de uma forma geral. . . . . . . . . . 76

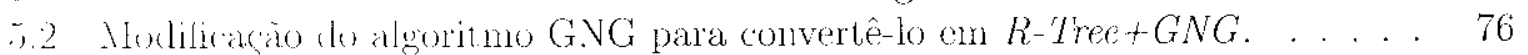

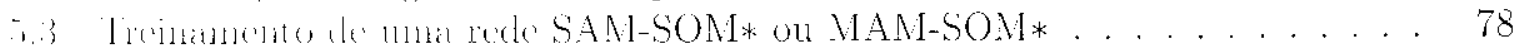

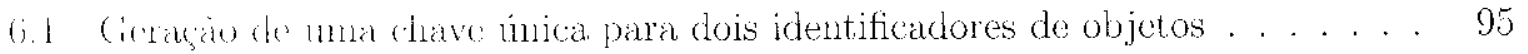

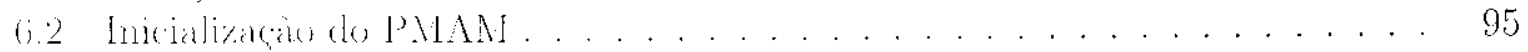

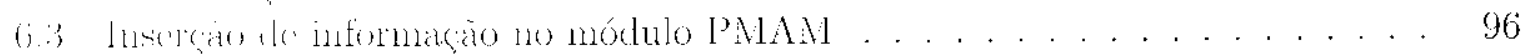

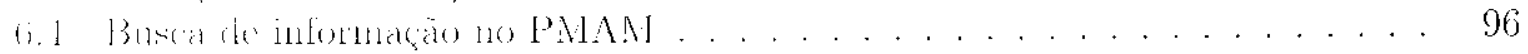

6.5 Utilizaga do P.MA.V durante uma consulta por similaridade . . . . . . 96 
IMiMD Indexação e Mineração de Dados Multimídia Indexing and Dala Mining in Multimedia Data Bases

LAESA Linear AESA

MA Método de Acesso

MAs Métodos de Acesso

MAE Métodos de Acesso Espacial Spatial Access Methods

MAENP Métodos de Acesso Espaciais Não-Pontuais

MAEP Mćtodos de Acesso Espaciais para Dados Pontuais

MAM Métodos de Acesso Métrico - Metric Access Methods

MBOR Minimum Bounding Omni Region

MBR Minimum Bounding Reclangle

MDS Multi-Dimensional Scaling

MLP Multi-Layer Perceptron

MST Minimal Spanning Tree

MVPT Multi-Vantage-Point Trees

NGCHL Neural Gas com Aprendizado Hebbiano Competitivo

PMAM Plug-in Module for Access Methods (P.MAM)

RI Recuperação de Informação (Information Retrieval)

RIS RIS Recuperação de Informação por Similaridade (Similarty Informatıon Retrieval)

RNA Redes Neurais Artificiais

SAM Spatial Access Methods

SAT Spatial Approximation Tree

SGBD Sistemas de Gerenciamento de Bases de Dados

SL-SOM Self-Labelled Self-Organizing Map

SOM Sclf-Organizing Maps

TMBR Telescopic Minimum Bounding Rectangle

TS-SL-SOM Tree-Structured Self-Labelled Self-Organizing Map

VPF Vantage-Point Forest - Excluded Middle Vantage-Point Forest

VPT Vantage-Point Tree

VT Voronoi Tree 


\section{Lista de Abreviaturas}

AESA Approximating Eliminating Search Algorithm

AHIGG Adaptive IIterarchical Incremental Grid Growing

ART Leoria da Ressonância Adaptativa Adaptive Resonance Theory

BKT Burkhard-Keller Tree

BST Bisector Trees

CHL Aprendizado Hebbiano Competitivo - Competilive IIebbian Learning

CSOM SOM Construtivos

DCSGCS Dynamic Cell Stuchures Growing Cell Structures

FHQT Fixd-IItight QT

FQA Fixed Queries Array

FQT Fixed-Queries Tress

GCS Growing Cell Structures

GHSOM Crowing Hierarchical Self-Organizing Map

GHT Generalized-Hyperplane Tree

GNAT Geometric Near-netghbor Access Tree

GNG Growing Neural Gras

GSOM Growing Self-Organizing Maps

GTM Generative Topographis: Mapping

HiGS Ilierarchical GCS

IGG Incremental Grid-Growing 


\section{Resumo}

A Recuperacĩo de Informacio por Similaridade (RIS) é um processo complexo que

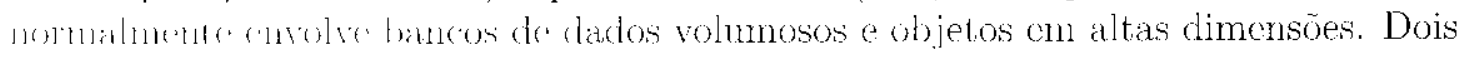

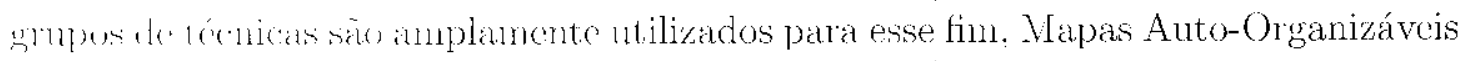
(S) X. Siff-()yamizing Maps) o Métodos de Acesso (MA).

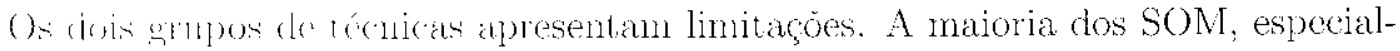

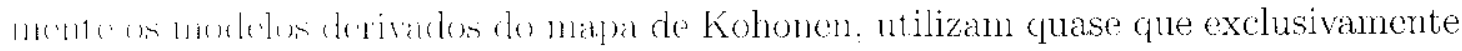
o processinnento seqüencial para encontrar a unidade vencedora. Por outro lado, tanto us Métodos de Acesso Espacial (MAE) quanto os Métodos de Acesso Métrico (MAM) não aproveitan o conhecimento gerado por consultas anteriores.

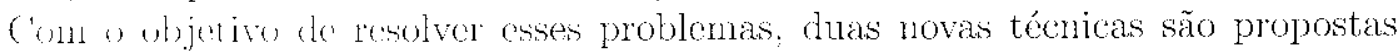

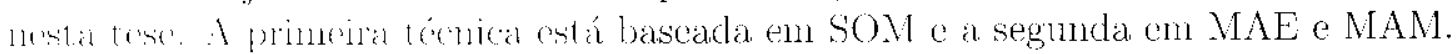

F.n prineire lugar. para melhorar o desempenho de sistemas bascados em SOM,

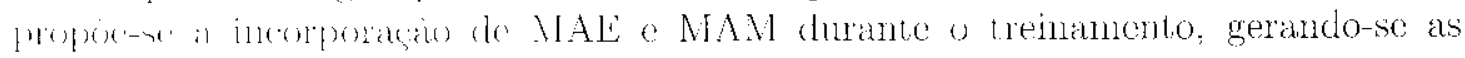

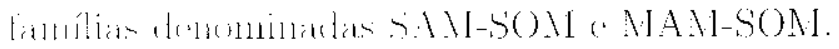

En segundo hngar: os MAE o MAM foran aprimorados através da criação do módulo denonninado P.MM, que é capaz de aproveitar o conhecimento gerado pelas consult as anteriores. A combinação do módulo PMAM com MAE e MAM deu origem iss fanilias $\mathrm{VAL}+\mathrm{MAN}+$, respectivamente.

Cono resultado deste tral)alho ressalta-se quo, tanto a família SAM-SOM quanto a MAM-SO M proporcionan uma nelhora considerável em relação aos modelos de

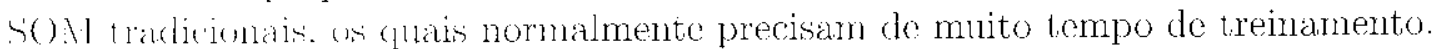

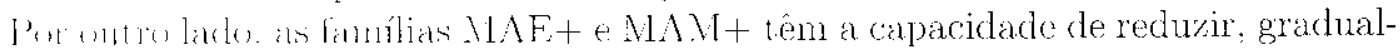
nente o numnoro de operaços necessárias para realizar uma consulta. Isto é possível porque o módulo P'NA.M permite reaproveitar o conhecimento gerado pelas consultas anderiores. 


\section{Abstract}

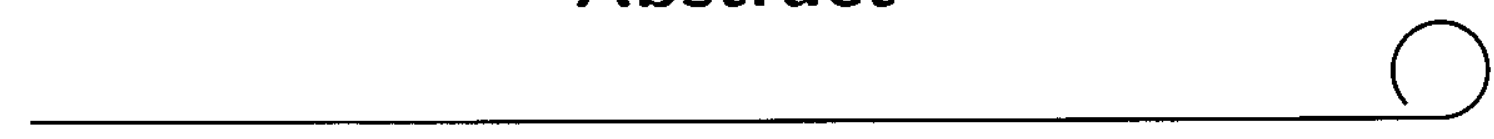

Sinilarity luformation Rotricval (SIR) is a complex process that usually involves large and complex Data Bases. Two groups of techniques are widely used for it, Self-Organizing Maps (SO.M) and -- Spatial Access Methods (SAM) and Metric Access Mombols (XIAM).

Hownere beth grongs of technicues present innortant drawbacks. Most of SOM make intensive use of segnential comparison to find winner units. On the other hand,

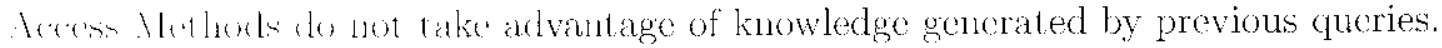

fis mele 16 (a) He. SIl process. Ithe first technique is based on SOM and the second one on SAM and MA.M.

Firstly SOM was used jointly with SAM and MAM in order to improve SOM based

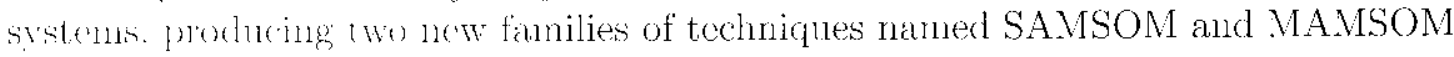
respertines

Serondly. SA. and MA.V themselves were improved by the creation of PMAM, a

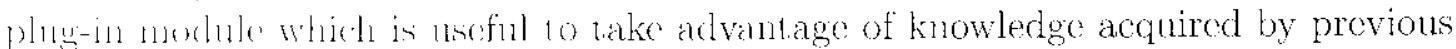

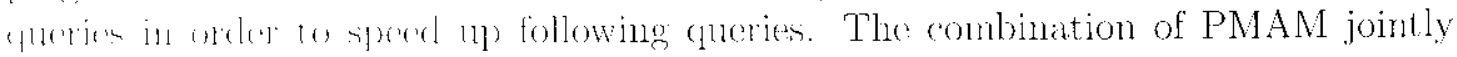
with S.M. and MA.M produced MAE+ and MAM+ familics of Access Methods.

As the main molt. SAM-SOM and MAM-SOM families ontperform considerably traditional SOMl based systents which normally need a long time for training.

Aditionally. MAF+ and MAM+ families are capable of reducing gradually tho nunber of operationis neded to answer a query, as new querics are introduced. This is possible because PMAM allows them to take advantage of knowledge generated by sulessive glacries. 



\subsection{Contexto e Motivação}

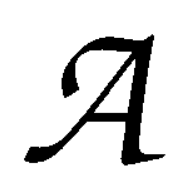

lgmes anow atrás os dados armazenados em um banco de dados envolviam apenas tipus sinn les laim como: números inteiros e de ponto flutuante, cadcias de caracters (strmys). etc. Hoje en dia, existe a necessidade de armazenar e recuperar informaçă crm dados mais complexos tais como seqüencias de DNA, vídeos, imagens, som, etc. Esses novos tipos de dados são estruturalmente mais complexos. Isso significa que podem estar compostos por dados de vários tipos, precisando de maior quantidade de menória e de equipanentos nais sofisticados para o processamento. As instâncias desses tipes de diulos siro conhecidas como objetos complexos.

Pode-so observar que há necessidade de melhorar as técnicas existentes para RIS (RIS) e

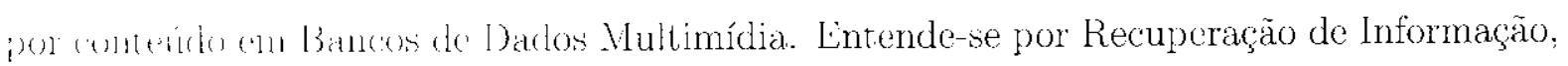
"ára cur estuda à manipulaçăo, representação, armazenamento, organização e acesso a iterss de informação (Baeza-Yates o Ribeiro-Neto, 1999).

Os Sistemas de Gerenciamento de Bases de Dados (SGBD) existentes são muito sofisti(akles. eficicnten e rápidos 110 processamento e recuperação de informação envolvendo dados de hipos simples (númeross strings, ctc), mas ainda apresentam muitas limitações quando o

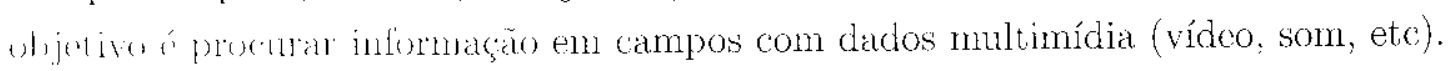

Ouando w dardes pertencenn a tipos simples, o tipo de consulta mais comum é conhecido como busca por coincidència exata (Exact Matching). Por exemplo: "recuperar o registro cujo código seja 20" ou "recuperar os alunos com idade entre 15 e 20 anos". Para resolver (esse tipe de consulta. os canpos envolvidos são previamente indexados através de estruturas Lais conno as árvores B (B-Trees) (Comer, 1979). A primeira consulta consiste em procurar, de forma direta na árvore. o valor 20 . No caso da segunda consulta, o valor que deve ser procurado a 15 a logo após, é iniciado um percurso seqüiencial até atingir o valor 20. Nesses casos, o tempo de recuperação de informação, $T$, está determinado pela Equação (1.1). 


$$
T=\text { tempo de } E / S+C P U \text { extra }
$$

onde o "tempo de E/S" representa o tempo gasto pelas opcrações de acesso a dispositivos de acesso secundário e o último fator representa outras operaçoes que a estrutula necessila internamente. Na grande maioria dos casos, o tempo de E/S a o fator que comrome mals tempo c, portanto, esse fator ć usado para calcular o custo computacional da cstrutura.

No caso de dados multimídia é mais útil tentar recuperar informaça similar. Por excmplo: "dada a foto de uma pessoa, recuperar as cinco pessoas mais parecidas com a foto fornecida como entrada". Este tipo de consulta não poderia ser respondida com consultas por coincidência exata.

Os tipos de consultas mais adequados para este caso são: Busca por Abrangência (Range Query) c $k$-vizinhos mais próximos (k-Nearest Noighbors).

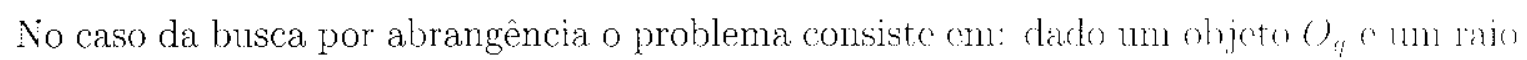
$r$, deseja-sc recuperar todos os objetos que se encontrem dentro desse raio de cobertura.

No segundo caso, dado um objeto $O_{b}$, deseja-se recuperar os $k$-vizinhos mais próximos em relação a esse objeto. O grau de dissimilaridade entre dois objetos pode ser calculado através de uma função de distância cuja complexidade depende da naturça dos dados envolvidos. Essa função pode ser computacionalmente simpless como no caso da distancia

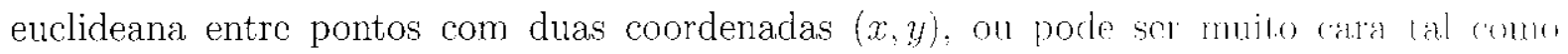
calcular a diferença cntre duas seqüências de vídeo.

Por isso, o custo computacional apresentado na Equação (1.1) pode scr adaptado para o caso de rccuperação de informação por similaridade em bases de dados multimídia. O now custo computacional é determinado pela seguinte equação.

$$
T=N C D \times \text { complexidade de } d()+\text { tempo de } E / S+C P U \text { ertm }
$$

onde $N C D$ é o número de cálculos de distâncias, $d()$ é a função de distância. Os dois réltimos fatores são similares ao apresentados na Equação (1.1).

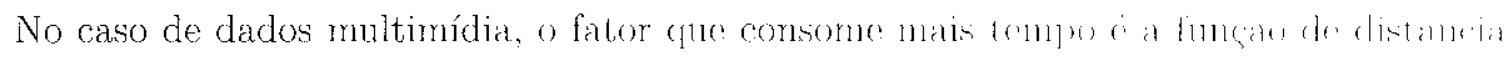

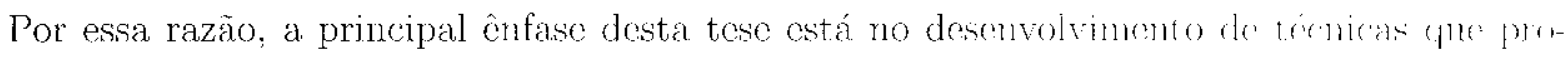
porcionem uma redução considerável nos cálculos de distáncias envolvidas no processo do Recuperação de Informação por Similaridade.

\subsection{Definição do Problema}

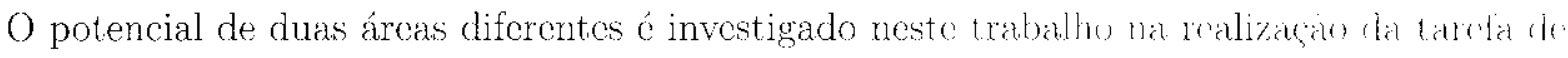
RIS (RIS). Por um lado, cncontram-so as técnicas de recuperaçăo de informaçăo om bases 
de datos multinidia por ontro. encontram-se as Redes Neurais Artificiais (RNA) do tipo Mal)a Aute-() Manizádel on Self-Organizing Maps (SOM).

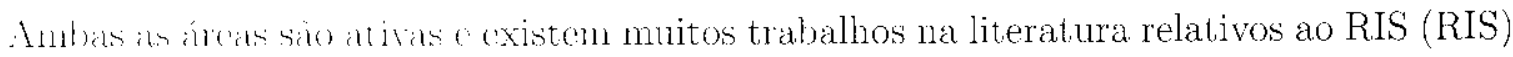
Kuhonen. 1997b: Haylin. 1999; Chávo el al., 2001; Baeza-Yates e Ribeiro-Neto, 1999). Anthas an siren possuem lécnicas que apresentan vantagcns e limitações na realização dessa

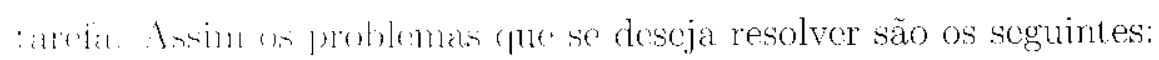

- Ir técnicito de Redes Veurais existentes, especialmente os SOM, utilizam de forma intemsiva a comparacáo seqüicncial para encontrar a unidade vencedora. Considerando

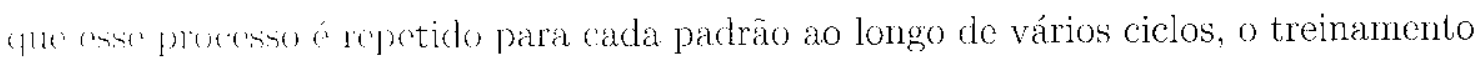

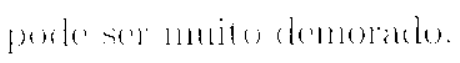

- Or Métodos de Acesso Espacial (MAE) e Métodos de Acesso Métrico (MAM) aprescntan ausência de aprendizado. Isso é, se consultas idênticas são realizadas, de forma consccutiva, o número de operações requeridas pelo método, como por exemplo cálculos de distáncia para responder a consulta é idêntico para ambas as consultas. As distancias calculatlas relativas à primeira consulta não são utilizadas quando da realizacaro da segunda consulta.

A idéia principal deste trabahlio é a de combinar o melhor das Redes Veurais e dos Métodos de Accsso com o intuito de propor-se métodos mais robustos.

\subsection{Objetivos}

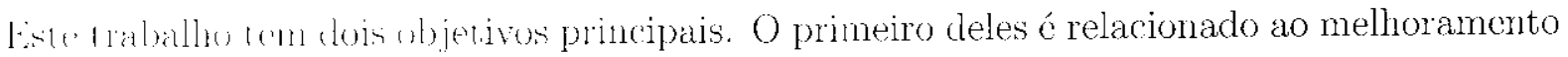

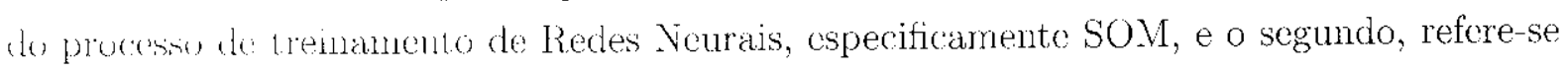
wo molhoramento de MAE e MAM, para estes que sejam capazes de adaptar-se ao comportamento do usuário. Lin ambos os casos, o que se deseja co melhorar o processo de Recuperação de Informagăo por Similaridade.

No primeiro caso, relacionado aos SOM, o objetivo é a criação de modelos que evitem a Iradicional compratraço secpiicncial con todas as unidades da rede cada vez que um novo

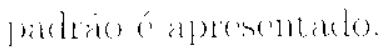

O segundo objetivo é a criação de unna nova família de métodos de acesso capazes de adaptar-se a comportanento do usuário e não apenas aos dados. A meta é que o tempo de revpusia soja reduziclo de forma gradual em função do conhecimento gerado pelas consultas anteriores. 


\subsection{Organização do Trabalho e Esclarecimentos}

Neste trabalho o termo "método de acesso" é entendido como a junção entre o algoritmo o a estrutura de dados utilizada. Esta tese está organizada da scgunto maneim:

No Capítulo 2 são apresentados os modclos de Redes Neurais Artificiais mais represcntativos para Recuperação de Informação por Similaridade.

No Capítulo 3 são apresentados os métodos mais represcntativos de Acesso lispacial e Métrico para Recuperação de Informação por Similaridade.

No Capítulo 4 são discutidas as principais vantagens e limitações das RNA. MAE c MAM em relação ao processo de recuperação de informação por simuilaridade.

No Capítulo 5 são propostas as novas técnicas SAM-SOM c MAM-SOM que sào o resultado da incorporação de Métodos de Acesso Espacial o Métrico no processo de treinamento de Mapas Auto-Organizáveis. Nesse capítulo tambérn são apresentiadas algumas possíveis variações, tais como, SAM-SOM híbrida, SAM-SOM* c MAM-SOM*.

No Capítulo 6 é proposta a utilização de um novo módulo denominado P.MA.M, que é capaz de adaptar-se ao comportamento do usuário. O módulo proposto utilizid o enheciment.o gerado pelas consultas anteriores para reduzir o tempo de resposta das comsultas. O PMA.I foi proposto para ser utilizado junto a qualquer Método de Acesso Fspacial on Métrico.

No Capítulo 7 são apresentadas as conclusões do traballio junto con as propostas de: trabalhos futuros.

As principais contribuiçõcs desta tese estão concentradas nos capítulos 5-6. 


\section{$\sigma$ \\ Redes Neurais Auto-Organizáveis

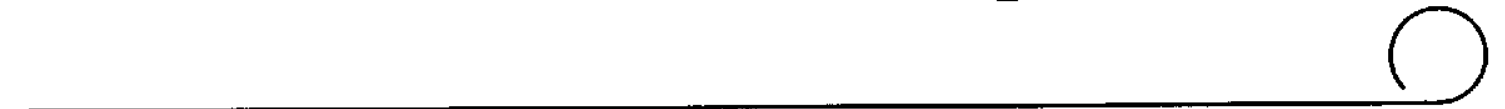

$O$

mohtuna do recuporaça do informação também ó estudado na área das Redes

Vourais Arlificiais (RNA). Existen vários trabalhos na literatura que utilizam

RNA para resolver essa tarefa. Neste capítulo, serão aprescntados vários modelos

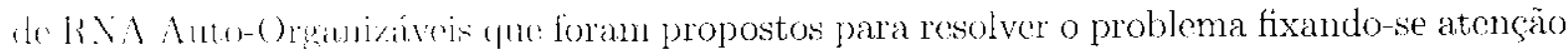

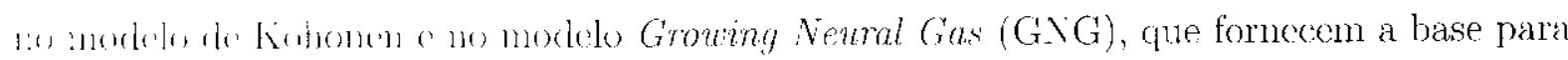
ats héchicas propostan nesta tese. Antes, porém, da apresentação desses modelos, algumas

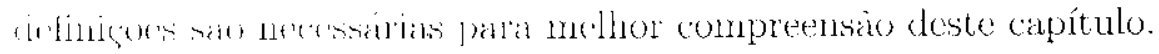

\subsection{Definições}

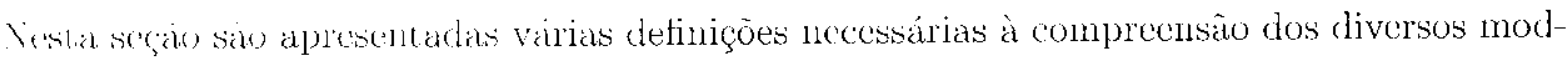

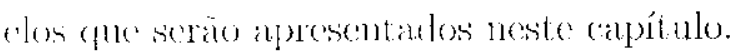

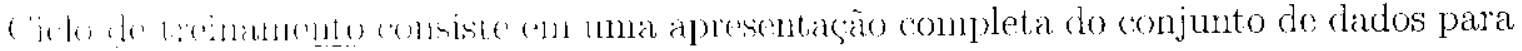

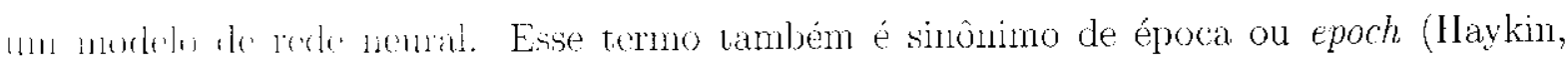
$1999)$.

Aprendizado Supervisionado é um paradigna de aprendizado no qual o sistema de apren-

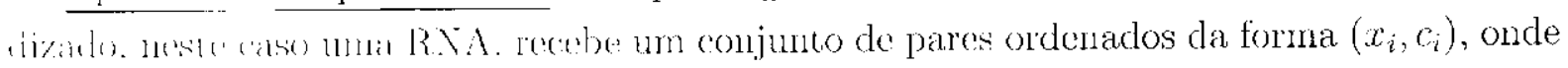
$c^{\prime}$; represcnta um dado de entrada e $c_{i}$ representa a classe à qual o dado $x_{i}$ pertence. Neste

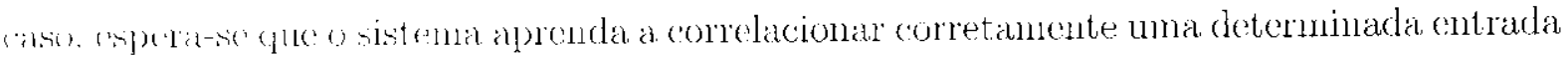

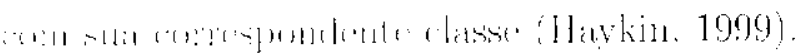

Aprendizado Vào-Supervisionado é um paradigna de aprendizado no qual o sistema de aprendizado. neste caso una RNA, reccbe apenas o conjunto de dados sem especificação da

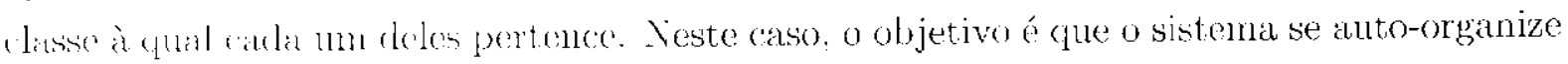

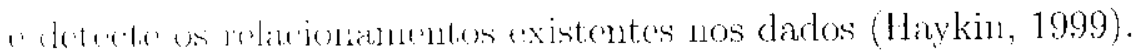

Estabilidade significa que un padrão de entrada sempre deve ser classificado na mesma (lasio an longo do processo de treimanento. Plasklicidade signilica que uma redo dove ser 
capaz de incorporar novo conhecimento sem afetar negativanente o clue já foi aprenctido. () Dilcma da Estabilidade-Plasticidade consiste no problema que existo para que um sistema de aprendizado mantenha a estabilidade o plasticidade simultaneamente (Grossbere, 1976a).

\subsection{Mapas Auto-Organizáveis}

O cérebro humano é nma das estruturas mais interessantes da fisiologia humana. Mesmo sendo muito complexo do ponto de vista microscópico, cle teu una estrutura uniforme a escala macroscópica.Os centros responsáveis pelos estímulos visuais (Hubel e Wiesel. 1962. 1977), anditivos (Suga, 1985), etc., são mapeados en diferontes áreas do crobro (11le alresentam ordenação topológica. Isto é, as áreas individuais aprestentam 1 ma ordenaça

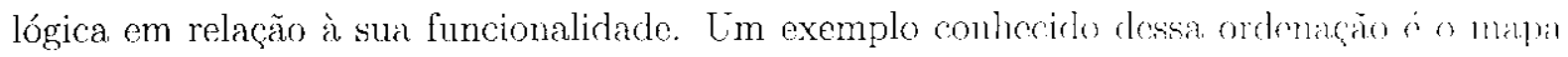
tonotópico das regióes anditivas. Nesse mapa, neurónion próximos ent pe si rexpondenn n freqüências similares de sons. Também é conhecida a existéncia do malpa somatotopico (plu ć o mapa dos nervos motores responsáveis por cada parte do corpo humano. Nosse tipo de mapa, regiões fisicamente próximas são responsáveis por mombros fisicamente próximos do

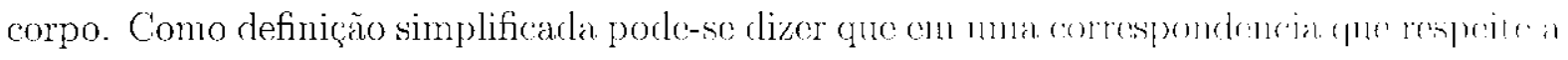
topologia, aquelas unidades que estejam fisicamente próximas umas das outras roponderão analogamente a vetores de entrada similares.

A tentativa de criar modelos computacionais com caractorísticas similares às olsscrvardas no cérebro humano, inspirou a criação dos Mapas Auto-()rganizáveis (SO M ${ }^{1}$ ). lim dos SOM mais importantes da literatura é o modelo de Kohonen que é detalhado a seguir

\subsubsection{Modelo de Kohonen}

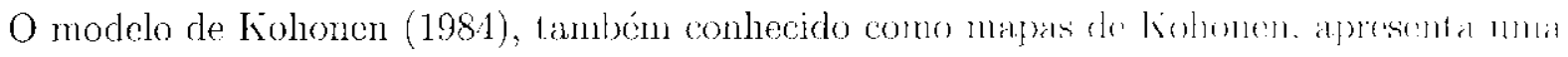
arquitetura relativamente simples composta por uma malha de neuronios conectados de acordo com a Figura 2.1. A mesma idéia, em um contexto hiológico, fá timha sido appresentada

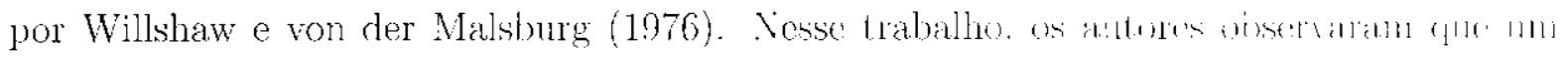
processo envolvendo aprendizado sináptico pode ser responsável pela ordenu lonal de rélulitin corticáas.

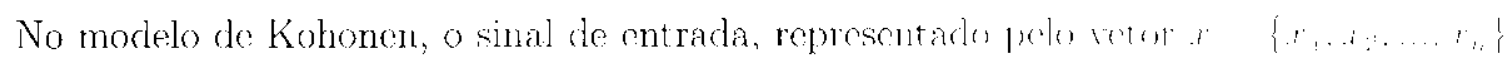

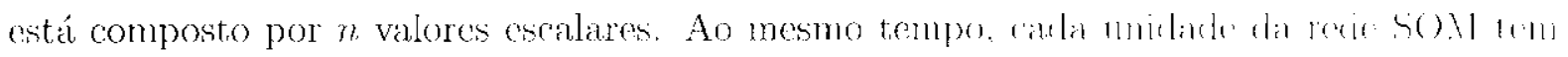
um vetor de pesos com o mesmo número de componentes que o simal de ontrata. Luto fi

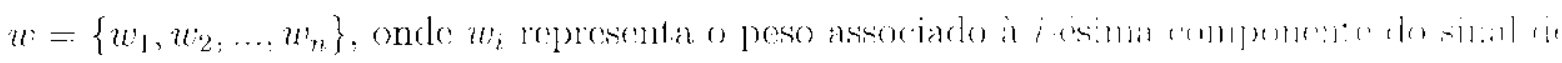
cntrada $x_{i}$.

\footnotetext{
${ }^{3}$ As siglas correspondem ao nome em ingles Self Organizing Mops.
} 


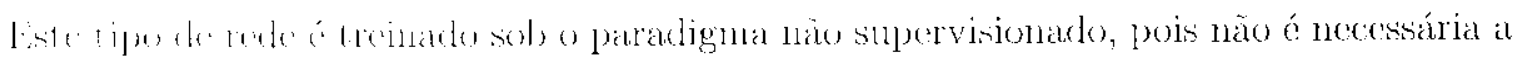

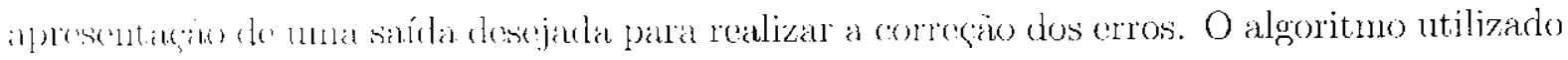

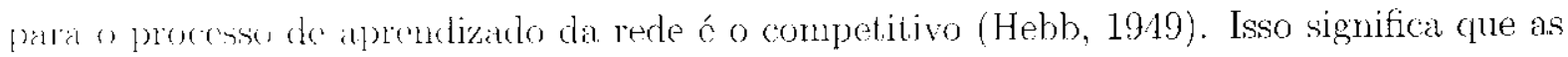
miciales conpon mentre si para ganhar o direito de se ativar.

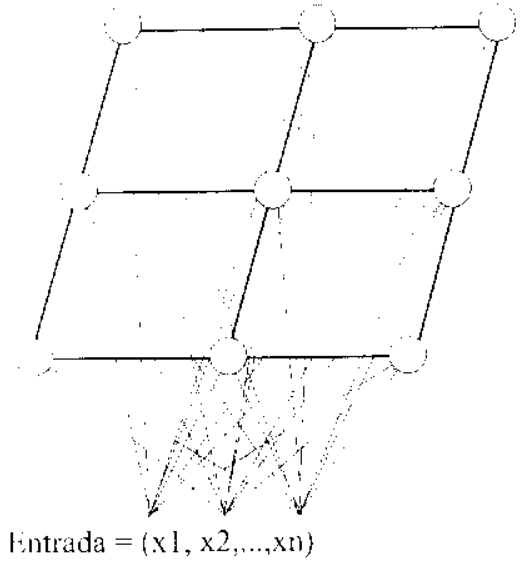

Figura 2.1: Arquitetura Básica de um Mapa Auto-Organizável.

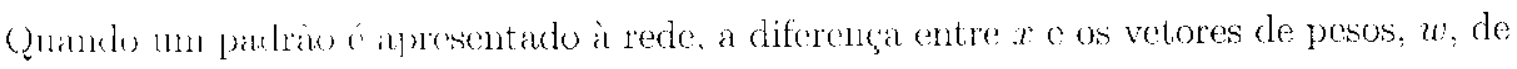
"ada nenronio da rexle ó calculada de acordo com a equaçào:

$$
\mid a-w
$$

Depois de calculada ussa diferença, o neurônio vencedor á aquele que apresenta a menor distanteiat inter

$$
\left\|x-w_{c}\right\|=\min \left\{\| x-w_{i} \mid\right\} \forall i
$$

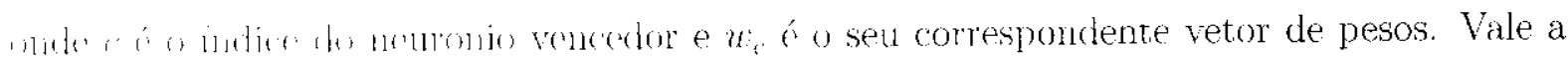
penta resialtar que a funçio para medir a distância, cntre o vetor de entrada $x$ e o vetor de

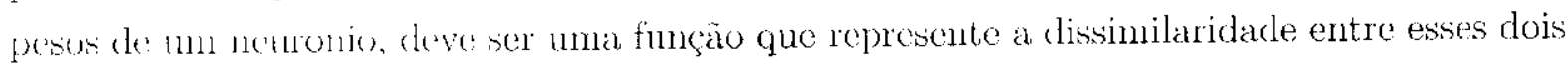
vereres. A distancia cuclickana é a mais utilizada, porém qualquer outra função que possa representar a diferençs entre a entracla o o vetor de pesos, poderia ser utilizada.

Vesse contexto, uma ver escolhida a unidade vencedora, seu vetor de pesos e os vetores de

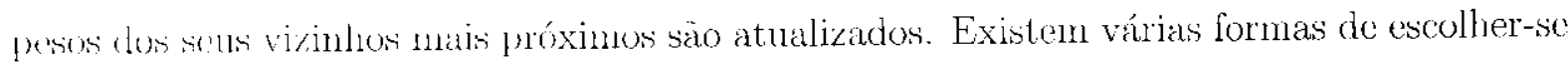

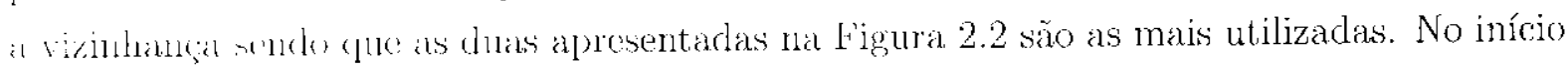
do processo de treinanento a vizinhança de neuronios atualizados é relativamente grande, purém as lengo do processiso de treinamento, a vizinlança é reduzida do forma gradual (Lo

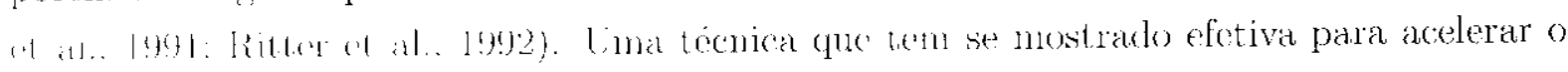
processo de convergencia de treinamento de um SOM é reduzir a vizinhança de acordo com uma funģo Ganssianla (Lo et al., 1991; Erwin et al., 1992a,b). 

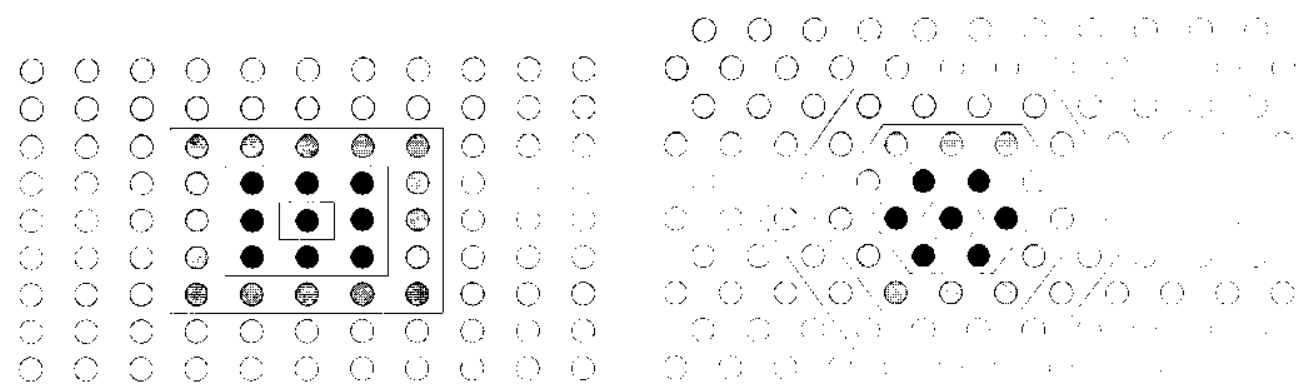

Figura 2.2: Duas configurações de mapa de Kohonen e de níveis de vizinhanģa do nemurouin vencedor.

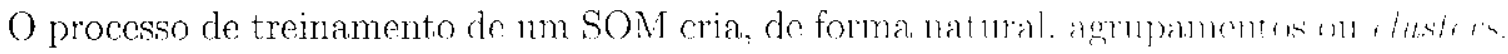
Cada cluster corresponde a um grupo de padrōes que compartilham caracteristicas similares. sendo que o centro corresponde ao padrão que melhor representa a alucla classe. Na Figura 2.3 pode-se observar a representação bidimensional de um chuster junto com tres das inagens que foram classificadas. Após ter realizado o processo de treinamento de um SOM, unidados próximas fisicamente na rede representam padröes similares (Kohonen, 1990).

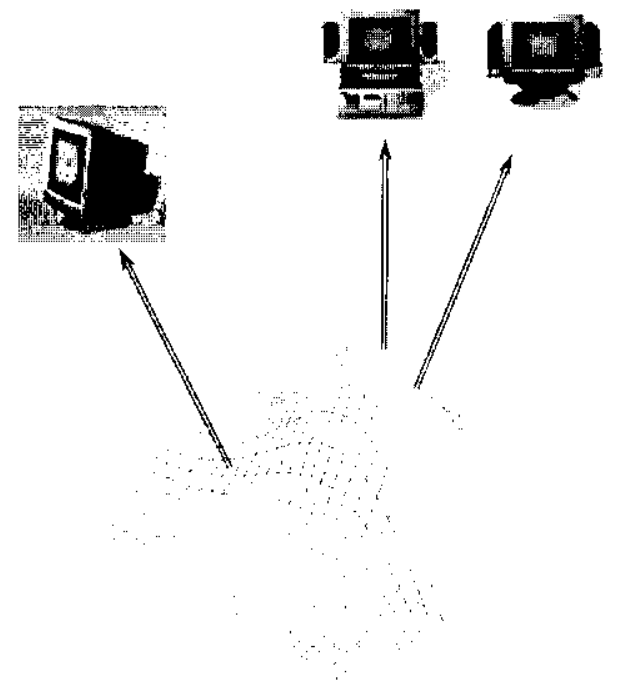

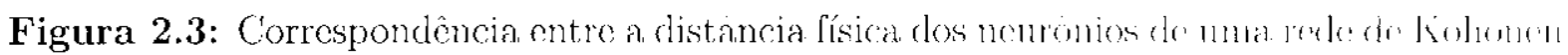
e o gran de semelliançáa dos padrócs por des reconluceridos.

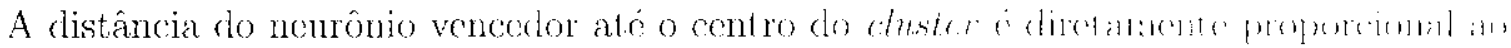
grau de diferença do padrão sendo apresentado com o padräo represtentardo ne rentro de cluster.

Mesmo sendo fácil visualizar essa similaridade ou proxinidado em forma de wma ma

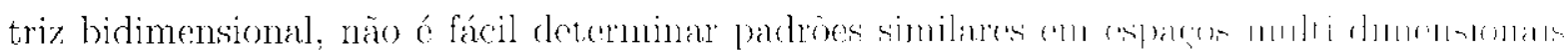
(Obermayer et al., 1990; Ritter e Kohonen, 1990).

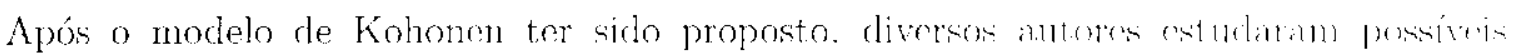

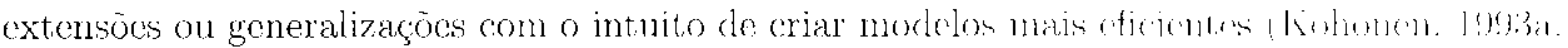




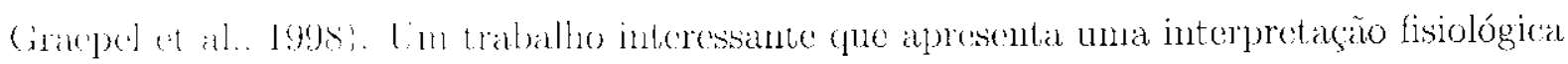

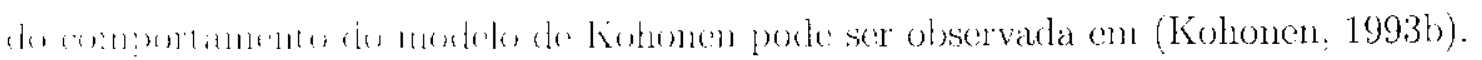

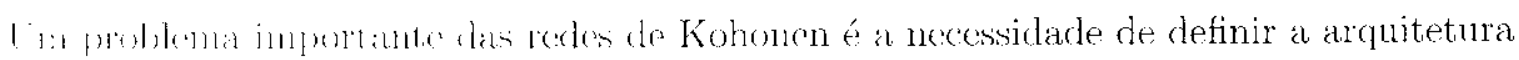

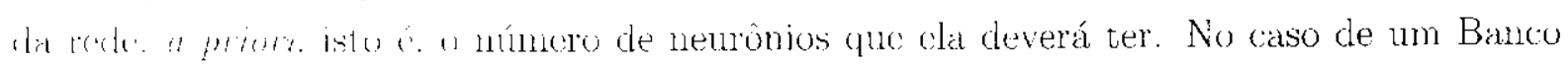

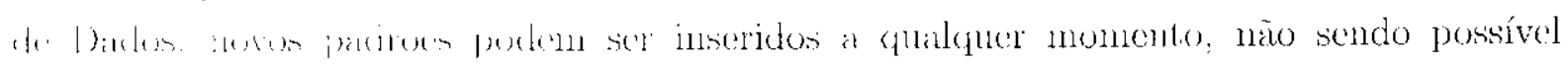

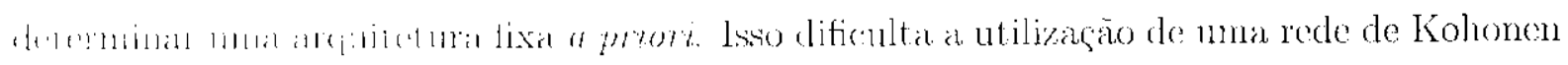

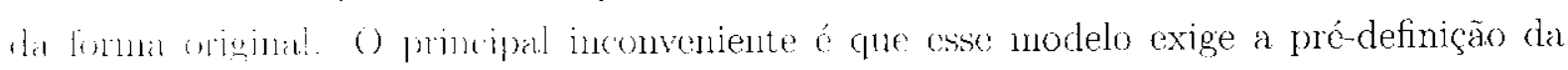

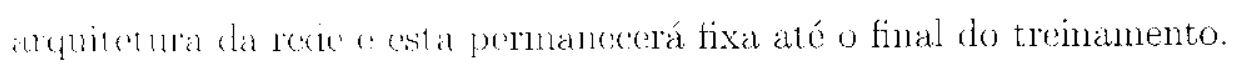

A maicria das deficiencias dos mapas auto-organizáveis foram discutidas em Kohonen

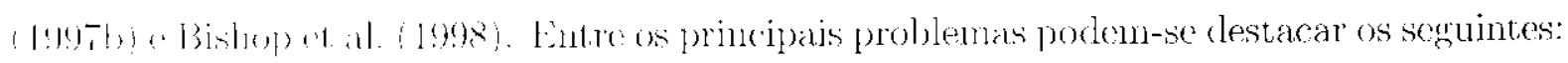

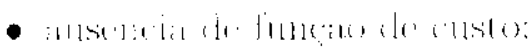

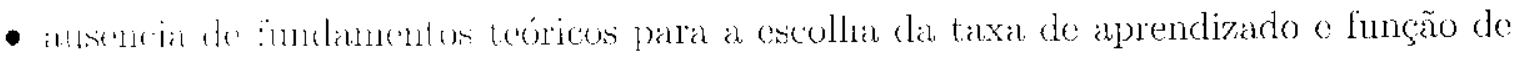
vizintianlugi:

- ancióncia de provas gerais de convergência;

- Lielta de defincicio de densidade de probabilidade.

Lin relayio às provas de comvergencia do modelo de Kohonen, foram realizadas algumas

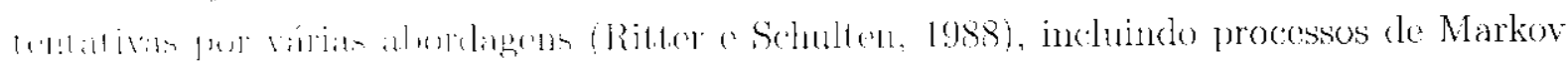

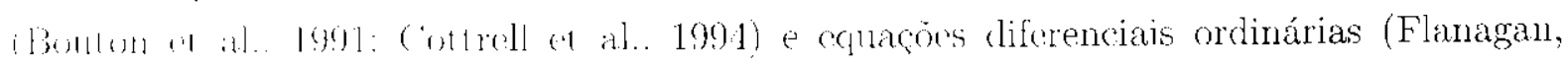
1994, 1996). Porém, a demonstração do processo de ordenação do SOM, só foi possível para o easo nnidinensional o $14 \mathrm{~m}$ sinal de entrada unidimensional (Kohonen, 1997b; Cottrell,

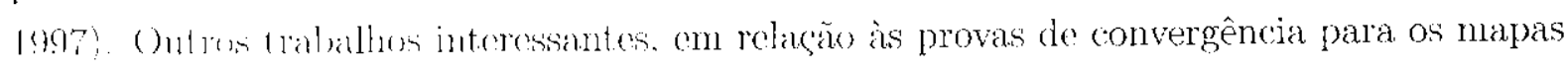
d. Kohonen. poden sen encontrados em (Cottrell et al., 1995, 1998).

Como já foi moncionado anteriormente, quando da indexacão e recuperação de dados

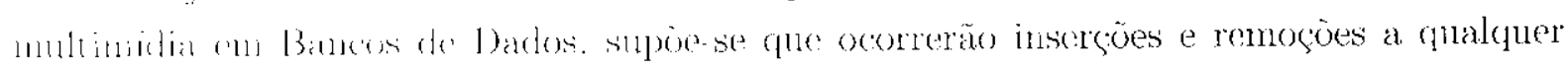
monento. busas condiçós fazenn supor que a rede utilizada deve ter a característica de crescer durante o treinamento on, inclusive, remover aquelas unidades que não sejam mais áteis depoin do und romoça de padrós. Essa característica do problenta restringe a

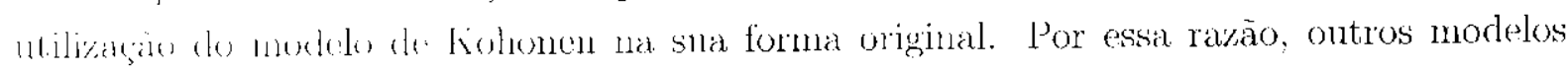
majis avalualos. tais cono os hicrárquicos e os construtivos, derivados do mapa de Kohonen, wrato analisados natio próximas soçoes.

\subsection{Mapas Auto-Organizáveis Construtivos}

() muxtelo brimion da Rede de Kohonen não é construtivo. porém, existem outras redes do tipo SOM que incorporann técnicas consurutivas e têm a capacidade de mudar a sua arquitetura 
ao longo do processo de treinamento. Esse ponto já foi discutido por diversos autores tais como Kangas et al. (1989, 1990); Koikkalainen c Oja (1990); Fritzke (1.991).

Um algoritmo construtivo tem duas alternativas para gerar uma rede apropriada. A primeira é reconhecer e corrigir aqueles neurônios que tenhan sido gerados em posiçoes impróprias para a distribuição dos dados. A segunda é prevenir o corrigir a fopologra existente para minimizar o crro.

A busca pela topologia mais apropriada para um determinado conjunto do padrốs pode ser um processo computacional muito custoso. As principais técnicas existentos na literatuma são analisadas nas próximas seções.

\subsubsection{Aprendizado Hebbiano Competitivo}

Um dos primeiros SOM que incorporou técnicas construtivas foi o meitorto denominarle Aprendizado Hebbiano Competitivo Competitive Hebbian Learning (CHI.) (Martinetze Schulten, 1991; Martinetz, 1993). Essa técnica permitiu criar conexós de foma dinanuica

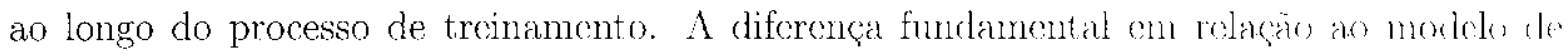
Kohonen clássico é que, depois de encontrar as duas unidades, so os s, mais proximats in

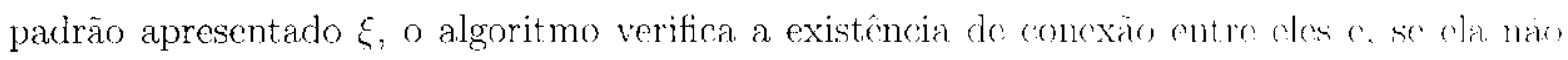
cxistir, o algoritmo se encarrega de criá-la.

\subsubsection{IGG}

O modelo Incremental Grid-Growing (IGG) foi divulgado atravós dos traballos apresentados por Blackmore e Miikkulainen (1993): Blackmore (1995): Blackmore o Miikkulainen (1995).

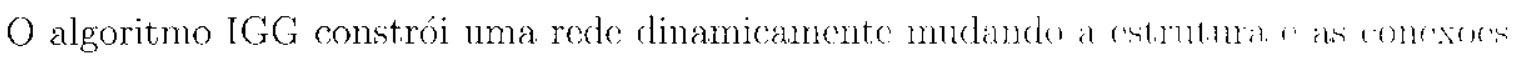
de acordo com os dados de entrada. O treinamento é iniciado com uma rede de apenis

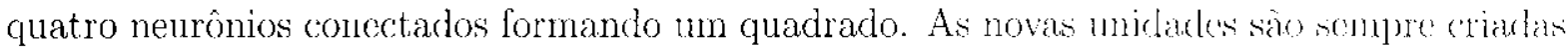
nos limites externos do mapa perto daqueles neuronios com maior crro acumulado.

A inserção de novas unidades, apenas nos limites externos do mapar, permite (fur o algoritmo IGG mantenha sempre uma estrutura 2-d. Mesmo considerando que os partroce

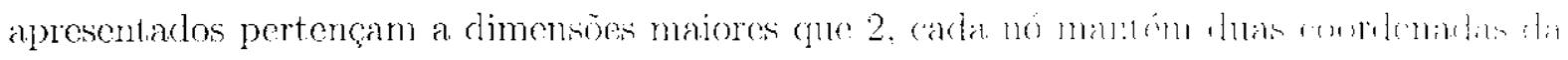

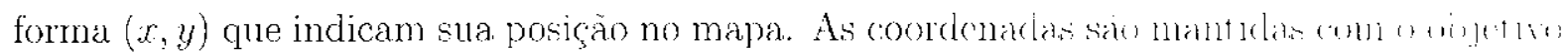

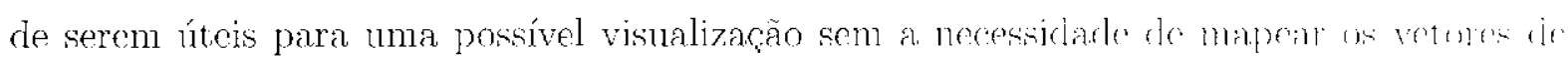
pesos.

\subsubsection{Neural Gas com CHL}

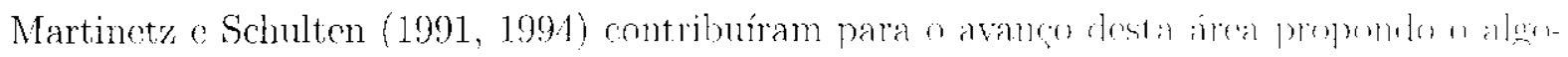
ritmo Neural Gas com Aprendizado Hebhiano Competitivo ( N ( 


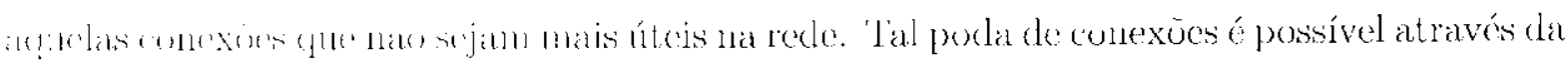

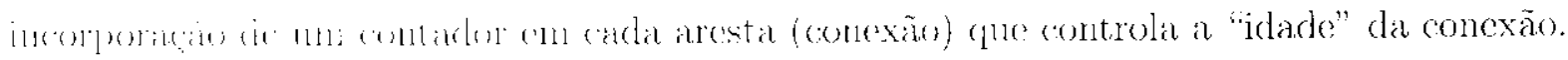

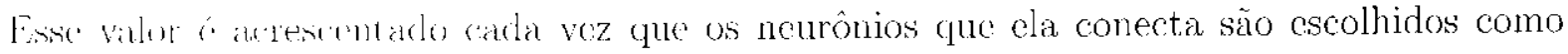
vencedores. So a contador de lunk concxào atinge un certo valor (determinado por un

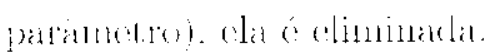

\subsubsection{Growing Neural Gas}

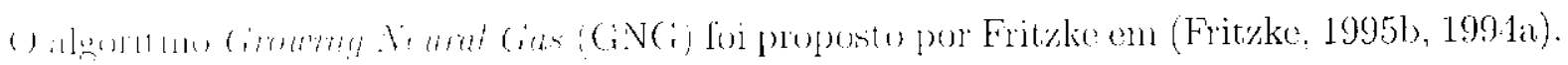

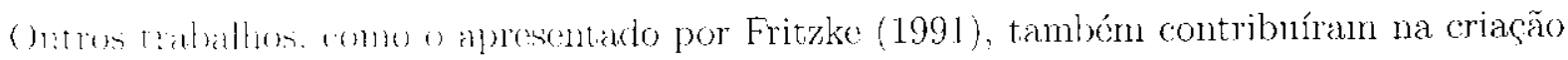
drotin lenenicat.

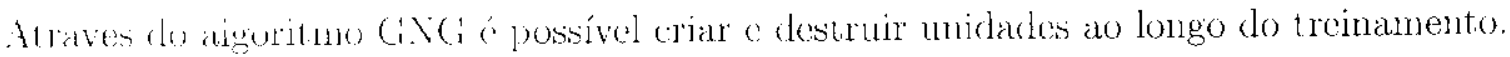

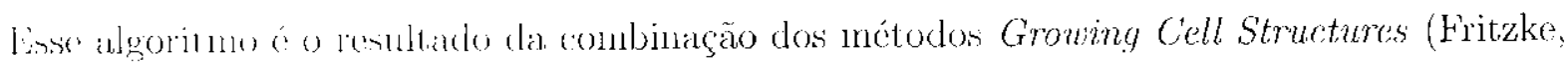

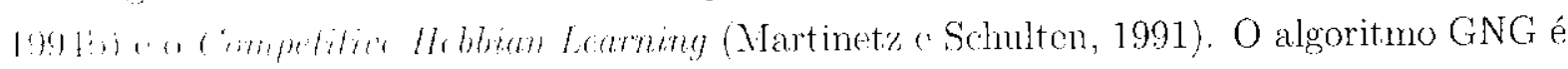

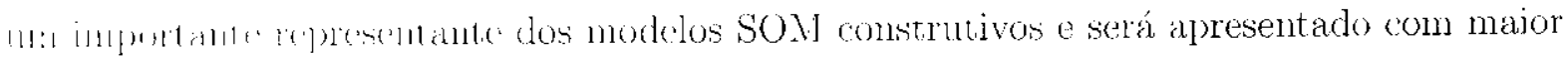
grau de delathe nesta seçä pois conforme será visto mais adiante, esso modelo será usado ma propostia destat terse.

Fiste modele surgin princip)alnente com o objetivo de melhorar algumas limitaçóes do modelo básico de Kohonen. Enquanto uma rede de Kohonen precisa da definição de uma

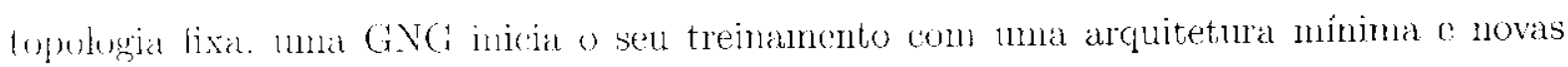

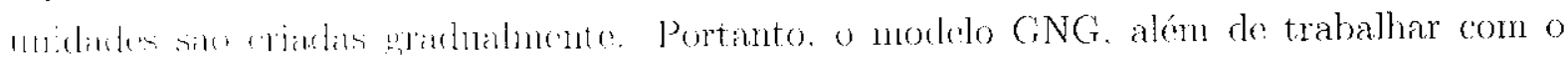
paradignal vấ Sinpervisionado, tanbém é construtivo, sendo capaz de gerar uma topologia diferente para cada tipo de problema.

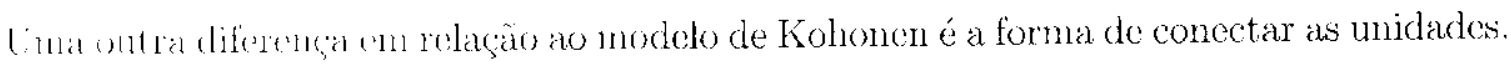
Co malja de Kulunem, as conexós crian apenas malhas retangulares como pode ser visto na Figura 2.1. Já no modelo GNG. uma unidade pode ter muito mais de quatro vizinhos gerando ctircrsis liguras geonnétricas² e uma rede com maior capacidade de aprendizado.

() meaninine paru o crescinnento de estruturas celulares (Fritzke, 1994b) junto con

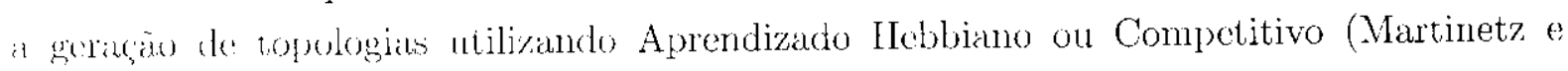
Sichulten. 1991 ) foran combinados para criar este novo modelo. O processo de treinamento de

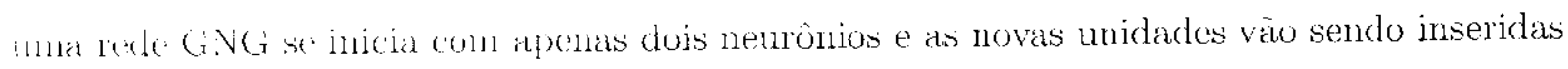
sucessivamente. Para determinar en que posição deverá ser inserida uma nova unidade,

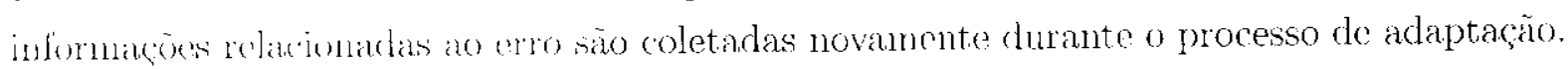
C'ada nove mikdule deverá ser inserida perto da unidade com maior erro. O algoritmo Growing Neural Gas é apresentado a scguir ${ }^{3}$.

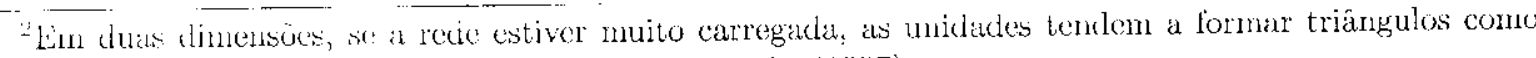

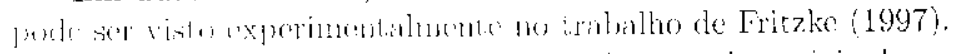

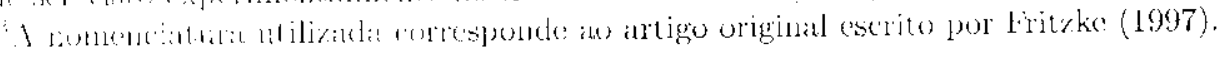


Algoritmo 2.1 Algoritmo de treinamento de uma rede (i.V)

1: Inicializar a rede $\mathrm{A}$ com duas unidades $c_{1}$ o $c_{2}$

$$
A=\left\{c_{1} \cdot c_{2}\right\}
$$

Os pesos devem ser inicializados com valores aleatórios, geralmente, no intervalo [0.1]. Inicializar o conjunto de conexões $\mathrm{C}, \mathrm{C} \subset \mathrm{A} \times \mathrm{A}$ por:

$$
C \cdots \emptyset
$$

2: Apresentar um padrão $\xi^{4}$ à rede de acordo com una distribuicăo nuiforme $p(\xi)$

3: Determinar os dois neurônios mais próximos $s_{1}$ e $s_{2} \mathrm{~cm}$ relaçăo a $\xi$ do acordo com as equações $(2.5)$ e (2.6) onde:

$$
\begin{gathered}
s_{1}=\min ! \mid \xi-w_{c} \quad \forall \in \in A \\
s_{2}==\min \mid \xi-w_{c} \| \forall c \in A-\left\{s_{1}\right\}
\end{gathered}
$$

onde $\left\|\xi-w_{c}\right\|$ representa a função de distância (neste caso euclideana) cntro os vetores $\xi \mathrm{e} w_{c}$.

4: Se não existe uma conexão entre $s_{1}$ e $s_{2}$, então criá-la.

$$
C-C\}\left\{s_{1}, s_{2}\right\}
$$

Inicializar a idade clesta nova conexão com 0

$$
\text { idade }_{\left(s_{1}, s_{2}\right)}=0
$$

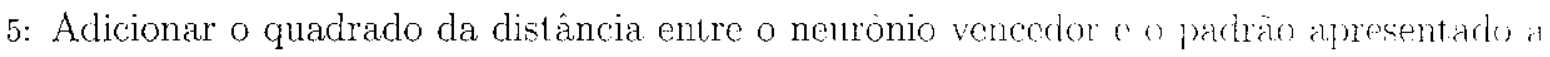
uma variável de erro local:

$$
\Delta E_{n, 1}=\left\{\cdots w_{n, 1}^{2}\right.
$$

6: Atualizalr o vetor de pesos de $s_{1}$ c os vetores de pesos dos sens virintes do acordo com as seguintes equações:

$$
\Delta w_{s_{1}}=\mu_{n}\left(\xi \cdots u_{*_{1}}\right)
$$

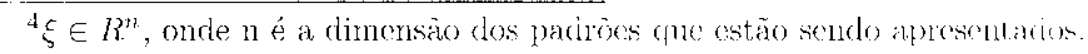




$$
\Delta u_{i}=\mu_{n i}\left(\xi-u_{i}\right)\left(\forall i \subset N_{n}\right)
$$

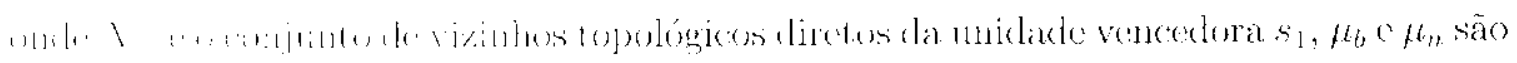

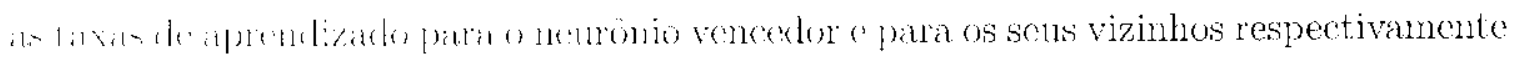

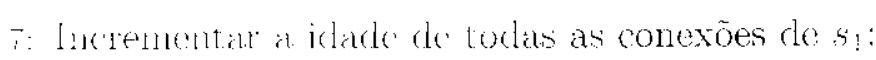

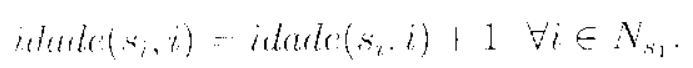

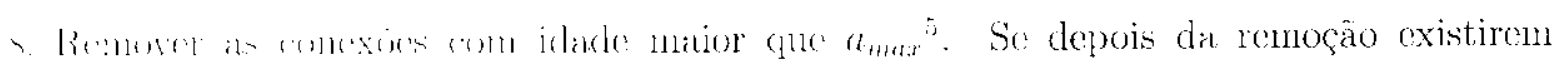

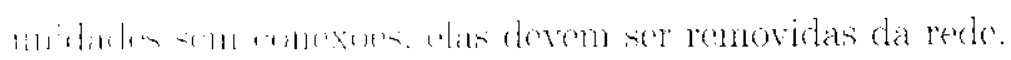

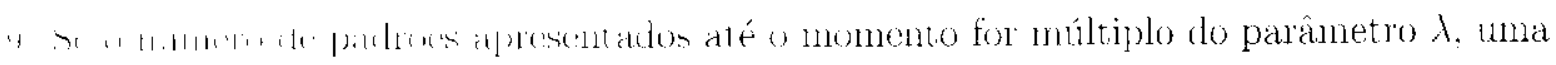

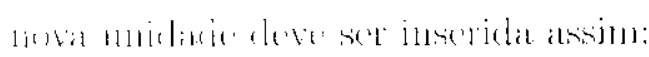

- Dexeminiar a mindider q com o maior erro acunulado de toda a rede.

$$
q=\max \left\{E_{c:} \forall c \in A\right\}
$$

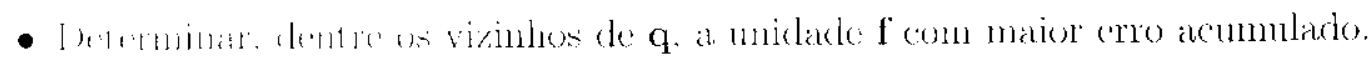

$$
f=\max \left\{E_{c}\right\} \forall c \in N_{q}
$$

- Arlicionar mat nova midade r à rede e interpolar sen vetor de pesos a partir de q ef de acordo com a Equlacão (2.16).

$$
\begin{gathered}
A=A \cup r \\
w_{r}=\frac{w_{q}+w_{f}}{2}
\end{gathered}
$$

- Inserir concxós de $\mathbf{r}$ até $\mathbf{q}$ e de $\mathbf{r}$ até f e remover a concxão original entre $\mathbf{q}$ e f:

$$
\begin{gathered}
C \cdots \cup\{(r, q),(r, f)\} \\
C=C-\{(q, f)\}
\end{gathered}
$$

- Diminuir as variávois de crro das unidades q e f em una fração $\alpha$ :

$$
\Delta E_{q}=-\alpha E_{q}, \quad \triangle L_{f}^{\prime}-\alpha E_{f}
$$

" 
- Interpolar a variável de crro de $r$ a partir do $q$ e f:

$$
E_{r}=\frac{E_{q}+E_{f}}{2}
$$

10: Diminuir a variável de erro de todas as unidades:

$$
\triangle E_{c}=-\beta E_{c}, \quad \forall c \in A
$$

onde $\beta$ é a taxa de correçào de erros

11: Se o critério de parada (isto é, o tamanho máximo da rede on alguma outra medida de (descmpenho) ainda näo foi alcançado, voltar ao passo 2.

De acordo com os experimentos realizados por Fritzke em (Fitzke, 1997), o algoritmo tem alta probabilidade de convergência.

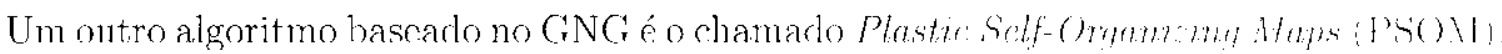
O crescimento da rede 6 controlado por um dos parametros que ó nun threshold be a distancia entre o padrão de entrada, $\xi$, e a unidade vencedora, $w_{1}$, for monor quo o threshold. a atualizaçào de $w_{1}$ e dos seus vizinhos ocorre de forma similar à Civc. So a distuncia for maior que o threshold, um grupo de unidades é criado e depois conectado a $u_{1}$. Todas as conexões também armazenam uma distância que cresce de forma gradual após a apresentaço de cada sinal de entrada. O algoritmo também remove as conexón com irlarde arma de lum certo valor e depois elimina aquelas midades que nào aprescutem comexizes.

\subsubsection{GCS}

A técnica conhecida como Growing Cell Structures (GCS) foi apresentada no trabalho do Fritzko (1992) e posteriormente estendido em (Fritzke. 1993a. 199/h). () alsoritmo ó muito parecido com GNG (ver Seçăo 2.3.4). A principal diferença, no caso do modelo GCS, é que a rede está limitada a um número máximo de simplexos k-dimensionatis. ond fo fi un numero inteiro escolhido antes de iniciar o treinamento.

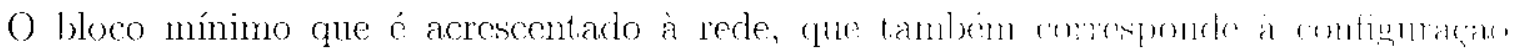

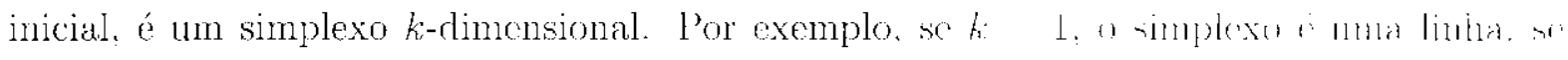
$k=2$ o simplexo é um triângulo, se $k=3$ o simplexo ć um telractro.

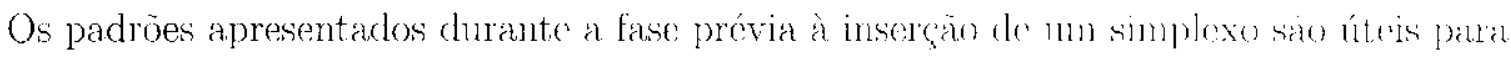
a. atualização de pesos e para armazenar informação relativa ao cruo do rada unidade. Essín informação ó útil para decidir a pusicão das novas minialess.

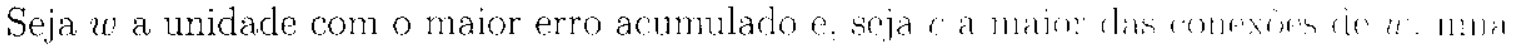

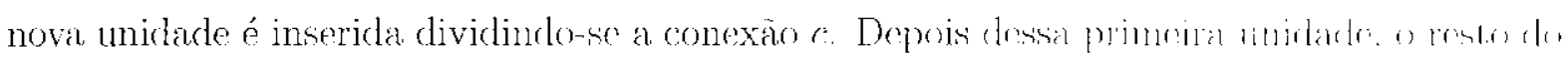




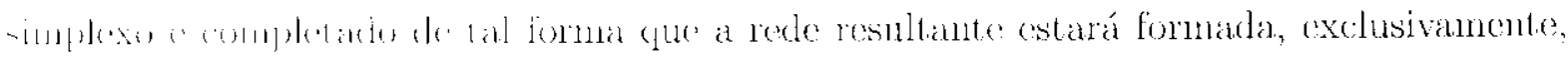

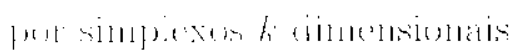

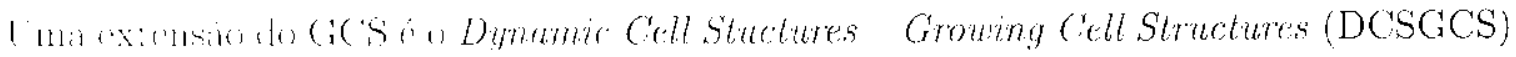

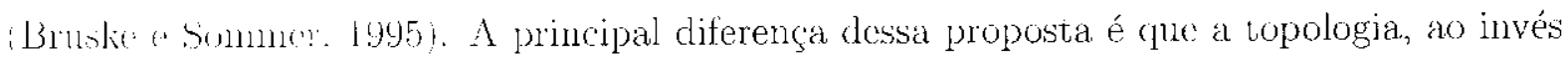

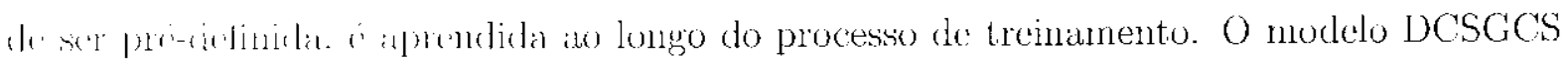

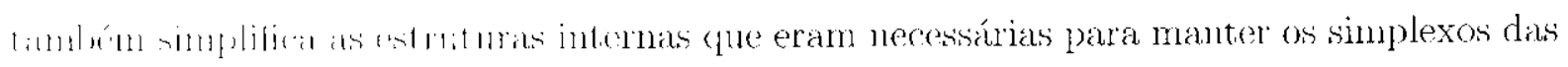
C:cs

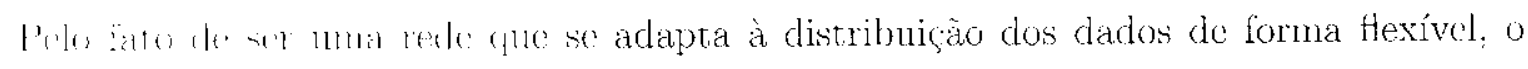

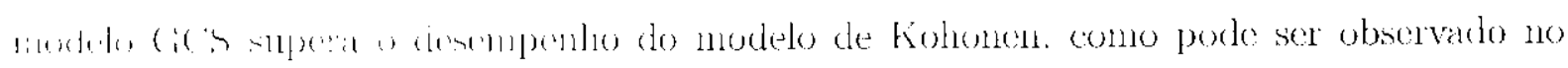

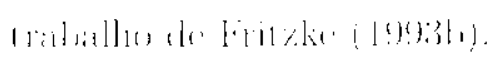

\subsubsection{GSOM}

() Crowing belf-Orqunting Maps (GSOM), apresentado por Alahakoon et al. (1998a,b, 2000;. \& 1 mu nut mo modelo gue pormite o crescimento da rede de forma dinânica.

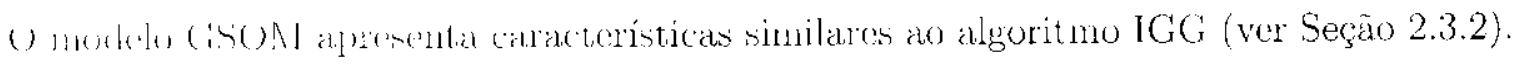
A contiguraçán inicial corresponde à unna rede com aponas quatro unidades formando un rofingulo. Ouando o algorilno docide que novas unidades devem ser criadas, a unidade "om a maim crro anmulado procurada e duas unidades são inseridas na direção das setas

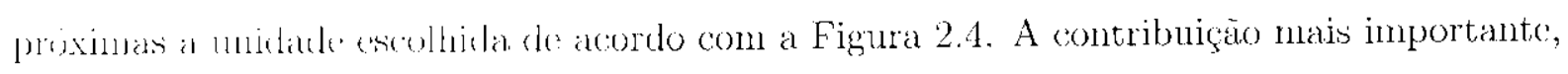
"m relaçize an algoritmo IGG ó que o GSOM utiliza um método de inicialização dos pesos

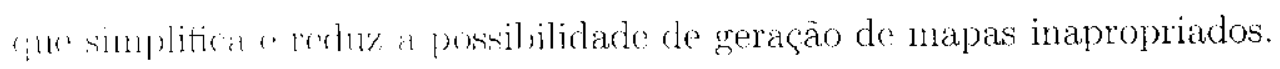

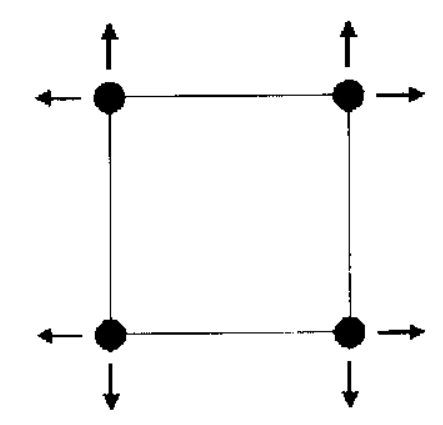

Figura 2.4: Listalo inicial de uma rede do tipo Growing Self-Organizing Maps (Alahakoon et al. 2000).

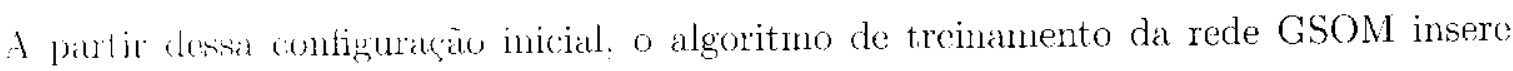

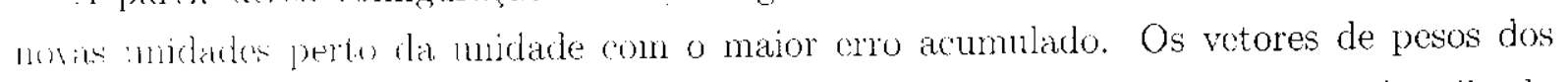

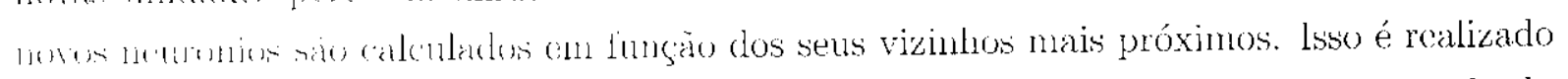
com o int uite de manter a continuidade das posiçoes entre unidades próximas. O resultado 6 mama rede que tem a capacirlade de adaptar-se melhor à distribuição dos dados cono pode ser observado na. Figura 2.5. 


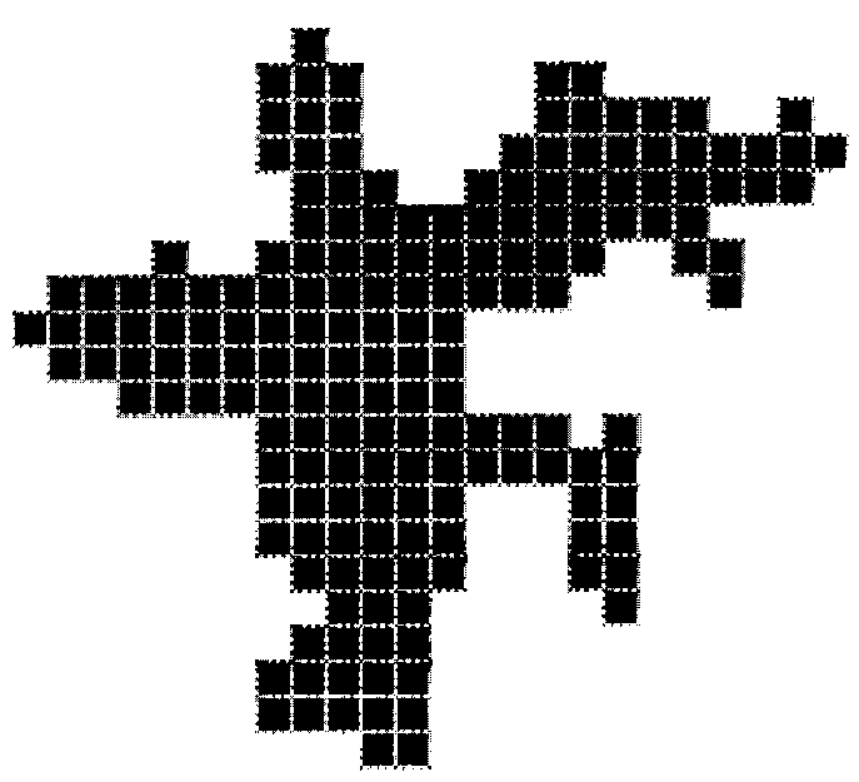

Figura 2.5: Estado final de uma redo do tipo GSOM (Alahakoon et al.. 2000).

\subsubsection{Mapas Auto-Organizáveis Esféricos}

Os Mapas Auto-Organizáveis Lsféricos (Self-Organizing Spherical Maps) (Boudjomail of al.. 2003), também chamados Spherical Maps. são modelos baseados em mathas trianguluaros.

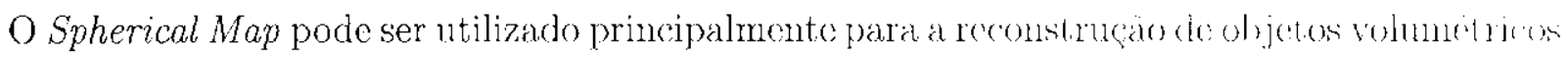
a partir de uma nuvem de pontos. Algumas redes resultantes podem ser olsservarlas ma Figura 2.6 .
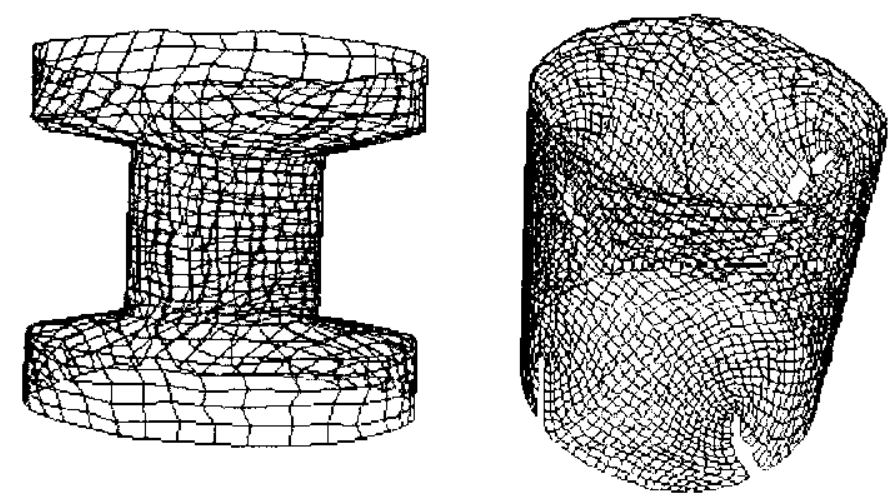

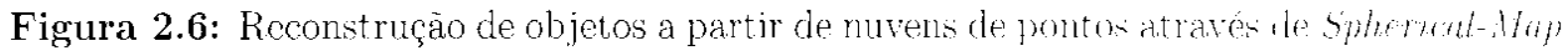
(Boudjemaî et al., 2003).

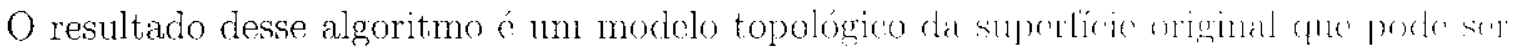
utilizado para a reconstruçäo de objetos volumétricos. 


\subsection{Mapas Auto-Organizáveis Hierárquicos}

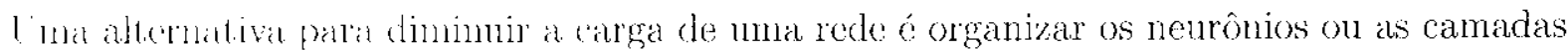
de un $\mathrm{S}($ ) M do loma hierárquica. O intuito em todos os casos é de diminuir o tempo de 1.reinanentu. tentando atingir un custo computacional de $O(\log n)$ em termos de cáleulos

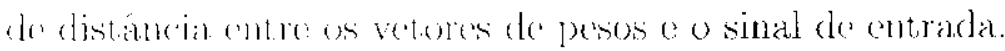

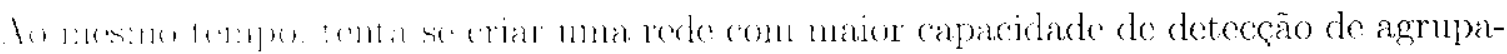

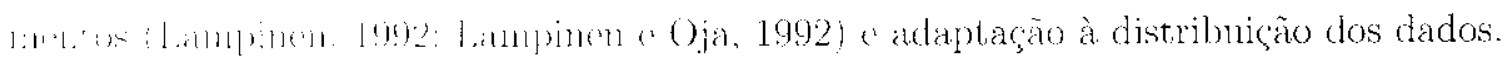

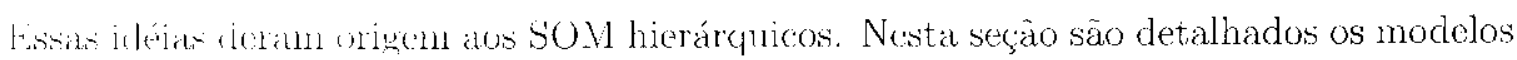

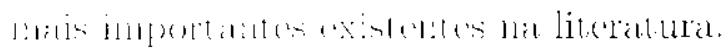

\subsubsection{Mapa Hierárquico}

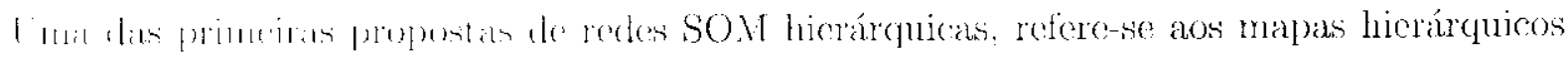

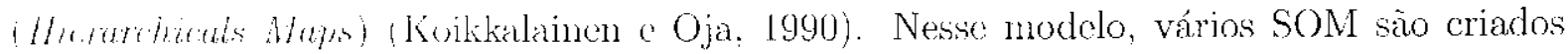
(ic loma hicrárquica gemondo ma cstrutura de forma piramidal, como apresentado na

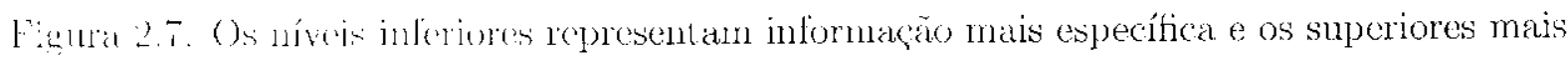

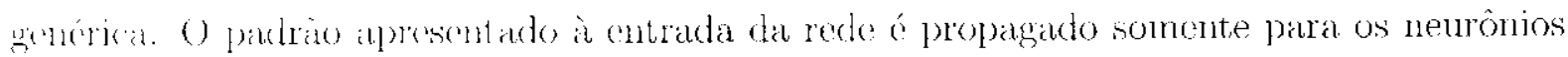
filhos da unidide vencedora em cada nível da rede.

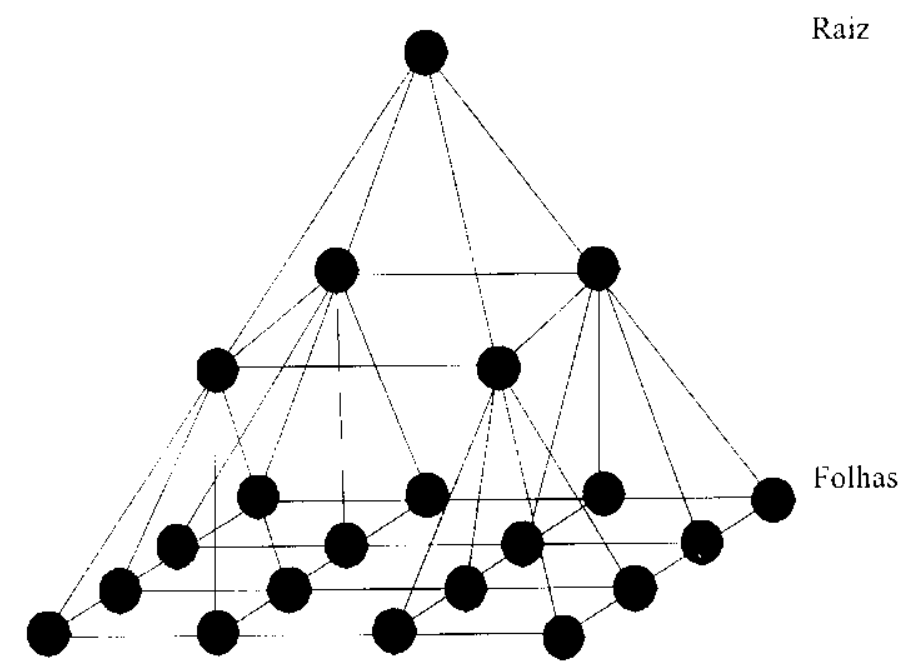

Figura 2.7: Arquitedura dos Mapas Hierárquicos (Hierarthical Maps) (Koikkalainen e Oja, $1090)$

Segundo os alltores, essa cestrutura ajuda a reduzir o custo computacional para encontrar a unidade vencedora, de $O(n)$ para $O\left(\log _{m}(n)\right)$, onde $m$ é o número de níveis e $n$ o número total de undades. Frse cálculo foi inferido devido ao lato de quo, depois de ter encontrado al midank: vencedora, no princiro nivel, o processo continua apenas na sub-rede descendente 
dessa unidade. Esse processo de descarte é repetido de forma recursiva em todos os subníveis até encontrar a unidade vencedora nos níveis inferiores da pirânide. Porém. o custo computacional, $O\left(\log _{m}(n)\right)$, que os autores mencionam, ainda porie ser cliscuticio. () problemis é que, dentro das redes individuais em todos os níveis, o processo para concontrar a unidade vencedora ainda continua sendo realizado de forma sequiencial (Krikkalainm o Oja. 1990).

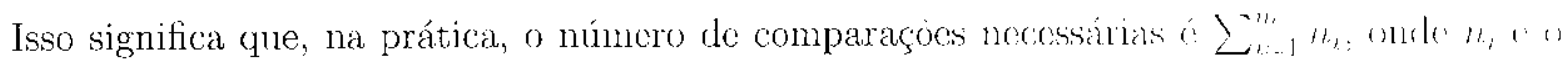
número de unidades na $i$-ésima camada.

\subsubsection{HiGS}

O modelo Hierarchical GCS (HiGS) (Burzevski e Mohan, 1996) cria submapas hierárenicos de forma gradual. Os subniveis são criarlos de acordo com a complexidade rlo problemia. Nis Figura 2.8 é mostrada uma rede gerada utilizando esse algoritmo.

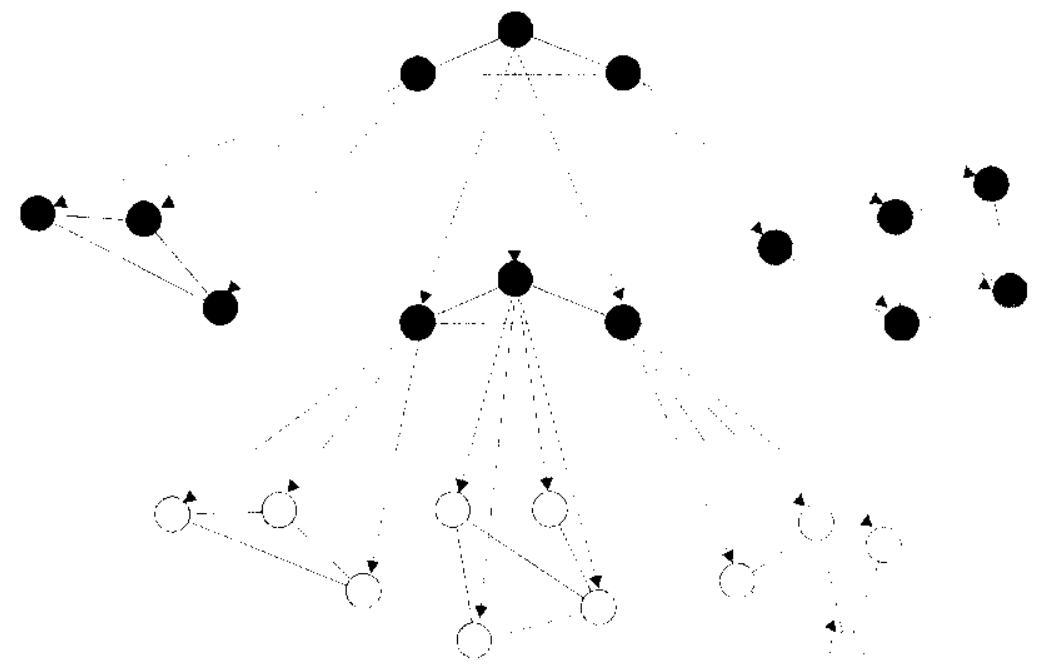

Figura 2.8: Hierarchical GCS (HiGS) (Burzevski o Mohan, 1996).

Comparando os HiGS com os mapas hierárquicos apresentados anteriomente. (xisto luma diforença interessante relacionala à ausência de conexöes entre as sub-redes do um mosmu nível. Dependendo da situação, essa característica pode ató representa un problema. pois

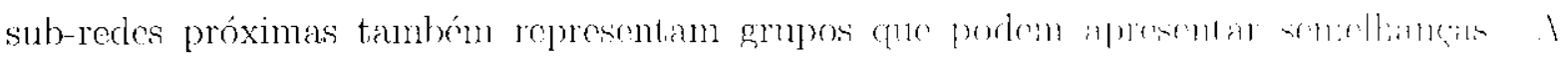

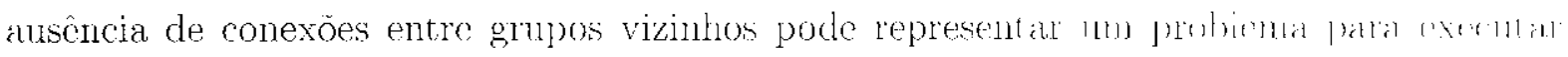
consultas próximas às región de frontrira de uma sub-rerde.

\subsubsection{TreeGCS}

O modelo TreeGCS, apresentado por 1 lodge e Austin (2001a), explora algmas deficincias

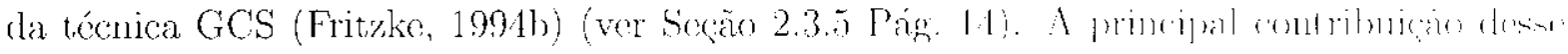




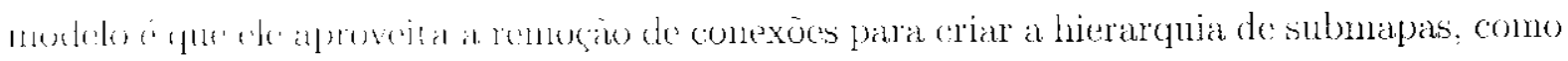

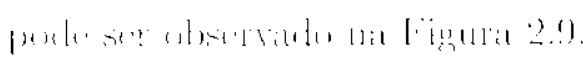

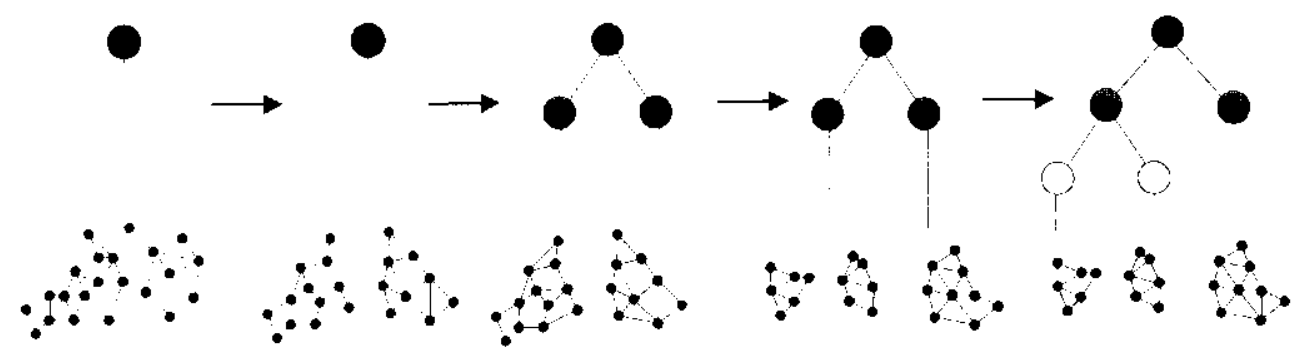

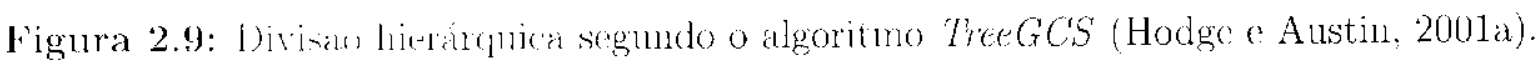

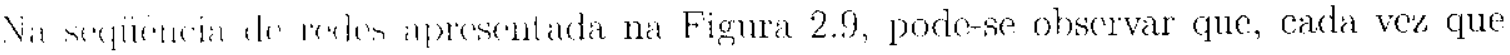

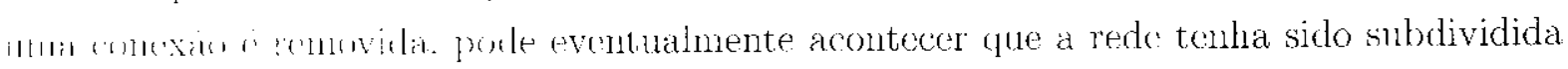

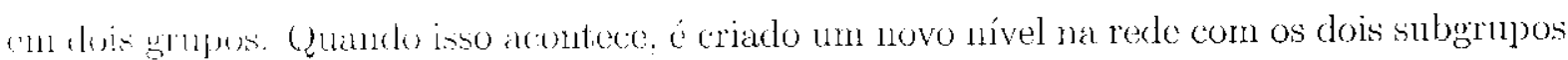
penicionatos unu nivel albaixo. A arquitetura proposta pelo modelo TreeGCS o torna apro-

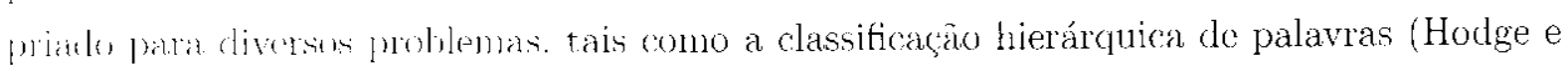
Alstint, 2002), entre ouldus.

\subsubsection{GHSOM}

U nodelo (inowng Herwhital Self-Organizing Map (GHSOM) foi proposto por Dittenbach

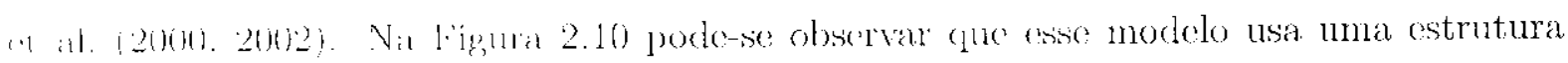

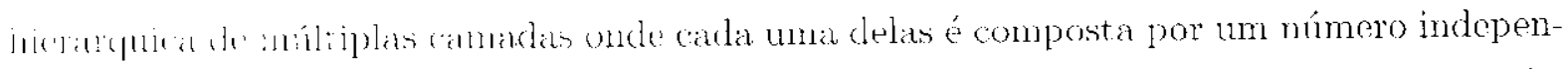
dente de SOM. O primeiro nível está composto por apenas um SOM. Para cada unidade, no primeire mapra $\$$ (OM, pode ser criada uma sub-rede no próximo nível da hierarquia. Fsse princípio a aplicado de loman recursiva aos outros níveis da rede. O modelo GHSOM pode ser útij pira prohleman romo por exemplo a classificaça hierárquica de documentos (Dittenbach

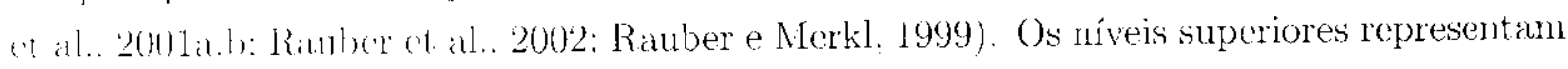

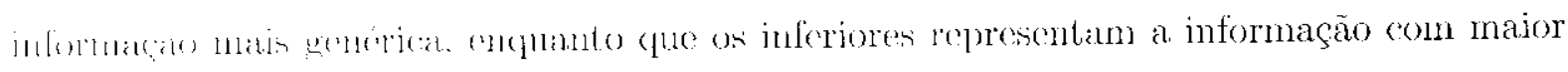
graur de detaline

Ao mesmo tempo. os SOM utilizados nos diferentes níveis são também construtivos e treinados com o algoritmu similar ao Crowing Grid (Fritzke, 1995a). A diferença é que

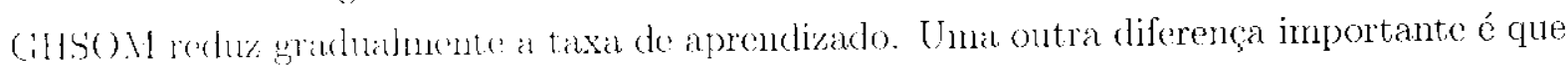
a virinhanea taumbén ce redurida de forma gradual.

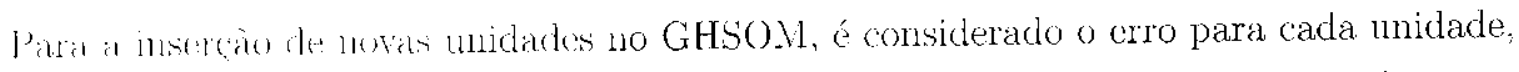
viranato Quantroutun Ltror (QL). () QE é a sonla das distancias entre o vetor de pesos he luna unidarle, wa, "lodos aqueles padrões que são mapeados nola, isto é, todos aqueles padroes que tim $w_{1}$ cono sua midade vencedora. Com esse valor também pode ser calculada a média de erros para cada unidade (Mean Quantization Error - MQE). As novas unidades 


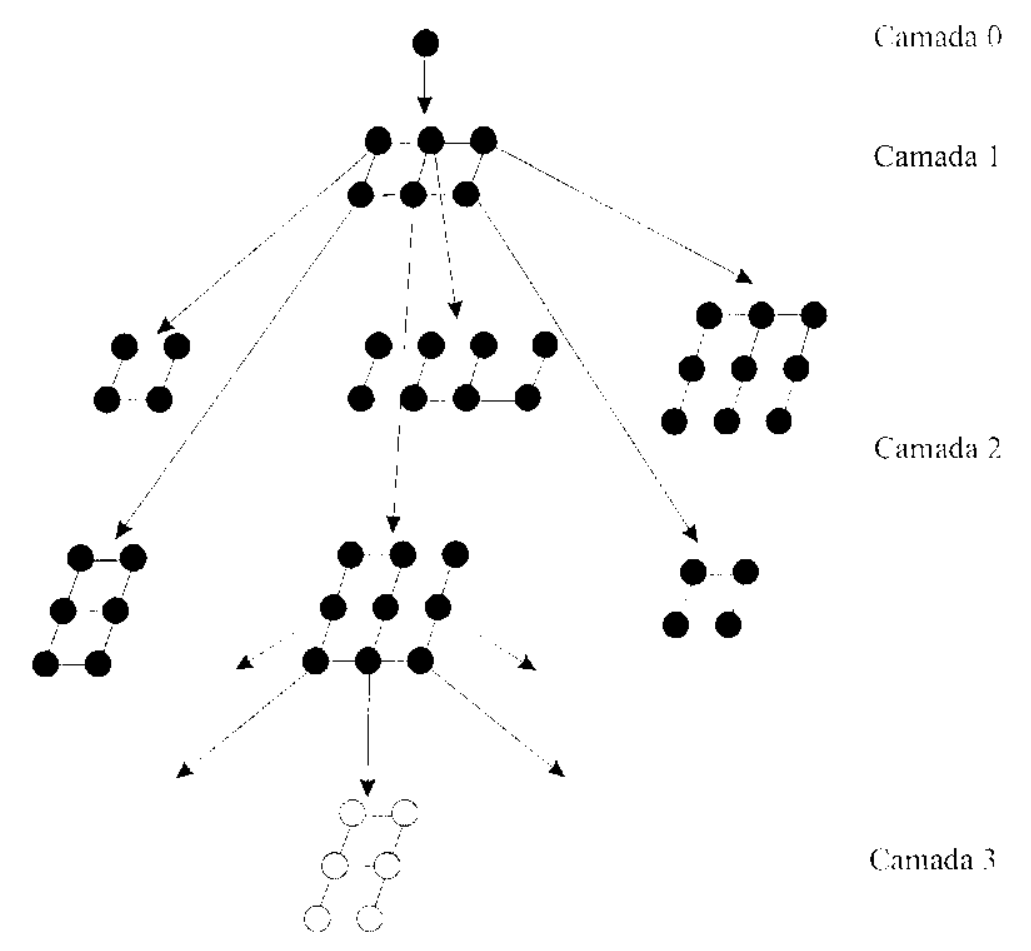

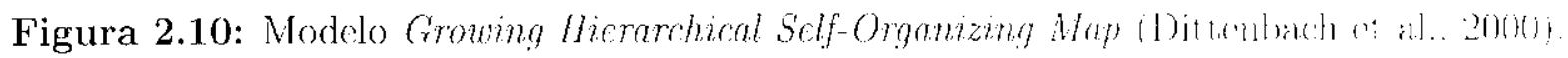

são inseridas entre a unidade com o maior MQE e o seu vizinho mats distante. () processo de inserçào adiciona uma fila ou uma coluna inteira na rede. Isso depende da posiçào das duas unidades entre as quais estão sendo inseridas.

No caso da criação de novas sub-rodes são consideradas aquelas mirdades cujo QE nestoja acima de um certo limite ou threshold, $\tau_{1}$. Esse threshold representia basicanente. o gran

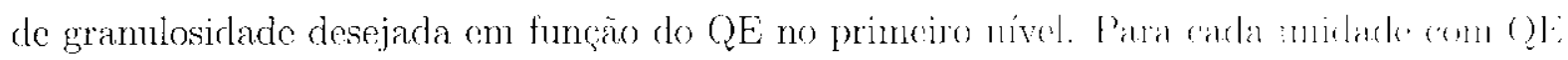
acima de $\tau_{1}$, um novo submapa é criado. O threshold da nova sub-rede ó nuna fracuăde de $\tau_{1}$.

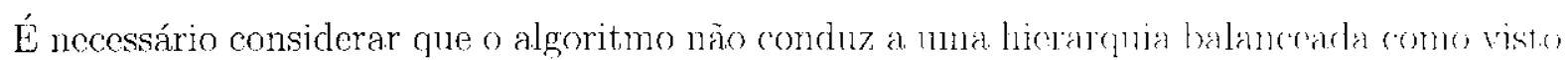
na Figura 2.10. A profundidade da árvore de SOM gerada é o reftexo da desuniformidade da distribuição dos dados apresentados.

\subsubsection{TS-SL-SOM}

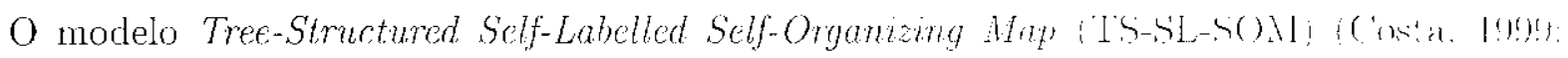

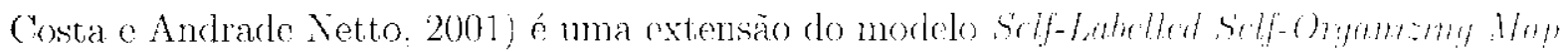
(SI-SOM) (1ue efetua o particionamento e rotulação automática de um mapa do lipo SO M. (Costa, 1999). Como pode ser observado na Figura 2.11, a principal contribuica do modelo

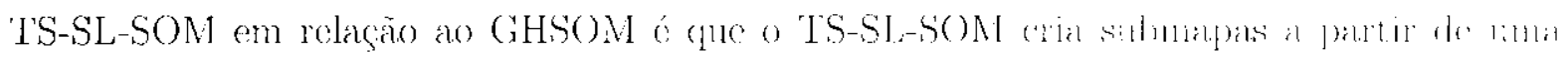
região e não apenas de mana única unidade. 

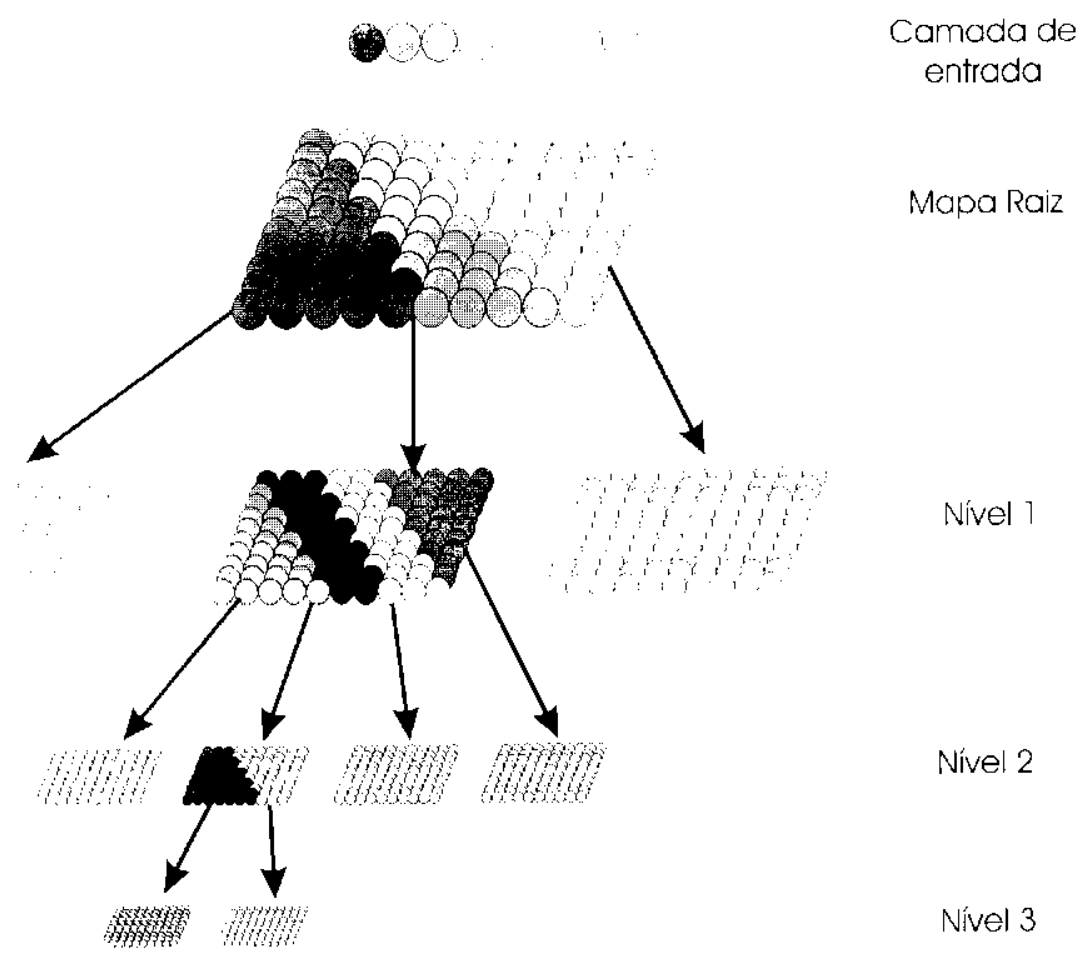

Mapa Raiz

Nivel 1

Nivel 2

Nivel 3

Figura 2.11: Tree-Structured Self-Labelled Self-Organizing Map.

l'ma onl ra vantagern de redes do tipo TS-SL-SOM ć que não é nocessário especificar, a prion\% o número de sub-redes para un determinado SOM em uma posição da árvore. Alóm

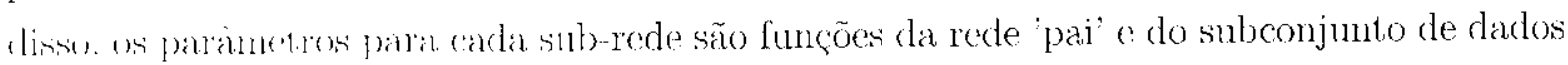

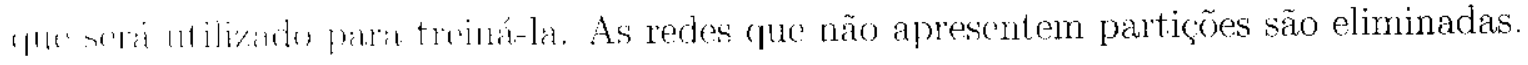

\subsubsection{AHIGG}

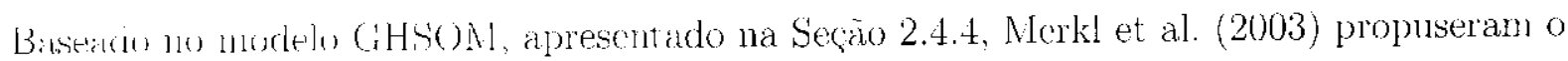
modelo Adaptine Herurchical meremental Grid Growng (AHIGG). As cantadas individuais

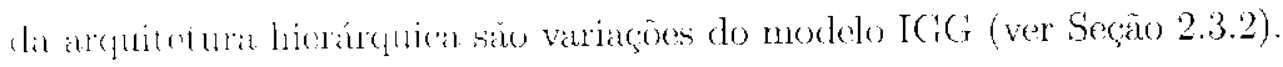

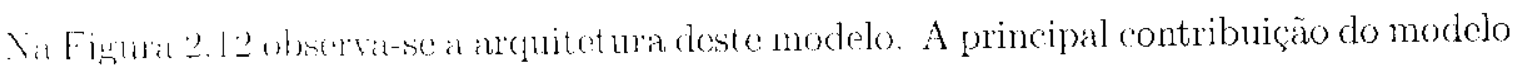
AHIGG, an comparaça ao GHSOM, é que os mapas individuais podem crescer de forma inregular. Ao nesmo tempo essses mapas podem, eventuahnente, remover conexöes cntre

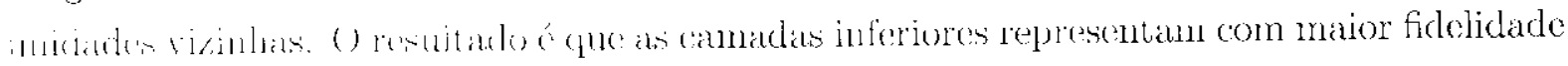
a distribuiçär dos darkos o que facilita a exploração dos dados visualmente.

Fxisto lambém un modelo hierárquico especial chamado Hierarchical Overlapped Neural (rus (HONCi) Snganthan. I9g9). Vesse trabalho os autores propöem un algoritmo onde as regione, polas quais as sub-redes säo responsáveis, apresentann sobreposição. A idéia pode sce aplicakla a qualcuu uma das redes hicrárquicas apresentadas nas seçōes anteriores. 


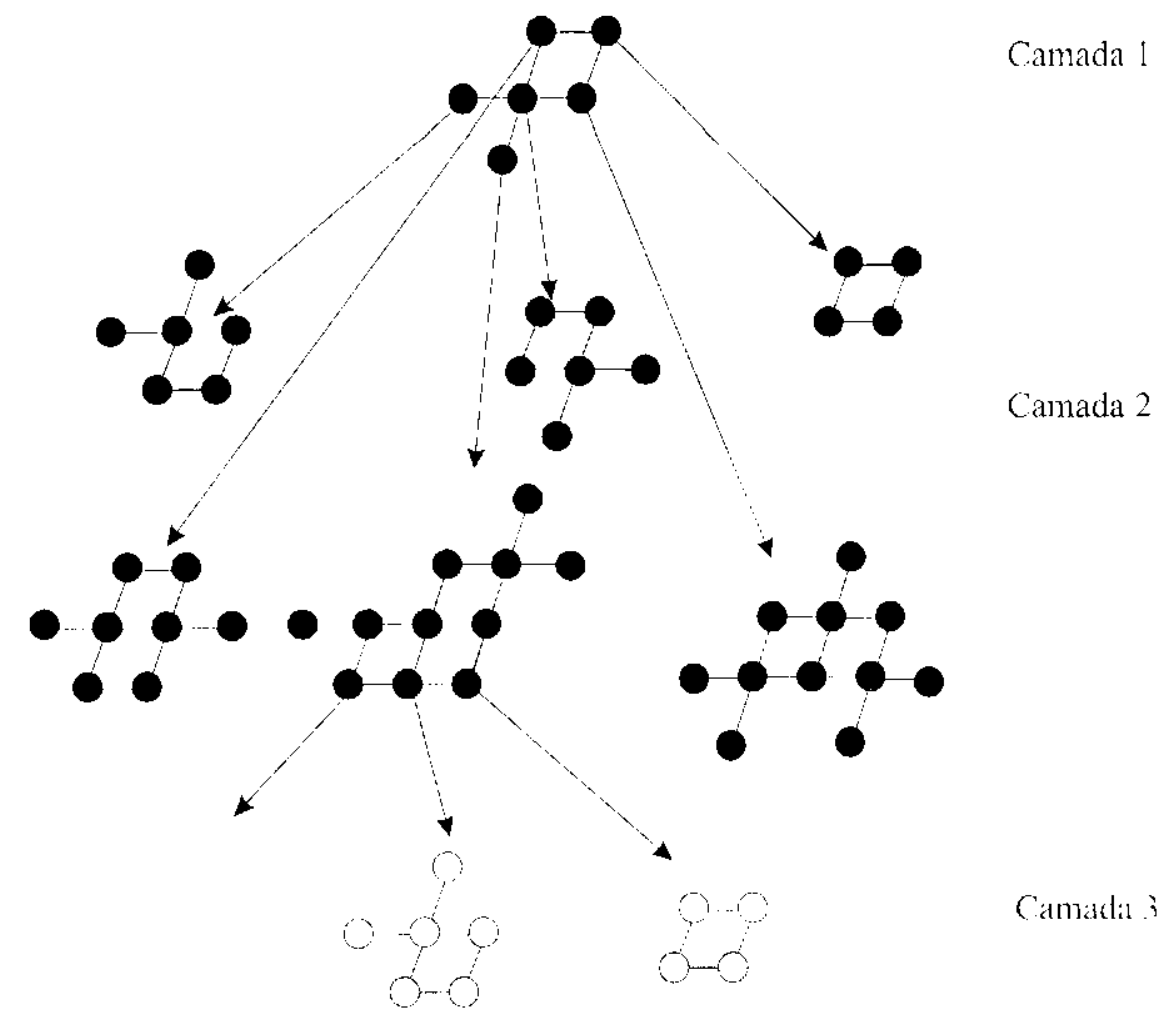

Figura 2.12: Arquitetura de uma rede $A H I G G$ (Merkl ct al., 20033).

Fm todas as redes SOM construtivas apresentadas anteriormente, o principio básico do um mapa de Kohonen é mantido. Quando um padräo é apresentado à entrada da rutr. o

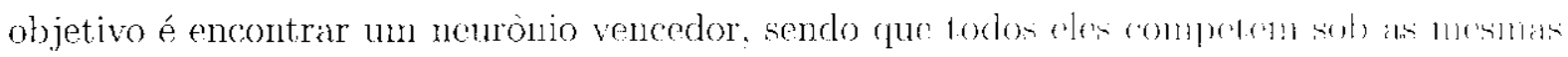
condiçōes. A idéia fundamental de utilizar-se um SOM hierárquico é criar uma reofo rapaz

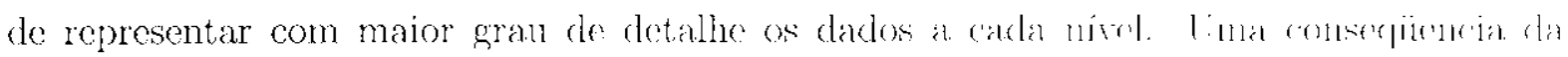
abordagem hierárquica é dimimuir o processamento necessúrio para (neontrar o neuronio vencedor.

\subsection{Considerações Finais}

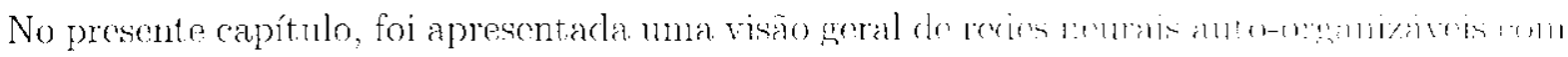

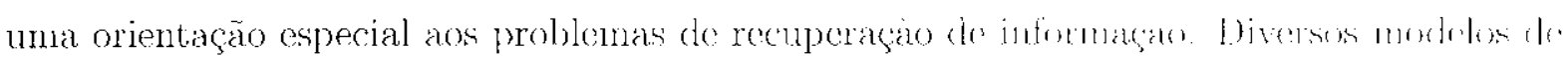
SOM construtivos também foram apresentados destacando-se suas vantagrns o linilacon.

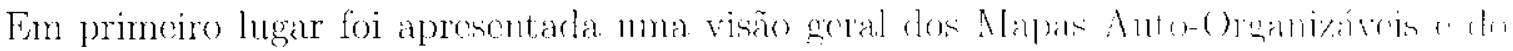

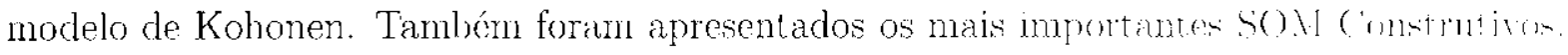

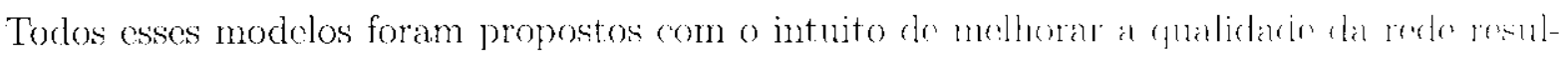

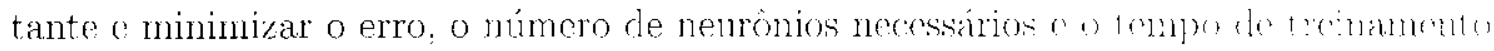




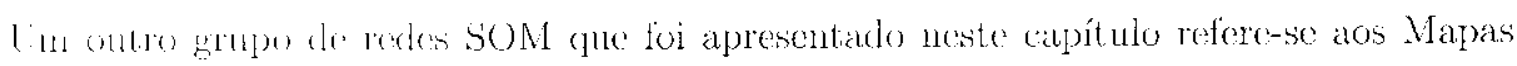

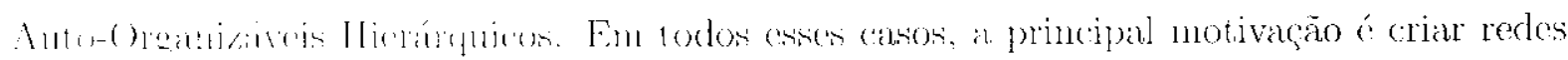

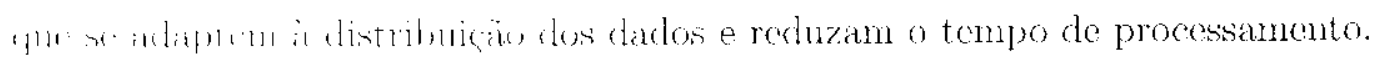

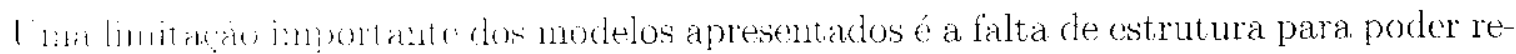

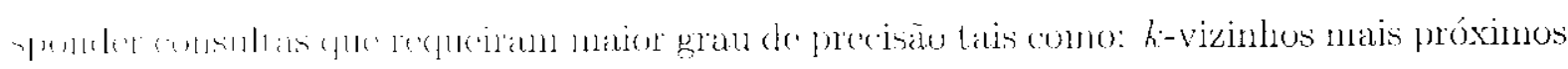

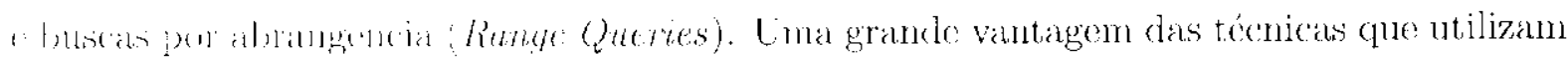
RYA contima scuto a slla capacidade de aprendizado o generalização, mesmo que isso signiticune maior quantidake de tempo envolvido.

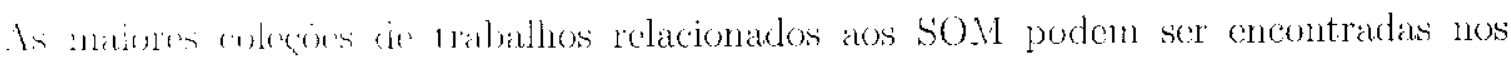

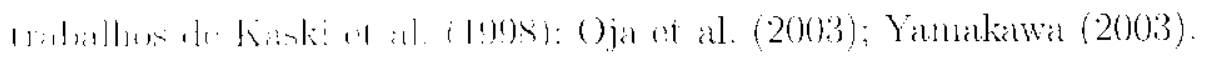




\section{Métodos de Acesso Espaciais e Métricos}

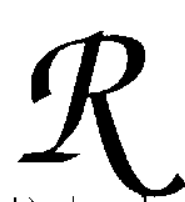

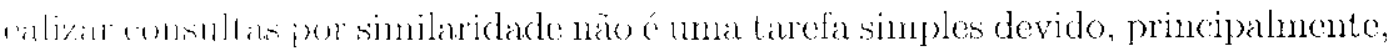

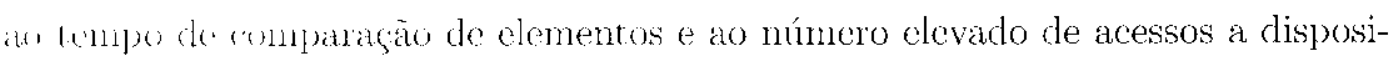
livos de ammzenamento (Baeza-Yates e Ribeiro-Ncto, 1999; Chávez et al., 2001).

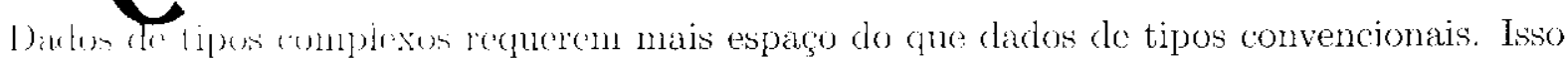

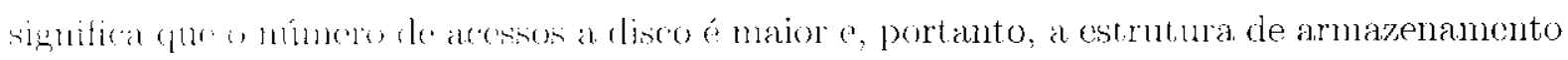
devo ser mais sofisticada. Também é importante considerar que comparar dois objetos

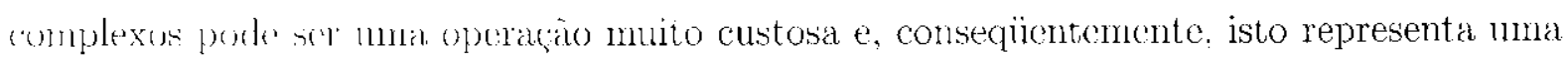

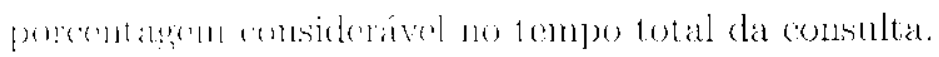

Para simplificar o processo de indexação de objetos complexos, são aplicadas técnicas de extrayar do características que dependem do domínio de dados. Fspera-so que as car-

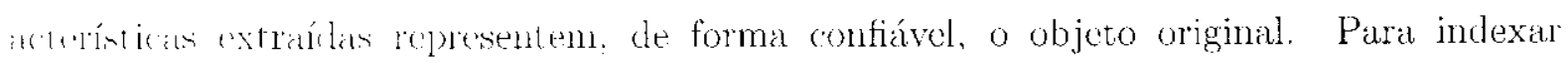

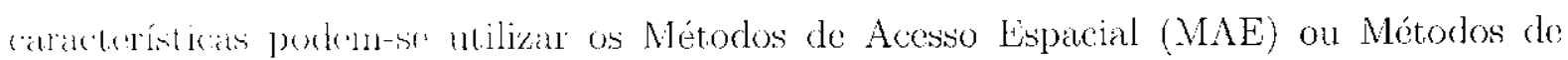
Acesso Nótrion (MAN) os quais serão descritos em detalhes neste capítulo. Antes de iniciar

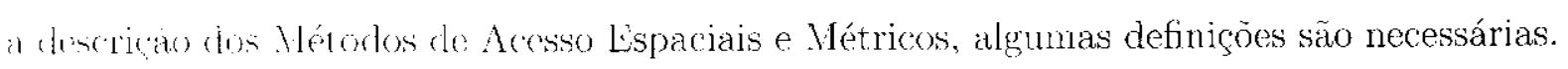

\subsection{Definições}

Yesta scrâo sian aprosculadas várias definições necessárias à compreensão dos métodos que seráo dincouticlos nester capílulo.

\subsubsection{Grafos e seus elementos}

Unu grafo (ver Figura 3.1) é um conjunto finito de pontos, chamados de nós, conectados atrave de arestas (Cakiwell, 1995). 


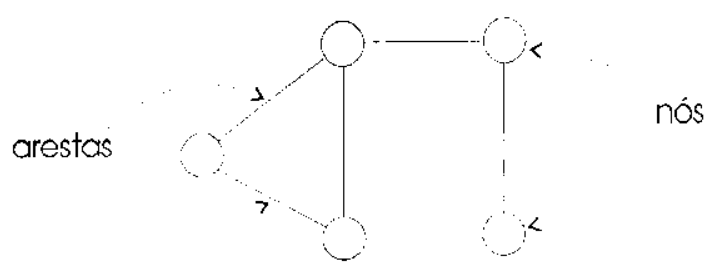

Figura 3.1: Componentes de mm grafor.

Um grafo completo com n nósé um grafo onde cada um doss nós é concctado com os $n-1$ nós restantes (através de arestas). Isso significa que, para qualquer par de nós distintus $(a, b)$, existe uma aresta que os conecta de forma direta.

Um grafo direcionado, ou simplesmente dígrafo, ó 1 m grafo no (lual as arestas säo direcionadas. Nesse caso, carla arestáa conecta dois nós em apcnas 11 m sentidn.

\subsection{2 Árvores e seus elementos}

Una estrutura de indexaçào de dados hierárquica, tambén conhecida cono árvore, possui certos elementos que são definidos a seguir (ver Figura 3.2). A matior parte das entruturas apresenta um nó que corresponde ao ponto de entrada da árvore chamado do raiz. Ouamu um nó $x$ aponta para um nó $y, x$ é chamado de nó pai e $y$ de nó filho. Se $y$ tiver 1111 on mais filhos, ele é dito nó interno. Caso contrário, y é denominado nó folha.

O subconjunto composto por $y$ e sens filhos é considerado uma sub-árvore de $x$, da qual y é chamado de raiz.

O número máximo de entradas que um nó pode tor é chamado de cardinalidade do

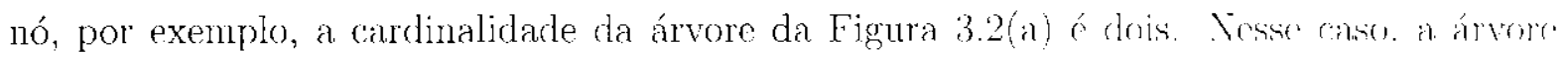
é chamada de árvore binária e os filhos säo chamados filho esquerdo filho direito respectivamente.

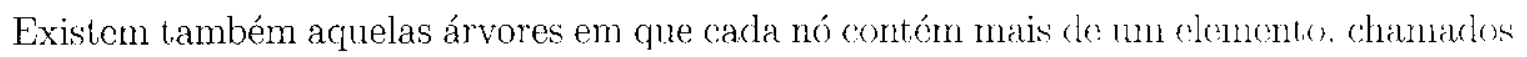
de entradas da página ou nó. Nesse caso, a árvore ć chamada do árvore multivias on árvore n-ária.

O número máximo de ligações de saída que um nó pode tor a chamado dr grau ui

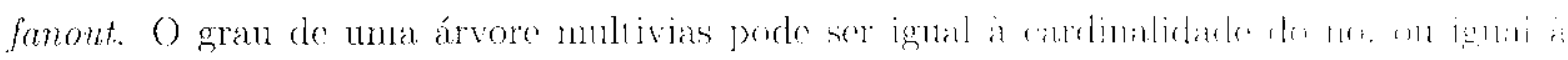
cardinalidade do nó acrescido de uma unidade.

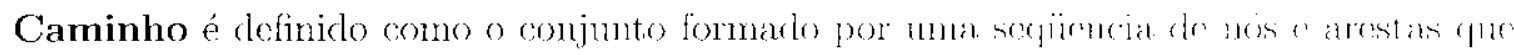

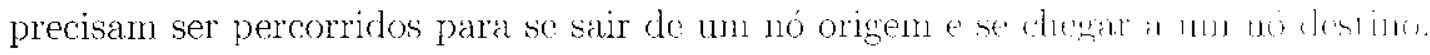

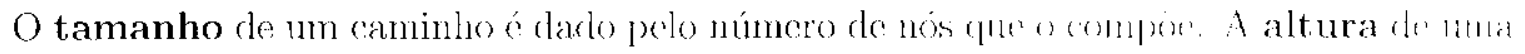
árvore é definida como o tamanho do maior caminho que pode ser feito a partir da rais. 


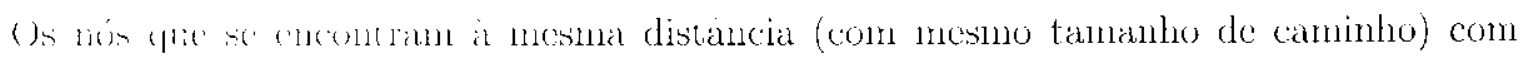

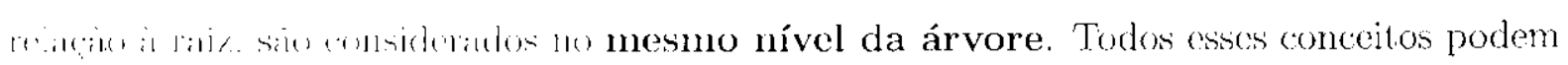

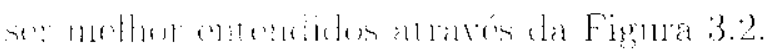

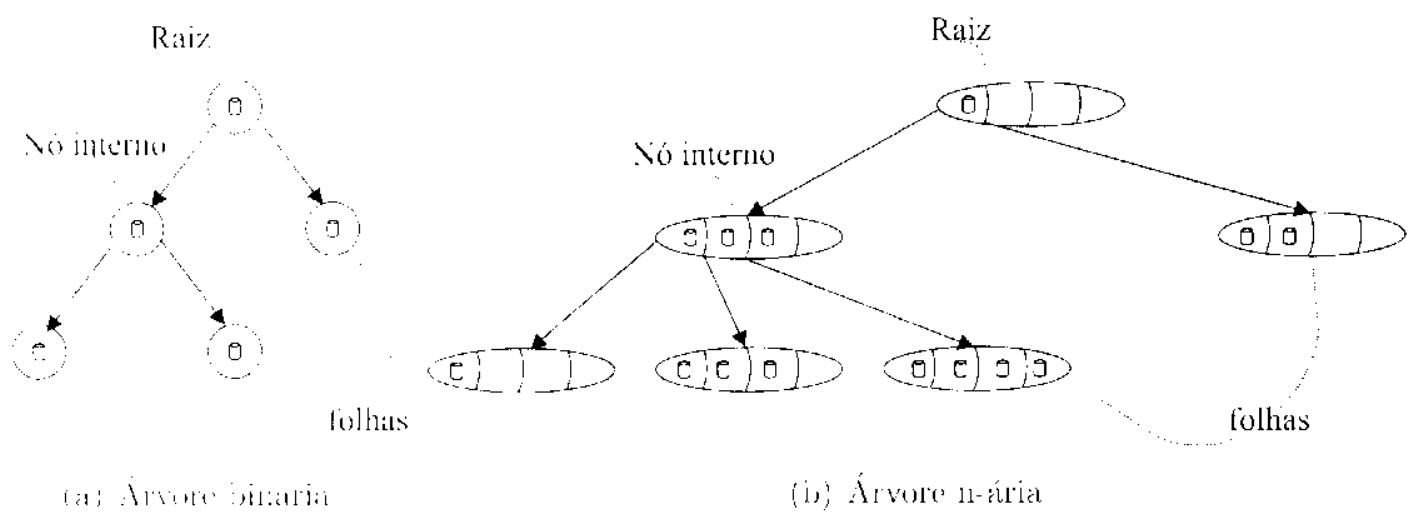

Figura 3.2: Elementos de uma árvore.

\subsubsection{Espaço Métrico}

('onsiderandu (pue sé o o dennínio on universo de objetos possíveis ou válidos. O subconjunto

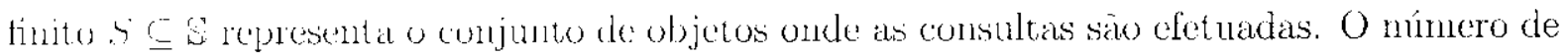
anemente $n$ de $S$ i dencotado por $n=|S|$. O conjunto $S$ poderia ser considerado como um dicionário. banke de dados on, simplesmente, conjunto do objetos ou elementos.

Aleru do conjunto $\$$. considera-se também a existôncid de una funçăo de distância métrica (hamealia do (). A funçäo do:

$$
d: \mathbb{S} \times \mathbb{S} \rightarrow \mathbb{R}
$$

("orrespende i medida de "distancia" entre dois objetos. Isso significa que quanto menor

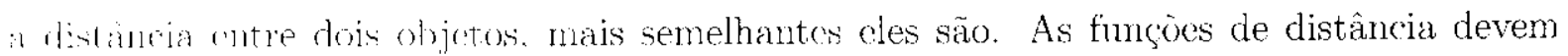

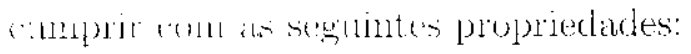

$$
\begin{aligned}
& \text { (p) } 1: \forall x, y \in S \cdot d(x \cdot y)>0 \quad \text { positival }
\end{aligned}
$$

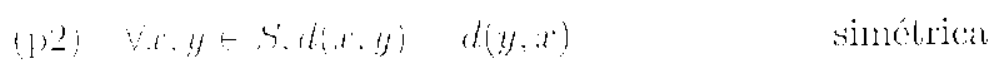

$$
\begin{aligned}
& \text { (1) } 3) \forall x \in S, d(x, x)-0 \quad \text { reflexiva } \\
& \text { a coul alguns casos, }
\end{aligned}
$$

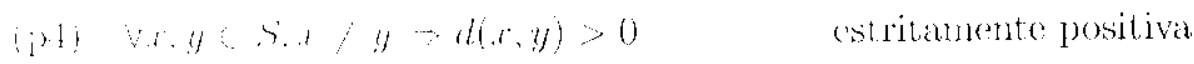

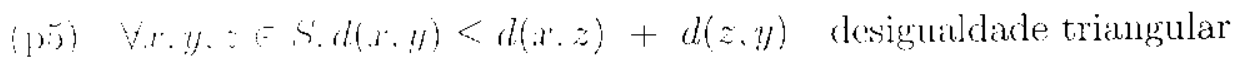

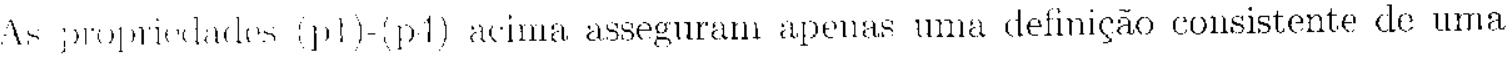
funçào de distància. Porém, se a função $d($ ) satisfizer ( 15 ), o espaço $\mathbb{M}$ definido pelo par ( $\boldsymbol{S}$, 
d()) é chamado Espaço Métrico o a função distancia é chamakta Função do Distância

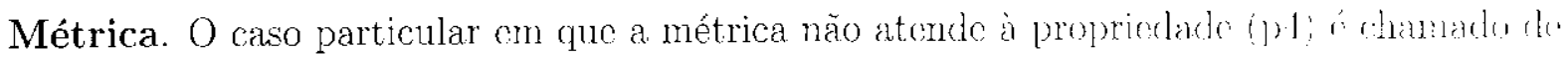

\section{Espaço Semi-Métrico ou Pseudo-Métrico.}

Lim exemplo de espaço métrico é o formado pelo conjunto do palavras da língna portuguesa e pela função de distância métrica de Levenshtcin on $L_{\text {Hat }}(x, y)$ (Trevenshtein. 1966; Sankoff c Kruskal, 1983). Essa métrica retorna a quantidide mínima de letras qur precisam ser substitúdas, removidas ou inseridas em $x$ para converticha lam $y$. Por exemplo. $L_{\text {Edit }}($ mesa, velas $)-3$.

\subsubsection{Espaço Vetorial}

Para entender melhor o conceito de espaço vetorial, considera-se a reguinte not açào:

$K$. é o corpo de valores escalares;

a. b. cou k, os elementos de $K$;

$V$, o espaço vetorial dado;

$u, v, w$, os elementos de $V$

Seja $K$ um corpo arbitrário e seja $V$ um conjunto não vazio com operações de adição e multiplicação por escalar que determinam, para qualquer $u, v \in V$, uma soma $u-v \in V \mathrm{r}$ para cualquer $u \in V, k \in K$, um produto $k u \in V$. Entáo, $l$ 'Alumadu Espaço Vetorial

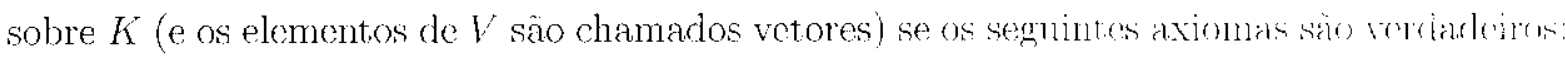

[A1] : Para quaisquer vetores $u, v, u \in V:(u+v) \cdot u:=u(v+w)$

[A2] : Existe um vetor em $V$, denotado por 0 e chamado vetor mulo tal que, para qualquer $u \in V, u+0-u$.

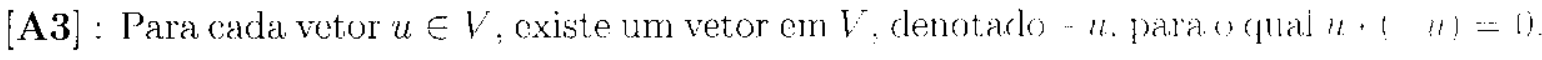

[A1] : Para quaisquer vetores $u, v \in V, u+v=\imath:-u$.

[A5] : Para qualquer escalar $k \in K$ o quaisquer vetores u. ${ }^{-} l^{\prime}$.

$k(u+v)=k u+k v$

[A6] : Para quaisquer escalares $a, b \in K$ o qualcuer wotor $\| \leq 1$

$(a+b) u=a u+b u$.

[A7] : Para quaisquer escalares $a, b \in K$ e para culalopuer wotor a : 1 .

$(a b) u=a(b u)$.

[A8]: $1 u=u$, para qualquer votor $u \in V$. 


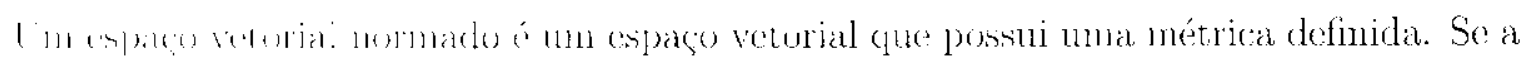

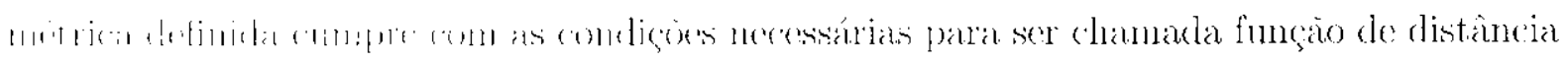
métrica ver Seço 3.1.3). O espago vetorial junto com a funçăo de distância podem formar man esparco metricos.

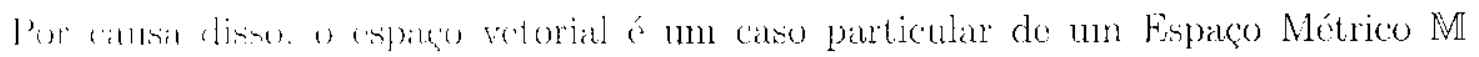

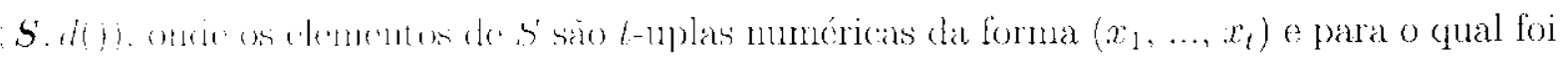

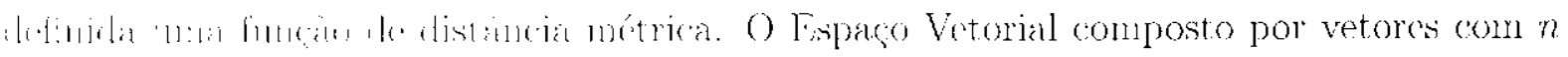

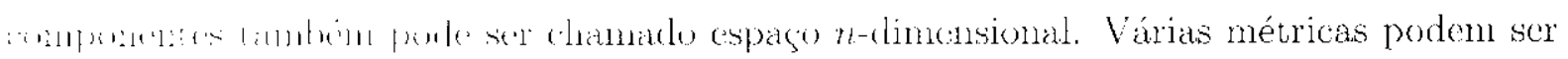

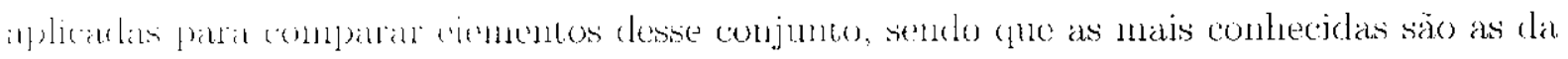

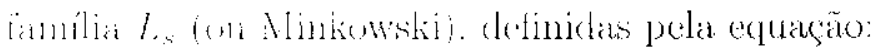

$$
L_{n}\left(\left(x, \ldots, x_{n}\right),\left(y_{1}, \ldots, y_{n}\right)\right)=\left(\sum_{i=1}^{n} \mid x_{i}-y_{i}\right)^{1 / s}
$$

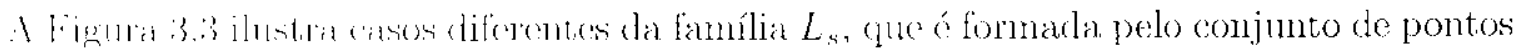
chle estric in mesina tistancia, $r_{q}$, a partir de um contro $o_{q}$. No exemplo, a métrica $L_{1}$, lambém (onlexida (onu Bloco ou Manhattan, corresponde ao somatório do módulo das diferenças untre as courtenaklat. A métrica $L_{2}$, nuais conhecida como distância euclideana, é a função

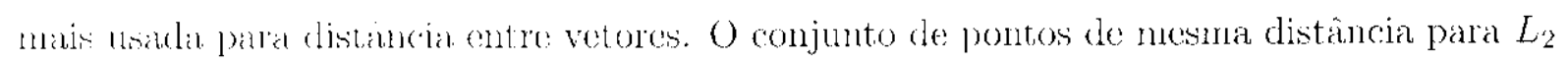
forma luna circunferomeja.

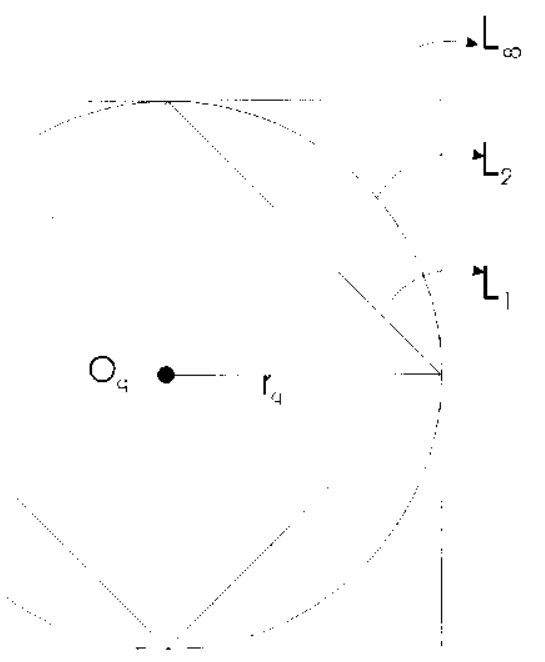

(a)

Figura 3.3: Representacá dos pontos situados à distancia $r_{q}$ a partir do objeto $o_{q}$,

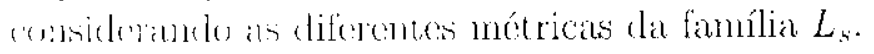

Calculande-se o linite de $L_{s}$ quando $s$ tende ao infinito, obtén-se a métrica $L_{\infty}$ apresentiula nat Equaçice (3.3), onde o conjunto de pontos com mesma distância formann um (fuikirituts. 


$$
L_{\infty}\left(\left(x_{1}, \ldots, x_{k}\right),\left(y_{1}, \ldots, y_{k}\right)\right)=\max \left|x_{i}-y_{i}\right| \forall i / 1 \leq i \leq k
$$

A família $L_{s}$ é vasta e outras variantes podem ser olutidas a partir rla Equacin (32)

\subsection{Métodos de Acesso para Dados unidimensionais}

Quando os dados são de tipos simples, o critério básico para a insercio chn 14 ma cstrulura de dados é a comparação cutre cles. Dessa forma é possível definir una relaçâo rle orden.

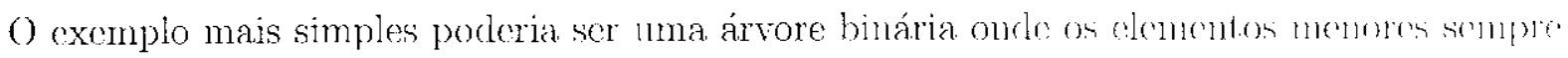
são inseridos à esquerda e os elementos maiores à direita. Na Figura 3.4, porle-se observar a posição onde foi inserida uma nova chave em uma ́́rvore que tem o domento s na raiz.

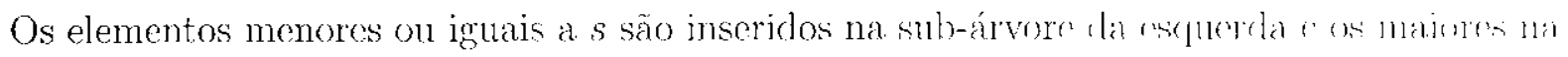
sub-árvore da direita.

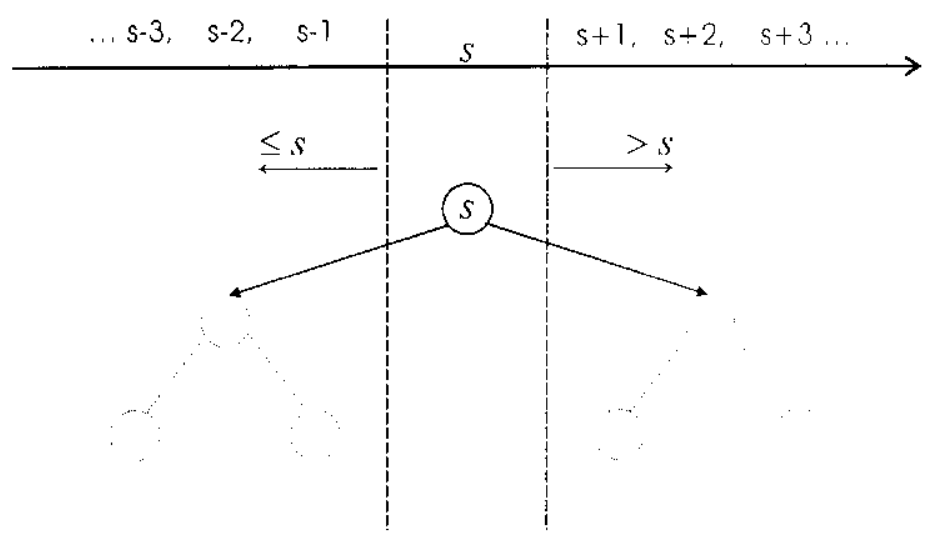

Figura 3.4: Critério de inserção em umáa árvore biıária simules.

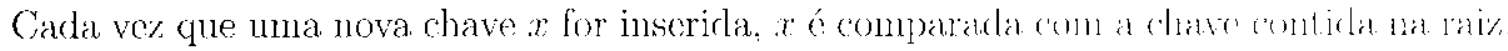
Se for maior, o procedimento é repetido recursivamente com o nó da direita e, se lor menor, com o da esquerda, ató alcançar um nó com o ponteiro correspondente vario.

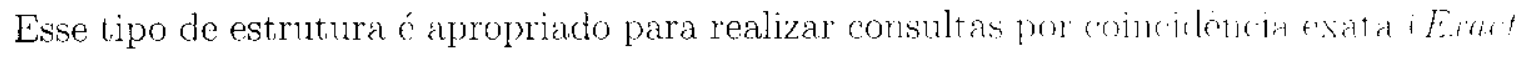

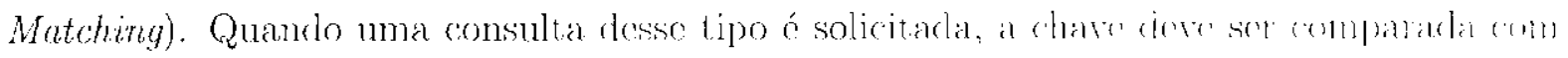

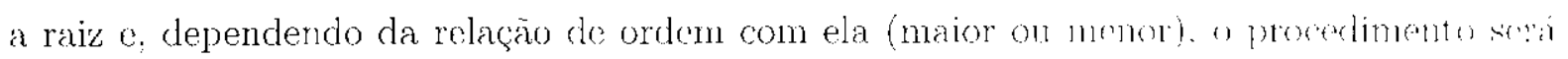

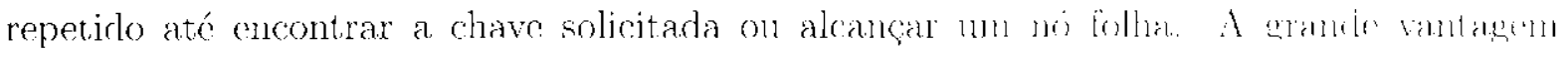
desse tipo de estrutura é que rlepois de comparar 1 me elemento com at chave ta raiz so muna sub-árvore será a escolhida para repoctir o procerlimento. Isso significa cpue para carda pergunta.

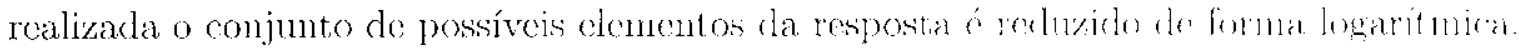

A mais conhecida dessas estruturas é a árvore B (B-Tres) (Comer. 1979). comsidermala

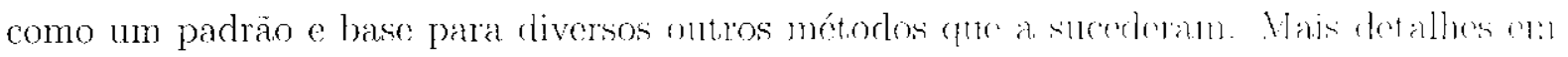




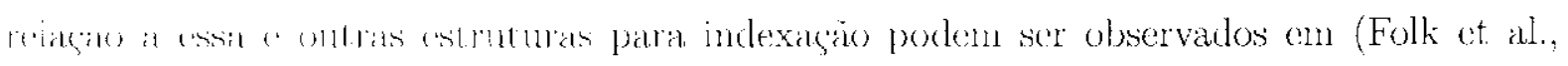

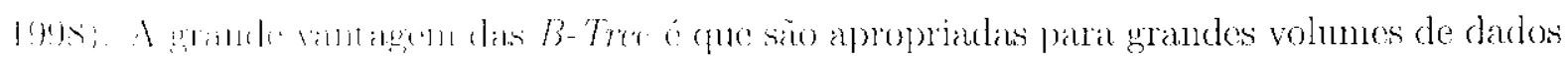
"arnazenannenter en menória secundária (disco). No caso de armazenamento em disco, cala página lógica conresponde, na maioria das vezes, a uma página física no disco.

I nat b-The difere da árvore binária convencional pois é construída de forma ascendente.

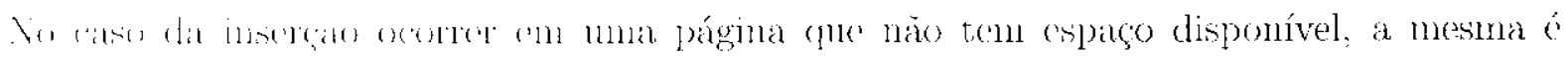

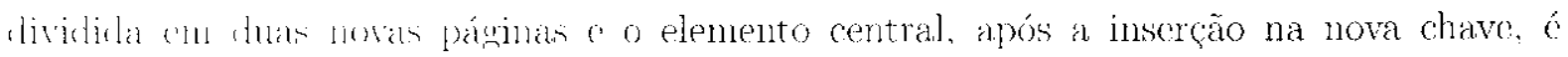

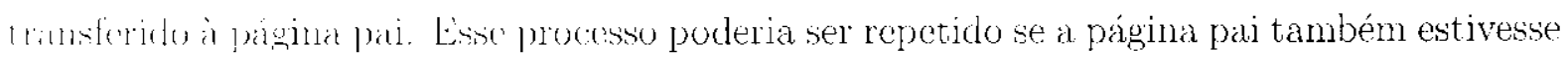

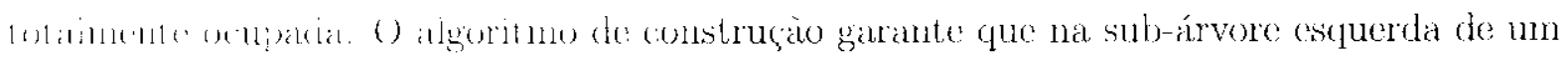

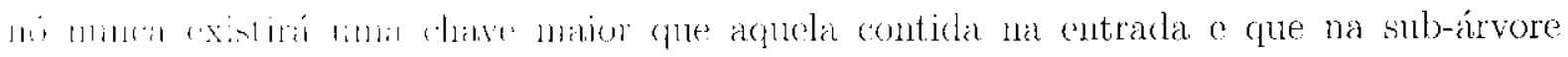

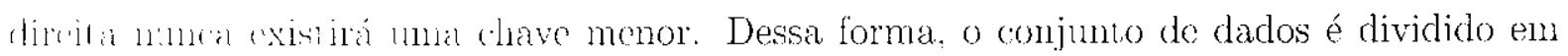
suluxuljunton disjunton. Vesse tipo de árvore, a interseçäo de sub-árvores do mesmo nívol

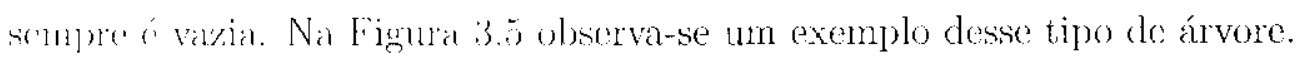

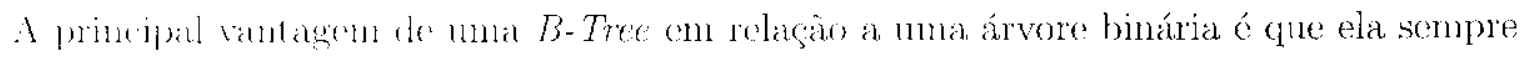
esté bulanceada. Isso significa que todos os nós folhas estào à mosma altura, permitindo

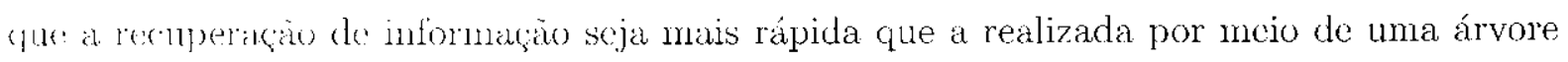

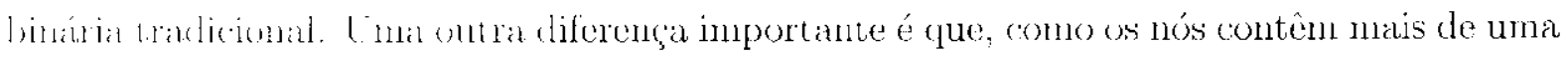

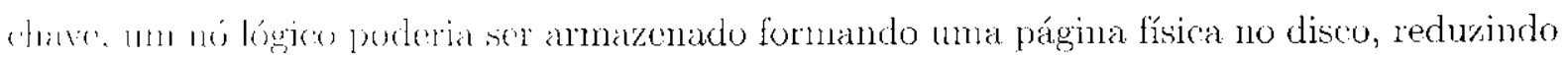
os acessos a memória secundária. O algoritmo de inserção de uma B-Tree garante que cada

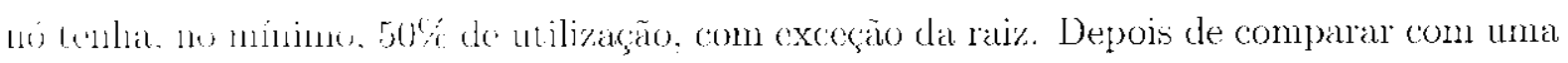

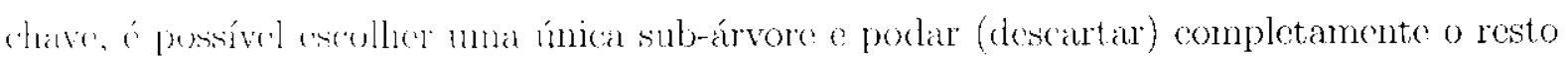
delas. Além de podar sub-árvoress lambém é possível reduzir as comparações com chaves do mesinos no.

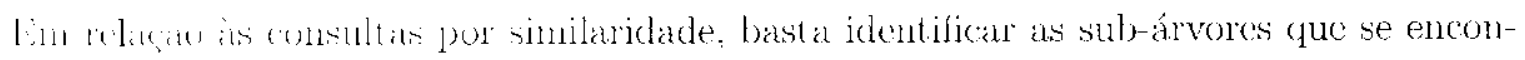
1.ran dentro da reglio de busea $R\left(2\left(O_{4}\right)\right.$ como apresentado na Figura 3.5. Nessa figura,

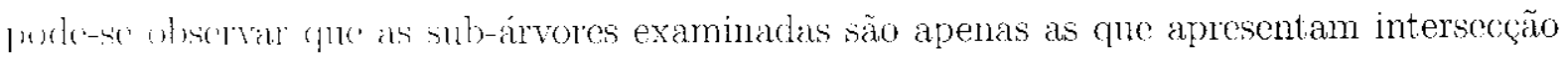
wnli a regian do buscal. Nij exemplo apresentado, o centro da consulta é o número 67 com unn raio de 10 unidades.

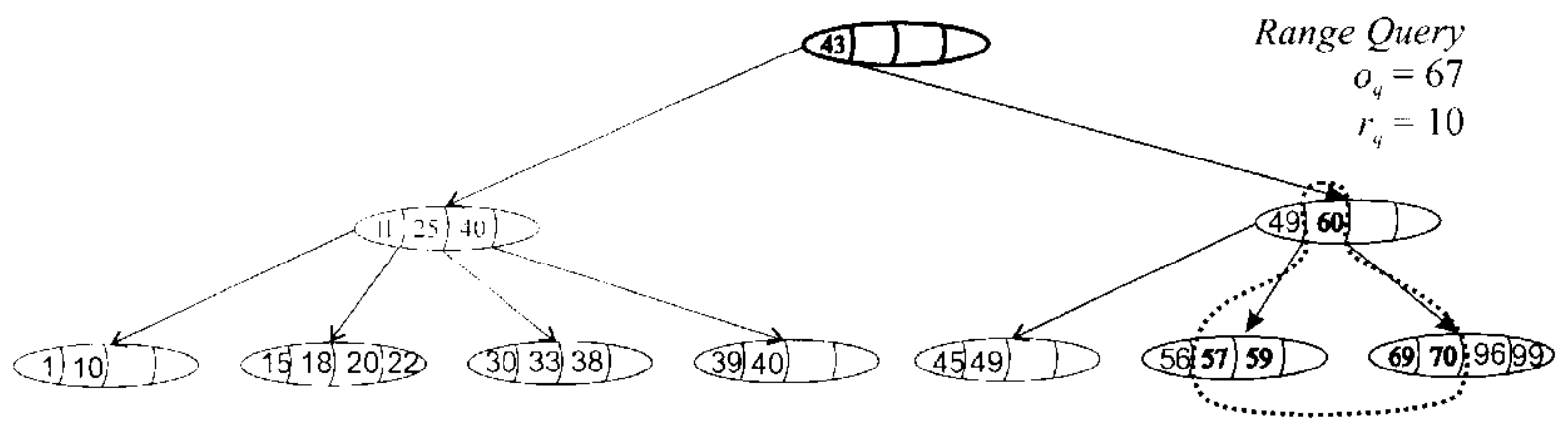

Figura 3.5: Range Query em umácúrore n-ária. 
No caso de consultas do tipo $k$-vizinhos mais próximos; o algoritmo ó inicializado cono uma consulta por abrangência onde o raio diminui à medida em que é cncontrado um vizinho mais próximo do que os existentes. Ou seja, inicialmente o raio de busca é considerado muito

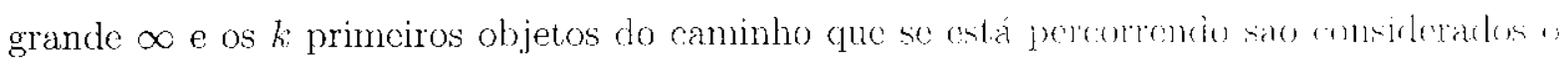
conjunto de candidatos. Vesse momento, o raio passa a ser a distancia tnt.pe o objeto cir busca $o_{q}$ e o mais distante dentre os que estão na lista. Para que o raio seja reduzido mais rapidamente, diminuindo o númcro de comparações, é usual que o primeiro caminho a ser. percorrido seja o que leva diretamente à região onde o objeto do busca sc cncontra.

Cada vez que um objeto mais próximo for encontrado, este deve ser inserido no conjunto

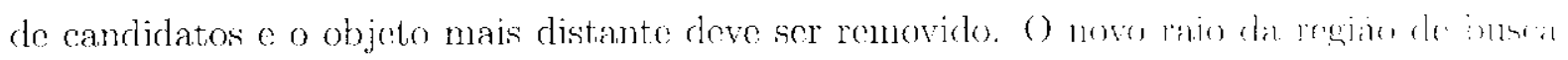
será a distância de op para o atual mais distante (que näo necussatianente ( ) novo). () mesmo procedimento é repetido atć que nenhuma outra sub-árore faça interscccào como raio de busca.

Os métodos descritos anteriormente são muito itteis para darlos simpless porém. para indexação de outros tipos de dados, tais como vetores, essas técnicas não säo as mais apropriadas. Para esses tipos de dados existem os métodos de aresson ceparial que sain detalliados a seguir.

\subsection{Métodos de Acesso Espacial}

Os Métodos de Acesso Espacial (MAE) são técnicas para indexar o recuperar informaçăo em conjuntos de dados vetoriais.

Uma das primeiras técnicas a serem propostas na literatura para a butexacio de datus espaciais foi Space Filling Curve. O primeiro trabalho foi o Peano Curne do Morton (1966).

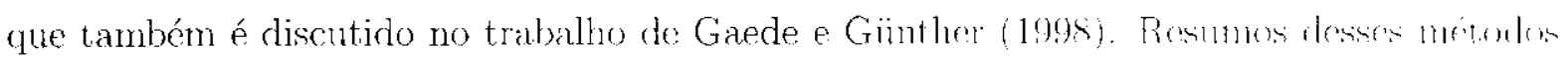
podem ser encontrados en (Samet, 1995; Gaede e Günther, 1998: 13öhm ot al.. 2001).

Como o objetivo é indexar pontos da forma $\left(x_{1}, x_{2}, \ldots, x_{n}\right)$, uma estrutura do tipo $B$-Tree não scria a mais adequada, pois nessa estrutura aponas podem ser inseridos objetes simples.

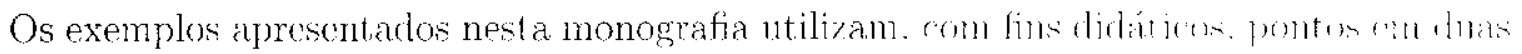

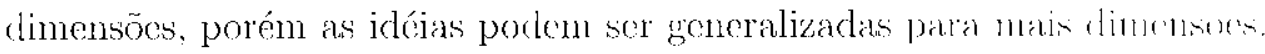

\subsubsection{Métodos de Acesso para Dados Pontuais}

Os chamados Métodos de Acesso Espaciais para Dados Pontulais (MAFP), tom sido matros

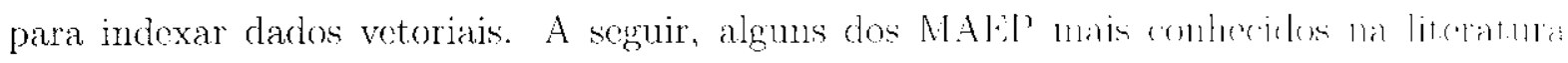
scrão apresentados. 


\section{PointQuad-Tree}

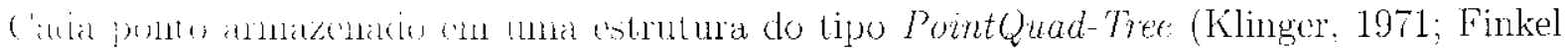

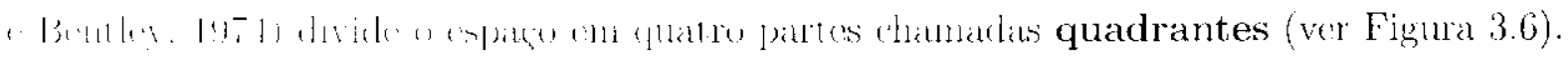

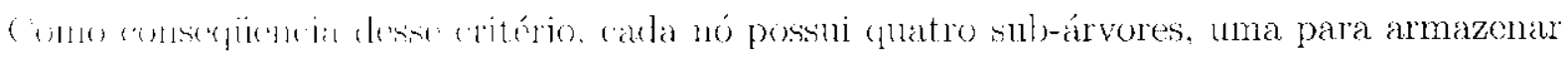
a inlormaga relacionada a cada quadrante (ver Figura 3.7(b)). A forma de definir a posição

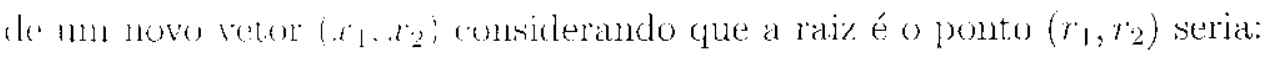

$$
\begin{aligned}
& \text { I (inadrande } \mathrm{XE} \text { (nordester): VLe se } x_{1} \geq r_{1} \text { e } x_{2} \geq r_{2} \text {; }
\end{aligned}
$$

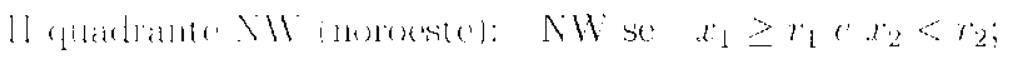

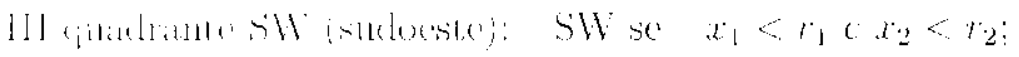

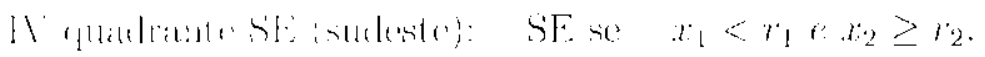

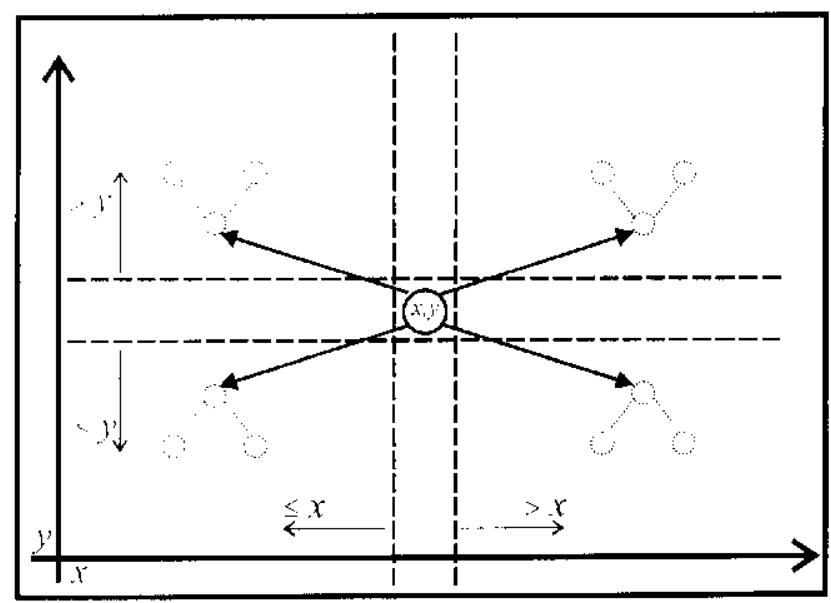

Figura 3.6: I)ivision do espaço en quadrantes utilizando PointQuad-Tree.

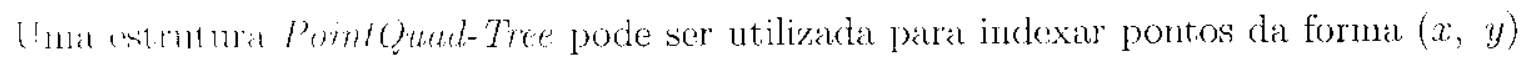

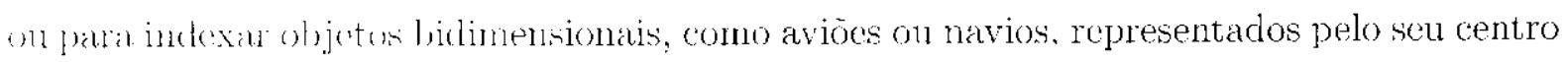
$(x . y)$. Na Figura 3.7(a) pode-se observar objetos que são indexados utilizando seu respectivo $(x+11,1)(x, y)$

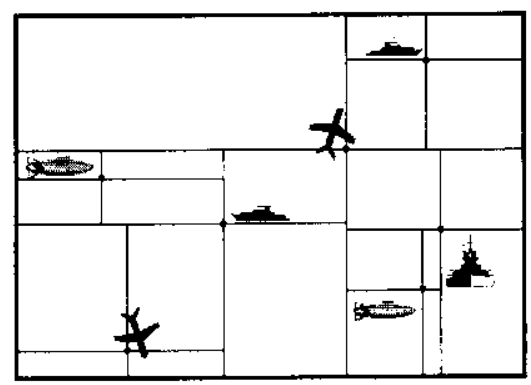

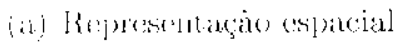

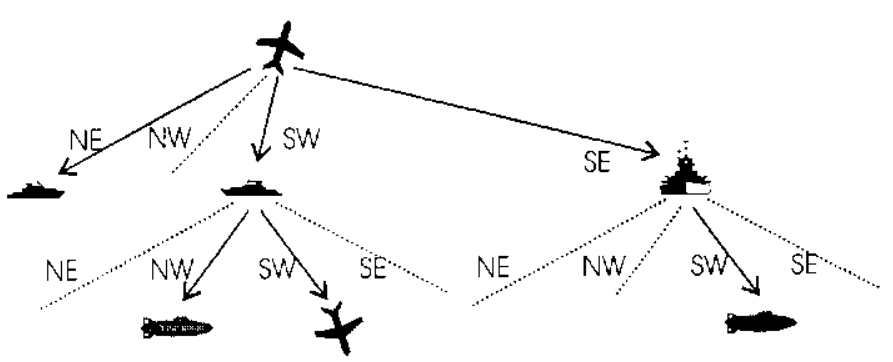

(b) Fepresentação esquemática

Figura 3.7: Estrutura de uma árvore PointQuad-Tree. 


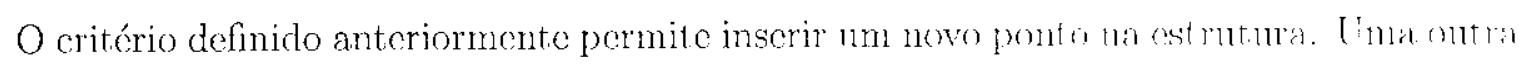
versão da mesma estrutura para pontos 3-d é chamada de Oct. Tree. Nesse caso o cepaco a dividido em oito octantes.

\section{k-d-Tree}

Una estrutura que tambóm permite a inserção de pontos did forma ( $x, y)$ ó conhecida como 2-d-Tree e foi apresentada por Bentley (1975). Essa estrutura ntiliza uma coordenada k cada vez para cada nível da árvore. Para indexar um ponto ch forma $(x, y)$, o valor do $x$ a utilizado para decidir, no primciro nível, se o ponto deve ser inserido à direita ou à escucrda

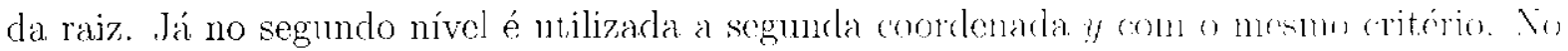
caso de pontos com duas coordenadas, o processo é repetido a partir do terceiro nivel com $x$, no quarto nível com y e assim em diante. como observado na. Figura 3.8.

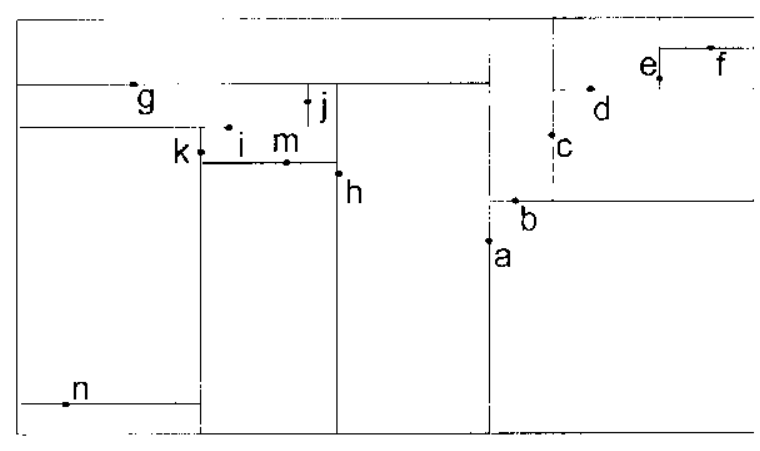

(a) Representação espacial

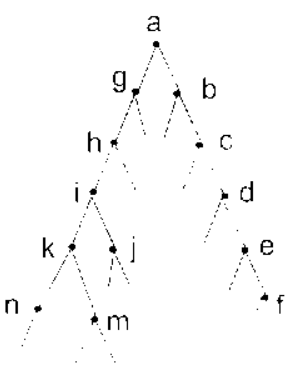

(b) Representacant escuenuáticial

Figura 3.8: Estrutura de uma árvore 2-t-Trer

$\Lambda$ generalização das estruturas 2-d-Tree para $n$ dimensões deu origem às estruturas

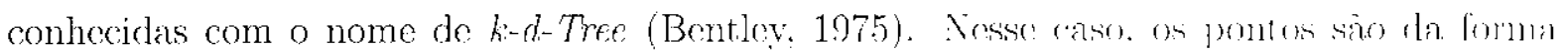

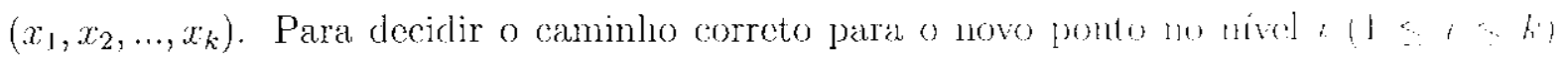
é utilizada a coordenara $x_{i}$. De forma similar às estruturas 2 - $d$-Tree. no nível $k+1$ a coordenada utilizada novamente será a $x_{1}$, para o nível $k+2$. a $x_{2}$, c assim sucessivanuento.

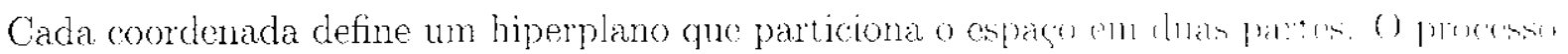

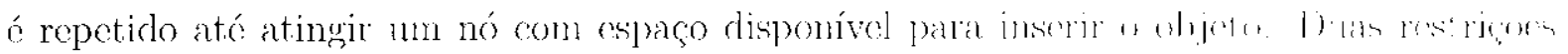
das k-d-Tree são que cla é voltada para memória principal e que a arvore criada näo ruta balancoada.

\section{k-d-B-Tree}

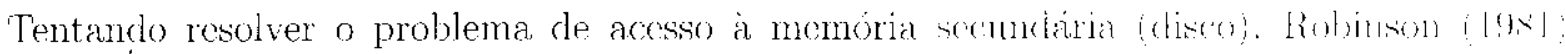

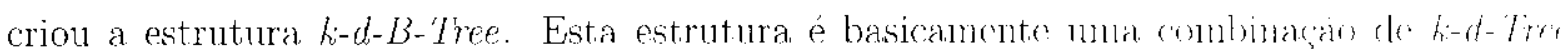
c B-Tree. Cada nó possui um Minimum Bounding Rectangle (MBR) fure chvolve todas 


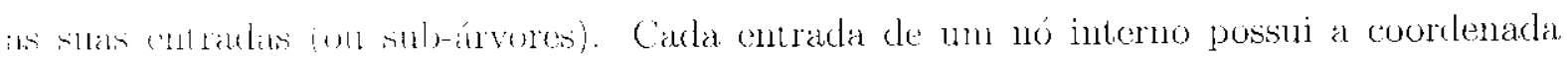

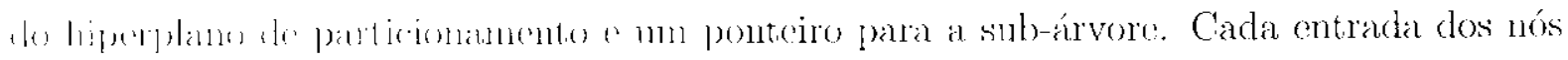

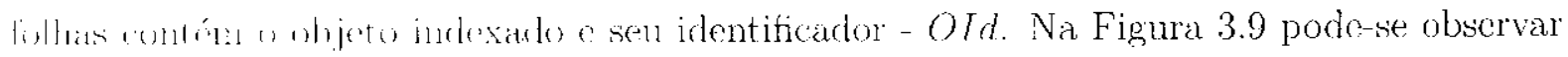

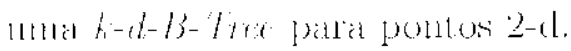

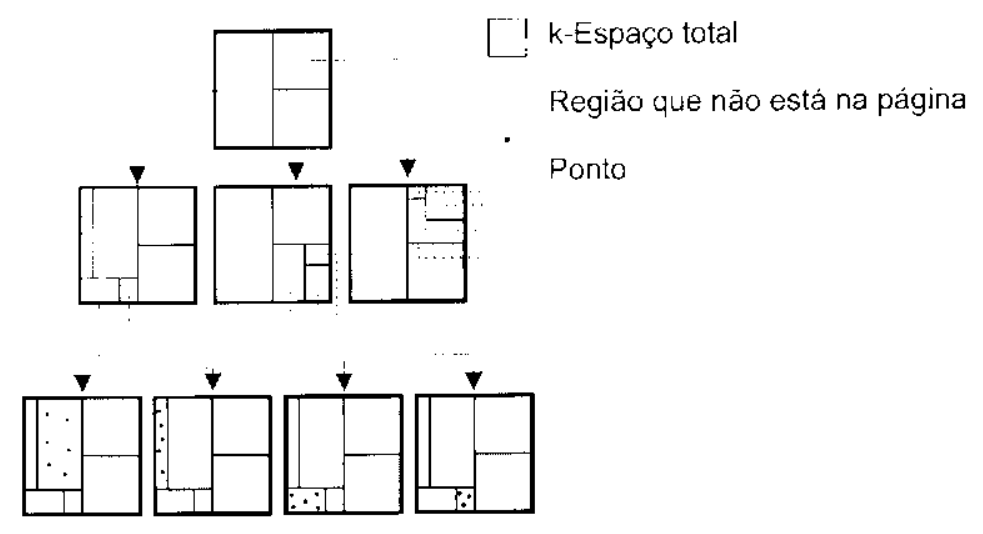

Figura 3.9: Lxemplo de una ostrutura 2-d-B-Tree.

Vima das principais linitaços que este método apresenta é que o particionamento de um

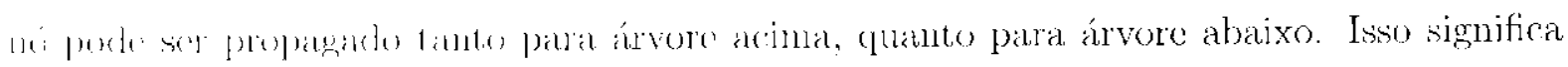

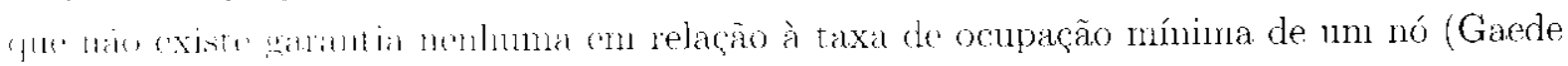
e Günther, 1998): podendo ser criados nós vazios.

Além dessis cstrut.uras, existem muitas outras variaçoes que foran criadas com o in-

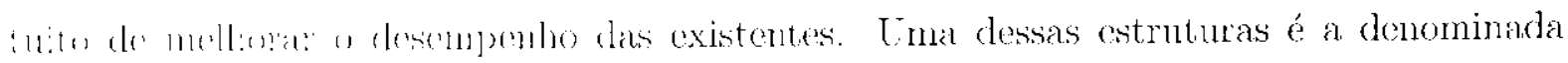

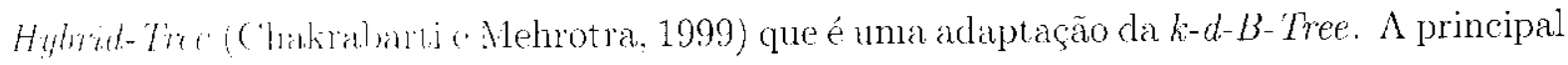
vant agem apresent ałlaté pernnitir a criação de regiöes sobrepostas (não disjuntas). Essa modi-

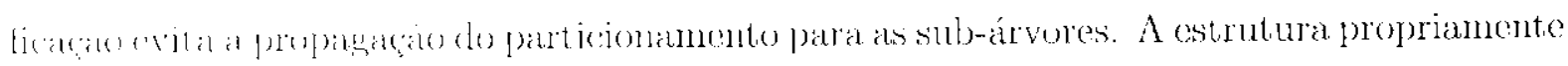
¿lita a semblhante a $k$ - $d$-B-Tree e, de forma análoga, gera uma árvore batanceada.

Todas as estruturas mencionadas anteriormente apresentam limitações quando os dados pertencem a dinensōes mais altas. Esse problema é denominado a "maldição da dimension-

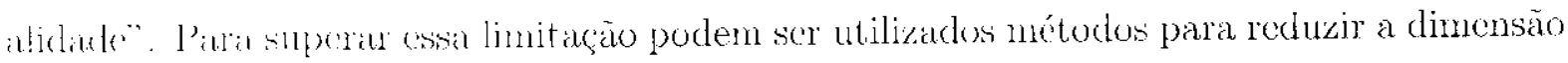
les dades lais (onus: Mulli-Dinensional Scaling (MDS) (Torgerson, 1952), Nonlinear Mapmug (NIAL) I.W.Sammon. 1969), a transformada de Karhunen-Loève ('K-L') (Duda c Ilart,

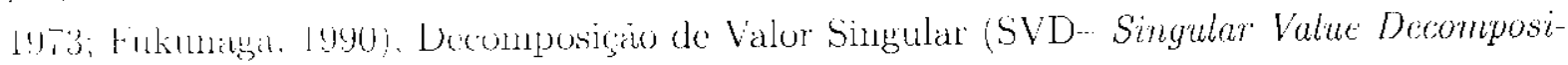
hom) (Strang, 1980; Press et al., 1988; Golub e Loan, 1989) on o FastMap (Faloutsos e Lin, 1994; Faloutisos (d al., 2003).

Para diminuir us efeitos elesso problema, foi criada a árvore TV-Tree (Telescopic-Vector) iLin et al.. 1994), que usia subconjuntos de coordenalas dos vetores em nós internos:

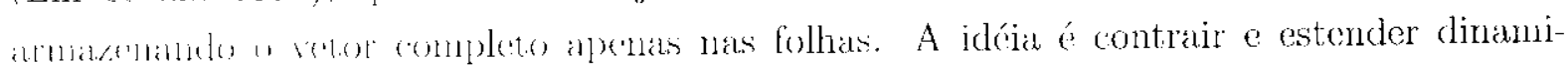

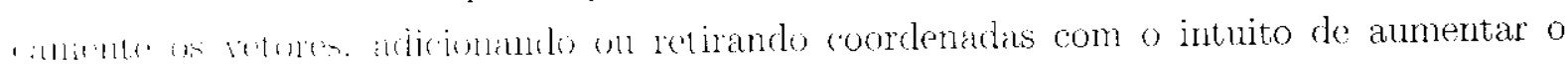
poder discriminatório. 
O nome desta estrutura, Telescopic-Vector, é uma analogia com o movimento do contrair c estender um telescópio. Um exemplo dessa função seria, simplesmente descartar algumas coordenadas e considerar apenas as primeiras. Estas estruturas saio somelhantes is R-Thre (ver Seção 3.3.2), com uma adaptação do MBR para organizar os vetores telescópicos, criando assim o Telescopic Minimum Bounding Reclangle (T'MBR).

$\Lambda$ idćia principal da criação de todas essas estruturas é manter of dudos organizados para que, dada uma consulta, seja possivel descartar todas aquelas sub-árvores com as quais năo exista interseção com a região de busca.

\subsubsection{Métodos de Indexação para Dados Não-Pontuais}

Existem outros tipos de dados tais como: triângulos, quadrados, retringulos que nào porten ser indexados como pontos isolados, pois são formados por mais de um ponto. Nesse caso não ć difícil perceber que os MAEP não seriam mais adequados. Para que isso fossc possívcl.

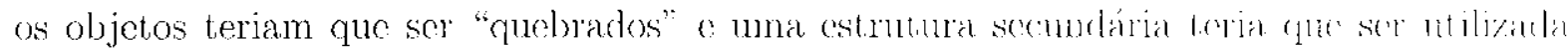
para conectar os pedaços. Esso tipo de problema é tratado atravís dos Vétodos de Acessus Espaciais Não-Pontuais (MAENP) tais como as árvores $R$-Tren. que são apresentadar a seguir.

\section{R-Tree}

A estrutura R-Tree (Guttman, 1984) foi a primeira propostat. palat diacios nato poulliats. existente na literatura. A estrutura R-Tree o amplamente difundida nestad direa e isso pode ser comprovado porque, quase sempre, ć a base de comparacăo pam mos rest muturas deste

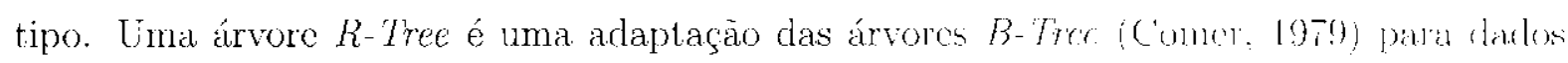
multidimensionais não pontuais. O algoritmo da $R$-Tree forma uma árvore com múltiplas vias balanceada em relação à altura, como obscrvado na Fïgura 3.10.

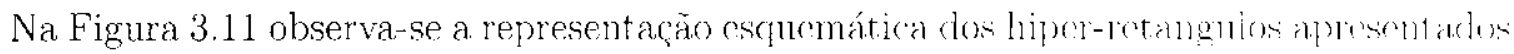

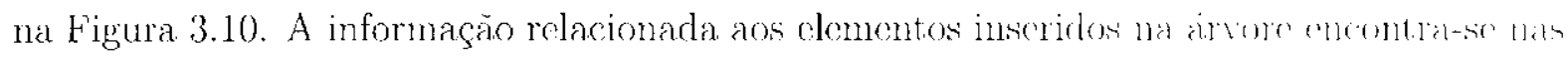
folhas. Nessa figura observa-se que cada nó interno. contém um hiper-retangulo. denominado

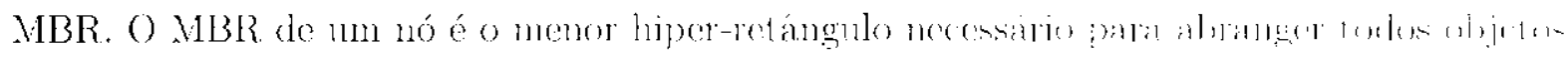
representados pelas sub-árvores daquele nó.

Uma importante diferencia apresentada pela R-Tree é (uace o particiomamento do espago

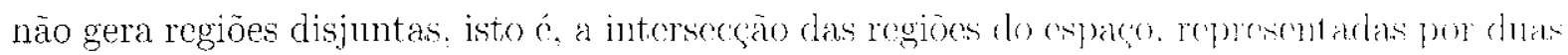
sub-árvores, de um mesmo nó, ponde não ser vazia.

No caso de objetos como triángulos. quadrados on qualquer ontres poligono. o gure se

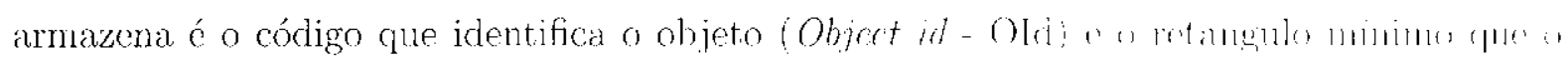
(nvolve (MBR). 


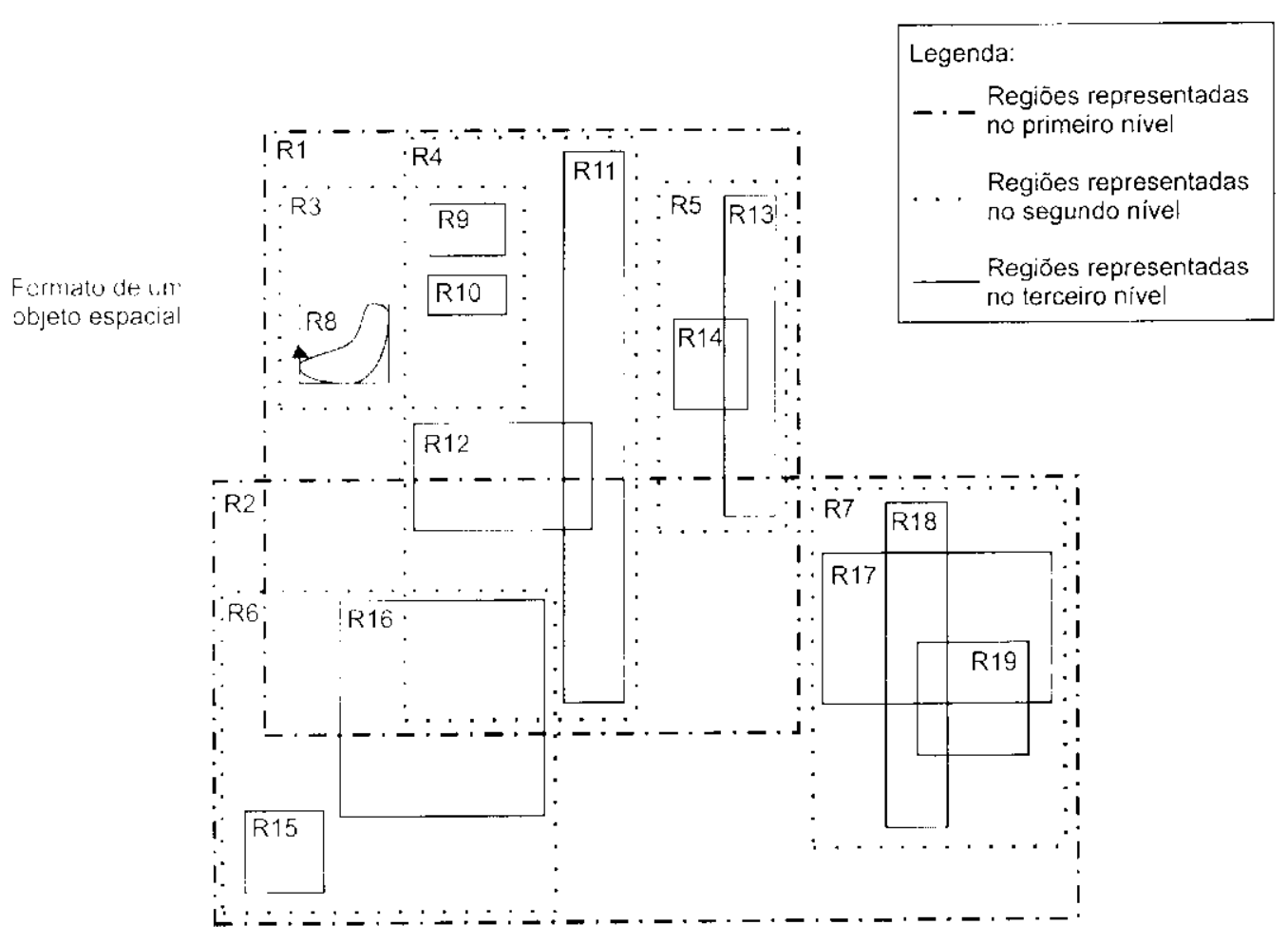

Figura 3.10: V113R represcentada por mudárvore R-Tree.

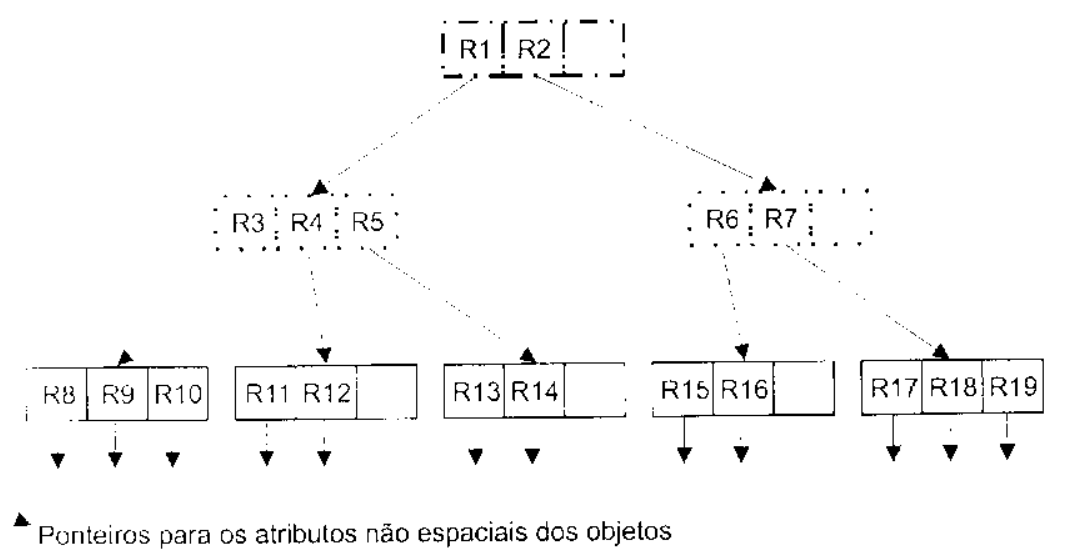

Figura 3.11: Roprestatacio esquenática dos elenentos armazenados cm uma R-Iree. scgundo a Figura 3.10.

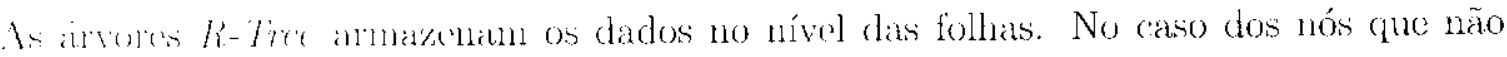
sio folham. cula nó contém a informação relacionada ao MBR englobando todas as suas sub-árvores. (onseqüentemente, o MBR contido na raiz da árvore abrange todos os objetos inclexartios

Vits consultas por abrangencia, aponas as sub-árvores que lenham intersecção com a

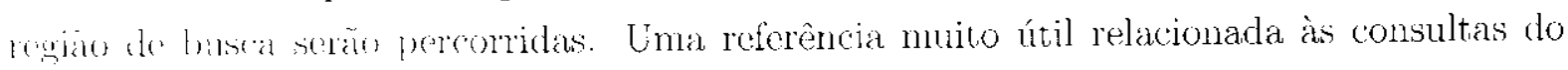
tipo t-vizinhos mais próxinos nlilizando R-Tree pode ser encontrada en (Roussopoulus et al., $1995 j$. 
Un grande problema das R-Tree ś exatamente, a sobreposicăo dne MBR Qunande 1111 ponto pertence à interseção do dois MBR, nenhuma das sub-árvores representadás pelos MBR pode ser descartada.

Em casos específicos, como os da PointQuad-Tree, o aumento de dimonsáo tem un cfeito muito adverso, pois cada ponto na dimensão $n$ divide o espaço $\mathrm{cm} 2^{n}$ "quadrantes". Depois de uma corta dimensão, o número de divisões torna impossível a utilização descta nsitrutura. Para resolver essas limitações, outras cstruturas apropriadas podrm ser utilizaktas e serào apresentiadas nas scçöes seguintes.

Depois da $R$-Tree, outras estruturas foram propostas com o intuito de molhorar o stell desempenho. As mais conhecidas säo $R^{+}$-Tree (Sellis et al. 1987), $K^{\circ}$ - Tre (Beckmann ot al.. 1990), $X$-Tree (Berchtold et al.: 1996), SR-Tree (Katayama c Saloh, 1997) e outros trabalhos apresentados por Hellerstein ot al. (1995) e Papadias et al. (1999).

As árvores $R^{+}$-Tree reduzem a sobreposição dos MBR quobrando os objetos sobrepostos e armazenando os "pedaços" em nós diferentes. Apesar de resolver osse problema o algoritmo gera a necessidade de propagar o particionamento árvore abaixo. ITm nut pro prolsma colatcral é que para procurar 1 mo objeto, várias sub-árvores poderian sẹ arositadas pon

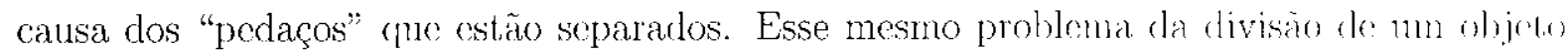
afeta a remoção, pois muitas sub-árvores deverão ser percorridas para remover um único objeto.

Em relação às $R^{*}$-Tree: as principais vantagens são que:

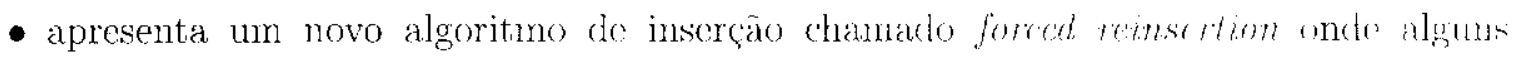
objetos são inseridos novamente na árvore antes de particionar 1 mon nó;

- ao contrário da $R$-Tree, que procurava apenas minimizar o volume dos nós gerados.

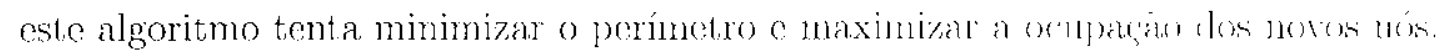

Uma evolução da R-Tree é a X-Tree (Berchtold et al.. 1996). Essa estrutura define

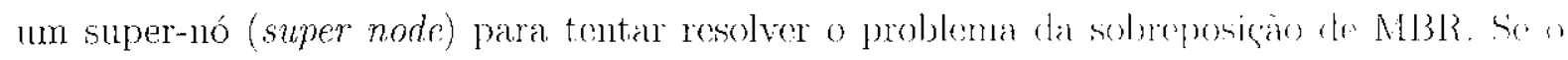

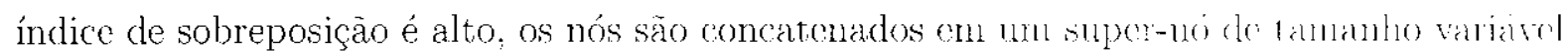

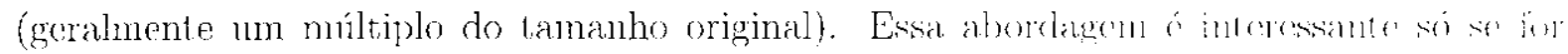

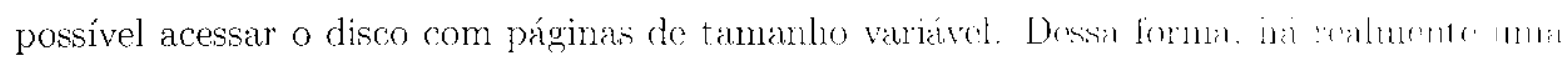

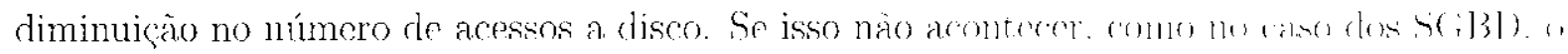
número de acessos aumenta e o desempenho pode ser proximo an la R-The.

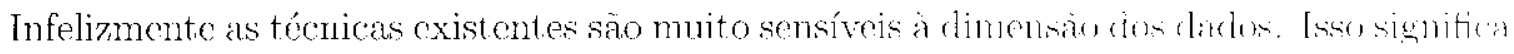

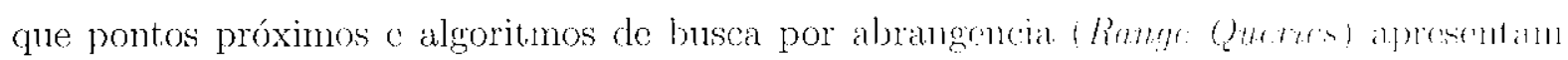

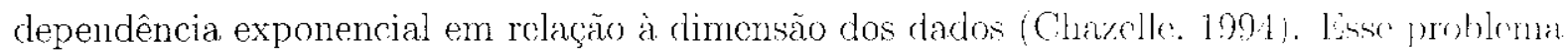

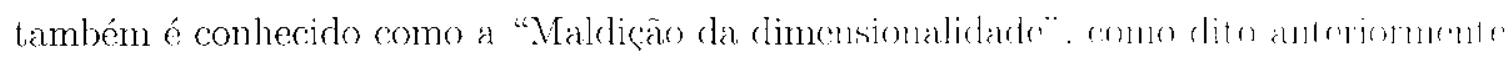




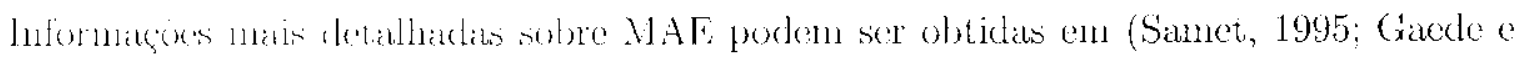
Giinther, 1998; Böhnn (2, al., 2001). Mesmo considerando o potencial que os MAE apresentarn. existem tipus de dados complexos que não possucm coordenadas e, conseqüntemente,

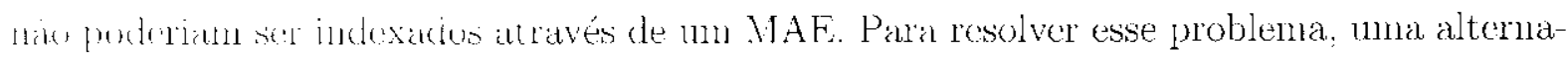

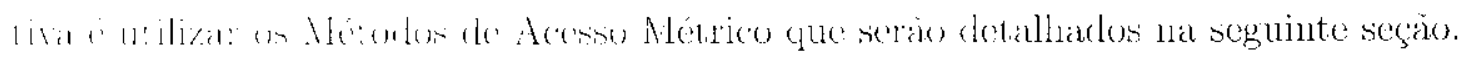

\subsection{Métodos de Acesso Métrico}

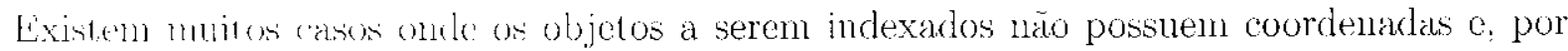

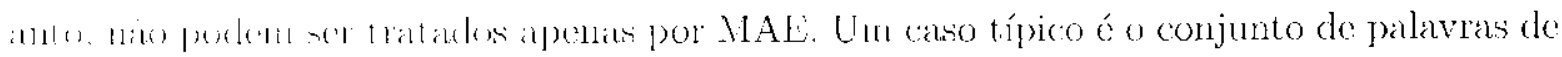

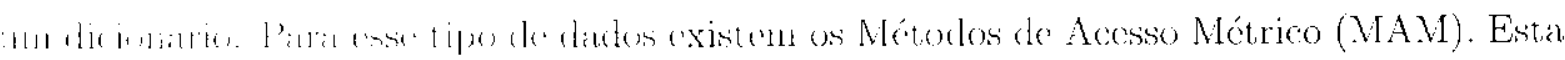
técnica tanbém pode ser htil para indexar dados vetoriais, pois o espaço vetorial é apenas

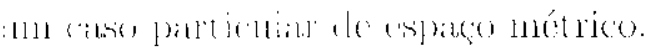

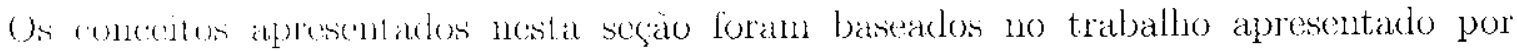
Cháve ot al. (2001) e são equivalentes a vários outros trabalhos correlacionados, como Burkhard o Koller (1973): Yianilos (1993); Bozkaya e Ozsoyoglu (1999).

\subsubsection{Método Burkhard \& Keller}

() prinkino tratratho encuntrade na literatura envolvendo a indexaçäo de dados mótricos ć o le Burkhard "Keller (1973). Vesse trabalho são propostas très técuicas para facilitar a comsulta por similarialade, adecpuadas para métricas que retornem valores discretos.

- A primeimar lecticia considera una árvore que possui apenas uma entrada om cada ni a gran maiser on igual a dois (definido arbitrarianente). Dado um objeto (chave)

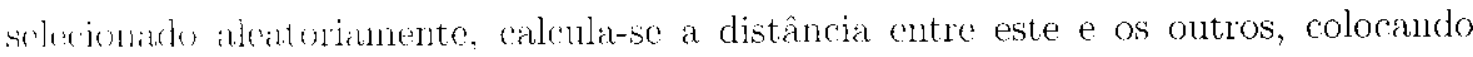
en mnat nesma sub-aivore aqueles que estào na mesma distáncia. Como, no estudo foito pelos antors, a clistância é discretal, csse agrupannento é sempre possivel. Fsse procelimento ó repetido recursivamente para cada sub-árvore; até que só reste um objejo. on até mam profundidade pré-definida:

- Na segrunda téchica propóo-se particionar o espaço, m função de um número fixo de objefes representativos. definindo márvore multivias. Para cada partiçáo (ou subconjunto) säo delinidos un objeto representativo o um raio máximo. Para que

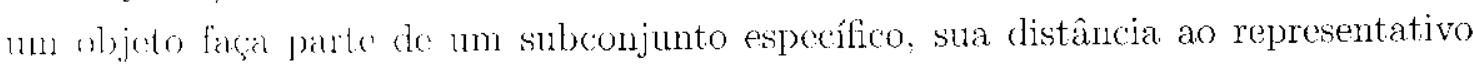
devo ser menor ou igual ao respectivo raio de cobcrtura máximo. Lisse procedimento é repeticio recursivanente; 


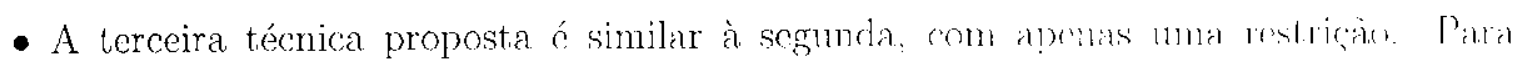
entender melhor essa idéia, o conjunto $S$ pode scr visto como $11 n$ grafo não direcionado onde seus objetos são os nós e as arestas são as distâncias entre eles: scja $S^{\prime}$ um subconjunto de $S\left(S^{\prime} \subseteq S\right)$, tal que dois objetos $x, y \in S^{\prime}$ estac concetarlou somente se $d(x, y) \leq c$, onde cé uma constantc previamente definida. Lim conjunto que define $u m$ grafo completo e que é maximal, ou soja, que nenhum ontro nó pode ser inserido sem que o mesmo deixe de ser completo, é chamado clique do grafo. A partir

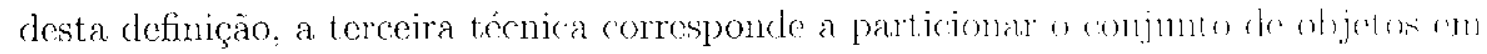
cliques, cada qual com um valor diforente para c (distância máxima entre os objetos).

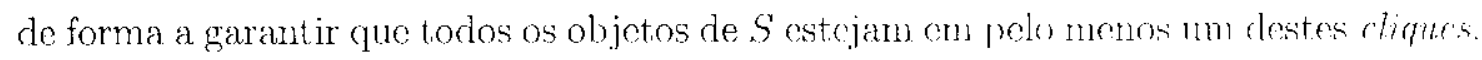
Vale observar que a definiçäo năo impede que um nosino objeto apareģa chu rlifucs diferentes. Fm seguida. um elemento arbitrário de cada clique é escolhido como scu representativo.

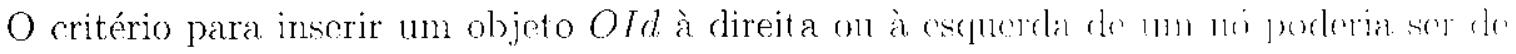
acordo com a distância em relação ao representativo. Se $d\left(O\right.$ Id. $\left.O_{\text {rep }}\right)>\gamma$ critão: o objoto OId deve ser inscrido à direita, caso contrário o objeto deve ser inserido à escruerda.

O princípio básico do método apresentado é utilizar a distancia entre dois elementos

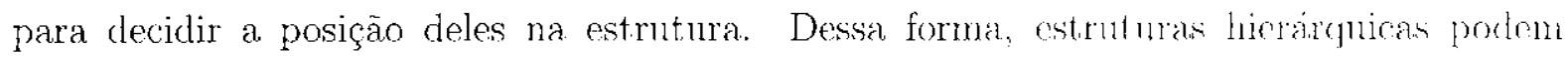

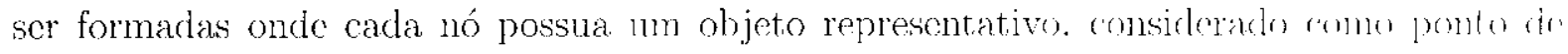

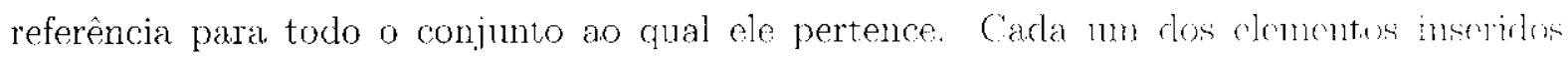
naquele grupo tcon a distância em relação ao seu represcntativo. Comhecendes as distancias de cada objeto a seu representativo, a propriedade da desigualdade triangular ver Figura 3.12) pode ser utilizada para descartar (podar) objetos. sem ter cule calcular a distência explicitamente. Isso é possível pois a função de distancia é una métričcl. A vantagen é que muitos descartes podem ser feitos sem a necessiclarle do calcular a distrincia cntre os objetos existentes na estrutura e o objeto de busca () q. mollomando abim. " desempenho das consultas.

Para descartar elementos utilizando a desigualdade triangular poele-se comideras o seguinte cenário: dados um esjaço nétrico $M=(S, d)$ o conjunto s $S \mathrm{~S}$. o objeno

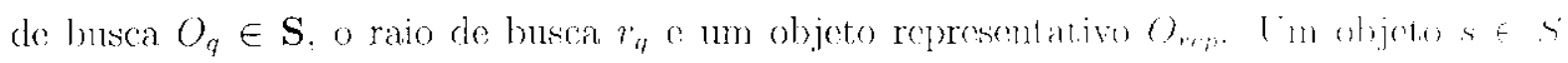
poderá ser descartado sc. o somente se, as equaçoes 3.4 e 3.5 forem atisfeitas df acorde com

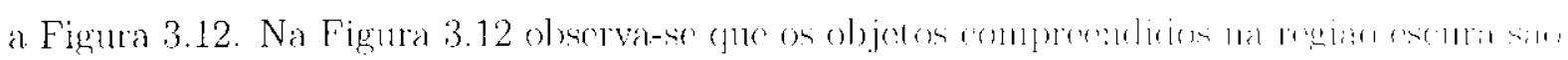
aqueles que, provavelmente, fazm parte do conjunto de resposin.

$$
\begin{aligned}
& d\left(O_{r e p}, s\right)<d\left(O_{r e p}, O_{q}\right)-r_{r i} \\
& d\left(O_{r c p}, s\right)>d\left(O_{r(p)} . O_{q}\right)-r_{q}
\end{aligned}
$$




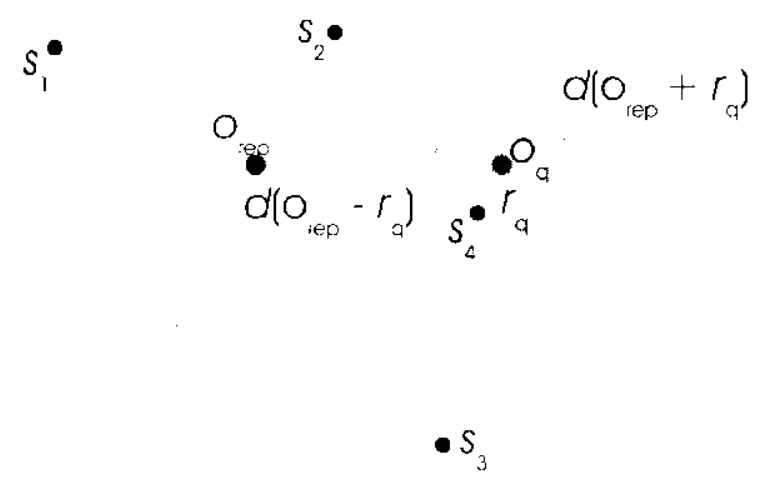

Figura 3.12: Propriedade da desigualdarle triangular.

A prova rlcita afimalào porke ser observada no trabalho de Burkhard e Koller (1973).

\subsubsection{AESA}

O métords Apprommating Eliminaling Search Algorithm (AESA) foi apresentado por Vidal (1986). Como o cáleulo de distanneias pode ser um processo demorado: o autor propöe manter a matriz de distancias pré-calculadas entre todos os pares.

Para realizar mula consulta do tipo Range Query, com centro q e raio $r$, o algoritmo escolhe um pivò. $p$. de forma aleatória e calcula a distanncia $r_{p}=d(p, q)$. A partir desse cálculo, são climinados todos aqueles elementos u que não satisfizerem $r_{p}-r \leq d(u, p) \leq r_{p}+$

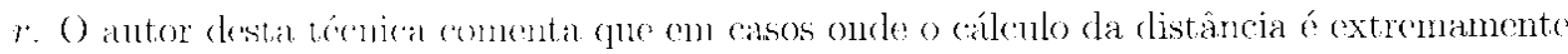
custoso. essa abordagem porle ajudar bastante. Porém. se o conjunto de dados contiver muitos elementos, essa técnica torna-se inviável devido ao tamanho da matriz triangular, $O\left(\left(n^{2}-n\right) / 2\right)$, unde $n=|S|$ representa o número cle elementos do conjunto $S$.

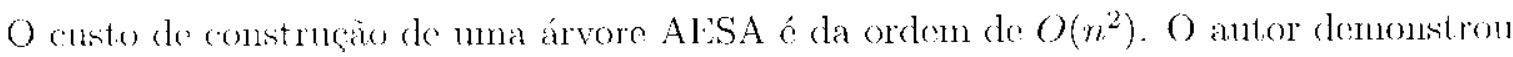
que o custo experimental de recuperagão de dados é de $O(1)$. A mesma icléia do AFSA uambćm foi explorada por Shasha e Wang (1990), que propuseram a criação de duas matrizes

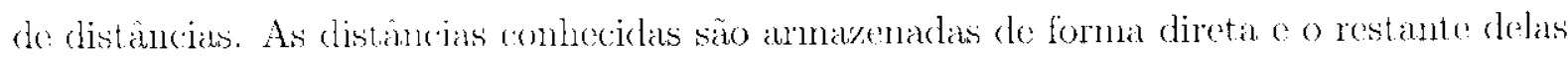
í calculato de forma aproximala em função das existentes. Cada cólula da primeira matriz armazena o limite superior da distrincia para um determinado par de objetos. A segunda matriz é utilizarla de formáa análoga para nanter o linnite inferior da distância entre carla par de objetos. 


\subsubsection{VPT}

Em 1991, Uhlmanm propôs o Metric-Tree (Uhlnann, 1991a) como uma estrutura de árvore descrnhada para funções de distância contínua. Un trabalho mais completo muito similar ó o Vantage-Point Tree (VPT) (Yianilos, 1993). Este trabalho aprosentou alguns resultados analíticos e sugeriu algumas técnicas úteis para escolher os chamarlos nanlage-points.

A estrutura VPT é umá árvore binária onde cada nó armazena un objeto s $\in S$ e um raio $r_{p}$ para particionar o espaço. O ráio é usado como critério para decidir con que sub-árvore um novo objeto deve ser inserido. Isto é, considerando o objeto s do nó raiz e um nó qualquer $y \in S-s$, aqueles que atendem a $d(s, y) \leq r_{p}$ devom ser inscridos na sub-árvore esquerda da raiz; e aqueles que atendem a $\mathrm{d}(s, y)>r_{p}$ devem ser inseridos na sub-árvore direita. $O$ mesmo critério é aplicado para qualquer nível da árvore (da raiz às folhas). O valor de $r_{p}$ édefinide como a mediana do intervalo de distancias dos ontros objetos temando mantor a árvore balanceada. Lma proposta para realizar buscas do tipo k-vizinhos mais próximos con este MAM pode ser observada no trabalho de Chineh (1994).

\subsubsection{FQT}

O Fixed-Queries Trees (FQT) foi apresentado por Baeza-Yates el al. (1994). A idéia é utilizar objetos de referencia (pivôs) para criar uma árvore multiviats. Nestá cutrutuma, os dados são arrmazenados nas folhas.

A contribuição desta técnica foi em relação à VPT. O FQT utiliza un ob jeto de referêneia para cada nível da árvore. Esse critério é aplicado para todos os nós intornos. Assinn, o número de objetos de referência é ignual à altura da árvore.

\subsubsection{LAESA}

O algoritmo Linear AESA (LAESA) é una nova versào de AFSA c foi apresentado por Micó et al. (1994). Os autores propõen a utilização de $k$ pivos de lal fornáa que o custo de construção é reduzido para $O(k n)$. Durante as consultas, os $k$ pivos sào utilizados para descartar aqueles elementos que não façam parte do conjunto le respostri. ()s clementos que não possam ser eliminados na fase anterior são comparados de formu direta com o objeto do buscial.

No trabalho de Micó et al. (1996), os autores propuseram a construçio de uma árvoro do tipo Generalized-Hyperplane Tree (GHT) com os pivôs para acelcrar o processo de

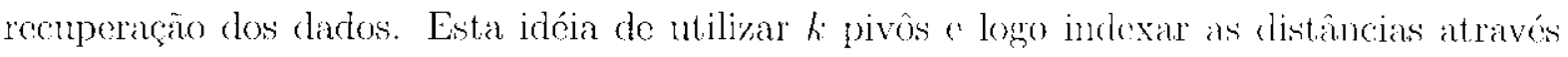
de outras estruturas também foi explorada na técnica OMNI (Santos-Filho et al., 2001). que será analisada posteriormente. Nos trabalhos de Nene o Nayar (1997) o Chávez et al. (1999a), as distâncias en rolação aos pivòs são ordenadas para permitir una busca bincíria. 


\subsubsection{FHQT}

A principal diferenca da estrutura Fixed-Height QT (FHQT) (Bacza-Yates et al., 1994; Backa-Yates, 1997) en relugrio ao FQT é (que todas as folhas estäo à mesma altura.

Esta técnica faz com due algumas follads sejann mais profindas que o nexessário. De aceordo com os traballo cle Baryar-Yates (1997) e Bacpa-Yates e Navarro (1998), se o múmero de pivon for igual a $O(\log n)$, a busca também tem un custo de $O(\log n)$ cálculos de distância. Porém, o custo depende exponencialnente do raio de busca $r$.

\subsubsection{FQA}

Os Fired Quertes Array (F(QA), apresentades por Chávey et al. (1999a), nào săo árvores.

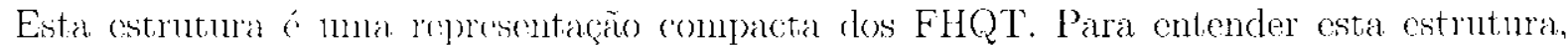
imagine $1 \mathrm{~m}$ FHQT de altura $h$, onde as folhas sáo percorridas da esquerda para direita e os elementos säo copiarlos sn unn vetor. O vetor resultante é denominado FQA.

Para carla clemento do vetor resultante são calculados he números representando as Jannificacôn que devem ser escolhidas em cada nívol para chegar até o elemento. Carla um dos he números co codificado cm bits e logo concatenados formando un intciro. Os bits que representann os níveis nais altos da árvore são codificados cono sendo os mais representativos nad seqüência de bits concalconades.

Como conseriuncia da codificaçăo dos bits, o FQA resultante cstará ordenado pelas secuïencias de hh-bits. Cada sub-árvore de uma fHOQ' corresponde a um intervalo de elementos no FQA. A diferença, no caso de FQA, é que, ao invés de percorrer sub-árvores, badsta realizar una busca binária. Fiste processo introduz un custo computacional da ordem

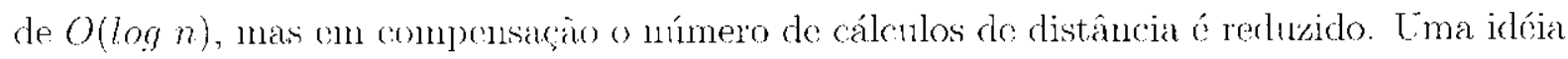
similar, para o caso de espaços vetoriais. pode ser observada 110 trabalho de Blott e Weber $(1997)$.

\subsubsection{MVPT}

Bozkaya o Ozsoyoglu (1997) propuseram a generalização das VPT para árvores m-árias formadas por m-1 perentis ao invés de medianas. O método foi donominado Multi-Vantage-Pont These (MVPT). Uma idćia similar também encontra-se no traballo de Brin (1995).

Nesta estrutura, a utilizaciuo de mais de un elemento por nó foi proposta, de forma similar ao trabalho do Shapiro (1977). Cada nó interno armazena um dos m percentis. Todos os objetos das sub-árvores subsegüentes são armazendados junto con a sua distäncia para cada objeto representalivo. Dessa forma, a AVPT ammazna un número maior de distáncias 
pré-calculadas (para os objetos representativos). Esta informaça adicional permite reduzir, através da desigualclade triangular, cm até $80 \%$, a quantidade de cálculos de clistâncias om consultas por abrangchncia (em comparação à VPT).

\subsubsection{VPF}

A estrutura Vantage-Point Forest (VPF) foi apresentada por Yianilos (1998, 1999). Esta estrutura é desenhada para consultas do tipo $k$-vizinhos mais próximes com raio limitado.

O algoritmo consiste em excluir, em cada nível, os elementos que se encontrem a uma

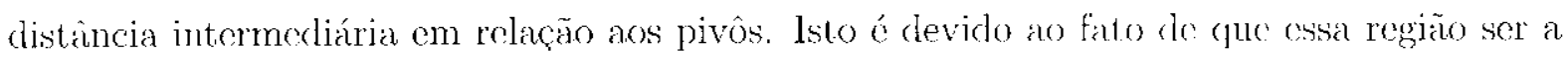
que apresenta maior populaçào de objetos. So $r_{0}$ e $r_{n}$ são os raios para o objeto mais próximo e para o mais distante em relação ao pivô $p$ os elementos u que devem ser excluídos da árvore siầ aqueles cujas distâncias cumprem a equação: $d\left(p, r_{0}\right)+\delta \leq d(p, u) \leq d\left(p, r_{n}\right)-\delta$.

()s elementos excluídos formam uma segunda árvore. () procedimento é aplicado de forma recursiva criando mma "floresta" de árvores.

\subsubsection{BST}

Os Bisector Trees (BST) foram propostos por Kalantari e MeDomald (1983). Este método de acesso ó uma árvore binária com dois pivôs, $c_{1}$ c $c_{2}$, para cada nó. Para cada elemento é calculada a distância em relação a $c_{1}$ e a $c_{2}$. Aqueles clementos que estiverom mais próximos de $c_{1}$ säo inseridos no lado esquerdo da árvore e aqueles mais próximes de ca no laclo direito. Para cada centro também ó armazenada a maior distância em rolaço aos elenentos que lhe foram atribuídos. Isso é realizado com o intuito de ajudar a podar sub-árvores na hora dia buscia.

Unar cxtensão desta idéia foi apresentada por Nolteiner el al. (1992) e foi chamada Monotonous BST. Nesta estrutura, $12 \mathrm{~m}$ dos dois elementos representallivos c ou cé considerado o centro "pai". Fsta técnica provoca uma diminuiço gratulat clo raio quando a. inspeção continua árvore abaixo.

\subsubsection{GHT}

O GHT foi proposto por Chlmann (1991b). A construçü desta árvore ́s similar ao BSt', porém, o GHT, ao invés de utilizar a distância cono critério de descarte, utiliza um hiperplano entre $c_{1}$ c c c. Esta árvore binária é constrúda da seguinte forma: cada nó é composto por dois objetos $s_{1}$ e $s_{2}$ escolhidos arbitrariamente: os objetos mais próximos ao primeiro objeto, $s_{1}$, são armazenados na sub-árvore esquerda (o 1ó; os objetos mais próximos a $s_{2}$ sãu armazenados na sub-árvore direjta do nó. O processo é repetide do forma recursiva, atée 
que todos os objetos tenhann side inseridos. Dependendo da boa solegáa des objetos chaves. a árvore tonde a sor balanceata.

Segundo o autor (Uhlnamm, 1991b), as árvores CHT apresentam melhor desempenlio) que o método VPT (m altas climensoes. Una variante dos GHT que suporta operações dinâninicas é o (-Thes (Vorbarg, 1995).

Lin outro traballu relaciumado com esta técnica foi apresentado por Bugnion et al. (1993). Nesse caso, a idóia ć rentibizar um nó "pai" com o intuito de evitar o cálculo de duas distâncias em cada nível.

\subsubsection{GNAT}

A generalizaçio do GHI para árvores m-árias, chamada Geometric Near-neighbor Access The (GNAT), lui proposta por Brin (1995).

No primeiro nived da cestrutura sio escolhidos $m$ centros $c_{1}, \ldots, c_{m}$. Para carla objeto no conjunto, é calculado aquele centro nais próximo. Depois disso, uma árvore é construída de forma rexursiva utilizando o mesmo critério. Além disso, en cada sub-árvore, sào guardadas as distâncias múnima o máxima dos objetos aos respextivos representativos, para que seja possivel podar objetos durante as consultas.

Esta idćia tem relaçào com a partição do espaço com regiôos de Voronoi (Voronoi, 1907; Aurenhammer: 1901).

\subsubsection{VT}

O Vorono Irce (VT), proposto por Delne o Nolteiner (1987), foi criardo com o int uito de melhorar o desempenho do $13 \mathrm{ST}$. A diferença ć que o V'T eria dois on três elementos e filhos para cada nó. Quando uma nova sub-árvore ć criada para armazenar um novo elemento, o clemento "pai" nlais próximno também é inscrido no novo nó.

Liste método tem a propriedade de que o raio de cobertura vai sendo reduzido em niveis inferiores. Lisso ajudil a manter elementos próximos nas subávores. A árvore resultante. é melhor e mais balanceada que os BST. No traballo de Nolteimer (1989), os antores demonstrarann que se, durante a inscrção, são aplicadas técnicas similares às utilizadas pela B-The (Bayere Me Creighn, 1972), o resultado é mu VT balanceado. Esta idéia foi cxplorada posteriormonte pola $M$-Tree.

\subsubsection{M-Tree}

A método de acosso M-Thee (Zezula et al., 1996; Ciaccia ot al., 1997c; Patella, 1999) é mma adaptação da árvore B-'Tree para dados métricos. Fsta técnica foi o primeiro MA.M dinânico 
proposto na literatura. Isto significa que a estrutura pode ser construída gradualmente, sem a necessidade de ter o conjunto inteiro de dados para iniciar a construção. Por causa disso, esta estrutura será apresentada com maior grau de detalhe neste trabalho.

A árvore gerada por este método é balanceada pela altura, o cune permite melhorar o tempo de acesso a disco. Uma ontra particularidade é que os dados están só nas folhas. De forma similar às $R$-Tree (Guttman, 1984): a interseçăo das regióes do espaço métrico) representadas por duas sub-árvores de $11 \mathrm{~m}$ mesmo nó, podo não ser vazia. Isso significa que, o particionamento do espaço métrico não necessarianente gera regiós disjuntins. A estrutura de um nó interno não é a mesma que a de uma folha. Cada elemento de uma folha contém: a informação que compõe o objeto propriamente dito, o identificador do objeto $(O I d)$ e a distância dele até o objeto represcutativo daquele grupo. Por ontro lado, cada nó interno contém o objeto propriamente dito, um pontciro relacionado à sua sub-árvore, um raio de cobertura abrangendo toda a sub-árvore e, o valor da distâneia entre ole o seu representativo, com exceção da raiz.

O objeto representativo de cada nó deve ser aqucle cuue esteja mais próximo do contro, com relação aos outros, isto ć, cle é o objeto mais similar aos outros elementos do mesmo nó. O algoritmo de inserção ́:

1. se a raiz for uma folha e tiver espaç̧o nela, inserir o objeto o sair;

2. se a rajz for uma folha e não tiver espaço nelat, particionar o nó do seguninte nnodo:

(a) gerar dois novos nós minimizando os diâmetros:

(b) armazenar a distância do objeto representativo ató cada nua das outras entradas do nó c copiar ambos os representativos para o nó pai. Se o nó particionado cra a raiz, uma nova raiz será criada contendo apenas os dols objetos representativos dos dois novos nós gerados. Se o nó pai estiver sem espaço, o processo de particionamento é propagado árvore acima:

3. se a raił não for folha, escolher aquela sub-árvore que não precise aumentar sen raio de cobertura. Se essa possibilidade não existe, inserir o nó narquela sub-árvore onde o objeto representativo esteja mais próximo ao objeto do increccio. () processo deve ser repetido até chegar no nível das folhas;

(a) se a folha tiver espaço disponível. inserir a sua distancia para o objeto representativo do nó, ajustar o raio de cobertura dos nós pais e finalizar;

(b) se a folha estiver lotada, particionar o nó o propagaga o particionamento árvore acima. 
No algorituno de construça de uma árvore M-Tree, o particionamento de um nó é realizado at ravés do algoritmo MinMax. Nesse processo todos os pares de elementos possíveis são testados até encontrar o par que minimize os raios resultantes. $\Lambda$ complexidade desse processo é de $O\left(n^{3}\right)$. Segundo os antores, o algoritmo de particionamento é um dos mais promissores (Ciacria o P’atella. 1998). Porém. nas próximas segós pode-se observar que cxistem outras altemativas mais eficientes.

Na Figura 3.13 pode-se observar como se organizam os pontos inseridos na estrutura junto com a respectiva. M-thet. Durante o processo de consultas as distancias armazenadas serão utilizadas para poeker pockar algumas sub-árvores. Só o fato de utilizar a desigualdade triangular para podar sub-árvores, reduz nuito o núnero de cálculo de distanucias e consequientemente o tempo de resposta. O cálculo de distância tornar-sc-á necessário, unicamente: quando ná seja possivel podar uma sub-árvore utilizando a desigualdade triangular,

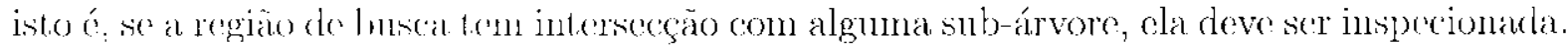

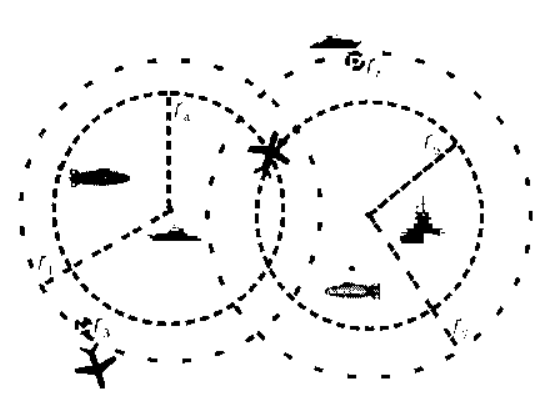

(a) Regurcsontacion grádicat.

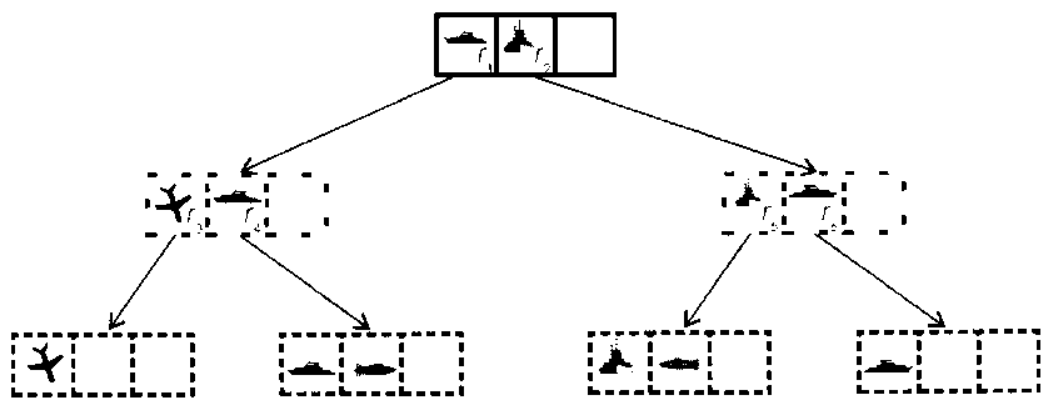

(1) Repressontagàn escunemítica.

Figura 3.13: Esitrutura de márvore $M$-Tree.

Segunclo os autores. M-The é uma estrutura resistente a altas dimensòes (Patella, 1999) e tanbém é competiliva em relaça aos $R^{*}$ - Trex (Ciaccia et al. 1997a). Este mótodo de acesso também foi utilizado para recuperação de informação por similaridade de forma aproximada (Lezula et al., 1998a: Ciakcia e Patella. 2002).

Existem tambén ontros trabalhos interessantes relacionados conn as M-Tree. Em Ciaccia (1. al. (19971) ) os antores apresentam mua análise de dexempenho desse método. A versäo paralela da M-Tret foi apresintada em Zčnla et al. (1998b)).

En (Ciaccia et al. 1999), os autores apresentam um modelo de custo para a $M$-Tree. Nesse traballo sâu realizarlas estimativas de custo em temos de cálculos de distância o tempo de entradia e saída na execugão de consultas por similaridade. 


\subsubsection{Slim-Tree}

O Slim-Tree foi proposto por Traina Jr et al. (2000b). O sen funcionamento é semelhante à $M$-Tree, porém o custo computacional do algoritmo de particionamento é menor, sern prejudicar o desempenho das consultas.

A principal contribuiçäo da Slim-Tree foi que apresentolu um critério para avaliar o gran de sobreposição entre os nós da árvore, chamado fat-factor. O problema apresentado no caso de espaços métricos ó que não é possível calcular esse volume. Fasso critério deu origem a $1 \mathrm{~m}$ algoritmo de reorganização dos nós, chamado Slim-Down. O objetivo desso algoritmo 6 reduzir o gran de sobreposição entre as sub-árvores como observado na Figura 3.14. Nessa figura pode-se observar que, como conseqüéncia do processos Slim-Down, o número de acessos a disco durante as consultas tende a ser menor, em comparação com o descmpenho obtido com a $M$-Tree. Outra diferença importante é que a inserçáo ć realizada na sub-árvore com menor taxa de ocupação, considerando que exista nais de uma que qualifique.

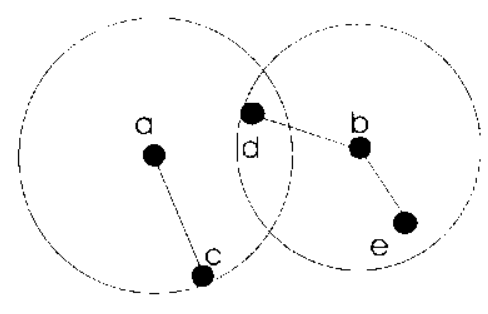

(a) Antes.

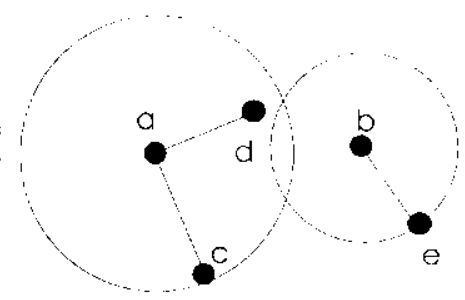

(b) Depuis.

Figura 3.14: Efeito da applicação do processo do Slim-Domm.

A diferença de desempenho em relação às $M$-Tree deve-se à utilização do algoritmo Minimal Spanning Tree (MST) durante a partição de un nó. Vestia lasió é gerado um MST envolvendo todos os clementos da página a ser dividida e a maior conexão é eliminada. Este algoritmo permite mellorar o custo do Min Lax, utilizado prela $M$-The, de $O\left(n^{3}\right)$ para $O\left(n^{2} \log n\right)$.

\subsubsection{SAT}

O Spatial Approximation. Tree (SAT) foi proposto por Nivarro $(1999,20102)$. O algoritmo ustá baseado na idéia de aproximação espacial, ao invés de pivôs.

A partir do conjunto de elementos $\mathbb{S}$, $u m$ semento $p$ é selecionate cono a raiz. Logo após, $p$ é conectado ao conjunto de vizinhos $N$, definido como o suhconjunto de elementos $u \in \mathbb{S}$ que tenham $p$ como sen elemento mais próximo. Carla remento do subconjumto restante, sem contar $N \cup\{p\}$, é atribuido ao respectivo elemento mais próximo de $N$, como apresentado na Figura 3.15. Dessa forma, cada clemento de $N$ se converte, recursivamente, na raíz de umáa nova sub-árvore. 


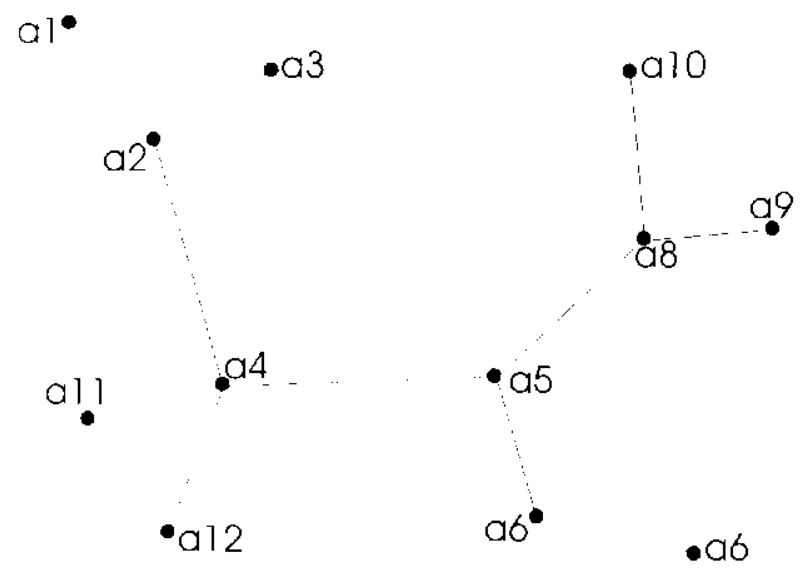

Figura 3.15: Exomplo de um SAT construído considerando a5 como raiz.

Existe tambóm uma versăo dinâmica desta cstrutura, que foi apresentada por Navarro e Reyes (2002).

\subsubsection{A família OMNI}

A familia de estrutuas ()MNI foi proposta por Santos-Filho et al. (2001); Santos-Filho (2003). Ao invés de pives locilis os autores proporm a utilização de pivós globais chamados de Foci. Para inclexar gualquer novo alemento, primeiro devem ser calculadas as distâncias deste para cada un dos cementos do conjunto de Foci. Os autores também apresentaram o algoritmo, chantado /1ull For (HF). A Figura 3.16 mostra o processo de indexação de um novo objeto.

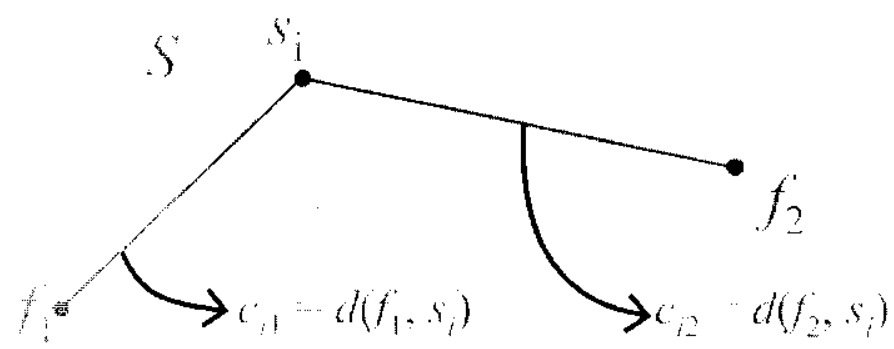

Figura 3.16: l'rocesso de indexaçăo de um novo objeto.

onde $\mathbb{S}$ é o conjunto de objetos e $s_{i}$ é um dos objetos de $\mathbb{S}\left(s_{i} \in \mathbb{S}\right)$. O vetor $D$ formado polas distancias calculatals para cada un dos Foci, $f_{1}$ e $f_{2}, D=\left(c_{i 1}, c_{22}\right)$ é channado de vetor de coordenadas OMNI. O vetor $D$ pode vir a ser indexado através de mina outra estrutura auxiliar, como a R-Tree. dando origem ao método de acesso denominado OmniRTree.

Uma outra estrutura proposta nesse mesmo trabalho é a OmniSequential. Neste caso năo são utilizadas estruturas auxiliares, mas apenas as distanncias aos foci são ntilizadas 
para realizar as consultas. Um ponto interessante da faunilia de estruturas OMNI ć que, mesmo sem cstruturas auxiliares, os resultados reportados foram muito positivos. Devido à existência dos Foci, a técnica OMNI pode ser considerada näo hiernireuica.

No caso específico da OmniRTree, o vetor $D$ é indexarlo através de uma $R$-Tree o que agiliza as operações de recuperação de informação. Na Figura 3.17 pode-se observar a forma de realizar uma consulta do tipo Range Query utilizando os froci.

Depois de calcular a distância do objeto de consulta $O_{\eta}$ até os dois Foci, o conjunto de candidatos, desde o ponto de vista de cada Foci, formam un anel. Depois de calcular a intersecção de ambos os anéis, o conjunto de candidatos que possivchnente formariam parte cla resposta é reduzido dramaticamente às duas regiōos escuras. So cexistir un terceiro Foci. o conjunto de candidatos poderia ser reduzido, ainda mais.

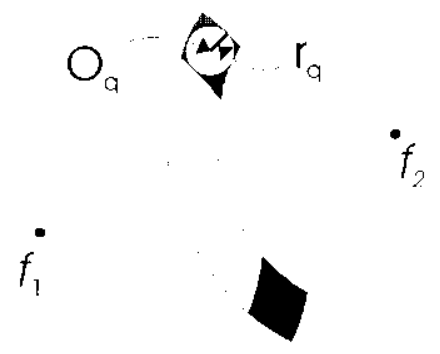

Figura 3.17: Utilização dos Foci para realizar consultas cm cstruturas da Familia OMNI.

Para recuperar informação através de uma OmniRTree calcula-se a Minimum Bounding Omni Region (MBOR), para a região de busca, isto é, a mínima região, seguudo as coordenadas (OMNI, que envolveria a região da consulta. Una vez calculada a MB()R, a R-Treé utilizada para recuperar os objetos envolvidos nessa área (ver Fignra 3.18).

Em (Santos-Filho, 2003), os autores também propöem a técnica demoninada Omni B-Forest. Nessa estrutura as distâncias para cada um dos Fon sho indexadas at ravés de un $B^{\dagger}$-Tree (Comer, 1979). A concxão seqüencial existente nas follats dos $B^{+}$- Tree ó aproveitadal. para tentar detectar os objetos mais próximos. Essa técnica tambúm pode ser observada no trabalho publicado por Traina Jr et al. (2002).

En todos os casos, um dos maiores problemas da técnica OMNI estŕ relacionado ao processo de determinaçăo do número de Foci. Fxperimentalmente. us antores demonstraram que o número de Foci mais apropriado é próximo à dimensäo intrínseca ou dimensão fractal do conjunto de dados. Una boa referência para realizar esse cálculo éo traballuo de Schroeder (1991). A dimensão intrínseca de um conjunto de dados é o número real de dinnensóses no qual 


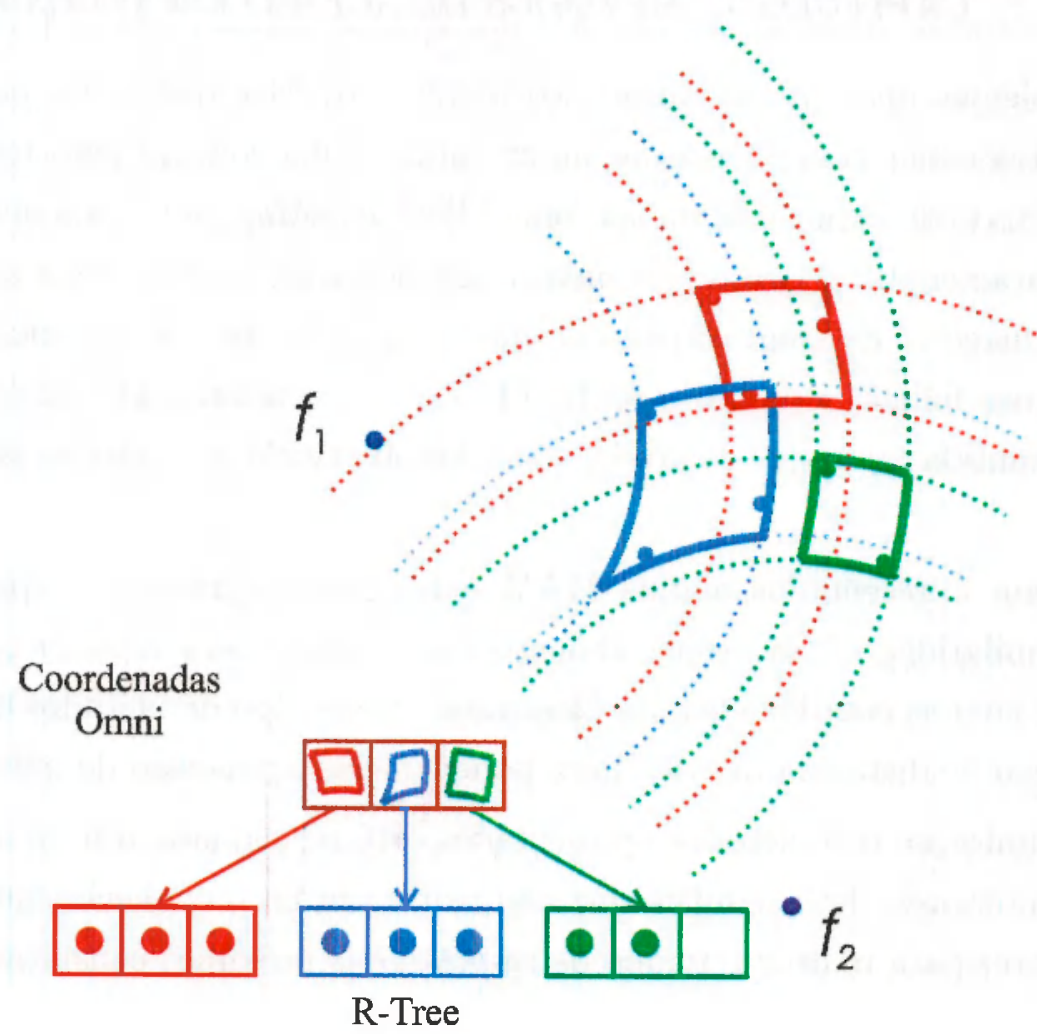

Figura 3.18: Utilização das MBOR para recuperar informação em uma OmniRTree.

pode ser representado um conjunto, sem afetar as distâncias entre os dados. Por exemplo, os pontos de um plano podem ser representados em dimensão 30, mas a dimensão intrínseca do conjunto de dados ainda continua sendo dois.

Outro trabalho onde pode ser observado o efeito da escolha dos pivôs sobre uma busca em espaços métricos é apresentado por Bustos et al. (2001). Maiores referências em relação aos MAM podem ser encontrados em (Chávez et al., 2001).

\subsection{Considerações Finais}

No presente capítulo foi apresentada uma visão geral dos métodos de acesso de dados espaciais e métricos. Primeiramente, foi apresentada uma rápida visão de métodos de indexação para dados unidimensionais. Logo após, foram apresentados os Métodos de Acesso Espacial (MAE) que são utilizados para a indexação de dados multidimensionais, como vetores.

Um outro assunto importante, abordado neste capítulo, foi o relacionado aos Métodos de Acesso Métrico (MAM). Os principais MAM existentes na literatura foram analisados. Nesse caso, a única informação disponível para realizar a indexação é a distância. Os MAM também são úteis para a indexação de dados vetoriais. Neste caso, basta definir uma função de distância. 
Um dos problemas mais preocupantes dos MAE e MAM é que todos eles apresentiam limitaçoos para trabalhà com dimensöes muito altas. Uma solução para esse problema é aplicar algum método de redução de dados como MDS, FastMap, etc. Uma outra alternativa ć descartar as características que sejam menos significativas. Porém, essa alternativa leva

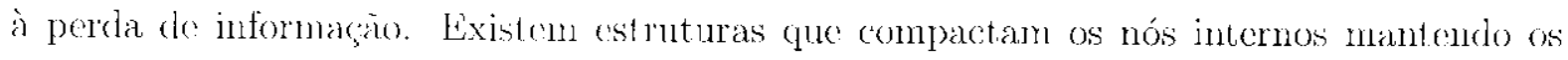
objotos intactos nas follaks como no caso da TV-Tree. No entanto, não há garantia do que a redução seja mantida cm todos os níveis. como foi observado no trabalho de Santos-Filho (1999).

Também foram apresentados alguns MAM existentes na literatura apropriados para consultas por similaridade. São especialmente apropriados para aqueles casos ondo não é possível contar com as coordenadas nos elementos. Nesse tipo de métodos de acesso basta definir uma funçäo de distància métrica para poder iniciar o processo de indexação.

A principal liniticuió dos métodos apresentados está relacionada à faltá de aprendizado com consultas anteriores. Isto significa que năo reaproveitam o conhecimento gerado pelas consultas anteriores para reduzir o tempo de resposta das próximás consultas. 


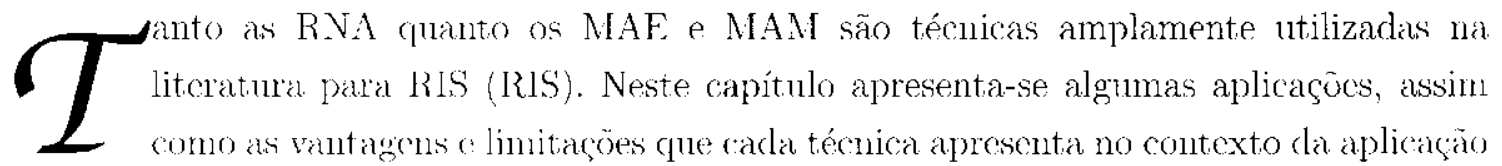
desinas téchicas en RIS.

\subsection{RNA na Recuperação de Informação}

() processo de RIS (RIS) ń pescuuisado em várias áreas do conhecinento, entre elas as RNA. Dentro dessa área, o problema de RIS pode ser tratado por vários modelos, como por exemplo, as Rexdes Nulti-Cannadas, Mapas Auto-Organizáveis (SOM), entre outros. Vesta

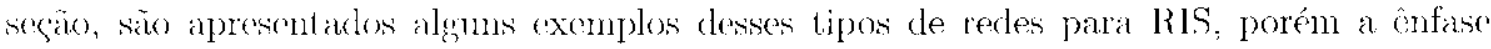
principal estáa oricutada a redes do tipo SOM.

Una das principain características de uma RNA é a tolerancia a fallhas. Esta característica.

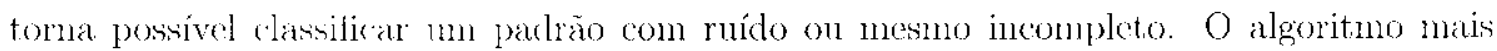
conhecido e provavelmonte o mais utilizado, é o Backpropagation (Rumelhart ct al., 1986). As redes treinadas com o BackPropagation pertencem ao paradigma supervisionado. Esse algoritmo deu início a mula grande variedade de técnicas. Entre as modificaçoes mais ronhecidas pode-se citar o alyoritmo BackPropayation com Momentum (Shiffmanm et a., 1994), Quich:Propagation (Fahlnan, 1988) e RProp (Riedmiller, 1994). Todos esses algoritmos

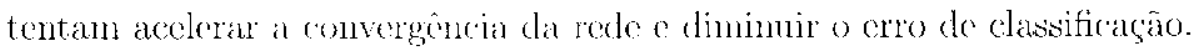

Outráa área de pescpuisa pemancente é a relakionada à definição da arquitetura da rede. Em (Rawtani et al., 2001). apresenta-se uma tentativa para a deliniçâo do número de nenrônios das cannadas intermediárias. Também existem os modelos construtivos, tais como a rede Cascado Comblation. (Fahlman e Lebiere, 1990), Upstar (Frean, 1989), Tiling e a generalizaçăo MTiling (Parekh ot al.. 1996). Tower e Pyramid (Parekh et al., 1995, 1997). que são algoritmos que treinan una RNA com o paradigma supervisionado. Em (Parekh 
et al., 1995), pode ser encontrado $u$ bom resumo das técnicas construtivas para as redes Multi-Camadas on mais conhecidas.

Um grupo de técnicas apropriadas para detectar agrupamentos corresponde às redes da família derivadas da Teoria da Ressonância Adaptativa (AR'I') que foram desenvolvidas por Carpenter e Grossberg (Grossberg, 1976a; Carpenter "Grossberg: 1986, 1987b). Existem diversos aprinoramentos destas primeiras idéias tais como ART2 (Carpenter o Grossberg, 1987a), ART3 (Carpenter o Crossberg, 1990). ARTNAP (Carpenter et al., 1991a), FuzzyART (Carpenter et al., 1991b). Fuz zy ARTMAP (Carpenter et al., 1992), Fully Self-Organizing Simplified ART - FOSART (Baraldi e Parmiggiani, 1998). En todos esses

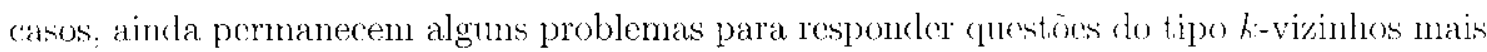
próximos e busca por abrangência. Uma aplicação interessante da rede ART-2A (Carpenter

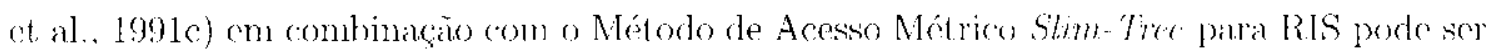
cncontrado em (Vicentini, 2002). Nesse trabalho, os autores mostraram que a combinaçào dessas duas estruturas foi mais eficiente, em termos de cáleulos do distruncia e múmeros de acessos an disco do que a própria estrutura Slim-Tree.

Mesmo os trabalhos mais recentes. envolvendo recuperaça de informação através de

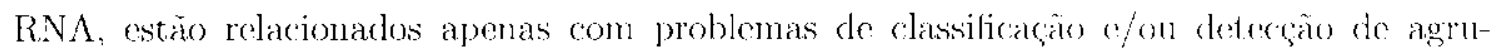
pamcutos (clustering). No entanto, o problema de RIS apresenta algumas características particulares que restringem os modelos que poderiam ser utilizidos.

Em primeiro lugar, como năo se conhece quantos aglomerados existem nos dados, o modelo de rede a ser utilizado deverá ser treinado sob o paradigma năo supervisionado (ver Segão 2.1 l'ág. 5). Por causa disso, neste capítulo, somente modreses anto-organizáveis săo apresentados. Um dos modelos mais conhecidos para realizar essa tarefa foi proposto por Kohomen (1981). Este modelo á conhecido como nulpa anto-organizávol on. simplesmente. mapas de Kohonen (ver Seção 2.2.1 Pág. 6). Os mapas de Kohonen são RNA que têm a capacidade de detectar aglomerados (chusters) nos dakdos. () trahbalhos de Kaski et al. (1998): Oja et al. (2003); Yamakawa (2003) são referéncias muito importantes para observar o crescimento de aplicações de SOM no processo de RIS e em outras áreas de pesquisa.

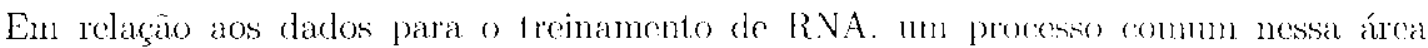
refere-se à transformação dos dados em uma representação adequada at ravés cle unn proccsso denominade pré-processamento. O pré-processamento do conjunto de dados pode envolver a normalização e/on a redução do número de atributos com o intuito de climinuir o número de neuronios das RNA, assim como o tempo requerido para o treinancnto. Fxistom várias formas de normalizar os darlos. 'Iodas clas têm a finalidade de transformat o intervalo ondo se encontram os dados no intervalo [0,1] ou :-1.1], uma vęz que as fimçoces de ativaçào utilizadas nos nemronios artificiais, normalnente, assumem valores nesses intervales. Para reduziro número de atributos podem ser utilizadas algumas técnicaus de extração de características. lais como a transformada de Karhunen-Loène ('K-L') ou Análise de ('omponentes Principais 
(PCA- Principal Component Analysis) (Pearson, 1901; Hoto, 1933; Duda c Hart, 1973; l'ukunaga, 1990 $\rangle^{\prime}$, Decomposiçào de Valor Singular (SVD-Singular Value Decomposition) (Strang, 1980; Pross et al., 1988; Golub e Loan, 1989), FastMap (Faloutsos a Lin, 1994; Faloutsos (it al., 20)13).

Outro fator importinute, que tem relação con a saída da rede refere-se à inicialização dos pesos. Unn estudo dos efeitos desse fator pode ser observado em Fernández-Redondo e Hernándes-Espinosa (2001). Un outro lator que pode afetar a precisäo das RNA são os parâmetres de aj)rendizado. Năo existe ma regra e sim muitas heurísticas (Haykin, 1994. 1999) para deterninar esses parâmetros. O problema do ajuste da taxa de aprondizado foi analisado nos experimentos apresentados por Wilson o Martinez. (2001).

Existem na literat.ula alguns trabalhos relacionados à recuperação de informaçào baseada em similaridade utilizando RNA. As redes neurais do tipo SOM säo freqüentemente utilizadas para detectar agrupancutos c projetar vetores de alta para baixa dimensão (Kohonen, 1982). O modelo original de Kohonen não preserva completamente a similaridade dos daclos projetadon. pois sempre que se reduz a dinensão de um dado, através de uma projeção, perde-se precisano nos dados result antes. Este problema da preservação dia topologia também foi escudado por Villnam et al. (1997) e por Ritter et al. (1992).

Lim ontro problena relacionado ao tratamento de dados multidimensionais relere-se à

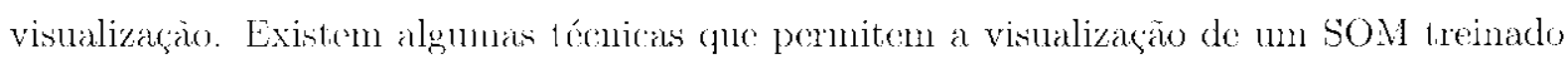
como a llatriz de: clistanciass on V-Matrix desenvolvida por Ultweh (1993a,b) e a P-Matrix, apresentada por Ultsch (2003). Ambas as téenicas são apropriadas para os processos de mineraça de dadus (Datu Mining) e descoberta de conbecimento (Knouledge Discovery).

Lma outra técuica que também pode ser utilizara junto aos SOM é o algoritmo conhecido como Watershed apresontado por Bencher e Lantućjoul (1979). Fsse algoritmo permite a detceção gradual clos agrupanentos existentes nos dados.

()s mapas do Kolomen também apresentam bons resultados com grandes volumes de dados (Kohonen, 1997a: Kohomen e Somervuo, 1997). Un dos exemplos mais representativos de projerano do grandes volumes de dados ó o sistema WEBSOM apresentado por Kohonen (1998), e também o PicSOM proposto por Laaksonen et al. (1999). Através do WEBSOM, aproximadamente, um milhão de documentos sào projetados en duas dimensões, 1.entando manter. o máxinu) pessivel, a similaridade entre eles. Para recuperar a informaça relacionada acos pontos projotados, cada ponto contém um ponteiro para o documento que este representa na base de dados. No caso do PicSOM, a mesma idéia é aplicada para recuperação de inagens. Vo trabalho de Koskela (1999) pode-se obscrvar um exemplo de recuperação de infomaño baseada no conteńdo com SOM.

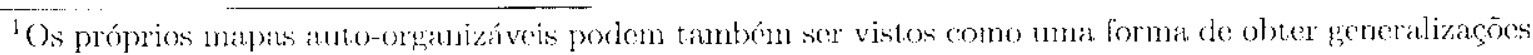
nà lineares de PCA (Rither, 1995).
} 
No trabalho apresentado por Merkl (1997), o autor apresenta resultados da exploração de textos através de SOM hicrárquicos. Nesses experinentos, a aborclagem hierárquica foi, aproximadamente, $600 \%$ mais rápida que a abordagem tradicional.

Fxistem também ontras ferramentas de uso geral, como o software Clementine (Grimmer, 1996). Porém, tanto no caso do WEBSOM como no caso do Clementine, a técnica utilizada para a deteção dos agrupamentos é a visualização. Há uma neccssidade de intervenção do usuário para o ajuste dos parâmetros.

Lma recente extensão dos mapas de Kohonen é o DIPOL-SOM (Distance Preserving On-Line Learning SOM), apresentado por König e Michel (2003). Nesse trabalho, os autores propuseram criar um modelo que combinasse a capacidade de projetar os dados a dimensões baixas com baixo custo computacional junto às vantagens que $11 \mathrm{~m} \mathrm{SOM}$ oferece.

Un ontro trabalho interessante é o sistema de recuperação de informação utilizando RNA apresentado por Hodge e Austin (2001b). Nesse trabalho, os autores apresentam uma rede neural híbrida: do tipo Tree GCS (Hodge e Austin, 2001a) com sub-redes do tipo GCS (Fritzke, 1993a, 1994b), para recuperação de informação a partir de grandes volumes de informaçio obtidos a partir da internet.

Un outro problema freqüente é o relacionado a variações dos dados ao longo do tempo. Nesse (áso, existem estudos como o Groung Self-Organizing Algorithm for Dynamic Clustering desenvolvido por Ohta e Saito (2001). Nesse trabalho, o crescimento cla rede ó controlado através de um contador existente em cada neurônio. Além clisso, o algoritmo permite a remoção virtual de unidades não descjarlas.

() trabalho de Shim (2001) também é um exmplo do intrograço de RNA em sistemas de recuperação de informação. Segundo o autor, o sistema proposto, Hierurchicul Associative Knowledge Learning Memory-HAKLM, é estruturado, inteligente e possui um mecanismo para aquisiçào, inferencia e extraçăo antomática de conhecinemto. () sistema tambúm apresentia um método seletivo para filtrar a informação encontradia.

Devido ao fato de que nem sempre é simples medir o grau de semolhanca entre dois objetos complexos, existem trabalhos, como os apresentados por Kaski ct al. (2001); Kaski o Sinkkonen (2001): Kaski (2001); Peltonen of al. (2003), ('ujo objelivo ó fazer com que as redes aprendam a calcular a distáncia métrica cntre dois objetos de forma automáticá. Xessa mesma linha de pesquisa encontra-se o trabalho apresentado por tim et al. (2001). () trabalho propõe a utilização de uma RNA do tipo Multi-layer I'ereptron (MLP) para aprender, dinamicamente, a função de distância.

En relaşão à quantidade de agrupamentos, Sun et al. (2001) ajpresentou unat técnica para medir o resultado do processo de deteção, de forma dinànica, do múmero apropriado de agrupanentos para um determinado conjunto de padróses. Os trabalhos de Baraldi e Blonda (1998): Jain (1999) são boas referências em relação a este problema. 
Lina ontra forma de reduzir o tempo de treinamento de uma Rede Neural é investir mais tempo no pré-processamento ou diminuição do número de padrões. Para isso, existen ostudos cono o apresentaklo por Su c Basu (2001). Nesse trabalho, os autores propöen um algoritmo patra solecionall alguns padrös que seräo apresentados à rede neural durante o treinamento. Essie processo reduz o tempo de treinamento de forma considerável.

Lma altcrnativa intcressante, que utiliza um princípio distinto en relação aos mậas do: Kohonen é a técnica conhecida como Generative T'opographie Mapping (GTM) proposta por Bishop) (t al. (1998). Nesse trabalho, săo utilizadas superfícies Gaussianas enjos parmmetros săo otimizados atravós do algoritmo Expectation-Marimization. (FM) (Dempster et al., 1977). Também existe unra versão hiorárquica do modelo GT.N chamada Hierarchical GTM (I'ino c Nabney, 2002).

Todas as técnicas mencionadas são viteis para agrupar os dados. Porém, além de procurar o agrupamento, muitos problemas exigem como resposta os $n$ padrões mais parecidos com o padrão de entradia. \&. Até nesmo em redes da família AR' o problema persiste, pois se

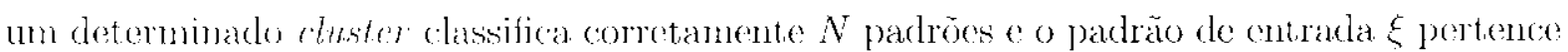
àguele agrupannento, não existe uma heurística para determinar os $n$ vizinhos mais próximos, $n<N$, de um determinado padrāo². O problema poderia ainda ser mais complexo se o objetivo fosse obter os $N-1$ vizinhos mais próximos, pois as sádas vizinhas em mir rede? ART nẫo necessialiannente representan os padrões fisicamente próximos.

No caso das redes SON, os padroes podem mudar de agrupanento ao longo do treindmento. Isso significa que o modelo de SOM não é estável, inviabilizando, dessa forma, a utilizaçào das nesmas até que seja conchuído o treinamento. Em um sistena de recuperaçào de informacaio roal, novos clados podem aparecer e ser inscridos a qualquer momento e nom sempre ć viável, depois de cada inserção. esperar por um tempo de treinamento.

Uma heurística utilizanda para reduzir o número de cáleulos de distância ao longo do treinamento é fazs (om que o sistema lembre qual é a midade vencedora, wi, para carla pardrào $\xi$, no $n$-ísinu ciclo (Kohonem. 1998; Kaski, 1999). Isso é realizado assumindo-se que existe una alla probabilidado de que as midades vencedoras, para um mesmo padrão, em ciclos consecutivos, sstejan fisicamente próximas. Porém, tssa técnica não pude garantir que ats muidades vencedoras, en ciclos consecutivos para um nesmo padrão, estojam próxinas sempre. Pode acontecer que as unidades vencedoras, para um mesino padrão em ciclos consecutivos, estejam fisicamente distantes no mapa. Fsse problema é mais visível no início do treinamento, pois a taxa de aprendizado não é tão pequena. Porém, à medida cm que o treinamento avança, a muidaxle vencedora -.- para $14 m$ mesmo padrão en ciclos conscentivos varia carda ve\% menos viabilizando a aplicação dessa técnica.

Hoje cun dia, é cad la ve mais connum a existência do maiores e mais complexos bancos de dados o que, necessarianente, significa um maior tempo de processamento e maior

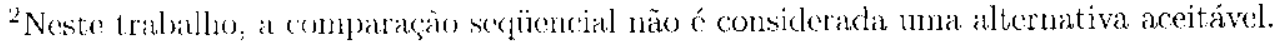


número de cálculos de distância. Por essas razões, é sempre importante continuar analisando possibilidades para tentar reduzir o número de operaçōes neccessárias para o treinamento de uma RNA. No presente trabalho foram utilizados Mćtodos de Acesso Espacial para criar redes com maior número de unidades, maior precisão, menor erro e menor tempo envolvido no processo de busca, como será apresentado no Capítulo 5.

\subsection{Vantagens das RNA no processo de RI}

As RNA possuem diversas vantagens que podem utcis para o processo de Recuperação de Informação (RI). Nesta seção, algumas das maiores vantagens são dotalhadas com o intuito de aproveitar o potencial existente para melhorar esse processo.

\subsubsection{Aprendizado através de exemplos}

Una das características mais relevantes das RNA é a capacidade que estas possuem de: adquirir o conhecimento através de exemplos apresentados de forma repetitiva durante o treinamento (Kohonen, 1982; Rumelhart et al., 1986; Haykin, 1999).

Cada vez que $11 m$ novo padrão é apresentado à rede, o algorituno de treinamento ajusta. os pesos existentes com objetivo de representar molhor o padrão aprescutado. Essa idéia foi inspirada na forma en que o cérebro humano aprende desde os primciros anos de virla. $O$ processo de apresentação repetitiva do conjunto de dados permite que, após o treinamento ter sido finalizado, a rede possa reconhecer padróes que nunca lhe foram apresentados.

Mesmo considerando uste item como uma vantagem, é necessário considerar que o processo de treinamento pode precisar de un tempo computacional considerável.

\subsubsection{Capacidade de generalização}

A capacidade de generalização é uma consequiencia do processo de aprendizado. Fsta característica significa que uma RNA seja capaz produzir uma boa aproximação para entradas que 1 ão fizeram parte do conjunto de treinamento (Haykin, 1999).

A idéia principal é que a R.VA possa reconhecer novos objetos que nunca lhe foraur apresentados ou mesno aqueles conbecidos, mas com pequenas variaģoes on ruído, en funçào do conhecimento adquirido a partir do subconjunto com o qual foi treinada. 


\subsubsection{Pouco espaço necessário para armazenar a estrutura}

Nat grande maioria das vezes. o número de nemónios $n$ existentes ma rexle é muito menor que o) nínıero, $m$, de padröes representades nela $(n \ll m)$. Isso representa uma grande vantagem em termos de espaço ('m comparano aos MAF e MAM

Esta vantagen ustá fortomente: relacionada à complexidade da distribuiçăo dos dados. Dependendo dia (omplexidlake. pode-se representar milhares de padröe com poncas unidades. Este item \& consiclerado ma vantagem. especialmente on relação aos MAM o MAE que armazenam todos os oljedos do conjunto apresentarlo.

\subsubsection{Capacidade de reduzir a dimensão dos dados}

Existem alguns modelos de RNA, tais como, os mapas de Kohonen (1984) podem ser utilizados para projetar dades multidinensionais para baixas dimensöes. Geralnente, esta técnica ó utilizada para projetar os dados para $2 d$ on $3 d$ de modo a facilitar a visualizaçäo (Duch, 1994). Lma grande vantagem desta abordagem é que os dados projetados conservm mua grande parte da sinilaridade dos dados no espaço original.

\subsubsection{Capacidade para detectar agrupamentos}

As RNA, ceperiahnente afuelas pertencentes ao paradigma não supervisionado, säo capazes de detectar us agrupannentos existentes nos dados. Também existem técnicas, como a U-Matrir (Ultsch, 1993a), que podem ser utilizadas junto com SOM para visualizar os agrupanentos. Essa capacidade representa uma grande vantagem para o processo de organizar a informagion.

\subsubsection{Capacidade para previsão de séries temporais}

Ima rede nemal lambén pode ser treinada para prever o comportannento de un conjunto que varia ao longo do tempo. A partir dessa informaģão, espera-se que a rede seja capaz de prever o comportanento que os dados teráo no futuro. Un exemplo claro da utilidade desta vantagen ó a previsto de clima, tomando como dados de entrada os dados climáticos de mun certo período de tempo

Alguns modelos de redes que aprescntan esta característica são o NETtalk (Sejnowski e Rosenberg. 1987) a o Tane Delay Neural Nelwork ('IDNN) (Land e Hilton, 1988: Waibel ct al., 1989$)$. 


\subsection{Limitações das RNA no processo de RI}

Nesta seção são detalhadas algumas limitações das RNA com expecial ênfase no processo de Recuperação de Informação (RI) em grandes bancos de dados.

\subsubsection{Definição da quantidade de ciclos de treinamento}

Durante o treinamento de uma RNA, nâo é trivial definir. a priom, o múmoro de ciclos do treinamento. Isto pode acontecer devido a vários fatores que influcnciam no processo do treinamento de uma RNA. Os mais importantes sado;

- a configuração inicial do conjunto de pesos antes do treinamento (Fomínder-Redondo) e Hernández-Espinosa, 2001; Alahakoon ct al., 2000);

- a taxa de aprendizado (Wilson e Martinez, 2001):

- os parâmetros específicos de cada modelo;

- a complexidade da distribuição do conjunto de dardos;

- a quantidade de padrões apresentados;

- a arquitetura e a quantidade de midades da rede;

- o algurit mo de inserção de novas unidades, no caso de redes construtivas (Fritzke, 1997; Parckh (t al., 1997).

A convergência do treinamento de una RNA, e conseqüientemcnte o número de ciclos necessários para finalizar o treinamento, depende da boa conbinaçato desses latores. Geralmente o processo de ajuste dos parâmetros de uma RNA depende, em grande parte, da experiência do projetista.

A determinação do número de ciclos de treinanento é un problenina sério que afeta diretamente o treinamento. Por esse motivo, este fator ć considerado nuna limitação.

\subsubsection{Definição da arquitetura apropriada da rede}

A definição da arquitetura de uma rede neural também é um fator que depende, em grande parte, da experiência do projetista. Porém, existem quatro abordagens mincipais para se obter uma arquitetura apropriada:

Empúrica: está técnica tanbóm é conhecida como tentativa-erro e lepende culase cxelusivamente da experiência do projetista. 
Evolutiva: rsta abordagen é bascarla em princípios baseados em algoritmos genéticos. A partir de uma populaçào inicial de redes, novos indivíduos (redes) são gerados a cada ciclo, mantendo aqueles com maior gran de aptidão ou que ajudem a minimizar o erro da rede (Goldt)erg, 1989).

Construtiva: nesta trenica, o processo é iniciado com uma rede com topologia mínima. Novos clementos, tais como neurônios, conexões on camadas são insericlos de forma gradual. segundo o problema (Parekh et al., 1995, 1997). Excmplos de modelos SOM construtivos foram apresentados na Seção 2.3 .

Pruning: esta abordagem visa reduzir ao máxino as unidades e conexöes redundantes su pouco relevantes. sem aletar a qualielade da saída produzida pela rede. Alguns exemplos desta abordagem podem ser observados no traballo de Reed (1993). Lxistem também técnicas que incorporam técnicas de poda junto com a abordagem construtiva como o algoritmo (iNG (Fritzke, 1995b).

As quatro al)ordagens apresentadas têm por objetivo obter RAA apropriadas para cada problema. Porém, c difícil deteminar, a priori, a arquitetura mais apropriada para $u m$ determinado problema.

Essa limilação dificulta, ainda mais, a utilização de modelos de RNA en um sistema que recueira respostas inediatas on onde novos padröes podem ser adicionados/removidos a dualquer momento, inclusive após o treinamento ter sido conclúdo.

\subsubsection{Reinicialização do treinamento}

O processo de troinamento de uma RNA tem por objetivo ajustar, de forma iterativa, os pesos existentes nas conexöes. É recomendável que o conjunto de treinamento seja aprescntado em mua orden distinta a cala ciclo. Isto permite que a RXA seja treinada de maneira miforme, com todos os padrós com a mesma probabilidade de apresentação.

Porém, se um novo padrão aparecessese após o treinanento ter sido finalizado, nẵo ó recomendável treinar a rede apenas para novo padrão. O que aconteceria seria que a rede perde o conlecinento armatenado até então e passaria a decorar o novo padrão. Para evitar essa situaçio, o treinanentu deve ser reiniciado. O problema é que reiniciar o tremamento envolve um custo compuacional alto. Existe um grande número de modelos de RNA que apresentann este comportanento.

Contude, existem morlelos que foran projetados com o intuito de resolver esse problema. romo ó o caso dos monleles da família ART (Grossberg, 1972, 1976a,b). Esse problema ó abordado através do dilema da Estabilidade-Plasticidade (Grossherg, 1988). Nas redes do tipo SOM, derivadas do modelo de Kohonen, o dilena da Fstabilidade-Plasticidade ó un problema que persiste. 


\subsubsection{Instabilidade}

No caso específico das redes do tipo SOM, sabe-se que canda neuronio é o encarregado do responder por uma determinada regiäo do espaço de darloss. As regioús que as unidades representam podem sor melhor entendidas através de un diagrana de Voronoi (1907) (ver Figura 4.1).

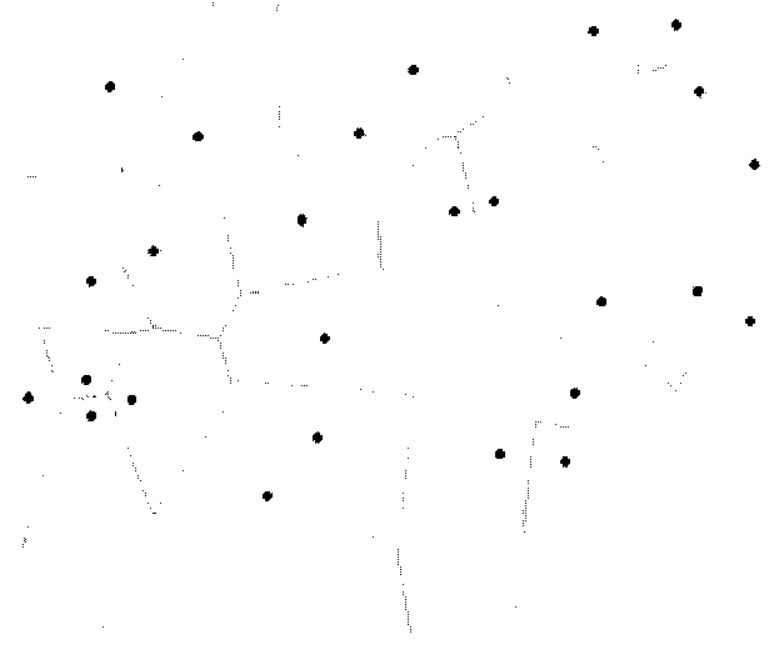

Figura 4.1: Diagrama de Voronoi para uma distribucẹáo arbitrária dr pontos.

Durante o treinamento, cada vez que um vetor de pesos é modificado, a região de Voronoi dacpuele neurônio e dos seus vizinhos também varia, como observaklo nal Figura 4.2.
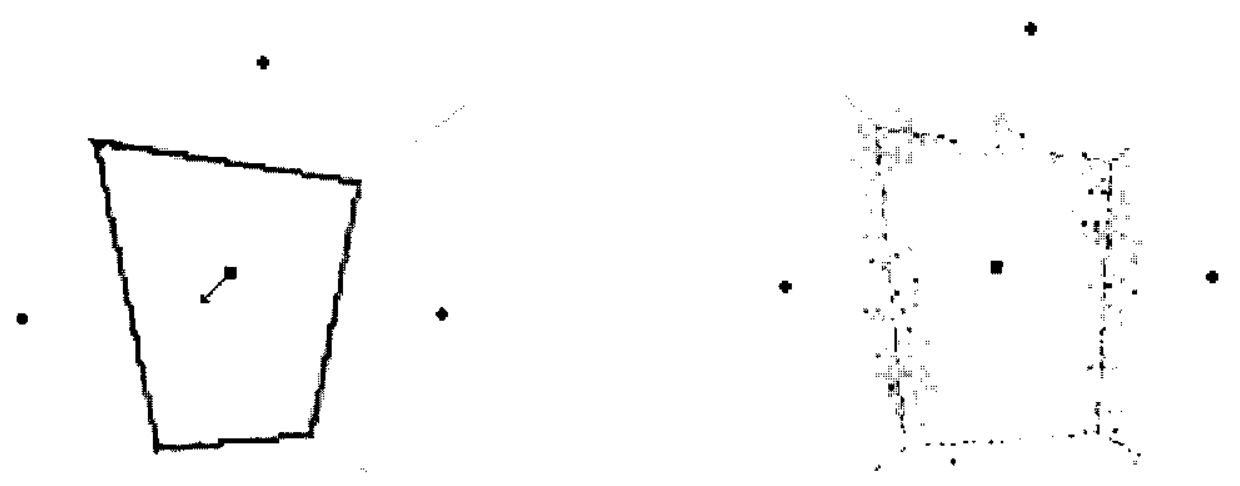

(a) Região de Voronoi afetada pela correção dos (b) Padrōes con alta probabilidade de mudar de pesos de umn neurônio região

Figura 4.2: Efeito do treinamento em um SOM derivado do modelo de Kohonen.

Como conseqüència da correção de pesos de mma unidade, vários padróes podem passar de uma região de Voronoi para uma outra adjacente. Isto significa que a execuçăo de consultas, 
durante o períck de treinanento, pode gerar resultados que não são confiáveis. I'ortanto, o único período de cstabilidade da rede acontece quando o treinamento é conclúdo.

Lim um sistema real. isto pode representar um problema sério pois, a (lasses de um determinado patráo poderia variar, inclusive, entre ciclos consecutivos.

\subsubsection{Projetadas para trabalhar em memória principal}

Devido a caparidake de representar un conjunto de dados com poncas uniclades, na maioria das vezes, as RXA podem ser treinadas inteiramente em memória principal, sen a necossidade de utilizar dispositivos de acesso secundário, tais como, disco rígido, et. Esse ponto é consirlerado uma limita(ño (nu relaçăo aos MAE e MAM.

\subsubsection{Falta de organização para responder consultas do tipo k:-vizinhos mais próximos e buscas por abrangência}

As RNA são bastante utilizadas para resolver problemas de classificação onde deseja-se conhecer o grupo ao qual pertence un determinado padrão, $\xi$, apresentado como entrada. Porém, existem muitos casos onde o usuário precisa conhecer mais informaçào, além do grupo. Alguus exempless dessise tipo de consulta são: "Quais são os três padröes mais parcriclos com o partrão c?" on "Quais são os padrōes que apresentam, no mínimo, são 90\% de similaridarle com relaça ao padrão $\xi ? "$. Na atualidade, a execuçáno desse tipo de consulta, por meio de RNA, apresenta deficiencias.

O primeiro obstáculo para responder estas consultas é a ansencia de organizaçăo entre os padröen que săo rassificados dentro de um mesmo grupo. A busca seqüencial não ó considerada, neste trabalho, como uma alternativa accitável. Por cansa disso, este ponto considerado mina linitaço das RNA.

Existem trabalhos, conos os apresentarlos por (Vicentini, 2002; Vicentini e Romero, 20003), que resolven parcialnomto o problema utilizando um MAE ou MAM dentro de carla grupo. Sesses trabalhos utilizon-se Redes Anto-organizáveis da família ART. Porén, esse modolo aincla apresconta problemas para responder consultas por similaridade porcue os grupos gerarlos näo tom relacio entre si. Por esse motivo, se um grupo classifica apenas n padröes, seria impossivel procurar $n+1$ elementos. O problema é que unidades fisicamente próximas na rede não necessariamente representam os padrōes mais próxinos. A única sárla neste caso 6 a comparayio seciüencial. 


\subsection{MAE e MAM na Recuperação de Informação}

Os MAF o MAM têm sido mais exploradas no ambiente acarlenico. Existem diversos trabalhos dessas técnicas relacionados ao processo de Recuperação de Informaçào (RT). No trabalhos de Faloutsos et al. (1993, 1994) pode-se observar um cxemplo de recuperação de imagens bascarda no conterído.

No projeto Informedia (Wactlar et al., 1996, 1999) desenvolvirlo na. Camegie Mellon University também foi usado o método SR-Tree (Katayama e Satoh. 1997). Esse algoritmo foi utilizardo junto com alguns algoritmos de extração de caractorísticas usiados para processar vídeos e gerar vetores em dimensão 1215 - $D$. Atualmente, o projeto Informedia utiliza a Omnisequential (Sautos-Filho et a1., 2001).

Existem poucas aplicaçoos industriais utilizando esses nétodos do acesso. Un exemplo de aplicação na indústria ó o gerenciador de bancos do dados Oracle que recentemente incorporou as R-Tree (Kantlı ot al., 1999). Nesse trabalho. a R-Tres foi utilizada para indexar dados de 3- $D$ até $10-D$, que ainda são consideradas dimensóes relativamente baixas. Em rolação à indexação de imagens pode ser observado o trabalho do Annamalai et al. (2000) que explica esse processo en um gerenciador de bancos de dados.

Um dos maiores problemas é que o investimento para incorporar ossas técnicas $\mathrm{mm}$ softwares comerciais é muito elevado. Por essa razão, inchusive as propostas mais recentes, como a NB-Treo (Fonseca e Jorge, 2003), tentam utilizar tócnicas já existentes no norcado. Nesse último caso, os autores argumentam que os métodos morlernos cutä́n cakla ve\% mas mais complexos, mas o desempenho nem scmpre melhora com o mesmo ritmo. Por esse motivo, os autores propoom reduzir a dimensão dos dados o logo inclexá-los conn uma $B^{\dagger}$ - Tree (Comer, $1979)$.

\subsection{Vantagens dos MAM e MAE no processo de RI}

Os MAE o MAM também apresentam diversas vantagens que podem ser aproveitadas no processo de Recuperação de Informação (RI). As maiores vantagens estão relacionaxas a custo computacional baixo e à capacidade de lidar com grandes volumes de dados.

\subsubsection{Não existe o conceito de ciclos}

No caso de MAE o MAM, os pactróces säo incorporados à cutrulura através de um algoritmo de inserção próprio de cada método. Cada pardrão só é processado uma única ve pará ser inserido na estrutura.

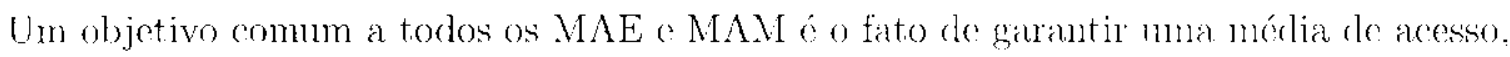
geralmonte da ordem logarítmica, independente da ordem em que os padrōes sào inseridos. 
Por causa dessia caractcrística incrente aos MAE e MAM, uma ínica apresentação do comjunto de palrócs é suficiente para a formação da estrutura.

\subsubsection{A incorporação de um novo padrão pode ser realizada a qualquer momento}

Nos métodos de axesso dinaninco, tais como M-Tree, Slim-Tree, etc., é possível inserir novos

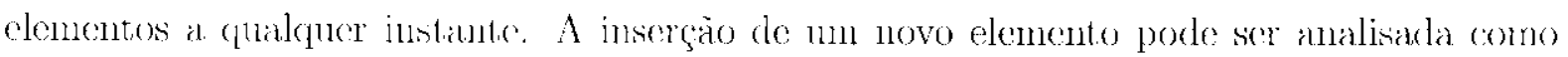
so cle fosse, simplesmente, o buttimo elemento da lista de partrões a serem inseridos. Tsto também significa que năo é relevante o intervalo de tempo que possa existir entre a inserçăo

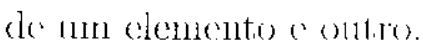

Porém ó nocrstário considerar que existem vários métodos de acesso que não apresent ann csta vantagem. pois á necessário ter o conjumto inteiro de dados antes de iniciar a construção da estrutura.

\subsubsection{Existe um ponto na estrutura para cada padrão}

Cada novo objeto inscriclo é representado por um clemento na estrutura de forma pontual. Esta vantagen tambrim significa cue a estrutura dispòe de maior quantidade de informaçäo para atender consulta mis complexas tajs como Range Queries on k-Nearest Neighbors.

Uma proocupacào especial relacionada a este ponto é o fato de que, maior quantidade de dados requer maior gluantidade de processamento. Porém, devido à organização dos dados. os MAF e MAM podem gamutir que, mesmo con grandes volumes de dados, o acessiso será realizado em tempo sub-linear, ou scja, cuja complexidade computacional seja menor que $O(n)$.

\subsubsection{Muitos deles foram projetados também para memória secundária}

Devido ao grande volume de dados com us quais se espera que una MAE e MAM lide, a grande maioria desses métodos são projetados, não apenas para serem ntilizados en momória principal, mas tambén en me'nória secundária.

Por outro lado, o acesso à memória secundária leva a um maior tempo devido às operaçócs de entrada/saída envolvidas. Porém, o custo conputacional de acesso sub-linear permite que o ganho seja maior e cola característica valha a pena de ser aplicada. 


\subsubsection{Maior facilidade para a execução de consultas do tipo $k$-vizinhos mais próximos e buscas por abrangência}

Devido à existência de uma unidade para cada padrão e especialmente devido à organização dos dados, esse tipo de consultas pode ser realizado com muita precisano. Muitus dos MAM e MAE, tais como os apresentados na Capítulo 3, utilizam a abordagem hicrárquicáa o que muitas vezes, facilita a operação de busca.

No caso de MAM com abordagens não hierárquicas, como as cstruturas da família OMNI (Santos-Filho et al., 2001), a poda de elementos utilizando Foci tambŕm ajuda muito na execução deste tipo de consultas.

\subsubsection{Tempo de construção e busca}

'Todos os MAE e MAM assumem que o processamento segülencial para buscar um objeto năo ć aceitável. Portanto, os custos computacionais de busca desscs métodos visam ser sempre menores que $n$, isto ó $O(n) \ll n$. Na Tabela 4.1, observa-so um breve resumo de custos dos principais MAM. Fssa tabela está baseada no trabalho de Chávez et al. (2001), porém algums métodos foram adicionados. Os custos computacionais para o caso de MAE podem ser obscrvados no trabalho de Gande e Cüntlier (1998).

Os custos computacionais apresentados na Tabela 4.1 não podem ser considerados como absolutos. Por exemplo, no caso do método Burhhard-Keller Tree (BKT) (Burkhard e Keller: 1973), os autores apenas fizcram uma proposta de três técnicas, sem existir implementação. Porém, o custón n log $n$ refere-se ao custo de construção de una árvore n-ária como sugere a idéia dos autores.

No caso da $M$-Tree, com custo $O\left(n\left(m . m^{2}\right) \log _{m} n\right)$, o termo $m . m^{2}$ depende de cortos parâmetros do algoritmo. Para maiores detalhess recomenda-se analisar os artigos citados para cada caso.

\subsection{Limitações dos MAM e MAE no processo de RI}

Mesmo considerando a rapidez dos MAE e WAM, essas também apresentam limitações que são inalisadas nesta seção.

\subsubsection{Não aprendem dos exemplos anteriores}

Fste problema pode ser melhor entondido executando-se duas vezes a mosma consulta por similaridade. Sem considerar mecanismos que ajudem à areleracão de consultas como 


\begin{tabular}{|c|c|c|}
\hline Método de Acessos & Custo de construçẫo & Custo de busca \\
\hline $\begin{array}{l}\text { Burkhard-Keller Tree (BKT) (Burkhard e Keller, } \\
\text { 1973; Shapiro, } 1977 \text { ) }\end{array}$ & $O(n \log n)$ & $O\left(n^{\alpha}\right)$ \\
\hline $\begin{array}{l}\text { Fixed-Queries Tres (IOQT) (Baya-Yates et al., } \\
\text { 1994) }\end{array}$ & $O(n \log n)$ & $O\left(n^{\alpha}\right)$ \\
\hline $\begin{array}{l}\text { Fixed-Heigh QT (FHQT) (Baeza-Yates et al. } \\
1994 \text {; Bayal-Yates } 1997 \text { : Backa-Yates o Navarro. } \\
1998 \text { ) }\end{array}$ & $O(n h)$ & $O(\log n)\left(^{*}\right)$ \\
\hline Fired Quertes Array (FQA) (Cháve et al., 1999b) & $O(n h)$ & $O(\log n)(*)$ \\
\hline $\begin{array}{l}\text { Vontage-Point The (VPl') (Uhlmann, 1991a; } \\
\text { Yianilos, 1993: Chineh, 1994) }\end{array}$ & $O(n \log n)$ & $O(\log n)(* *)$ \\
\hline $\begin{array}{l}\text { Multi-Vantage-Prim These (MVP'T) (Bozkaya o } \\
\text { Orsoyoghu, 1997: Brin. 1995) }\end{array}$ & ()$(n \log n)$ & $O(\log n)\left({ }^{*}\right)$ \\
\hline Vantage-Point Fontst (VPF) (Yianilos, 1999) & $O\left(n^{2-\alpha}\right)$ & $O\left(n^{1} \times \log n\right)$ \\
\hline $\begin{array}{l}\text { Biscclor Trees (BSI) (Kalantari o MeDonald, } \\
\text { 1983; Nolteimer et al., 1992) }\end{array}$ & $O(n \log n)$ & nào anıalisado \\
\hline $\begin{array}{l}\text { Generalizcl-Hyperplane The (GHT) (Chlmann, } \\
\text { 1991a: Bugnion et al. 1993: Verbarg, 1995) }\end{array}$ & $O(n \log n)$ & não analisado \\
\hline $\begin{array}{l}\text { Gommetric: Near-nesghbor Acesss Thee (GNAT) } \\
\text { (Brin, 1995) }\end{array}$ & $O\left(n m \log _{m} n\right)$ & nâo analisado \\
\hline $\begin{array}{l}\text { Vormon Tree (VT) (Dethe o Nolteimer, 1987: } \\
\text { Nolteminter, 1989) }\end{array}$ & $O(n \log n)$ & năo analisado \\
\hline M-Tree (Ciaccia et al., 1997c) & ()$\left(n\left(m . m^{2}\right) \log _{m} n\right)$ & nào analisado \\
\hline $\begin{array}{l}\text { Spatial Appromimation Tree (SAT) (Navarro, } \\
1999,2002 ; \text { Navaro e Reves, 2002) }\end{array}$ & $O(n \log n / \log \log n)$ & $O\left(n^{1-\odot(1 / \log \log n)}\right.$ \\
\hline $\begin{array}{l}\text { Approximating Elminaliny Scarch Algorithm } \\
(\Lambda \mathrm{ESA}) \text { (Vidal, 1986) }\end{array}$ & $O\left(n^{2}\right)$ & $O(1)(* * *)$ \\
\hline $\begin{array}{l}\text { Linect AESA (LAESA) (1licó et al., 1994, 1996: } \\
\text { Nene e Vayar, 1997: Chave ot al., 1999a) }\end{array}$ & $\overline{O(k n)}$ & $k+O(1)(* * *)$ \\
\hline Slim-Tree (ST) (Traina Jr ot al., 2000b) & $O\left(m^{2} \log _{2}(m) \log _{m} n\right)$ & nào analisado \\
\hline OmniSetuential (Sintos-Filho ot al., 2001) & $O(k: n)$ & não analisado \\
\hline
\end{tabular}

Tabela 4.1: Custos computacionais de construgão e busca em MAM.

menória Cuche, o núnero de operaçós que o algoritmo realizaria seria o dobro do que: no caso de numa fubica combulta.

No caso de bancos de dados multimídia, as consultas são na sua grande maioria por similaridade. Isso significa que não adiantaria apenas utilizar memória Cache para procurar por una consulta ralizada anteriomente. Na grande maioria das vezes, as consultas fut uras polerian estar apenas relacionadas a dados sinilares que nunca fizoram parte de consultas próvias. 
Fsse comportamento pode ser interpretado como uma falta de habilidade para reaproveitar o conhecimento gerado por consultas antcriores. A idéia fundamental é que, naquelas áreas onde scjam realizadas várias consultas, o número de operaçoes para consultas posteriores seja reduzido de forma gradual.

\subsubsection{Maior espaço necessário para armazenar a estrutura}

Lista limitação surge pela presença de uma unidade na estrutura para cada padrão apresentado. Fm termos de espaço: isto pode ser interpretado como um problema. Porém, os recursos de memória principal e secundária hoje con dia sîo relativanente baratos.

Além disso, a grande maioria de MAE e MAM objetivam nào apenas o uso da memória principal, mas também dia memória secundária. Nesso último caso, a restriçăo de espaço praticamente desaparece. Poróm, aparece o problema de tempo extra causado pelo acesso ao dispositivos do armazenamento secundário.

\subsubsection{Maior complexidade da implementação}

A implementação de um MAM e MAE ć relativamente mais complexa que a de uma RNA. Un dos fatores que aumenta a complexidade é que são considerados tauto u acesso à memória principal quiknto à memória secundária.

Além disso, devido ao maior volume de objetos armazenades nal cstrutura, uma preocupação permanente é que os dados estejam organizados de tal forma cule possa ser garantido um tempo de recuperação constante. 'lambém é necossário considerar que o fato do ter que lidar com memória sccundária significa que se deve considerar o tempo de espera caulsado pelas operaçôes de entrada/saída.

\subsection{Considerações Finais}

No presente capítulo foram apresentadas as diversas aplicações. vantagens e limitações cxistentes, tanto nas R.NA quanto nos MAM e MAE, no processo de RIS.

Diversos trabalhos recentes relacionados à Recuperaçĩo de Informação utilizando RNA foran apresentados. As maiores colecooses dos trabalhos relacionados ans $S(), M$ podem ser cncontradas nos trabalhos de Kaski et al. (1998); Oja ct al. (2003); Yamakawa (2003). Algumas aplicaçoes de Métodos de Acesso no processo de RIS também formu apresentadas. Duas boas referências para este caso são apresentadas em Gaede e Günther (1998): Chávez (t) all. (2001).

As principais vantagens e linitagoes das RNA no processo de RiS forann detalhadas. Lintre as principais pode-se citar: o aprendizado através de exemplos e itcraçoes, a generalização 
do conjunto de partröes com poncos neurônios e pouco espaço necessário para armazenar a estrintura.

As limitaçôs das RNA, em relaçăo ao procenso de RIS, referem-se à falta de estrutura, de parte da rede para responder consultas fue requeiram maior grau de precisaio, lais como, k-vizinhos mais próximos o buscias por abrangencia (Range Query). Um outro aspecto que, dependendo do problema podo ser crítico é o fato de que näo é trivial definir a priori, o tempo de treintumento de man RAA.

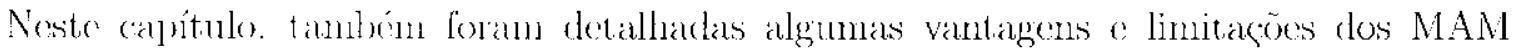
e MAL. Lintre as principais ressalta-se o fato dessas ténicas năo precisarem de mais de uma única apresentação do conjunto de padröes apresentado e que requerem um tempo de

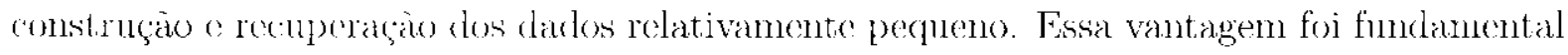
para a propesta das trénicas SA M-SOM C MAM-SOM, detalhadas no Capítulo 5.

As principais lintitacos dos MAM o MAE também foram apresentadas neste capítulo. $\Lambda$ principal delas é a ansência de algum mecanismo de aprendizado que reaproveito o conhecimento das consultas para acelerar graduahnente as consultas posteriores. Essa joćia ¿́de grande nilidade para um mellor entendimento dos métodos de acesso MAL-e MAMpropostos no ('apítulo 6. Alóm disso, os MAM o MAE precisan de maior espaço necessário para armazenar a estrutura o sua complexidade da implementaçào é maior. 


\section{As técnicas SAM-SOM e MAM-SOM}

\section{As técnicas SAM-SOM QMAM-SOM}

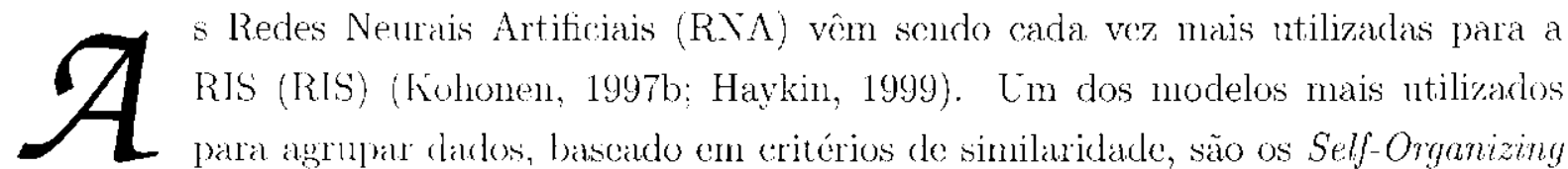
Maps (SOM) ou Mapa Auto-Organizáveis de Kohonem (1982). Esse tipo de rexte vem sendo aplicado con freqǘncia para grandes volumes de dados e altas dimensões (Kohonen et al., 1996; Fohonen, 1997a, 1998: Ultsch, 2003; Kaski, 2003; Oja, 2003).

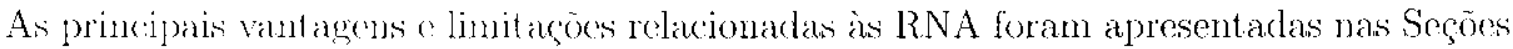
1.2 e 1.3, respertivamente. Com base nessas características, propöent-so neste capítulo duas novas técnicas para RIS, denominadas SAM-SOM e MAM-SOM. Essas duas técnicas são o resultado da incorporaçäo de Métodos de Acesso Fspacial (MAE) e de Métodos de Acesso Métrico (MAM), respectivanente, no processo de treinamento de 110 SOM. A sigla SAM corresponde no torno on ingles Spatial Access Methods (SAM). Ambas as técnicas são propostas con o intuito de reduzir o número de comparaçôes para encontrar a unidade vencedora, ma vo que nos modelos existentes, esse processo tem sido feito de forma secjïncial.

Para entender molhor a necessidade da incorporação de MAF e MAM no treinamento de um SOM será malisado, primeiranente, o custo computacional cnvolvido durante o

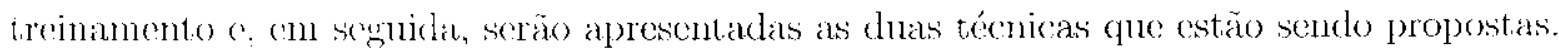

\subsection{Análise do custo computacional do treinamento de redes do tipo SOM}

Para analisar o custo computacional do treinamento de uma rede neural do tipo SOM, é necessário lombrar que, anda vez que um novo padrão $\xi$ é apresentado à entrada da rede, o algoritmo dew monitrar afucla unidade que melhor o represente na rede, isto é, aquela 
unidade, $s_{1}$, cuja distância entre o seu vetor de pesos $w_{s_{1}}$ o parlräo apresentado seja a menor possível, como obscrvado na Equaçăo (5.1).

$$
s_{1}=m i n \mid \xi-w_{i} \| \forall i
$$

O número de cálculos de distância, $N C D$, nocessários durante o treinamento de uma rede neural do tipo SOM convencional está determinado pela Equaçào (j.2).

$$
N C D=N U \times N P \times N C
$$

onde $N U$ é o número de unidades da rede, NP é o númcro de padröes apresentados e NC é o número de ciclos. A Equaçio (5.2) é derivada do fato de cue cada ver que um padrão é apresentado à rede, este deve ser comparado com o vetor de pesos de carla uma das unidades existentes antes de determinar a midade vencedora. Esse mesmo processo é repetido para cada ciclo, gerando um total de NCD cálculos de distancias. Por outro lado, deve-se considerar que cada cálculo de distância é affetado dirctancnte pela complexidade incrente à função de distancia cnvolvida e pela dimensão dos dados.

Quando a rede SOM é do tipo construtiva (CSOM), o númoro de unidades $N U$ varia aw longo do tempo. Nesse caso, o múmero de cálculos de distáncia, NCD cson até o t-ésimo padrão apresentado à rede, é determinado pola equação de recorrencia (5.3).

$$
\begin{aligned}
N C D_{C S O M}(t) & =N U(t) \times N P+N C D_{C S O M}(t \quad 1) \\
N C D_{C S O M}(1) & =N U_{0}
\end{aligned}
$$

onde $t$. representa o índice do padrão apresentado à rede, $N U(t)$ ó o mumero de unidades nacquele instante e $N U_{0} 6$ o número inicial de unidades na rele.

Supondo que o algoritno insere uma nova unidade à rede, a cada $\lambda$ paclröes apresentados, o múmero de cálculos de distância acumulado, $T C$, para atingir uma rede com $N$ unidados ó determinado pela Equação (5.4). A variável $\lambda$ representa un intervalo do padrões apresentados, após o qual uma nova unidade será criada na rede. Por excmplo. se $\lambda=500$, significa que a cada 500 padrós apresentados, durante o treinamento, mna nova unjadade é criada na rede. 


$$
\begin{aligned}
N\left(D D_{\operatorname{CSO}}\right. & -\sum_{i=N l_{0}}^{N-1} i \lambda \\
& =\lambda \sum_{i=N U_{0}}^{N 1} i \\
& =\lambda \frac{\left(N U_{0}+N-1\right) \times\left(N-N U_{0}\right)}{2} \\
& =\lambda \frac{N(N-1)-N U_{0}\left(N U_{0}-1\right)}{2}
\end{aligned}
$$

onde $N b_{0}$ ́r o mumero inicial de midades na rede. Observando-se a Equação (5.4) nota-so que a velocidade de invergàn de novas unidades, determinada por $\lambda$, afeta diretamente o tempo de treinamento da rede.

No caso das redes Croming Neural Gas (GNG), o número de unidades no início do

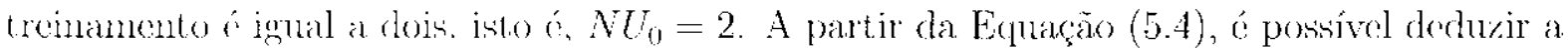
Equarão (5.5), que representa o numero de cálculos de distância que uma redo GNG, com und taxa de inserçio $\lambda$ arbitrária, precisaria para atingir um número $N$ de unidades.

$$
N C D_{G N G}=\lambda \frac{N^{2}-N-2}{2}
$$

Lin valor alto de $\lambda$ pode anmentar, consideravelnente, o tempe de treinamento e, ao mesmo tempo, reduzir a glantidade de midades criadas em um período de tempo. Se o valor de $\lambda$ for muito pequeno. a algoritmo de treinamento não terá tempo suficiente para arlajtar a. nova unidade it shrutura da rede, gerando assim redes deformadas (Cuadros-Vargas a Romero, 2002).

Na Figura 5.1. us dados de entrada da rede estào sendo gerados de maneira uniformo dentro dos objetos apreschtados na mesma innagem. Nessa figura, pode-se destacar a deformagăo produzida pola diminuiçáo de $\lambda$ em uma rede do tipo GNG (Fritzke, 199ab). Na Figura 5.1(a), por exemple, apomas un número pegueno de unidades foram criadas porque o valor de $\lambda$ r relativamente alto (500). Isto reduz o número de unidades que poden ser criadas em un certo períorlo de tempo. En compensaçäo, as midades encontrann-se benı distribuídas an longo do ubjeto gue está sendo reconlecido. Nas Figuras 5.1(b) e 5.1(c), onde $\lambda \quad 100$ : $\lambda=10$, respectivamente pode-se observar com mais freqüencia midades fora da área do objeto sendo reconhecido. Isso acontece por dois motivos: o prinneiro é que, quando o algoritno GNG cria una nova midade a posiçäo é resultado da interpolaçäo de duas muidaxles já existentes. l'orém, o algoritmo nồo avalia se a nova midade está sendo criada dentro da distribuição de dados ou no meio de uma área "vazia". O segundo motivo 
é que. com um valor de $\lambda$ perpneno, o algoritmo năo tem tempo para corrigir a posição das novas unidades e levá-las até algum ponto onde possam realmente ser úteis.

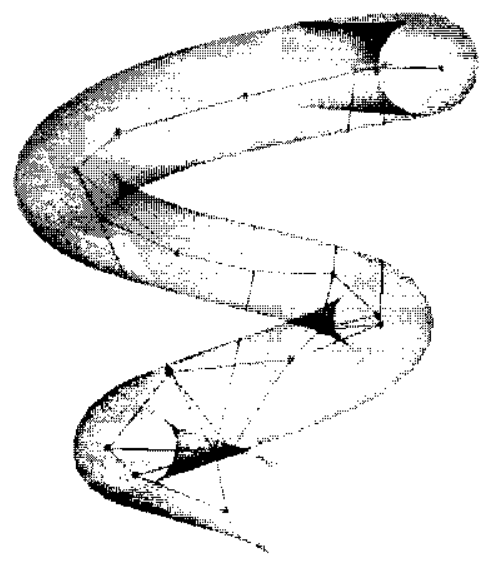

(a) 10000 padrics, $\lambda=500$

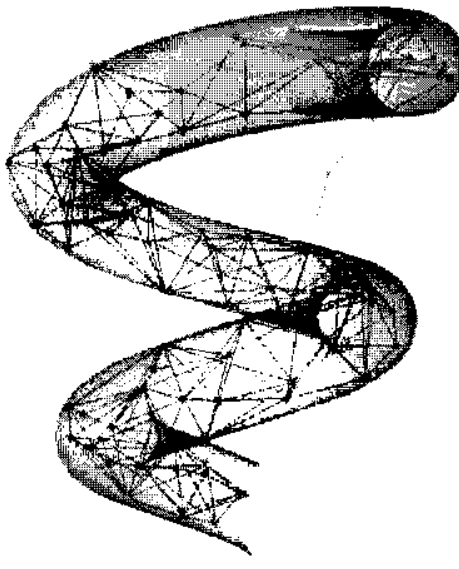

(b) 10000 padrões, $\lambda=100$

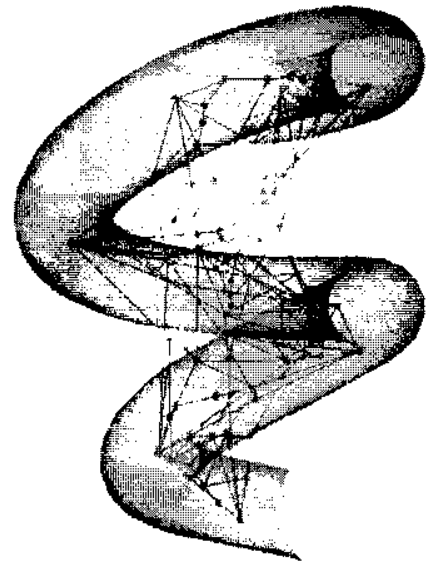

(c) 1000 padrões, $\lambda=10$

Figura 5.1: Lefeito da diminuição de $\lambda$ utilizando mua rede do tipo GNG.

O processo para encontrar $11 n$ valor de $\lambda$ apropriado não é uma tarefa fácil e nem trivial. Isso depende de múltiplos fatores, tais como, complexidade da distribuição e volume dos

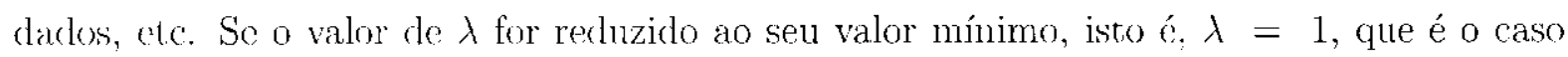
no qual mina nova midade é criada na rede para cada padrão apresentado, o algoritmo nào teria tempo suficiente para adaptar as novas unidades à estrutura existente, gerando assim redes visivelmente deformadas.

Em todos os cálculos. aprescentados nas Equações (5.2), (5.3) e (5.4), pode-se observar que, para encontrar a unidade voncexlora sempre são consideradas todas as unidades existentes. Isto é, o padrào apresentado, $\xi$ é sempre comparado com todas as unidades da rede antes de decidir qual é o neuromio vencedor.

O mesmo acontece com an redes SOM hierárquicas, apresentarlas na Seção 2.4. De fato, a proposta de todos esses métodos está diretanente relacionada, cutre outros fatores, com a tentativa de redução do munero de cáleulos de distância durante o treinamento da rede. Existem autores, como por exemplo Koikkalainen e Oja (1990), que afirmam ter reduziclo o custo computacional, de $O(n)$ para $O(\log n)$, pelo fato de ser uma abordagem hicrárquica. Fssa afirmação é apenas teórica, pois na prática, as redes desse tipo ganham um ponco de tempo pela existoncia da hierarquia mas, dentro de cada sub-rede, ainda utiliza-se a abordagen seqüencial. Existem vários autores, tais como Huntsberger e Ajjimarangsee (1990); Demian o Mignot (1993. 1996); Chan et al. (1995); Kohonen (1997b); Kolinumni et al. (2000); Hämälainon (2002), que afirmam que o tempo de treinamento pode ser melhorado através de processamento paralelo. Fin todos esses casos, as operaçôes são distribuídas mas, o número delas é o mesmo. Isso significa que o custo computacional continua sendo o mesmo. 
O motivo da preocupação com a redução do tempo de treinanento pork ser explicado pelo custo computacional apresentado na Equarăo (5.5) que depende diretamente de $\lambda$ e também de forma quadrática en relaçào ao número de unidades da rede, $N$. A inserção de nuna nova midade representará un ammento de cálenlos considerável.

A seguir, será axplicado, com maior grau de detalhe, o processo proposto no presente traballıo para a incorporação de? Métodos de Acesso Espacial (MAE) e Métodos de Acesso Métrico (MA.M) para a relluçio do número de cálculos de distância ao longo do tremanento do un SOM.

\subsection{Incorporação de MAE e MAM em SOM}

Para poeder incorporar Mótodes de Acesso Espacial (MAE) e Métodos de Acesso Métrico (MAM) em redes SOM, derivadas do mapa de Kohonen, é necessário, on primoiro lugar. estabelecer uma correspondència entre cada nó do Método de Acesso (MA) o as unidades on agrupamentos da rede gue está sendo treinada. Essa relação permitirá realizar as operaçõos de RIS através do MA prescindindo do processannento secpiiencial.

A incorporação de MAE em SOM dá origem à téenica SAM-SOM. Dentro dessa técnica existem duas variaçers. No primeiro caso, os MAF são utilizados para substituir o processo seqüencial de detcminaçăo da unidade vencedora, utilizado em redes do tipo SOM, por mm mecanismo mais rápido. Bsse mechnismo consiste em aproveitar a organizaçăo existente em um MAE, cono será (xemplificado mais adiante. Em seguida, o processo de correçăo do pesos dos neurónios da rede é realizado de acordo con o algoritmo do SOM envolvido. Para cada neurônio cujos pesos sào atualizados, deve existir una correspondente atnalização no clemento que o representa no MAE. Esta técnica é denominada cono SAM-SOM híbrida.

O segundo raso difere do primeiro no seguinte sentido: una nova unidade é criada para cadia padrăo apresentado e, de acordo com um fator de conectividade, essa nova inidade é conectada a una quantidarle finita de neurônios da rede. Lissa nova unidade é criarla com um vetor de pesos exalumente igual ao vetor de atributos do padrão de entrata. Năo existe o processo de corregão de pesos. Esse processo possui a vantagen de que o próprio algoritmo de coustrução da rede faz com que os nemronios fiquem conectados aos seus vizinhos mais próxinnos. Isso evita que seja preciso um treinamento exaustivo para

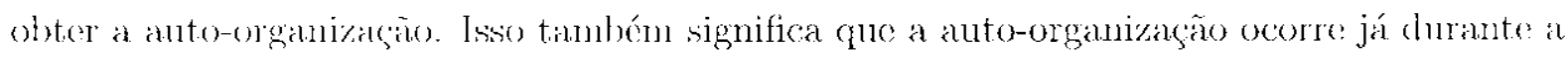
fase de construção dia rede. Fsta téenica é denominarla SAM-SOM*.

A incorporação de WAM en redes SOM dá origem à técnica MAM-SOM. Lesse caso, de forma anciloga às variaçoes dir técnica SAM-SOM, também pode-se falar das técnicas MAM-SOM híbrida e MA.M-SOM*. Porém, no caso da técnica MAM-SOM híbrida, deve ser considerado que, en um espaço métrico, apenas existe a função de distância o os objetos 
propriamente ditos. Isso significa que não pode ser considerada a existència de coordenadas dos objetos, as mesmas que são necessárias para o processo de correcão de vetores de pesos. Por isso, é contraditório falar de correção de pesos e ao mesmo tempo da técnica MAM-SOM. No entanto, existem autores, como Somermo (2003). que apresentam técnicas de correção de pesos nesse tipo de espaço.

Para cntender melhor o processo de incorporação de un MAE em um SOM é necessário lembrar os passos envolvidos no treinamento desse tipo de redes. No Algoritmo 5.1, pode-se observar, de uma forma geral, os passos envolvidos nesse processo.

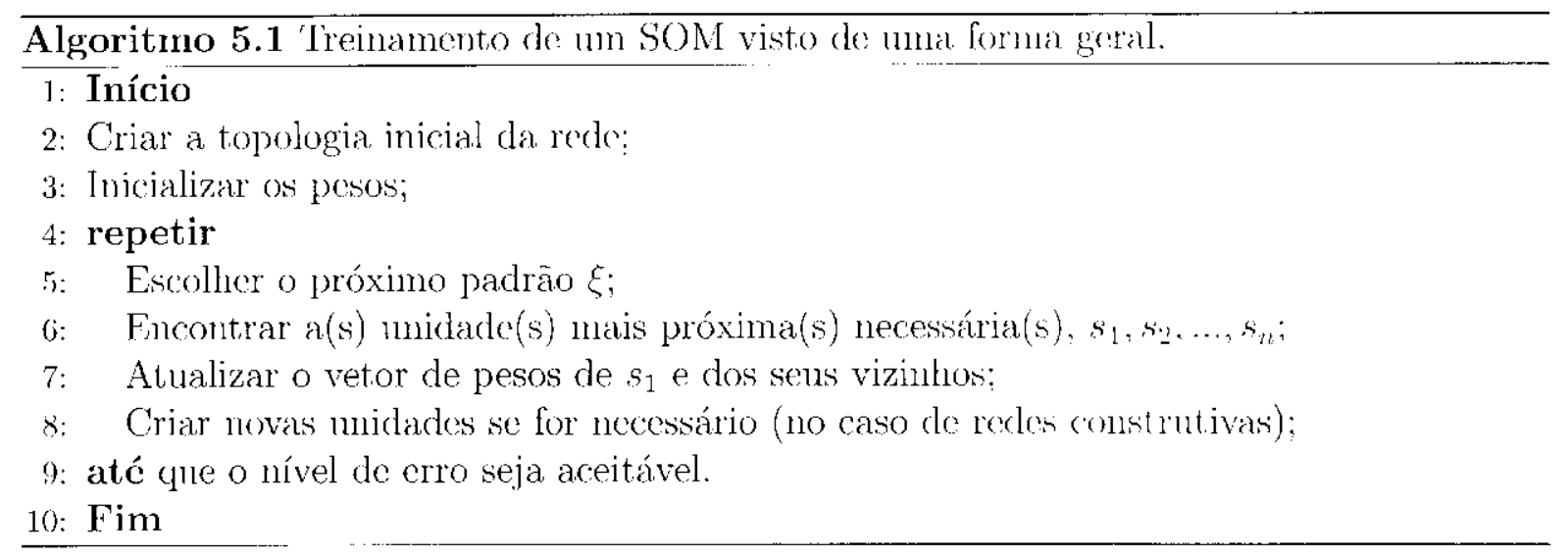

Para usar a técnica SAM-SOM híbrida, é necessário modificar apenas os passsos corresponclentes à busca da unidade vencedora e à atualização dos vetores de peses no Algoritmo 5.1. Por excmplo, se o objetivo fosse utilizar a R-Tree com o algoritmo de treinannento da ${ }^{4} \mathrm{NG}_{x}$ (ver Pág. 12), o passos 2.3.4 e 2.3.4 do treinamento de GNG devem ser realizados de acordo com o Algoritmo j.2. As modificações no algoritmo estào sublinlardas.

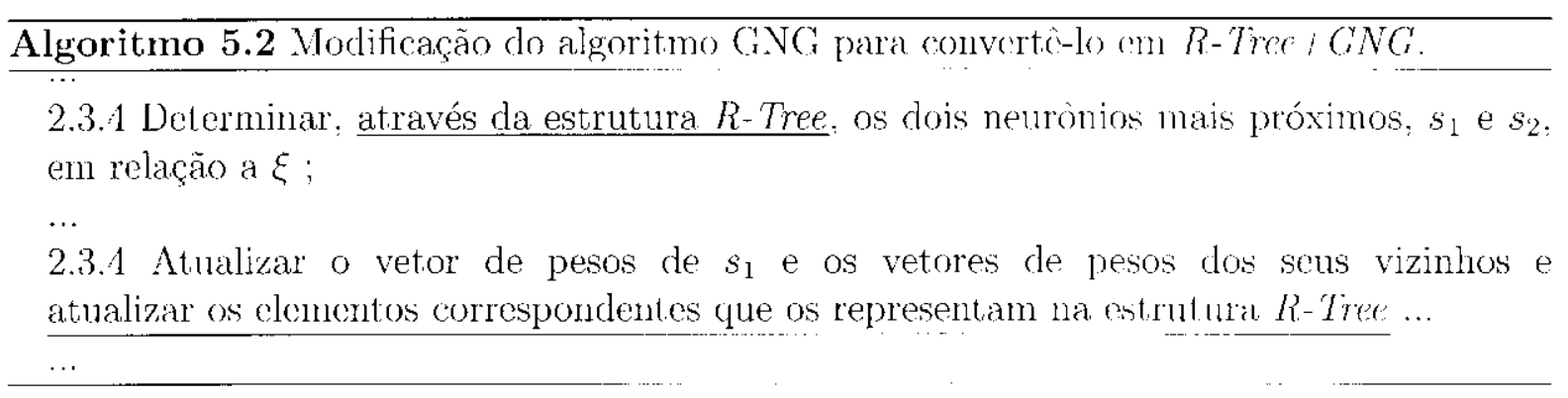

Os métodos de acesso podem ser de grande utilidade no processo de concontrar a midade vencedora sem ter que recorrer à comparaçäo seqünencial. P'or excmplo, na Figura 5.2, pode-se? observar, em vermelho, a área de cobertura de una consulta por abrangencia (Range Queny). Na sequiência de Figuras 5.3, 5.4 o 5.j, pode-se observar os retzingules atingides pela consulta no primeiro, segundo e terceiro nível da árvore. respectivanente. Do lado direito de carla figura, encontra-se a sub-árvore correspondente envolvida na comsulta realizada. O descarte on inclusão de um retângulo, na área atingida pela consulta é realizado analisando se existe 
interseç̧ão entre a área da consulta e o retângulo. Dessa forma, a informação é recuperada com um custo computacional muito menor que a tradicional busca seqüencial.

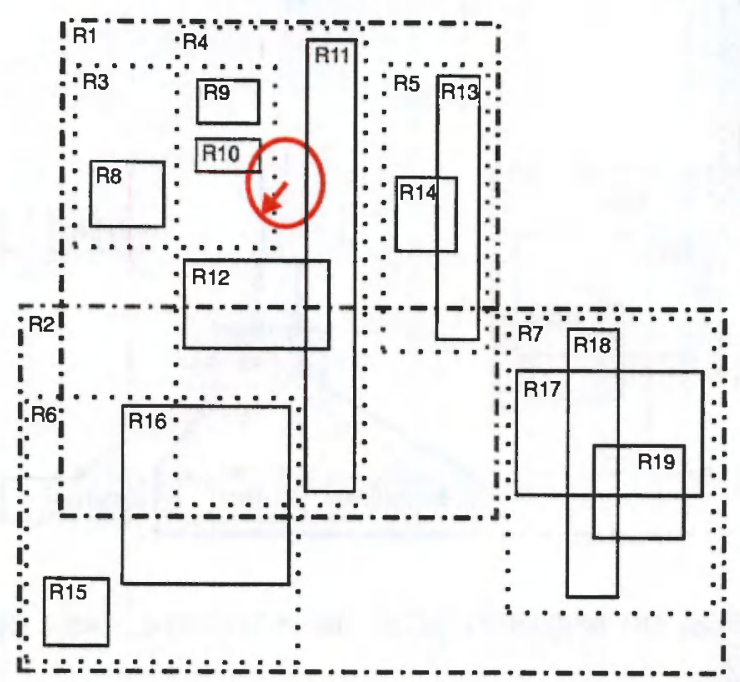

Figura 5.2: Consulta por abrangência em uma $R$-Tree.
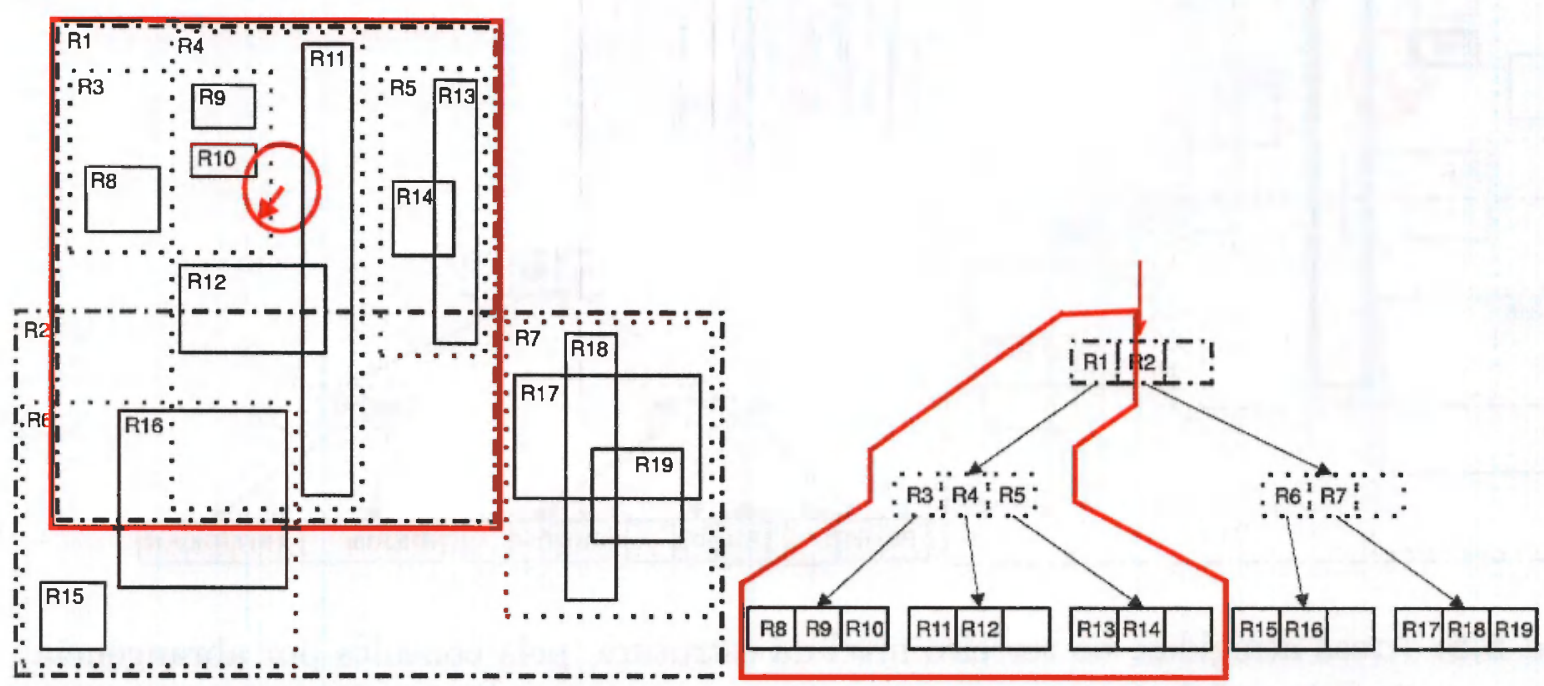

Figura 5.3: Áreas atingidas, no primeiro nível da estrutura, pela consulta por abrangência da Figura 5.2.

No Algoritmo 5.3, apresenta-se a seqüência de passos para criar uma rede com as técnicas SAM-SOM* e MAM-SOM*. Ao mesmo tempo, o algoritmo introduz o parâmetro $\phi$, que representa o número de unidades mais próximas com as quais um novo elemento deve ser conectado quando é criado. A variável $\phi$ pode ser vista como o fator de conectividade para as novas unidades.

A idéia que está sendo proposta leva em conta os seguintes casos:

1. para o treinamento de redes SOM em lotes (batch learning), a estrutura de dados escolhida deve ser reconstruída completamente após cada iteração, pois todos os pesos são atualizados simultaneamente; 


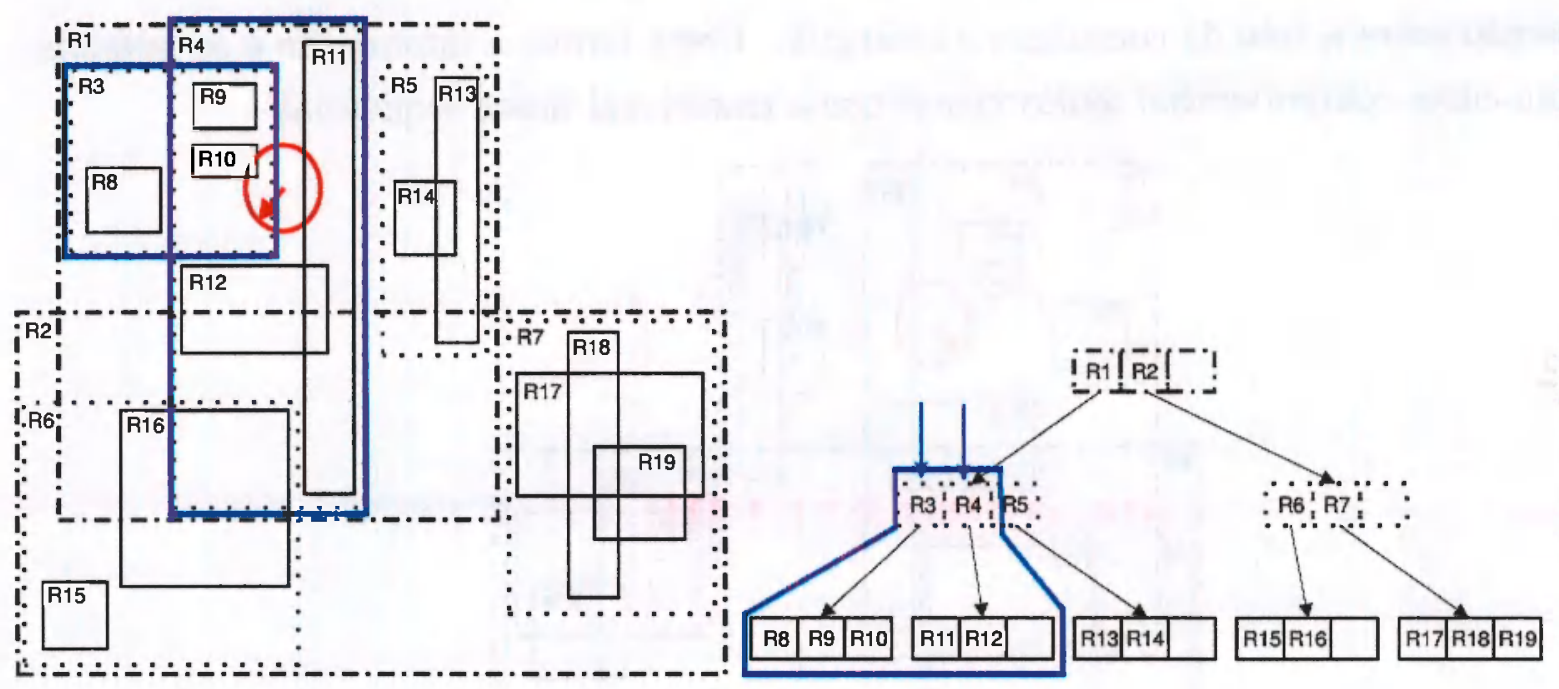

Figura 5.4: Áreas atingidas, no segundo nível da estrutura, pela consulta por abrangência da Figura 5.2.

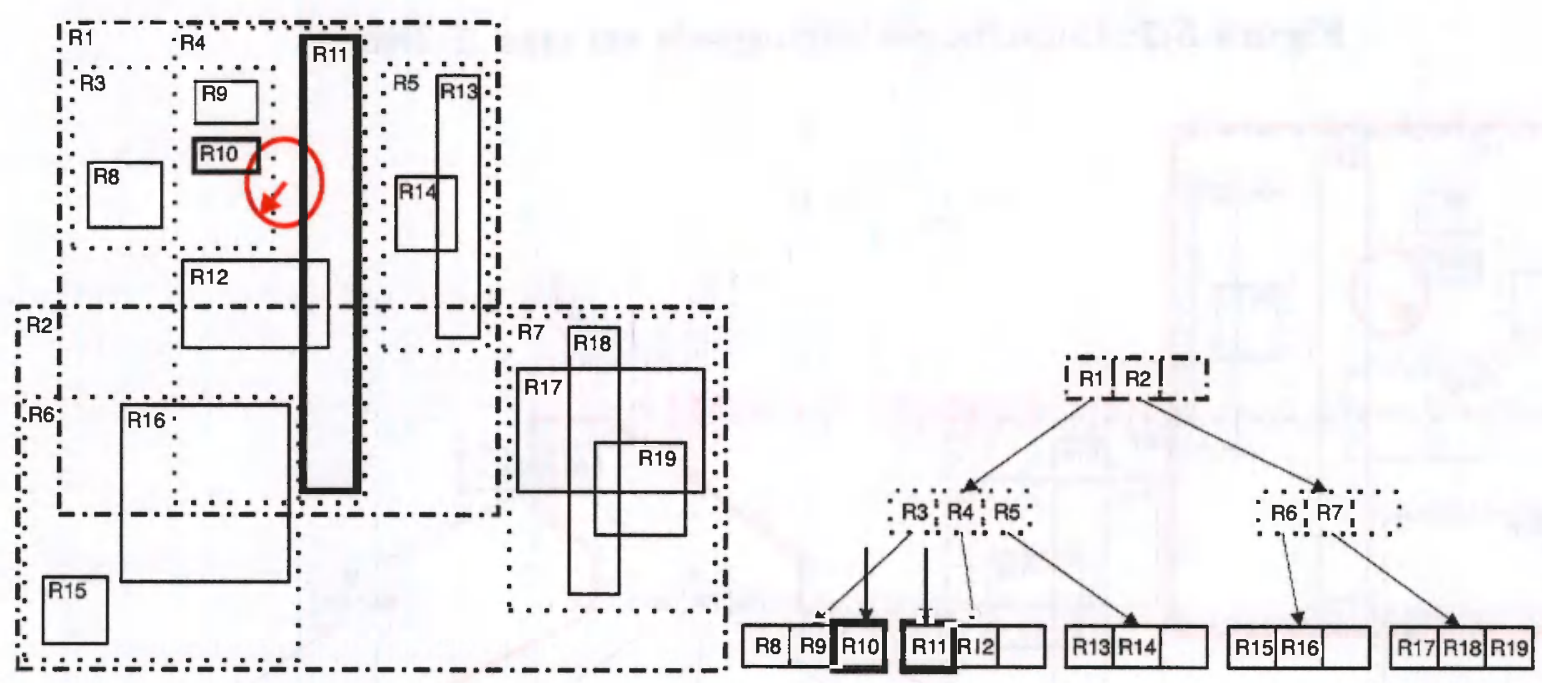

Figura 5.5: Áreas atingidas, no terceiro nível da estrutura, pela consulta por abrangência da Figura 5.2.

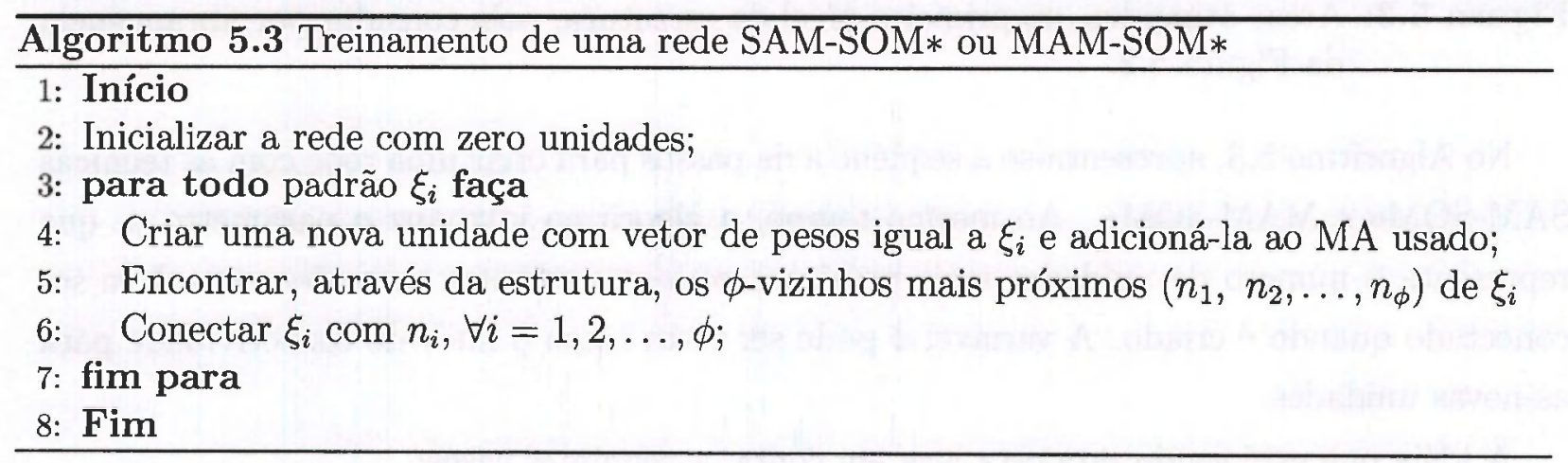

2. para os casos de treinamento on-line, onde apenas um pequeno grupo de vetores de pesos são atualizados ao mesmo tempo, apenas os nós correspondentes a esses pesos da estrutura são modificados. 
Para poder encontrar as unidades mais próximas utilizando um MAE on MAM, durante o treinamento da rede, existe uma grande variedade de algorimos que podem ser utilizados (Chlmam, 1991a: Roussopoulus et al., 1995; Claccia el al., 1997c; Clarkson, 1999; Yianilos,

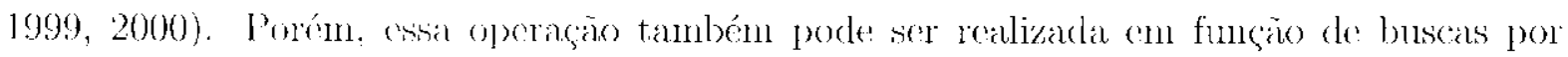
abrangência (Range (unry) com um raio apropriado. Nesse último caso, o problema principal é calcular mu raio apropriado para poder reduzir o número de operaçós e o tempo para recuperar a infornaçüo. Nos cxperimentos realizados neste trabalho, foi adotadia a segundat. téenica com un raio inicial cmpiricanente deterninddo. Porém, pode ser utilizada alguma técnica para estimativas do seletividade (Traina .Jr et al., 2000a).

As técnicas SAM-SOM e MAM-SOM apresentadas nesta tese são a generalizaçäo da idéia apresentada por Chachos-Vargas e Romero (2002). Nesse trabalho, foran apresentades

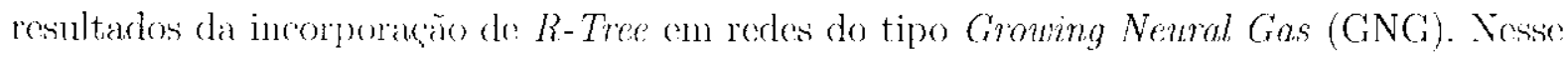
estudo, para cada nouronio na rede GNG, existe seu correspondente nó da R-Tree. Os k-vizinhos mais próxinnos são determinados através de unla busca na R-Tree.

Para utilizar hi-d-Ther on clualquer outro MAE, o princípio é o mesmo, isto é, os k-vizinhos mais próximos săo deverminados através do algoritmo fornecido pelo próprio método de accsiso. A diferenca que possa existir, em termos de desempenho, deve-se principalmente, ao custo computacional especílico de cada algoritmo para recuperar a informação.

Durante o processo de treinamento, os objetos contidos podem ser mudados de posiçăo com frequiencia. Dependende do MAE ntilizado, d modificacão de um objeto podo ser $11 m$ processo simples nu complexo. Por exemplo, no caso dos k-d-Tree existem problemas para a remogáo de midarles (Bentley, 1975; Samet, 1995). Além disso, as árvores h-d-Tree

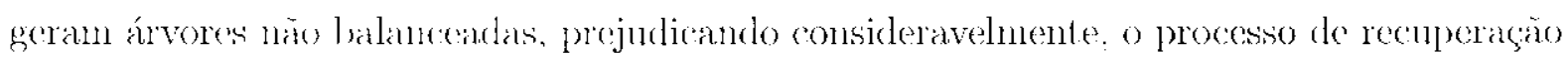
de iuformação (vor Sução 3.3.1 Pág. 34).

Nos experimentos apresentados a seguir foram escolhidos os métodos de acesso R-Tree e $k$-d-Thee para porler demonstrar que, mesmo considerando as limitações conhecidas desses métodos de acesso, o gintho, en termos de desempenho, ó considerável em relação ao processementes seciünuial. l'orém, existem muitos outros MAE que porkerian vir a ser utilizados, tais como as apresentadas nos trabalhos de Gaede e Gïnther (1998) e Samet $(1995)$.

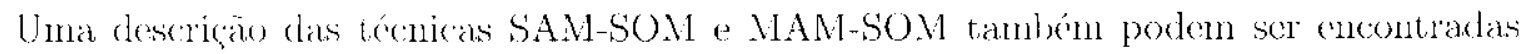
en Cuadros-Vargas et al. (2004).

\subsection{Experimentos}

Os experimentos foram realizados visando comparar, em termos de cálenulos de distâncias, o método sequiuncial, o alguns SOM utilizando alguns nuétodos de acesso. 
Esta seçào está dividida em duas partes. A primeira envolve experimentos con a técnica. SAM-SOM híbrida com os algoritmos k-Mćdias (k-Means), mapas de Kohonen tradicionais e redes GNG. $\Lambda$ segunda parte apresenta experimentos com at técnicas SAM-SOM* o MAM-SOM*.

\subsubsection{Aplicando a técnica SAM-SOM híbrida}

A técnica SAM-SOM híbrida é o resultado da incorporação de . MAE no processo de treinamento de SOM. Nessa técnica, os MAF sào ntilizados apenas para concontrar a unidakle vencedora. (O resto do processo do tremamento do SOM contimula sann moelificaçós.

O método seqüiencial foi utilizado porque tradicionalmento os SOM o utilizam. O método de acesso k-d-Tree foi utilizado devido a recentes experinnentos apresentados por (Gray e Moore, 2000). Finalmente, escolheu-se o método de acesso $R$-The porgue, na comunidade cientifica de métodos de acesso, an $R$-Tree é 1 m dos principais pontos de referencia utilizados para as novas técnicas apresentadas.

Os experinentos foram realizados utilizando os seguintes bancos fle dados:

ABALONE: Este banco de dados está composto por 4177 vetores 8-D, os quais descrevem formas. O arquivo foi obtido do UCA-Irvine repository of mathme learning databases and domain theories ${ }^{1}$;

LETTERS: Fste banco de dados está composto por 20986 vetores 17-D, os cluais descrevem formas de caracteres escritos a mão. O arquivo foi obtido do UCI-Irvine repository of machine learning databases and domain theories';

FACES: Este banco de dados está composto por 11900 vetores 16- $I$ ), os quais descrevem propriedades de faces. Fste conjunto de dados foi obtidu do Projeto Informedia da Carnegie Mellon University (Wactlar et al., 1996. 1999);

IMAGES: Este conjunto de dados está composto por 80000 vetores de características do imagens em dimensão 1215. Este conjunto de dados foi obtido do Projoto Informedia da Carnegie Mellon University (Wactlar et al., 1996, 1999).

Para us experimentos con aprendizado em lotes (batch leaming). foram realizardos experimentes envolvendo $k$-Médias (MacQueen, 1967; Moody o Darken. 1989), os Mapas de Kohonen (1982) a Grouing Neural Gas (Fritzke. 1995b)). Porcin, para aqueles métorlos com aprendizado on-line, onde a operação de remoção e reinserçào de elcuncitos ó contínua: as árvores $k$-d-Tre nào puderan ser testadas. Isso aconteceu devirlo an fato de gue, duranteo

\footnotetext{
${ }^{1}$ ftp://ftp.ics.uci.edu/pub/machine-learning-databases/abalone/

${ }^{2} \mathrm{ftp}: / / \mathrm{ftp}$.ics.uci.edu/pub/machine-learning-databases/letter-recognition/
} 
treinamento de $11 m$ SOM, as posiçoos dos vetores contidos na estrutura săo modificadas com muita freqüènciil. Essse problema poderia ser inicialnnente resolvido por uma remoçâo seguida de 1 ma reinscreçu do elemento. mas a remogão nessa estrutura porle obrigar à reconstruçäu 1otal, afetando consideravelnente o tempo de treinamento.

Nas Figuras 5.6-5.11. pode-se observar o número de cálculos de distância, para poder encontrar a unidade vencedora, en função do número de agrupanentos para o método k-Médias. Lesses experinnentos foran realizados utilizando o conjunto de dados $A B A L O N E$, FACES o LETTERS. Nas Figuras 5.6-5.11, ó importante observar que no cixo $x$, depois dos valores 90 e 100 . os próximos pont os correspondem a 200 a 300.

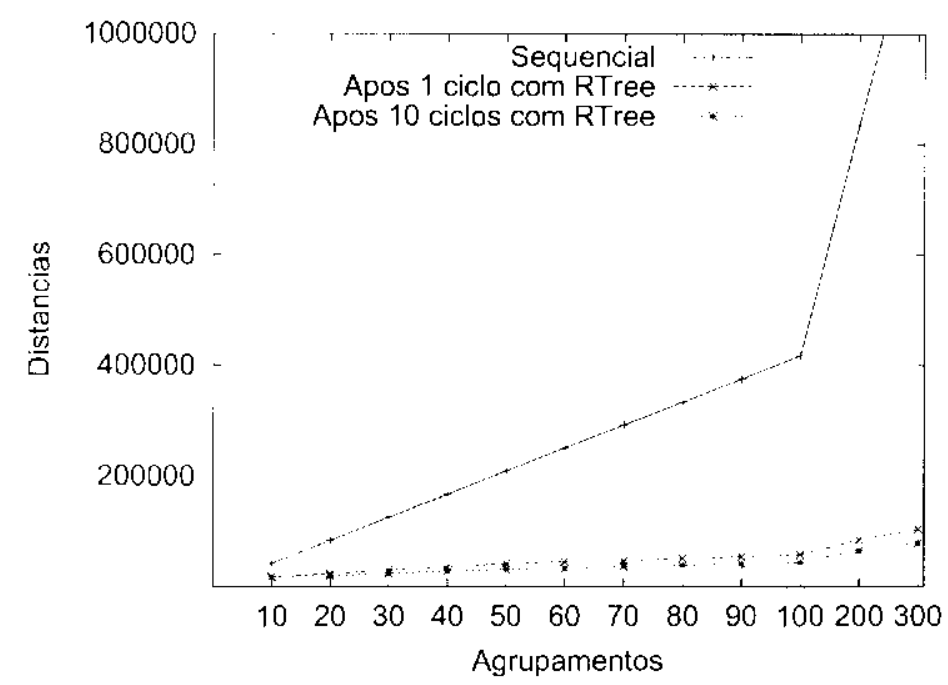

Figura 5.6: Número de cálculos de distância por ciclo em funçào do número de agrupanuentos no treinamento on-line de $k$-Médias no conjunto de daxlos ABALONE.

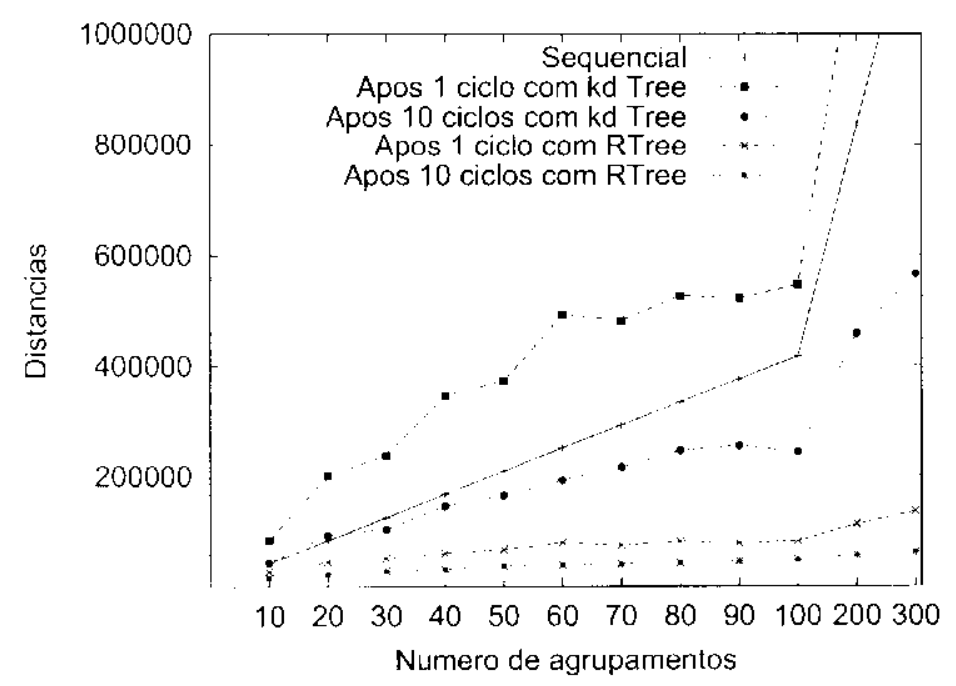

Figura 5.7: Número de válculon de distáncia por ciclo en função do mímero de agrupanen1.s ne treinannento en lotes de k-Médials no conjunto de dados ABALONli. 


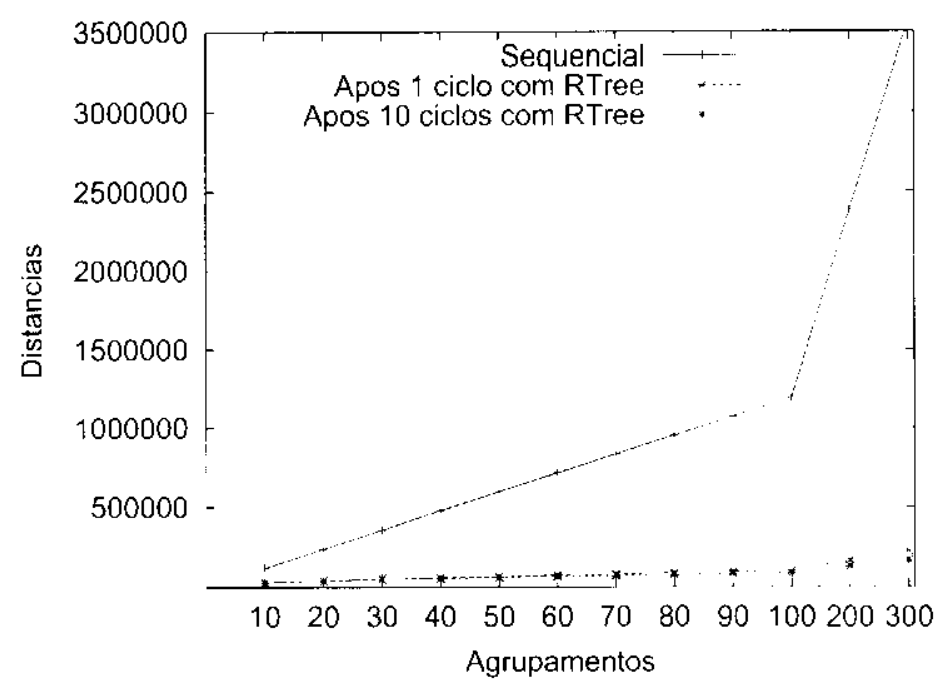

Figura 5.8: Número de cálculos de distância por ciclo en função do número de agrupamentos com treinamento on-line de k-Médias para o conjunto do dardos FACES.

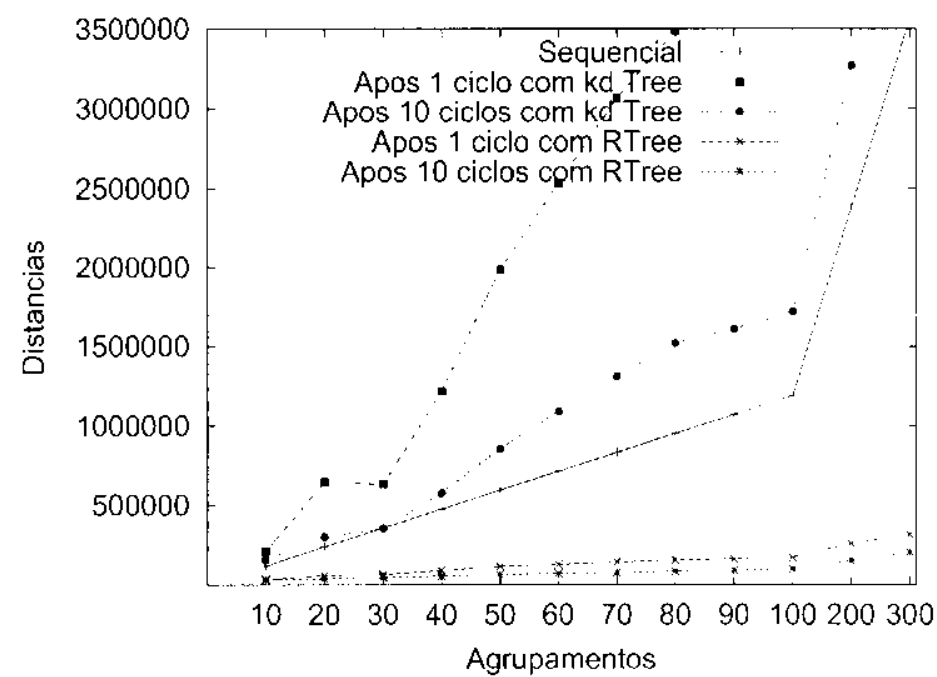

Figura 5.9: Número de cálculos de distância por ciclo em funçăo do número de agrupamentos com treinamento em lotes do k-Médias paral o conjunto de darlos FACES.

No caso da utilização de MAE existe um processamento extra para atuatizar os pesos na estrutura mas, mesno assin, o desempenho obtido usando o MAE foi muito superior ao obtido utilizando apenas processamento seqüencial. T'umbém i possivel observar uma diforença considerável entre o desempenho da $k$ - $d$-Thee e da R-The. Fssa diforença surge principalmente porque o algoritmo de inserção de elementos en uma $h$-Tree gera uma árvore balanceadia. Vo caso da k-d-Tree, dependendo da ordem de insercio dos elementos, a estrutura resultante poderia ser uma lista concadeada, cleteriorando assinn o processo de recuperação de informagào. 
Na. Figura 5.11. pode-se olservar que a linha do processamente següencial, comparada com a linha da R-Tree, apresenta um melhor desempenho apenas no primeiro ciclo. Isso acontece porque o algoritmo utilizado envolve buscas por abrangencia (Range Queries)

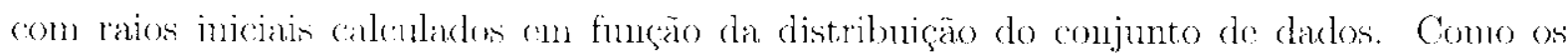
agrupamentos iniciais cstäo em posições aleatórias, a distribuição inicial não corresponde à distribuiçáa dos dados e isso almenta o tempo necessário para encontrar a uniclade veneedora. Para solucionar exte problema poderia ser utilizardo o processamento secuüencial apenas nos primeiros ciclos.

Ainda nas Figuras 5.10 e 5.11, observa-se que, quando o número de agrupamentos aumenta, a R-The consegne anment ar ainda mais a proporçäo de tempo ganlo. Isso pode ser claranente perechido nikpeles pontos que representam 200 e 300 agrupamentos.

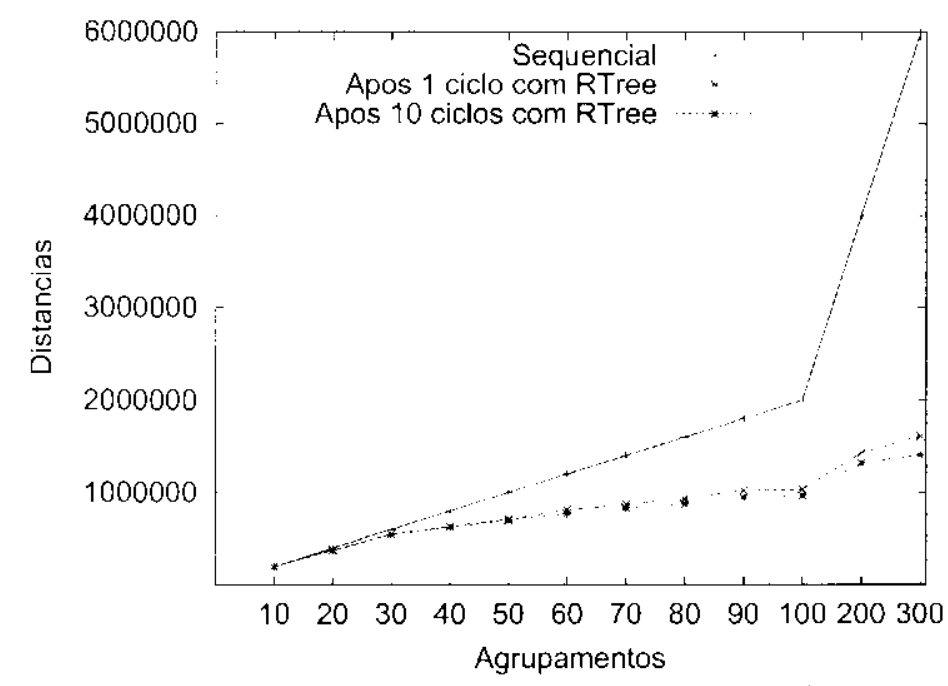

Figura 5.10: Número de cálculos de distância por ciclo em função do número de agrupannenteis com treinajnento on-line de k-Médias para o conjunto de dardos LETTERS.

Na Figura 5.12, ol serva-se o resultado da utilização de MAE junto às redes tradicionais de Kohonen (1982). O número de cálculos de distância necessários durante o treinamento é apresentado en funçào do número de padròes. ntilizando-se o SOM com processamento secü̈encial e o SON conn a li-Tree. Apesar do tamanho dessa rede ser de apenas $10 \times 10$, a diferença em temos de desempenho ć considerável. Fm uma aplicação real, com bancos de dados volumosos e una rede maior, a diferença seria ainda mais acentıada.

Na Figura 5.13, à)resenta-se o resultado de um experimento similar, utilizando redes do tipo GNG com a alyordagem següencial e utilizando R-Tree. Na Figura 5.13(a), pode-se observar o número de cálculos de distânéa para o número de unidades representado no cixo $x$. Na Figura $5.13(b)$ pode-se observar o número de cálculos de distância acumulado descle o início do treinamento até atingir o número de unidarles, representarlas no eixo a. Desde o início do treinanonto até a rede atingir 10 unidadess, só foi utilizado processannento 


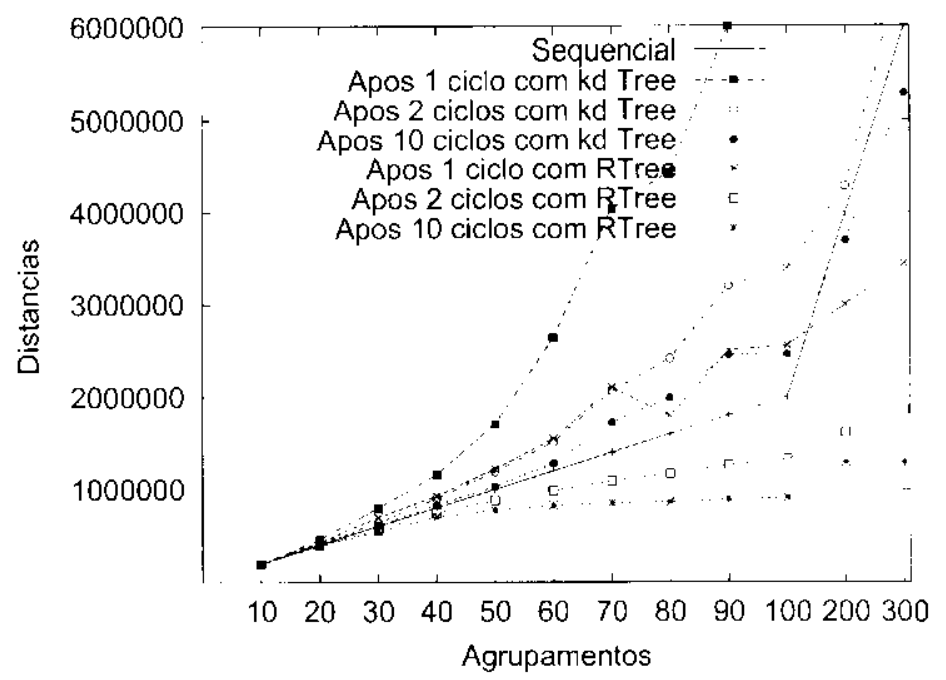

Figura 5.11: Número de cálculos de distância por ciclo en função do mímero de agrupamentos com treinamento em lotes de k-Médias para o conjunto de dardos LETTFRS.

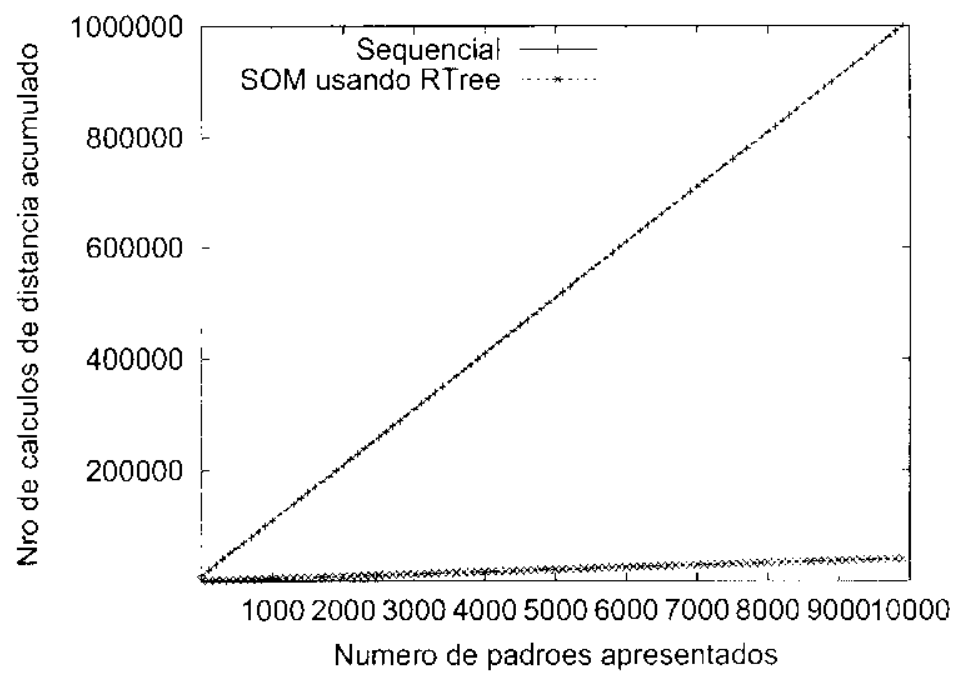

Figura 5.12: Número de cálculos de distância em função do número de padròes apresentados utilizando um SOM de dimensão) $10 \times 10$ com treinamento on-line com o conjunto de dados IMAGLS.

sequiencial em ambos os casos. Isto é devido ao fato de que, com poucas unidades, o ganho cm termos de cálculos não foi significativo.

No caso dos modelos k-Médias, rede de Kohonen e GNG, soment é necessírio encontrar um vizinho mais próximo. Isto ocorre porcue, no calso das redes de Kohonen e GNG, a vizinhança está determinada pelas conexões da unidade vencedora e. no caso do algoritmo k-Mélias, sonnente é atualizada uma única midade por ve\%. Porén. a mesma técnica poderia ser utilizada para encontrar mais de um vizinho mais próximo.

Como já foj discutido na Seção 5.1, se a taxa de insergào dos olenontos, $\lambda$, for reduzida ano mínimo, isto é, $\lambda=1$, a rede resultante será deformada de forma gradual, como apresentado 

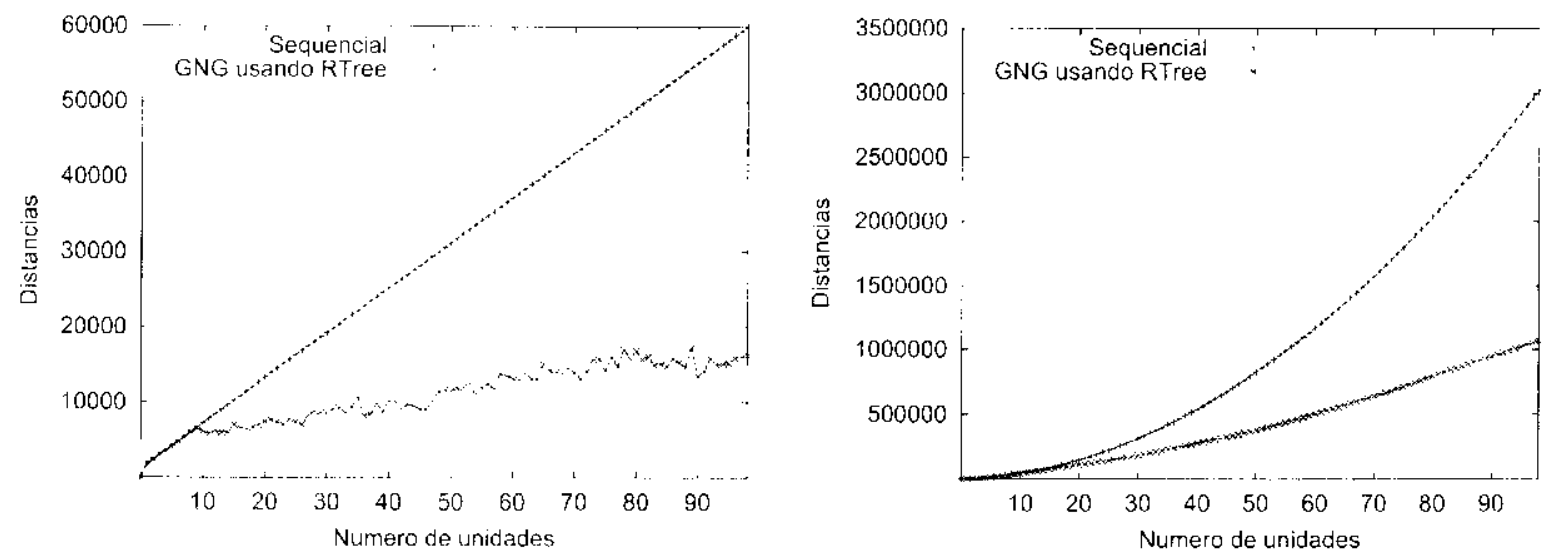

(a) Cáleulos de distraneia descde a insergăo da unidade (b) Número de cáleulos de distáncia acurnulado até a interios.

n-ćsima tuidade

Figura 5.13: Nínuero de cáleulos de distância para uma rede Crowing Netrul Gas utilizando o conjunto de dados IMAGES. Os parâmetros utilizados para esta simula(ão săo: $\lambda=600, \mu_{b}-0.05, \mu_{n}-0.0006, \alpha=0.5 . \beta=0.0005$ c $a_{\text {max }}=100$.

na Figura 5.14. Na próxima seçào, experimentos similares com $\lambda-1$ são apresentados com a única diferença de (1ue, desta vez, serão utilizados métodos de acesso para evitar a deformaciono o melhorir ar chalidade da rede resultante.

\subsubsection{Aplicando as técnicas SAM-SOM* e MAM-SOM*}

No caso específico de rextes comstrutivas, um dos pontos críticos é deteminar quando e cm que posição uma nova unidade deve ser inserida. Na rede GNG (Fritzke, 1995b); a velocidade de inserção está controlada pelo parâmetro $\lambda$ : cujo valor recomendado pelos autores é 600 .

De acordo com a Fiquaço (5.4) (ver Pág. 73), o número total de cálculos de distancias, $N C D$ Csom e m una rede $\mathrm{SOM}$ construtiva que insere elementos a cada $\lambda$ padröes apresentartos

$$
N C D \operatorname{cson}=\sum_{i=N U_{0}}^{N 1} i \lambda
$$

A reduça de $\lambda$ promite a criaģa de uma maior quantidade de midades na rede mas, ao mesmo tempo. reduz o tempo para adaptar as novas unidades à estrutura existente. Na Figura 5.14, observa-se uma rede GNG treinada $\operatorname{com} \lambda=1$. A rede resultante está visivelmente deformada o contém várias midades em posiçòes inapropriadas para a distribuição dos dados. Como já foi explicado anteriormente, a deformaçäo da rede deve-se, entre outros fatores. ao fato de que as posiçóes das novas unidades são resultado da interpolação de outras duas unidades.

Entào, unn dus problentas a serem resolvidos, para evitar a deformaçào da rede é criar nujdades en posiçoes onde sejam realmente úteis para a distribuição dos dados. Isto ó 

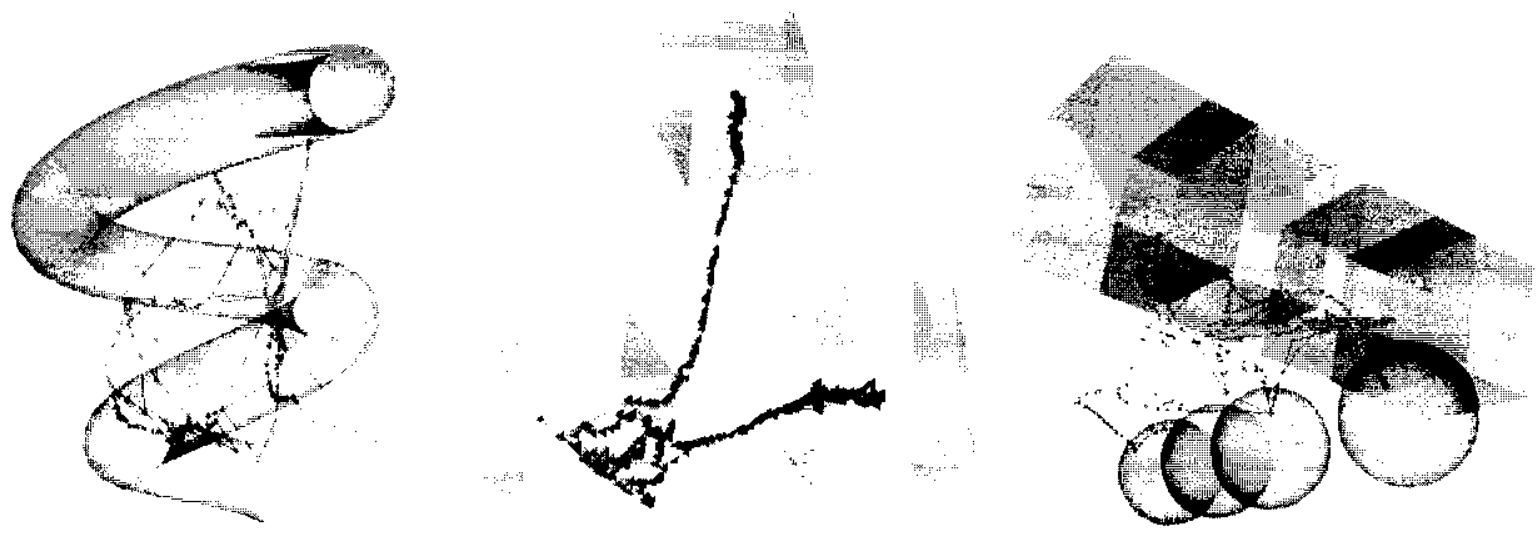

Figura 5.14: Redes GNG tradicionais treinadas com $\lambda=1$.

necessário porque a téc'nic'a da intcrpolação cria unidades em posições onde nem sempre existem dados. Para resolver csse problema, o Algoritmo 5.3 (ver Pág. 78) cria uma nova unidade para cadia parliăo apresentado.

Na Figura 5.15, pode-se observar una rede do tipo GNG depois de treinada com a técnim SAM-SOM*. Xeste caso en particular, a combinaçâo SAM-SOM utilizada foi de uma estrutura $R$-Tree com o algoritmo GNG.

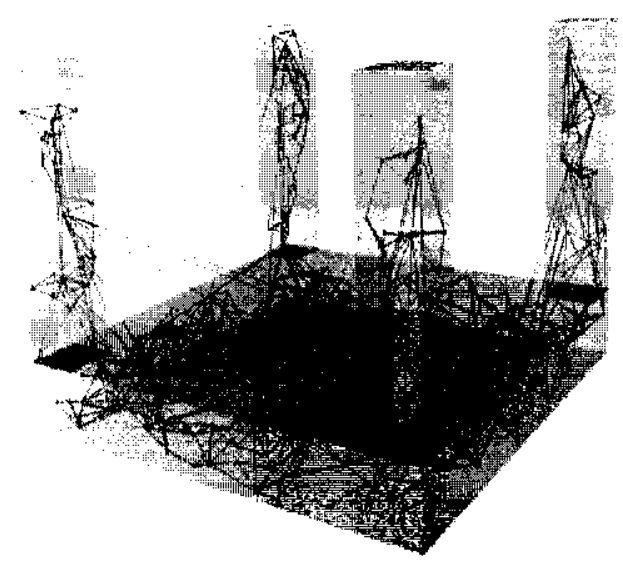

Figura 5.15: Rede $R$-Tree $+G N G$ com 5000 padrões e $\phi=3$.

Na Figura 5.15, tambón observa-se algumas conexões relativamente grandes. Isso acontece una voz que, no Algoritmo 5.3, as novas unidades são conectadas aos $\phi$ vizinhos mais próximos, porém, no início do processo de treinamento, as primeiras unidades nà̃o estarão necessariamente próximas umas das outras.

Um outro ponto, que agora pode ser molhor entendido refere-se à família de redes MAM-SOM, isto a a combinação de um MAM com redes do tipo SOM. Como já foi explicado nas Segons 3.4 a 5.2, no espaço métrico näo existe o conceito de coordemadas (próprio de espaços vetoriais). A única informação disponível é fornecida pela função de 
distância métrica. Por causa dissiso, o procedimento de correção de vetores de pesos dos SOM não poderia ser aplicado na sua forma tradicional. Entretanto, no Algoritmo 5.3, observa-se que năo existe o processo de correção de vetores de pesos, deixando aberta a possibilidade de usar ambos métodos de acessoso, espacial (MAF) e métrico (MAM).

O fato de ter eriado $5(300$ unidades na rede GNG da Figura 5.15 leva a crer que o múmero de cálculos de distancia também é grande. No entanto, isto não ocorre, como pode ser observado na Tabela 5.1. No caso da GNG tradicional, observa-se claramente un custo quadrático, de acordo con a Épuaçào (5.5) (ver Pádg. 73).

\begin{tabular}{|c|c|c|} 
No de padroes & $R$-Tree $+G N G$ & GNG \\
\hline 500 & 7844 & 124749 \\
1000 & 15617 & 499499 \\
1500 & 23884 & 1124249 \\
2000 & 32191 & 1998999 \\
2500 & 40926 & 3123749 \\
3000 & 49548 & 4498499 \\
3500 & 59109 & 6123249 \\
4000 & 67750 & 7997999 \\
4500 & 77007 & 10122749 \\
5000 & 85439 & 12497499 \\
\hline
\end{tabular}

Tabela 5.1: Comparação en termos de cálculos de distância ontre R-Tree +GNG e GNG $\operatorname{com} \lambda=1$.

Vale a pena ressialtar que essa técnica poderia ser aplicada com qualquer outra rede do tipo SOM incluindo os modelos construtivos e hierárquicos. Também vale a pena ressaltar que, no caso da R-Tre / CNG os k-vizinhos mais próximos são calculados m função de buscas por alorangência (e. en vários casos, foi preciso realizar mais de uma busca para encontrar os k-vizinhos mais próximos. Dependendo do MAM ou MAE utilizado para recuperar os vizinhos mais próxinos, o núncro de cálculos de distância poderia ser aindà menor.

Fssa mudanca no algoritmo tradicional de redes do tipo SOM confere às famílias de téenicas SAM-SOM o. MAM-SOM uma série de propriedades apresentarlas a seguir.

\subsection{Propriedades das técnicas SAM-SOM e MAM-SOM}

Yo caso da técnica SAM-SOM híbrida, o algoritmo das redes SOM apenas é modificado na fase de busca da unidade vencedora. Ao invés de realizar a busca de forma sepuiencial, o algoritıno utiliza um MAF. A principal conseqüência dessa mudança no algoritmo original é 
a aceleração do processo de trinamento e a possibilidade de trabalhar com redes maiores. O resto do processo continua praticamente sem alterações.

As técnicas SAM-SOM* o MAM-SOM*, além de ajudar ma aceleraçio do processo. apresentam ontras características. Nesta seçano, as principais proprindades dessas técnicas são apresentadas com enfase espocial em relação à propriedades menciomadias mo Capítulo 1.

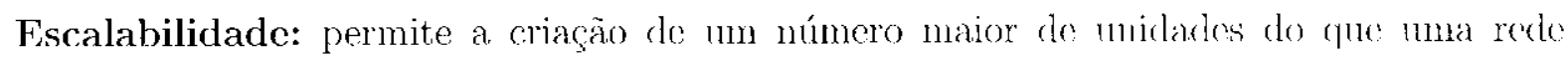
similar derivada do modelo de Kohonen;

Menor custo computacional: apesar do maior numero de midades. o custo computacional é consideravelmente monor que as redes SOM que utilizam a comparação sequïen(iicl;

Reflete a distribuiçāo dos dados: a rede resultante reflete melhor a distribuiçàco dos darlos, prois o algoritmo garante que unidades novas sojam rialias de aroordo com a distribuição dos dados e não por interpolação, etc. Isso pode ser observado comparando-se as Figuras 5.14 e 5.15 ;

Menor espaço necessário: devido ao fáto de que o algoritmo de geraçào da rede cria

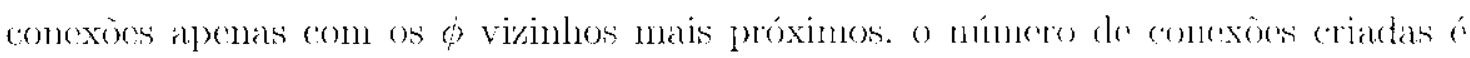
consideravelmente menor que a matriz de distancias complela:

Maior informação nas conexões: en redes derivadas do nodelo de kuhonen e nos nodelos derivados da rede GNG (com distribuições não retangulares), as conexões são úteis apenas para a visualização e para baber quais säo os vizinhos. No calso das técnicas SAM-SOM* e MAM-SOM*, as conexões podem conter a distàncid, uma vez que năo existe mudança nos vetores de pesos. A distância ć una informaçăo muito b́til para a a recuperação de informação;

Maior informaçāo para prever consultas: a estimativa de seletividakd de ma consulta

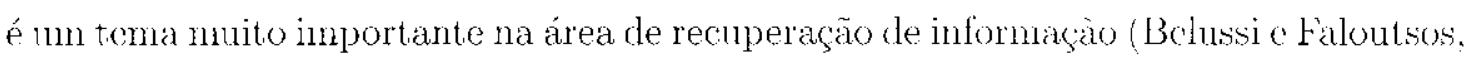
1995, 1998; Traina Jo ef al, 2000a). Com a informacaia lias distancias des vizinhos mais próximos, ó mais fácil realizar cáleulos de estimativas de seletividiude Vos MA.M c MAE tradicionais, os objetos inseridos na estrutura não armazenam informaçao relacionatala as vizinhos mais próximos;

Maior informação para a detecção de agrupamentos: considecando (jue a função do distincia representa a modida de dissimilaridade ento os elementos. a partir desta técnica pode se estudar a possibilidade de detectar agrupanentos nos dados. Uma

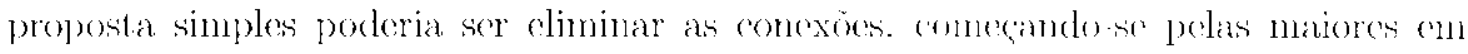
ordem decrescente de distâncias. Cada vez que a climinação do uma conexão gera dois 
grupon separatos, es dois novos grupos podem ser considerades dois agrupamentos distintos, de forma análoga às redes Tree GCS (ver Seção 2.4.3, Pág. 18) ou ao processo utilizado para a partição dos nós utilizado pelá Slim-Tree (ver Seção 3.4.15, Pág. 48). Também ó inportante (onsiderar (jue mesmo os trabalhos recentes relacionados com esto problema, como o apresentado por Jain (1999), não abordam o caso do accsso espacial on mótrico:

Maior estabilidade-plasticidade: do ponto de vista de redes neurais, especificamente em relaçäo ao dilcma da estabilidade-plasticidade (Grossberg, 1972, 1976a,b), una rede do 1.ipo SA.V-SOM é estavel, pois um padrão sempre é representado pelo mesmo nexurónio. A plasticidade também é uma propriedade presente, pois a inserção de novos padrón não provoca a perda do conhecimento adquirido anteriormente;

Aprendizado incremental: dependendo do dinamismo existente no MAE ou MAM utilizado. o modelo proposto permite a inserção de novos elementos em qualquer instiante, sem que isto obrigne a reninicialização do processo em nenhum dos casos;

Independência em relação à ordem de inserção: Está é mma propriedade herdada an função da ntilização de MAF e . MA.W, os quais sempre têm por objetivo que a estrutura resultante não dependa da ordem de inserção dos dados.

\subsection{Considerações Finais}

Neste capítulo foi apresentada a forma em que os M ME e M $\Lambda \mathrm{M}$ podem ser incorporados no treinamento de redes SOM, cumminando no desenvolvimento das técnicas SAM-SOM O MAM-SOM propostas neste trabalho.

Os . WAE podem ser incorporados en SOM tradicionais apenas para encontrar a unidade vencedora, mantentu a corregüo de pesos sen alteraçoes. Essa técnica é denominada SAM-SOM Híbrida. Devido ao fato de que nos espaços métricos não existe o conceito de coordenadass nos objetos a seren tratados. os MAM não podem ser aplicados de forma dircta cm um processo cono o trinamento de SOM. Isto acontece porque a rorregão dos pesos é realizadia em vetores (com coordenadas vetoriais). Para solucionar esse problema foram aprescntadas as técnicas SAM-SOH* e MAM-SOM*. A idéia proposta é eliminar a correção de pesos e inscrir uma miclade na rede jara cada novo padrão apresentado. Tudo isso foi realizado com um ganho de custo computacional. Isso é possível, mesmo com a existência de um número maior de unidades, porque a busca pela unidade vencedora é sempre realizada através do método de acesso e não de forma seqünencial.

Como nào existe mais a correģăo de vetores de pesos e o algoritmo para criação de SAM-SOM* e MAM-SOM* não depende dà existència de coordenadas, ambos os métodos 
de acesso, vetorial e métrico, podem ser utilizados sem restriçoes. Fm sceguida, foram apresentados diversos experimentos que demonstraran a diferenca dramática em termos de desempenho o tempo ganho dessas técnicas cm comparacăo ì abordagem secüuncial.

Finalmente, foran também apresentadas as principais propriedades conheridas que as

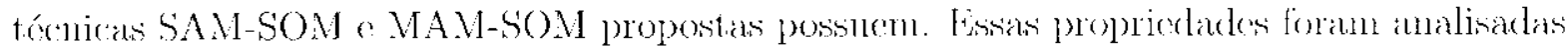
com especial énfase nas vantagens o limitaçōes dos SOM, apresentadas no Capítulo 4.

Hoje em dia, os problemas reajis envolvem bancos de dados cada ve\% maiores. Ao mosmo tempo, a função de distâneia entro dois objetos é cada vez mais complexa. Por todos

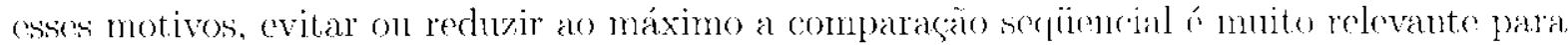
contimuar pensando en bancos de dados cada ve maiores e mais complexos. Considerando esses pontos, as técnicas SAM-SOM e MAM-SOM provavehnente representam a próxima geracaio de mapas anto-organizriveis. 


\section{Métodos de Acesso baseados no}

\section{comportamento do usuário}

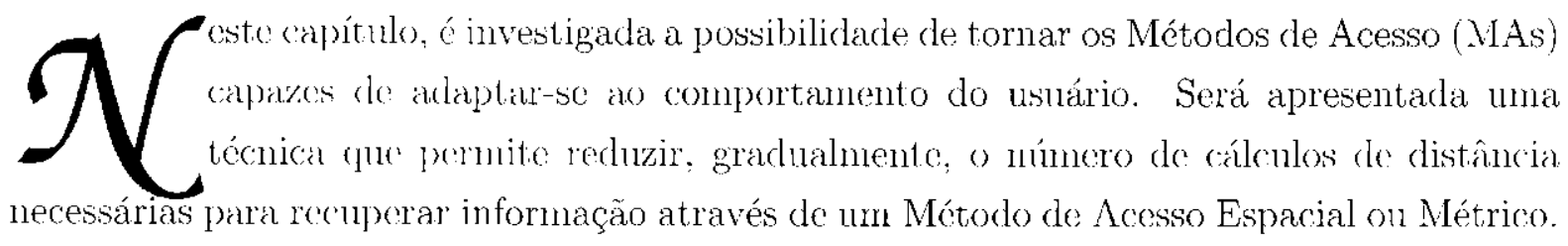

\subsection{Análise do problema}

Para poder rednzir gradualmente o número de cálculos de distância necessários para realizar uma consulta é necessírio que o nétodo de acesso seja capaz de adaptar-se ao comportamento do usuário, isto é, que ajuroveite a distribuição de consultas realizadas. Fxistem alguns trabalhos na literatura que tontaram eriar estruturas adaptativas. Dentre os principais, pode-so citar os Adaptive B-Tree (Baeza-Yates, 1990), Self-Organizing Data Structures (Albers e Westbrook, 1996) o as Self-adjusting binary search trees (Splay-Trees) (Sleator e Tarjan. 1985). Porém, nenhuma dessas propostas ó orientada a MAF on MAM.

No caso de comsilt at por sinilaridade en dados complexos, o fator que consome mais tempo na Equação (1.2) (ver Pág. 2) é a funçào de distância. Un caso claro desse problema pode ser observado no cálculo da distància métrica entre duas seqüências de DNA. Por esse notivo, todos os Métodos de Acesso (MAs) tentam evitar ou pelo menos reduzir, à medida do possível, esso tipo de cálculo.

Uma técnica amplannente utilizada para cvitar os cálculos de distância em uma consulta ć a desigualdade triangular, apresentada por Burkhard o Keller (1973) (ver Seção 3.4.1). Essia técnicá permite apenas reduzir o múmero de cúleulos de distância. Mesmo assinı, o MA não é capaz de reaproveitar o conhecimento gerado por unid determinada consulta para melhorar o descmpenho de consultas futuras.

Para entender molhor o problema, pode-se inaginar o seguinte cenário: dado um MAM, chimnado $M A M X$ e una consulta por abrangencia, $R Q_{1}\left(O_{q}, r\right)$, onde $O_{q}$ é o objeto de buscá 
c r é o raio. Quando a consulta $R Q$ é executada, o $M A M X$ precisará de mu múmero $n$ de cálculos de distância. O problema apłarece ao tentar executar uma sceunda consulta, $R Q_{2}$, cue apresente interseçäo significativa com a área cobertá por $R Q_{1}$. Cortamente, parte dos cálculos de distância gerados por $R Q_{1}$ poderiam ser útcis para rexluzir o processamento necessário em $R Q_{2}$. No entanto, na realidade isso năo arontece. pois torlas as distancias calculadas por $R Q_{1}$ são descartadas. O mesmo problema aparece se a mesma consulta, $R Q_{1}$ : for repetida várias vezes de forma contínula Em todos os casos. o múnero do cáleulos de distância seréá $n$.

Ambos os problemas, com a mesma consulta e com uma consulta similar, estão presentes (m tudos os Métodos de Acesso citados no Capítulo 3. Nestre crupítulo. esse problema i investigado e uma solução é proposta.

\subsection{Algumas soluções existentes}

Na área de Inteligència Artificial, pode-se observar alguns trabalhos relacionados com o problema de inserir inteligêneia em sistomas computancionatis. No tinal cla década do 50 " início da década de 60, Arthur Samuel realizon um trabalho, pionciro nessa área, ntilizando o clásisico jogo (le damas como base do sen experimento (Sammol, 195?) 1967). O objetivo desse programa cra que o computador aprendesse a jogar damas para poter competir com scres humanos. Bascados nesse trabalho, Schaeffer et al (1992) criaran Chimook rue é um programa con a capacidade de aprimorar sua técnica de jogo cm funçà das jogadas do adversário, especialmente aquelas jogadas que desencadeavam a perda do jogo. Lina vez quo

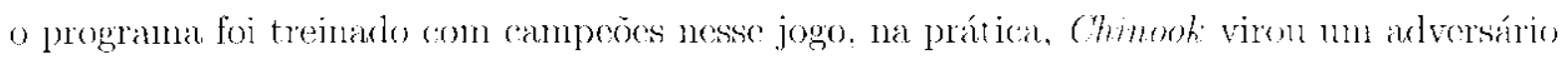
quaso imbatível. A técnica utilizada por este programa foi a de armazonar as distribuiçoes de pecas no babuleiro a partir do momento que existisse apenas s pecas. Também foi considerada a informaçăo relacionada às partidas nas quais o adversário humano ganhava. Isto foi realizado com o intuito de detectar a jogada que levou i perta do jogo para má repeti-la no futuro. O bom desempenho do programa Chmook deve-se ao fato que de memoriza todas essas jogadas. Contudo, essa proposta, ainda nabo pode ser considerada

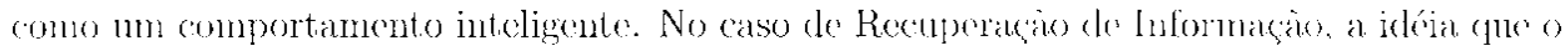
Chinook inspira é a de criar um MA capaz de nelhorar a si próprio. ao longo do tempo em finçio ra experiencia que obtém através das contsultas.

Na área de Recuperação de Informação (RI) através do Métodos de Acesso (MAs). existem algumas tentativas para reduzir o núnero de cáleules de distáneia. A granklo maioria foi apresentada no Capítulo 3. No trabalho de Shasha o Wang (1990), os autores propôem que duas matrizes de distânecias sejaun criadals antes de começr as consultas. Cada

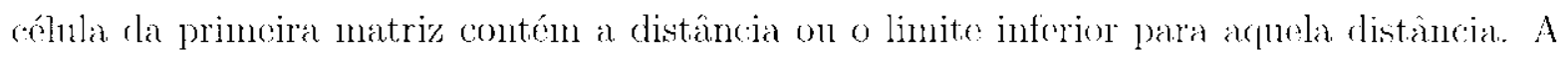
única diferença na segunda matriz é que esta armazena os limites superiores. Quando uma 
distáncia é conhecida, a mema é armazenada de forma direta, mas se não for conhecida, será aproximada on funçào das distáncias existentes.

Un outro traballıo na mesma direção é o AESA (Vidal. 1986), que propóo que a matriz triangular de distâncials seja armazenada completanente (ver Seçäo 3.4.2, Pág. 41). O custo computacional de construção desse método é de $O\left(n^{2}\right)$. En compensação, o tempo experimental de recuperaço de una distancia é de apenas $O(1)$. O grande problema desta proposta é cune, na prática, é inviável realizar essa cuantidade de cálculos e manter uni matriz que cresce de forma quadrática. Além disso, espera-se que novos elementos possam ser inscridos on removidos de forma dinânica na estrutura a qualquer instante.

Una proposta posterior do mesno trabalho é conhecida como LAESA (Micó et al., 1994) (ver Seyão 3.4.j, Pág. 42). Nesse caso, os autores propöen reduzir a matriz de distâneiaś através da utilizacio de me cenjunto reduzido de objetos fixos que funcionam conno àncoras. Para qualquer novo objeto. $O_{i}$, apenas são calculadas as distâncias de $O_{i}$ até os objetos âncoras. Para a recuperação de informaçào, as distâncias existentes aos objetos àncoras são utilizadas para reduzir o conjunto de respostas através da designaldade triangular. O custo computacional de construgăo neste calso ó de $O(\mathrm{kn})$, sendo $k$ o múmero de ancoras e $n$ o número de objetos. Essa idéia tambén foi cxplorada na OmniSequential (Santos-Filho et al., 2001). Neste ńltimo caso. cada objcto ancora é (hamado de focus e o conjunto de todas as âncoras ó denominado fort.

Em ambos os cascos; as distancias até um mesmo objeto âncona nầo são organizadas. Existem algunas propostas para reduzir o tempo computacional que esse percurso sequiencial podo levar. En (Micó ot al., 1996), os autores propöen reduzir esse tempo extra de CPU através da criasano de mula cstrutura no estilo das GHT, utilizando os objetos ancoras. Una ontra idéia ritil para usto caso é a de ordenar o conjunto das distâncias, relacionado a cada objeto âncora, através de alguma outra estrutura. Essa idéia pode ser observada nos traballhos de Venee - Vayar (1997), no método Spaghellis (Chávez et al., 1999a) e nus métudos OmniRTree : Ommi B-Forest (Santos-Filho, 2003). Nesses casos, a única consideraçào especial é que a estrutura adicional exige maior quantidade de espaço.

A maior vantagem de manter a matriz de distâncias é que isso permite una recuperação rápida da informaçào. Pormém. essa técnica impòe un alto custo de construçào om termos de tempo e espaco.

A técnica de utilizar objctos âncoras reduz bastante o número de cálculos de distância necessários, porém a escolha apropriada dos objetos âncora pode afetar a qualidade da resposta (Santos-Filho ot al. 2001; Bustos et al., 2001). 


\subsection{A família MA+}

Na maioria dos casos, a distribuiçăo das consultas apresenta un conpontanento similar ao princípio de Pareto, isto é, quase sempro existirá um grupo. relativamente perqueno dos dardos, que são os mais consultados e existirá também uma grando majoria deles que süo acessiadon com ponca frequînucia. O dilema está exatamente em como detectar cssas distâncias ou regiōes do espaco, que são as mais acessadas, sem ter que comstruir a matriz de distâncias completa.

Sos métodos existentes, as distâncias são apenas utilizarlas para verificar se o objeto faz parte ou não do conjunto de resposta e logo após são descartadas. Por isso, se a mesinal consult a é repetida, o algoritmo não dispõe dessa distância o deve calculá-la movamente.

Para solucionar esse problema, propóc-se uma nova técnica denominada Plug-in Module for Access Methods (PMAM) (PMAM), que tem por objetivo ajudar lla aceleracano do processo de Recuperaçăo de Informaçào por Similaridade. O módulo foi projotado para ser utilizado junto a algum Método de Acesso.

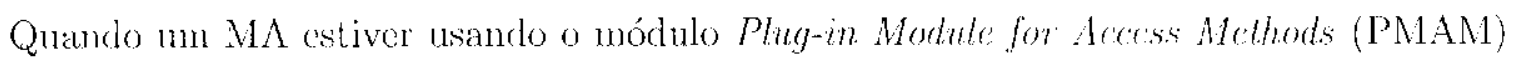
(P.MA.M), adotar-se-á o símbolo + para indicar que aquele MA está utilizando a nova técnica.

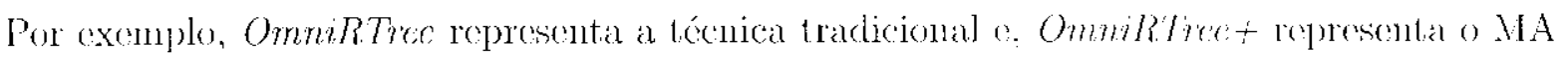
OmniRTree utilizando o PMAM.

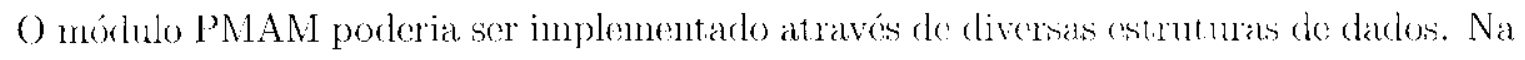
scguinte seção, é apresentada uma das possíveis implementaçoes ulilizande árvores $B^{*}$.

\subsection{Implementação do PMAM através de árvores B*}

Inicialmente. PMAM ó uma estrutura vazia que será "retroalimentada" "le forma gradual

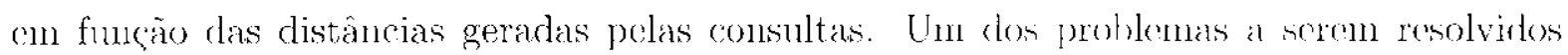
está relacionudo à estrutura que o módulo deve ter para armazonar o trio $\left(O_{i} \cdot O_{j}, d\left(O_{j}, O_{j}\right)\right.$ ), oncle $O_{i}$ e $O_{j}$ são dois objetos o d() c a distância cutre eles. Uma considoracào especial é

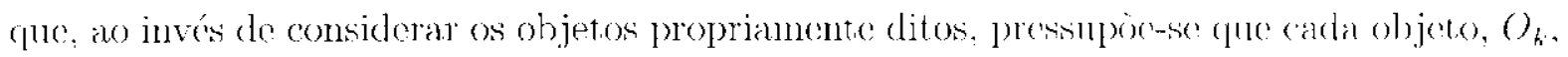
tem $\mathrm{um}$ identificarlor único, $I D\left(O_{k}\right)$, associado. Por essa razào a informagào que deve ser amakenarla o: $\left(I D\left(O_{i}\right), I D\left(O_{j}\right), d\left(O_{i}, O_{j}\right)\right)$.

Também deve ser considerarlo que o objetivo do PMAM é, dado num par de identificadores

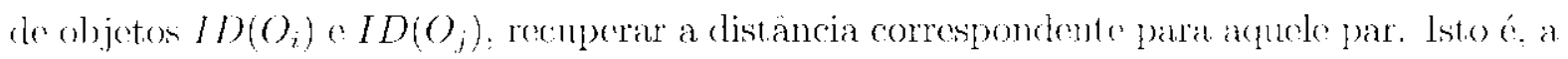
chave da consulta deve ser criada apenas em função dos dois identificadores, de acordo com o Algoritmo 6.1. Nesse algoritmo, supere-se que os identificarderes sio interiros de 32 bits o a (have gerada ć um inteiro de 641 bils. 


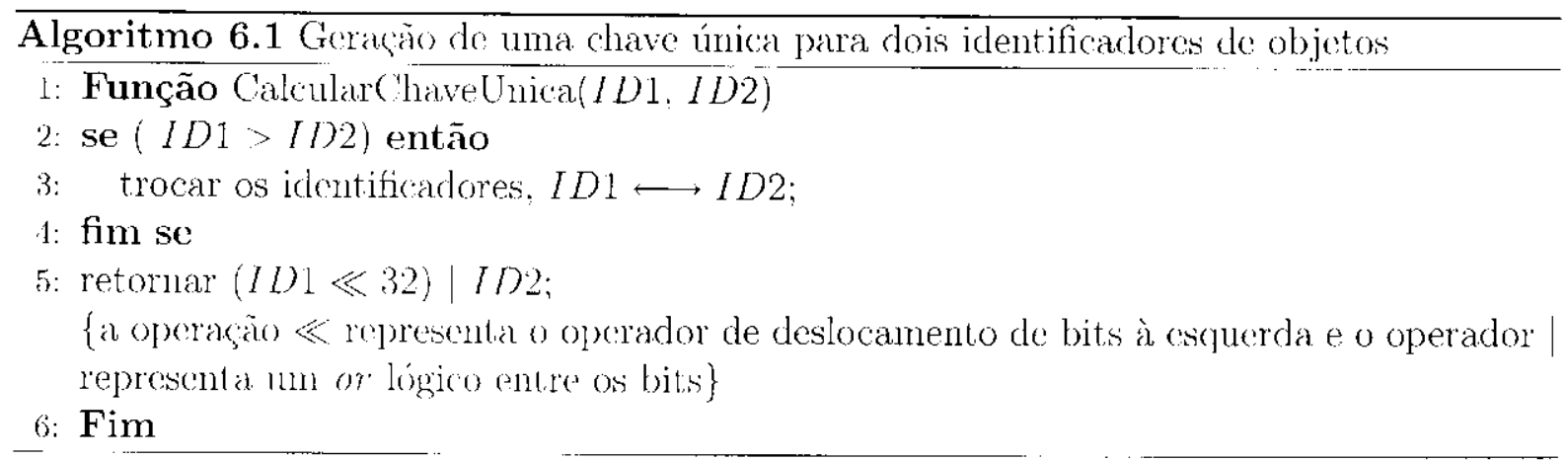

Depois de ter geraulo a (have, através da função Calcular ChaveUnica (ID1, I D2), o problema se reduz a armazenar a distància respectiva junto com a chave. Uma solução poderia ser utilizar una árvore B-'Tree (Bayer o McCreight, 1972) ou uma B* (Kinuth, 1973). No caso do P.MA.M. opulu-be pela implementaçăo com árvores $B^{*}$.

Apesar dlas árvores $B^{*}$ serem eficientes para a recuperaçăo de dados midimensionais, o tempo de resposta poleria ser melhorado, ainda mais, criando-se uma tabela de heshing de árvores $B^{*}$. No Algoritmo 6.2, pode-se observar a inicialização dos membros do PMAM. Lisse módulo está composto por una tabela de Hashing de tamanho HashTableSize.

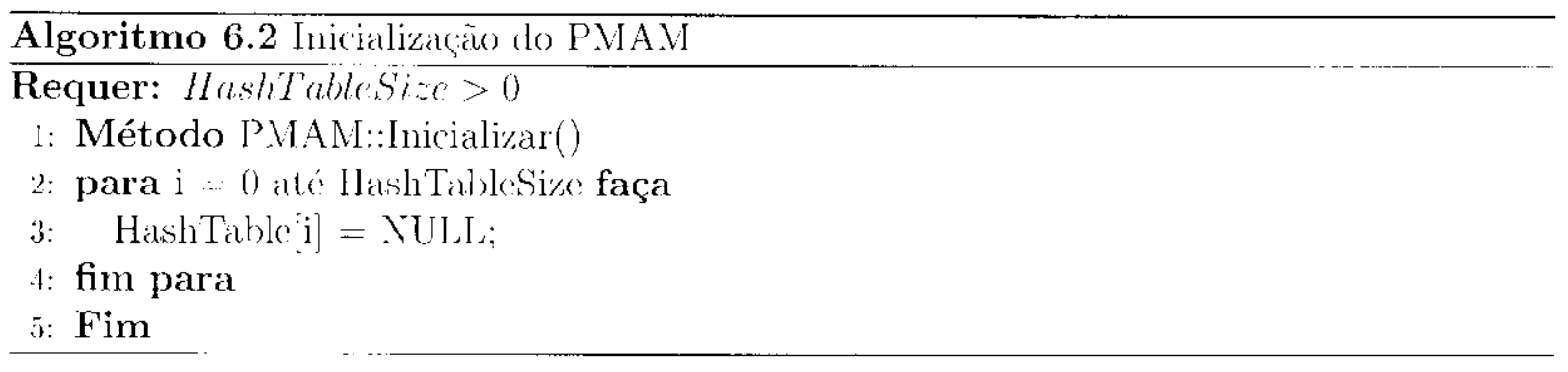

No $A$ lgoritmo 6.3 , observa-se a forma de inserir novas chaves no módulo PMAM. Cada célula dessa tabela é unn ponteiro para uma árvore $B^{*}$.

Para poder recuperar os dados associados a uma chave inserida na árvore, cada elemento também armazena um número. Esse valor pode ser usado de forma livre pelo usuário para armazenar alguma informaçá que seja útil para conectar a chave com o objeto que esta referencia. No caso da técnica proposta PMAM, esse valor é usado para armazenar a distância associada com a chave inserida. Além disso, a estrutura da $B^{*}$ foi modificada para armazenar un contador de uso para cada chave inserida na árvore. Esse contador é atualizado caula vey que a chave ó acessada. Essa modificaçũo pode ser útil para decidir, no futuro, quais as chaves que poderiam ser descartadas, devido a uma eventual falta de espaço. No Algoritmo 6.4, pode-se obscrvar a técnica utilizada para recuperar uma distância entre dois objetos identificarlos por $I D 1$ o $I D 2$.

O procenso de "retroalimentaçao" do PMAM pode ser realizado durante a execuçio de qualquer consulta por similaridade que precise de cáleulos de distância. Como pode 

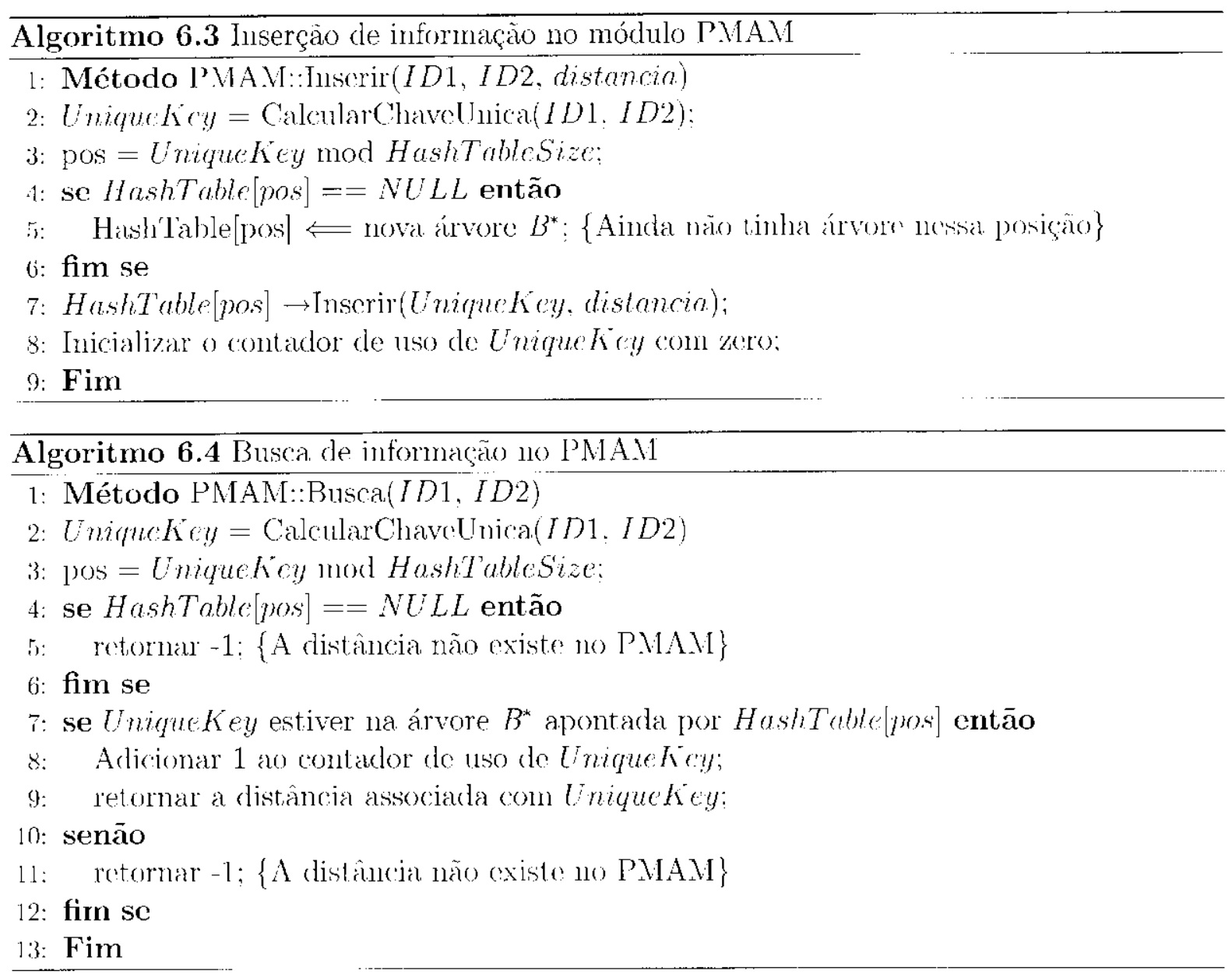

ser observado no Algoritmo 6.5, a única mudança necessária nos MAs cxistentes está no

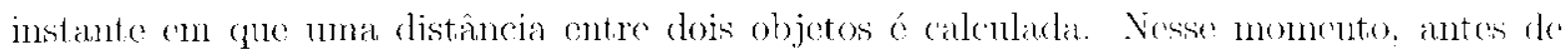
realizar o cálculo da distância, a mesma é procurada no P.MAL. Se a distáncia já estiver

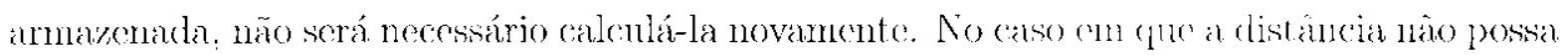
ser recuperada através do PMAM, o MA deverá calculá-la dia forma convencional e depois inseri-la no PMAM para eventuais futuras consultas.

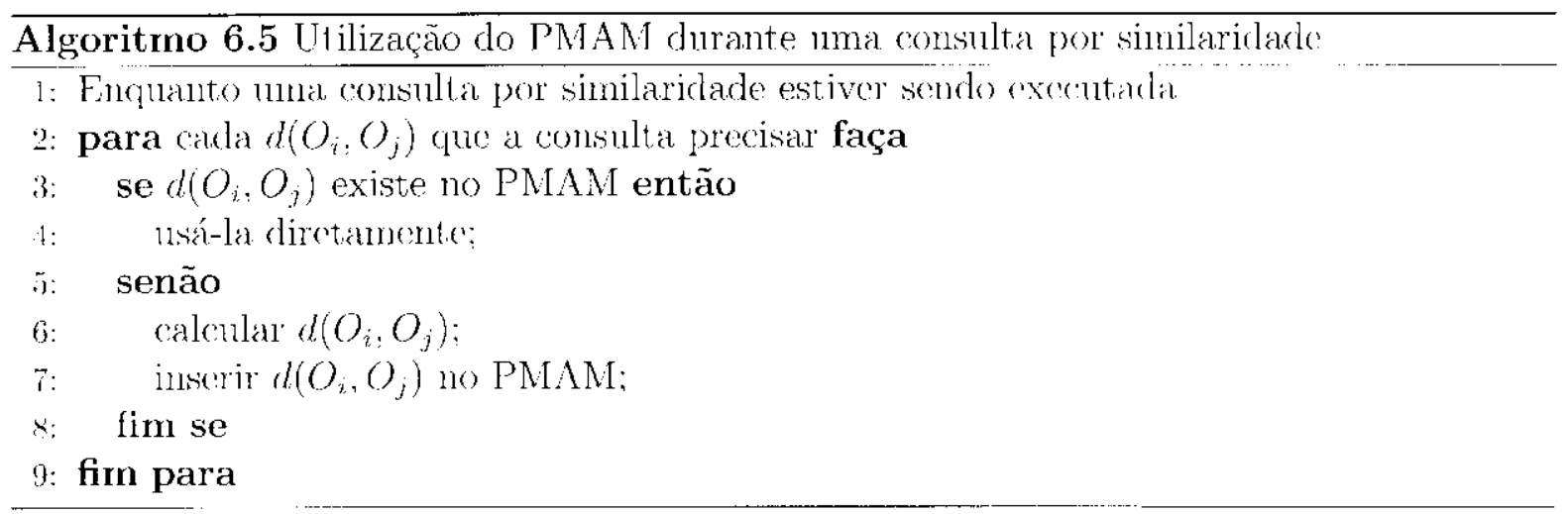


O tempo extra cule o P.MAM acrescenta, no processo normal de recuperação de informação de um MA, está determinado polo tempo de inserção e recuperação de dados cm uma árvore $B^{*}$.

O PMAM permite recuperar its distancias com un custo computacional de $\log _{m}(s)$, onde \& representa o número de distáncias armazenadas e $m$ representá a ordem da árvore $B^{*}$. Devido ao fato de que. na maioria dos casos, as consultas obedecem ao princípio de Pareto. porle-se alimar que:

$$
s=\alpha \frac{n(n-1)}{2},
$$

onde $n$ é o múmero de oljetos existentes, a é a laxa de ocupação da matriz $(0 \leq a \leq 1)$ o $\frac{n(n-1)}{2}$ ć o número de distâncias possíveis em uma matriz triangular completa. Se as consultas estivercm distribuílas de acordo com o princípio de Pareto, espera-se uma taxa de ocupação relativamente baixa.

No caso de usar una tabela de Hash de tamanho HashTableStize, como foi feito no PMAM. é possível reduzir ainda mais o tempo de recuperação de uma distanncia para. aproximadamente, $\frac{s}{\text { Hash Tablus bizi }}$.

Apesar de obscrvar-so que o custo computacional apresentado na Equação (6.1) é de ordem quadrática em função do número de objetos $(n)$, na realidade os objetos inseridos na estrutura estăo apenas conectados a um número finito de vizinhos mais próximos. Portanto, a Fquação (6.1) pode ser lambém escrita da scguinte maneira:

$$
s=\frac{k n}{2},
$$

onde k representa a módia do múmero de vizinhos com os quais un objeto está conectado na estrutura. Para grandes bancos de dados, espera-se un valor de $k$ muito menor que $n$, isto é: $k \ll u$. De acordo com esse cálculo, o custo computacional de recuperação de uma distância, através do P.HAM, ó O $\left(\log _{m}(k n)\right)$.

\subsection{Experimentos}

Os experimentos apresentados nesta seção foram realizados com os mesmos conjuntos de dados apresentados 11a Seçio j.3.1 (ver Pág. 80). Na Figura 6.1(a), pode ser observado o desempenho, em termes de tempo, da OmniRTree tradicional e da OmniRTreet. Nesses experimentos, foran realizadas 500 consultas por abrangência (Range Queries) com centros escolhidos de forma aleatória para ambos os métodos. Nesse grálico, também observa-se que, ao longo do tempon, o PMAM permite que a diferença entre anubas as técnicas seja mais acentuada. 
A diferença de tempo, a favor do OmmiRTreet, pode ser melhor entendida através dia linha apresentada na Figura 6.1(b). Essa linha representá o núnoro de cálenlos de distáncia

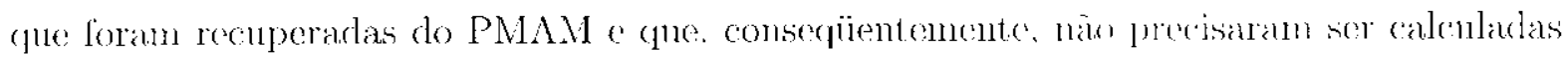
mais de una vez. Nesse experimento, todas as distáncias geradas foran inseridas no PMAM, porém diversos critérios poderiam ser utilizados para filturar as distancins mais relevantes. Uma heurística poderia ser armazenar apenas as distâncias dos objetos mais próximos, pois

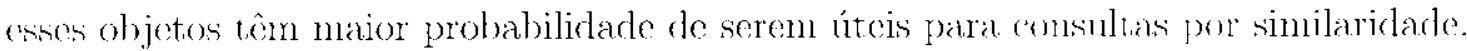

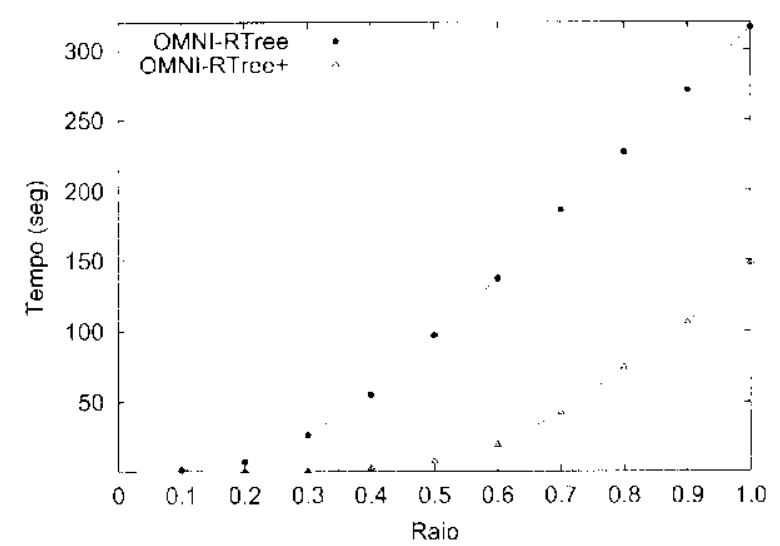

(a) Desempenho de consultas do tipo Range Query

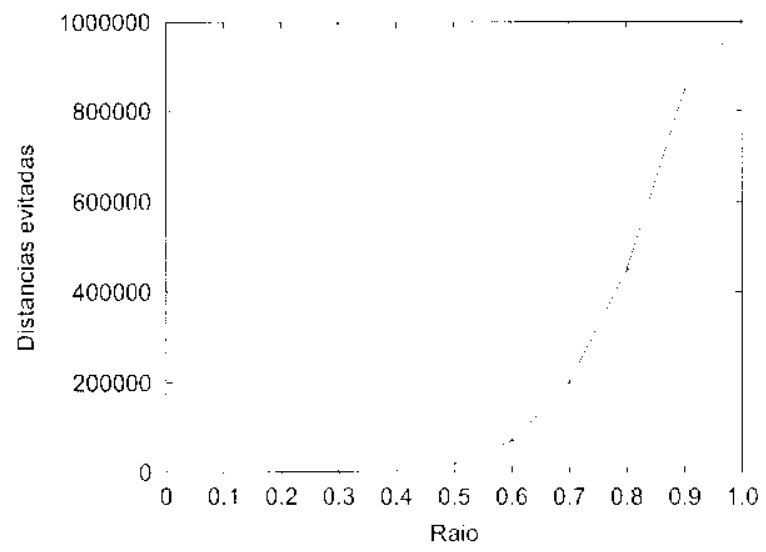

(b) Distencias rexneradas atraves do PMAN

Figura 6.1: Ffeito do nso do PMAM na OmniRtree, con jo fort e o conjunto IMACiES.

Na Figura 6.2(a), pode-so observar oresultado de aplicar ontras 5y) comsultan com raios aleatórios com o conjunto do dados FOREST. Nesse caso, para o primeiro raio apresentado, a

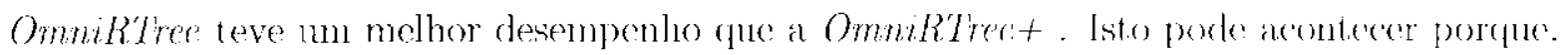
nesse instante, o PMAM está sendo "alimentado" pelas novais distancias c isso consono

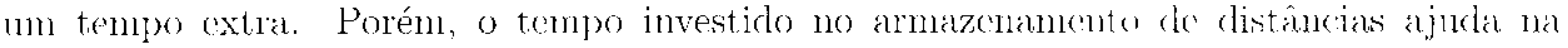
reduça de cálculos de distancia no futuro, como pode ser observade nos pontos dos ontros raios. A diferença de tempo entre ambas as abordagens tambom pode ser explicada pela

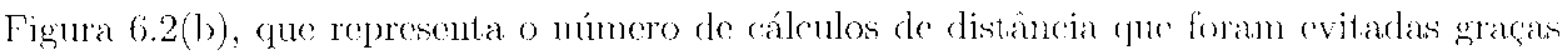
ao nso do PMAM.

Cumo já foi explicaklo na Equação (1.2) (ver Pág. 2), ne caso de darkes complexos, o fator que consone mais tompo está representado pelos cálculos do distancia. A diferença

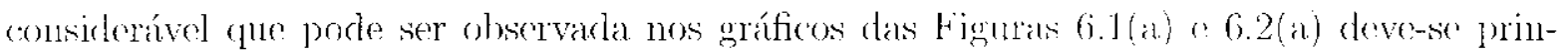
cipalmente ao tempo consumido pela função de distáncial. que a maior que o tempo de

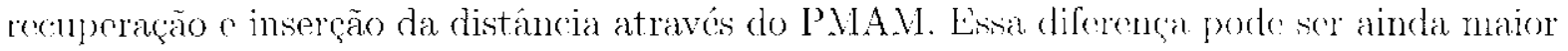

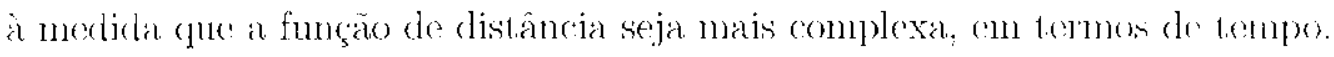

No caso de baixas dimensões, onde o cálculo de distância precisa do menos tempo. o 1.empo de consulta e inserçăo no PMAM pode ser maior que o tempo ginho. Na Figura 6.3. observan-ses us resultados dos experimentos utilizando o conjunto do dados LEI"TLRS 


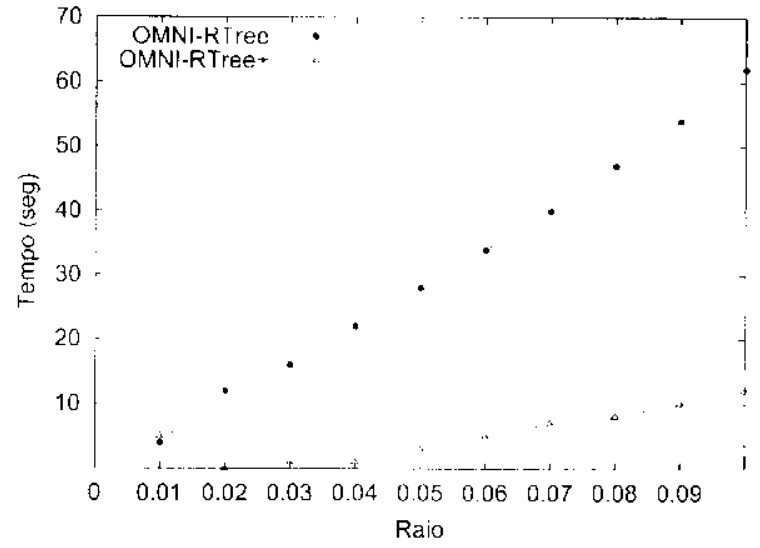

(a) Dosempenho de consultass do tipo Range Query

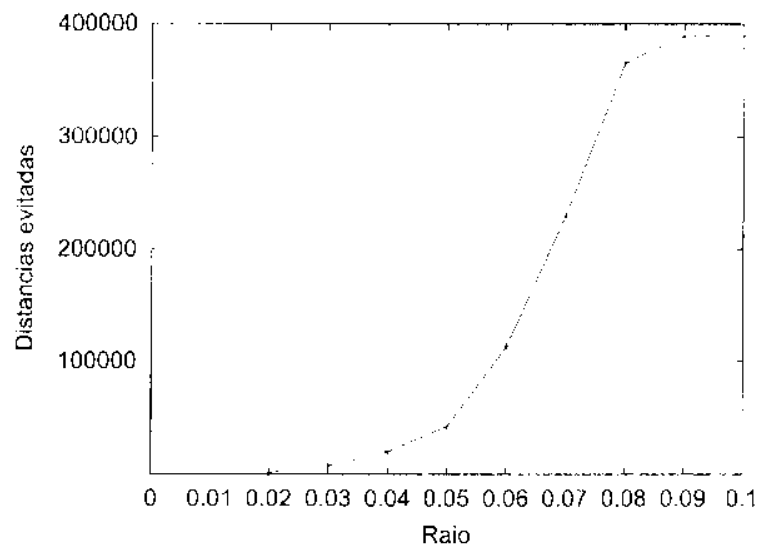

(b) Distâncias recuperadas através do PMAM

Figura 6.2: Efeito do nso do PNAM en OmniRTree, com 3-foci, no conjunto FOREST $(5 \cdot 1-D)$.

(16-D). Tesse último caso, a OmniRTree tradicional teve um melhor desempenho devido ao fato de que a funçäo de distancial o relativamente simples e por esse motivo consumin menos tempo que a inser(ão das distâneias no PMAM.

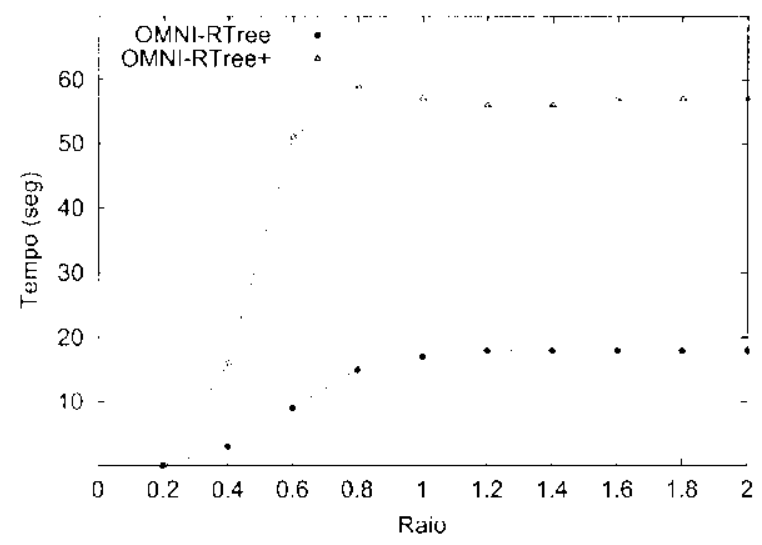

Figura 6.3: Efeito do uso do PMAM com uma função de distância con baixo custo computiacional utilizando OmniRTree, com 7 -foci e o conjunto de dados LETTERS (16-D).

A Figura 6.3 6 rolevante apenas para ser comparada com as Figuras 6.1 e 6.2. Em problemas reais. o PMAM deve ser utilizado apenas con funções de distância que consomem uma quantidaude considerável de tempo. Isto é funsóos anjo cálculo leve mais tempo que a inserção na árvore $B^{*}$.

\subsection{Propriedades da técnica proposta}

O módulo P.MAM apresenta as seguintes propriedades: 
Generalizável para qualquer MAM: o PMAM pode ser perfeitamemte usado junto a qualcuer MAM conhecido, pois a commicasaio entre o MAM a PMAM está bem estabelexida através da função de cálculo de distancia:

Aplicáveis também para MAE: o PMAN pode ser nuado também junto aos . WAE. A única adaptação que deve ser considerada é que o PMAM pode ser utilizado apenas em conjuntos de objetos nos quais esteja cstabelecida 1ma função de distancia;

Dinamismo: uma das principais contribuiçōes do uso de PMAL á que, diferentemente dos métodos AFSA C LAESA, O PMAM não precisa conleecer. a priom o número de objetos. Qualquer distância pode ser inserida no PMAM a culalcuer nomento;

Conexionismo: cada distância armazenada no PMAM pode também sole vista como mun concxão entre dois objetos. Um MAM on MAL tradicional não cria conexöes com os vizinhos mais próximos como no caso de $u m$ MAMt on MAL+. No pior caso desta proposta, o PMAM ainda está vazio e corresponde ao caso MAM on . MAF original;

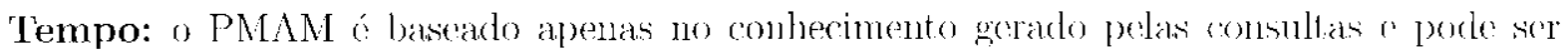
construído on-line. O único tempo extra de CPL desta proposta extá relacionado ab tempo cnvolvido na inserção e busca de distancias no PMAM. No caso de funçós de distância complexas, o que se espera é que consumbm um tempo maior que o tempo de inserção e consulta no PMAM:

Simplicidade: a incorporação do PMAM cm um MAM on MAE apenda precisa criar mm ponto de conexão. Esse ponto está na função de distância nuétrica (ver Algoritmo 6.5);

Bascado no comportamento do usuário: a grande natioria do MAs sio constrúdos scm

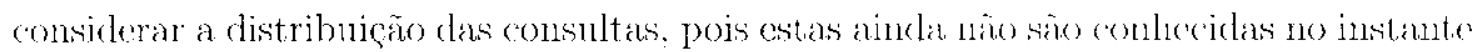
da construçăo. No caso do PMA.M, a construçio be realizada de acordo com o comporlánucnto do usuário.

Além das propriedades citadas anteriomente vale a pena ressaltar que a entrada do

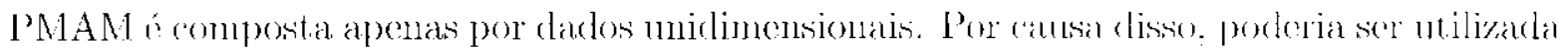
qualquer estrutura que permita recuperar os dados de forma rápida como por exemplo, as irvores $B^{*}$.

Lin outro ponto importante que deve ser ressaltado a que. no saso de consultats por similaridade, como por exemplo un Range Query $\left(O_{t}, r\right)$, existe ma grande probabilidade de que ma consulta năo seja repeticla de forma exata on (pur a objoto () năo faça parto dos objetos armazcnados. Nesse caso, a estratégia poderia ser encontrar o objeto $O_{1}$ mais próximo em relaça ao centro da consulta o utilizar as distancias existentes para acuele objeto e a desigualdade triangular para realizar a consulta. 


\subsection{Considerações Finais}

Neste capítulo foi apresentado o módulo PMAM que pode ser ntilizado junto a qualquer MAM ou MAE (xistente. No (asso dos MAE, a única restriçăo é que deve ser estabelecidal una funçăo de distcincia.

A principal contribuiça introduzida pelo uso do módulo proposto é o fato deste ser bascado no comportannerto do usuário e nào apenaśs nos clados.

O PMAM foi criado pela constatação de que os MAs existentes se comportan de uma forma mecânica e nàio reaproveitan o conhecimento gerado pelas consultas. Uma soluçäo existente é armazenar todas as distâncias possíveis, porém essa solução é inviável devido ao alto custo computacional que envolve. Para reduzir o custo computacional, o P'MAM armazena apenab apulatis distancias produzidas pelas consultats que o usuário executa sen precisar de um proesso extra. O PMAM, comparado com a abordagem anterior, permite reduzir considoravolmente a quantidade de distâncias necessárias. O PMAM é construído com base nas consultach do usuário considerando que, se una distảncia foi necessária em unn tempo t, a probabilidiude de ser necessária no futuro aumenta.

Una vantagem importante do PMAN é que as adaptaçós nocestárias om um MA são mínimas. Apenas é necrssário estabelecer uma comunicação entre o MA e o PMAM no ponto enu culo a função de distância é calculada.

Além disso, o. MA + incerpora o conceito de conexionismo entre a vizinhança dos oljoctos

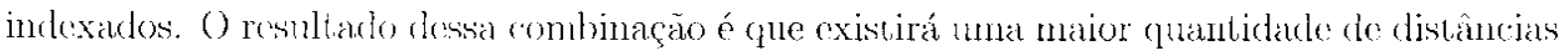
naquelas áreas onde o usuário realize mais consultas. Uin MAM ou MAE tradicional, pode ser visto cono o pior caso de un MAM+ ou MAEt, pois representam o caso onde não se dispõo de informação relacionada às distancias calenladas anteriormente.

Os MAM+ o MAE+ representam o ponto de equilíbrio entre espaço, simpplicidade e tempo de const ruçào. Essisa técnica é especialmente útil para aqueles casos onde a função de distäncia consune un tempo considerável, que é o que acontece no caso de bascs de dados multinnílic. 
CAPITULO 6. METTODOS DE ACESSO BASEADOS NO (OMPORTAMENTO JO) 102

USUÁRIO 
$\circlearrowleft$

\section{Conclusões e Trabalhos Futuros}

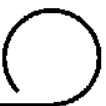

$\mathcal{A}$

indexação o recuperaçào de informaçào por similaridade en dados multimídia é un problenia complexo. Nesta tese foram propostas novas técnicas para melhorar o descmpenho tinuto de Redes Venrats Artificiais quanto dos Métodos de Acesso. Mesmo utilizando as ténicas dos Métodos de Acesso e modelos de Redes Neurais Artificiais mais avançadas aindà existem problemas en aberto.

No Capítulo 5, loran propostas as técnicas SAM-SOM e MAM-SOM que pornitiram a incorporação do MAE o MAM en SOM. O objetivo principal desta incorporaçăo é poder encontrar a unidade vencedora com um custo computacional de aproximadamente log(n), onde $n$ é o número do mindades existentes na rede.

A técnica SAM-SOM apresenta dluas variantes que foram denominadas SAM-SOM híbrida "SAM-SOM*. To caso da técnica SAM-SOM líbrida, os MAE são incorporados ao processo do treinamento de um SOM tradicional. A única diferença é que o processo scqü̈ncial para encontrar a unidade vencedora é substituído pela utilização de um MAF. A principal vantagen dessá técnica é que o tempo de treinamento é reduzido de forma considerável. Fssa diferença pode ser ainda mais acentuada à medida que o número de unidades aumenta. Nesse caso, o processo de correção de pesos continua sendo realizado de acordo com o algoritmo de treinamento do SOM cnvolvido.

No segundo casso, SAM-SOM*, a principal diferença é que uma nova unidade é inserida na rede para cada objeto do conjunto de treinamento apresentado. Esse caso representa o limite de exigencia possível para uma rede do tipo SOM construtivo tradicional, pois o tempo de adaptação das novas unirlades é reduzido ao mínimo, abrindo a possibilidade de criar redes deformadats. Apesar dessas condiçöes, aparentemente adversas, o desempenho melhora consideravelmente; graças ao 1150 de MAE. Isto acontece mesmo considerando um número muito alto de unidades, conforme comprovado nos experimentos realizados.

No caso da técnica MAM-SOM, foi discutida apenas a técnica MAM-SOM*, que permite a criação de uma nova midade na rede para cada objoto apresentado. Neste caso, náo 
foi analisada a técnica híbrida pois seria necessário estabelecer um processo de correģa de vetores de pesos. Fon espaces métricos, isso nem semper a possível devido ao fato

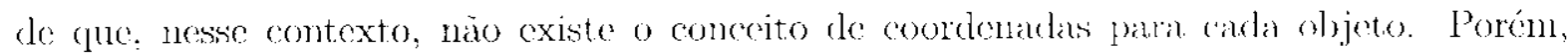
so for estabelecida alguma lécnica que permita realizar um processo similar à correção de posos para espaços métricos, também poder-se-ja falar da téenica MAN-SOM híbriclá. Lima técnica, recentemente apresentada para atingir esse objetivo por se scr observada no trabalho de Somervno (2003). Nesse trabalho, o antor demonstra como podr ser calculardo um ponto intermediário entre duas palavras de um dicionário.

Considerando que:

- a cliferença obtidla, em termos de desempenho, através dis técnicas SAM-SOM o MAM-SOM é muito considerável (ver Seçào 5.3 Pág. 79);

- o custo computacional do treinamento de um SOM ́́alto (ver Sonão 5.1 Pág. 71);

- o processo para encontrar a unidade vencelora é utilizado con nuita freqüència:

- em bancos de dados multimídia, a dimensão dos clados porte ser alta;

- a funcão de distancia entre dois objetos complexos pode ser muito complexa e demorada. ospecialmente quando se trata de dados multimídia;

- existe muna temelência marcada ao anmento do volume a complexidarde da funcáa de cálculo de distânociá,

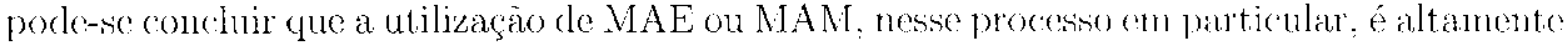
recomendável para reduzir custos en termos de cálculos comput acionais e, por conseqüoncia, reduzir o tompo de treinamento de $m$ SOM.

Uma outra conchusão importante é que, depois de conhecer a lomla de utilizar $\mathrm{MAE}$ ?

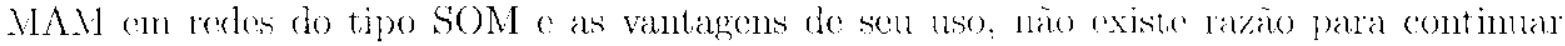
utilizando a comparação seqü̈encial para encontrarar a uniclade vencedora.

As vantagens da utilizaçäo de MAE e MAM no treinamento de SOM pollem ser ainda mais accutuadas à medida en que o volume de padrōes e o tammunu da rede aunnentann.

Una consegüencia direta da redução do tempo necossiário para o treinamento é que será possível pensar en redes com un maior núnero de unidades possibilitando um maion aprendizaklo por parte das mesmas.

Por ontro lado, após torem sido analisadas as principais vantagens "linnitacoes dos MAE e MAM. descobriu-se que esses métodos náo possuem capacidade de aprendizado. Isso

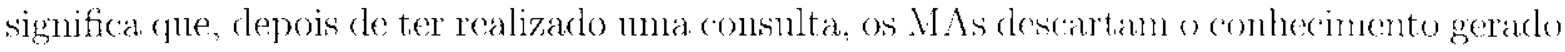
(representado pelas distáncias). Por causa disso. no Capítulo 6, foi proposto o módulo 
PMAM, que permite armazcnar as clistâncials geradas pelas consultas con o objetivo do reaproveitá-las para oulras comsultas.

Esta técnica permite dispor de una "psendo-matriz de distâncias", de forma análoga à técnica AESA. conn a grande vantagem que O PMAM precisa de una fração de espaço quando comparaka com AFSA. O módulo PMAM contém apenas aquelas distâncias que são as mais usadas pelas consultas. Esta técnica represcnta o ponto de equilíbrio ontre a velocidade de recuperarão de distâncias, $O(1)$, dat técnicá AESA (Vidal, 1986) e o cspaço repuerido pela nova estrutura. () módulo PMAM permite rexuperar a distâneia com un custo computacional de $O\left(\log _{m}(h n)\right)$. como apresentado na Seção 6.3 (ver Pág. 94).

\subsection{Principais Contribuições}

Os resultados desta lese representann contribuiçöes em duas áreas de pesquisa: Redes Neurais Auto-Organizáveis e Métodos de Acesso Espacial e/ou Métricos. As principais contribuições sio apresentadas a seguir:

- A prova de que á possível criar redes do tipo SOM com um grande mímero de unidades, inclusive iglabl ao numero de objetos do conjunto de treinamento, com um tempo de treinamento aindia mener que o apresentado pelos modelos antecessores;

- Antes da ajpresentação das técnicas SAM-SOM c MAM-SOM, as conexóes de un SOM eram úteis apenas para acessar os vizinhos conectados com unia unidade (informação topológica). Com essas técnicas, as conexões também podem conter a distância, que é una informação muito útil para o processo de recuperação de informação por similarielinde:

- A apresentaçáo de una técnica que permite a redução do tempo de treinamento de uma recie SOM;

- A criação de $u m$ modelo, derivado dos mapas de Kohonen, que resolve o dilema da estabiliclade-plasticidade. Esse modelo permite adicionar novos padrões a qualaner instante sem perder o conhecimento adquirido;

- A criação de um modelo de SOM com capacidade para poder atender consultas do tipo k-vizinhos mais próximos e buscas abrangência (Kange Query):

- A incorporação de conexionismo, m métodos de acesso, entre os objetos vizinhos, bascado na distribuição das consultas realizadas pelo usuário;

- A apresentação de una técnica para o armazenamento de distâncias que permite que un MA+ jussa criar uma maior quantidade de conexōes nas regióes nas quais exista 
maior concentração de consultas. O PMAM tem a vantagenn de ser construído om função do comportamento do usuário e näo apenas em função de conjunto de dados:

- A ulilização do PMAM junto a um Método de Acesso pode ser realizada, om termos de implementação, com 1 m impacto nínimo, pois para retroalimentá-lo, apenas ó necessário modificar una linha de código, no ponto onde a distancia entre dois objetos s calculada.

Fsta tese de doutorado fez parte do Projeto IMiMD - Indexaçăo o: Mincração de Dados Multimúdia (Indexing and Data Mining in Mullamedia Data Bascrs) (Traina Jr e Faloutsos. 2000), que vom sendo desenvolvido de forma conjunta entre o ICMC-USP o Carnegie Mellon Universily-ELA.

Os resultados obtidos nesta tese geraram publicaçoes através de Relatórios Técnices (Cnadros-Vargas e Romero, 2000), artigos en Conferencias Internacionais (Cuadros-Vargas

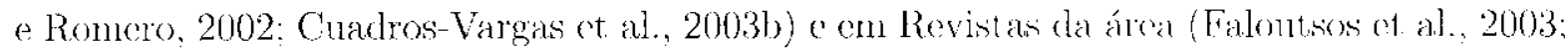
Cuadros-Vargas et al., 2003a, 2004; Cuadros-Vargas e Romero, 20)44).

\subsection{Propostas de Trabalhos Futuros}

Em relação às Redes Neurais Artificiais, uma extensão natural deste trabalho á a general-

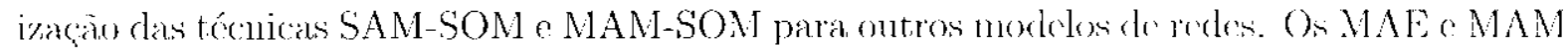
podem tambón ser ulilizados junto a redes com múltiplas camadas, como nos experimentos

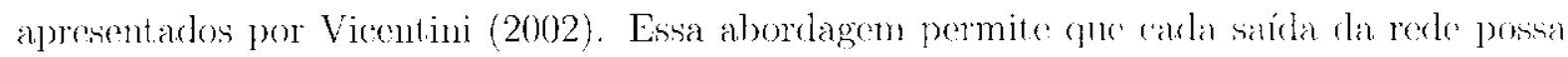
organizar os dados classificados por cla con o intuito de realizar consultas por similaridade.

Nos experimentos apresentados nesta tese foram nilizados, preponitalmente. métortos do acesso, lais como como R-Tre (Guttman, 1984), k-d-Tree (Finkel o Bentley, 1974) que săo relativanente antigos. Mesmo considerando a antiguidade desice médodos. os resultados foram positivos. Porém, há necessidade de realizar cxperinentes com estruturas mais avançadas.

In aspecto inportante gue porle ser melhorado no P'MA.M. refere-se à política do descarte das distàncias menos úteis, com o intuito de minimizar o espaço necessário para

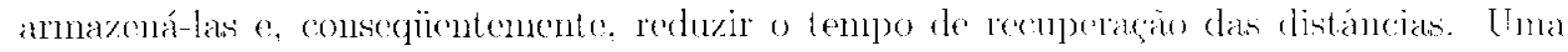
idéia em aberto é manter aquelas distâncias que säo as mais acessakdas. P’ara atingir esse objetivo, poderia ser adicionado um contartor a cada distancia armazenarla no P.MAM. Esso contador seria atualizado cada vez que a distância fosse recuperada. Na Figura 7.1, observa-se a possivel estrutura lógica da informação amazenada polo PMAM proposto. A altura de arda coluna representa o contador do uso do ada distancial. Vustat estrutura, poder-se-ia aplicar urm plano de corte horizontal, de forma similar ao algoritmo Watershed (Beucher e 
Lantuéjoul. 1979). para manter aquelas distâncias com maior freqüência de nso. O problema é minimizar o custo computacional desse processo.

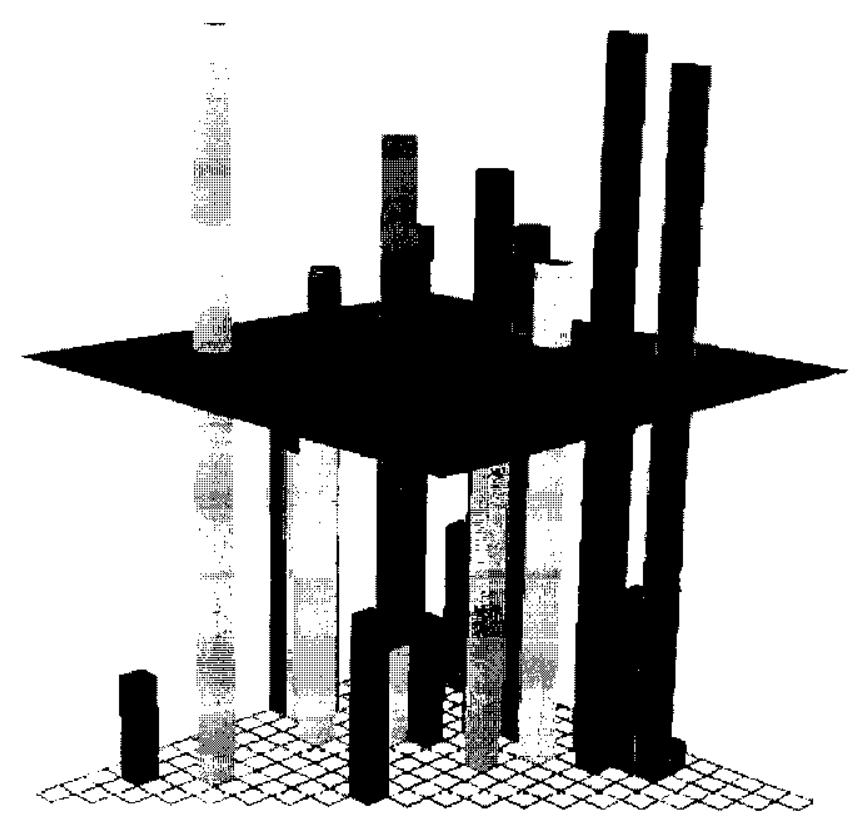

Figura 7.1: Representinăo das distancias armazenadas no PMAM cm forma de uma matriz. triangular. A altura de cada barra representa a freqüència de acesso para uma distancias.

Una outra heurística que poderia ser aplicada para reduzir o número de distânciass do PMAM ó clininar as majores distancias, pois representam concxöes entre objetos distantes. Neste caso, o intuito é manter as distâncias dos objetos mais próximos.

A terceira heurística para a redução das distâncias armazenadas denominada Least Rt'cently Used (IRU) (Folk ct al., 1998: Webster, 1980) é descartar aquelas menos usadas recentiemente.

Outro problema gure continua cm aberto é o estudo de deteção de agrupamentos a partir dar rede gerada com as técnicas SAM-SOM ou MAM-SOM.

Também pode ser estudada a possibilidade de aplicar a generalização da desigualdade. triangular com base nas distancias disponíveis da mesma forma que a técnica proposta por Shasha e Wang (1990).

Finalmente, um outro trabalho futuro refere-se à incorporação de mecanismos de aprendizado increncintal em MAlí ou MAM. Nesta tese, o PMAM pode ser visto como una espécie de memória Carhe. Mesun assimn os resultados foram mnito positivos en relação aos MAM que näo o usaram. To futuro, acredita-se na possibilidade de criar métodos de acesso com maior eficiencia, capazes de aprender e generalizar o comportamento do usuário para acelerar consultas à medida fure mais conhecimento seja gerado. 


\section{Referências Bibliográficas}

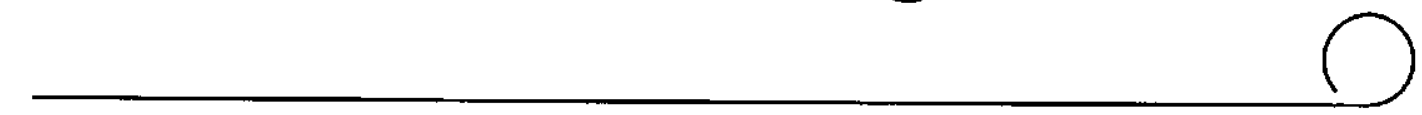

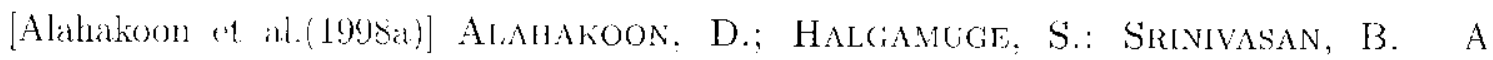
Structure Adaputing Feature Nap for Optimal Cluster Representation. In: Intcrnational Conferente on Ncural Infonmulion Processing. Kitakyushu, Japan, 1998a, p. 809 - 812.

[Alahakoon et al.(1998b)] Alahakoon, D.; Halgamugf, S.; Srinivasan, B. A sclf growing chuster developnent inproath to data mining. In: IEEE International Confenence on Systems. Han and (ybometies, 1998b, p. 2901 2906.

[Alahakom of al.(20)(0))] Alahakoon, D.: Halgamuge, S.: SRinivasan, B. Dymanic self-organizing map) with controlled growth for knowledge discovery. IEEE Transactions on Neural Networks. v. 11, 11. 3, p. $601+614,2000$.

[Albers e West brook(1996)] Albers, S.; Westbrook, J. Self-organizing data structures. In: Ontine Algonithms, 1996, 1) 1351.

Disponível chl http://citeseer.nj.nec.com/albers98selforganizing.html (Acessado em $08 / 01 / 2004)$

Annamalai et al.(2000); Anvamalai, M.; Chopra, R.; Defazio, S. Indexing Inages in Oraclesi. In: AOM SICHOD) internalional Conference on the Management of Data,

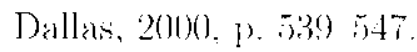

[Aurenhammer(1991)] Aurérhamer, F, Voronoi diagrams a survey of a fundannental geometric data structure. ACM Computing Survey, v. 23, n. 3, 1991.

[Bacza-Yates(1997)] BAEZA-YATes, R. Searching: an algorithmic tour. In: Kent, A.; Williams. J., eds. Encyrlopedia of Computer Science and Technology. Marcel Deker Inc., 1997, p. 3331359.

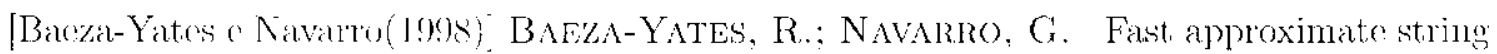
matching in a dictionary. In: South American Symposium on String Processing and Information Retrieval. ILEE CS Press, 1998, p. 14-22. 
[Baeza-Yates(1990)! BAeZa-Yates, R. A. An adaptive overflow trehnique for h-trees. In: Extending Database Technology. 1990, p. 1628.

Disponível em http://citeseer.nj.nec.com/99409.html (Acrisiado (III (18/01/2004)

[Baeza-Yates el al.(1994)] Baezh-Yates, R. A.; Cunto, W.; Manber, U.: WU: S. Proximity matching using fixed-queries trees. In: Crocinemore, M.; GusFIELD, D., eds. Annual Symposium on Combinalorial Pattern Matching. Asilomar, CA: Springer-Verlag, Berlin, 1994, p. 198212.

Disponível em http://citeseer.nj.nec.com/219706.html (Acessado em (18/01/2004)

[13aza-Yates o Ribeiro-Neto(1999)] Baeza-Yates, R. A.; Rmbiro-Xmto, B. A. Modem information retrieval. ACM Press / Addison-Wesley, 1999.

Disponivel em http://citeseer.nj.nec.com/433337.html (Aressialo cm 08/01/2004)

[Baraldi e Blonda(1998)] Baraldi, A.; Blonda, P. A sumey of fuzzy clustering algorithms for pattern recognition. T'R-98 038, International Computer Scionce Inst itute. 1947 Ccuter St. Suite 600, Berkeley, California 94704-1198, 1998.

[Baraldi e Parmiggiani(1998)] Baraldi, A.: ParmigGani. F. A fuzzy noural network model capable of generating/removing neurons and synaptic links dynanically. In: P. Blonda, M. C.; Perrosino, A., eds. II Italian Workshop on Fuzay Logic, Singapure: Workl Scientific, 1998, p. 247259.

[Bayer e MrCreight(1972)] BAYER, R.; MCCREIGH', E. Organiyation and maintenance of large ordered indexes. Acta Informatica, v. 1. 11. 3. p. $173 \quad 189,1972$

[Beckmam et al.(1990)] Brckmann, X.; Kriegel, H.; Schneldrk, R.: Seeger, B. The $R^{*}$-Tree: An efficient and robust access method for points and rentangles. In: ACM SIGMOD International Conference on Management of Data. 1990. p. 322331.

Bolussi e Faloutsos(1995)] Belussi, A.; Faloutsos, C. Frtimating the Solectivity of Spatial Queries Using the 'Correlation' Fractal Dimension. In: International Conference on Very Large Data Bases, 21st, Zurich, 1995, p. 299 310.

Belussi e Faloutsos(1998)] Belussi, A.; Faloutsos, C. Self-Spacial Join Selectivity Estimation Using lractal Concepts. ACM Transactions on Information Systems, v. 16 , 11. 2, p. $1612(01,1998$.

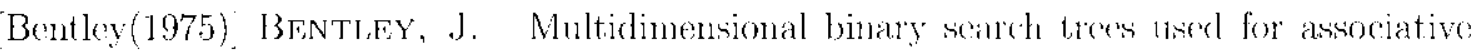
searching. Communications of the ACM, v. 18, n. 9, 1). $5099517,1975$.

[Berchtold ot al.(1996)] Brizch'lou, S.; Krin. I).: Kratails, II. The X-Tree: An index structure for high-dimensional datia. In: International Conferene: on Very Large Data. Bases. Diond, Mumbai (Bombay), 1996. p. 2839. 
[Bencher e I:antúgonl(1979j] Beucher, S.: LANTLÉJoul, C. Use of Watersheds in (ontour I)dectism. In: Inly Workshop Image Processing, Real-Thme Edge and Motion. Defertion / Fstimation. Rennes, France. 1979.

[Böhm ot al.(2001)] Bönм, C.; Berchrol.1), S.; Kerm, D. Soarching in High-Dimensional] Spaces Index Structures for Improving the Performance of Multimedia Databases. ACM Compnting surteys. v. 33, 11. 3. p. 322 373. 2001.

[Bishop et al.(1998)] Bisilop, C. M.: Svensen, M.; Williams, C. K. I. GTM: The Generative 'lopographic Mipping. Neural Computation, v. 10, 11. 1, p. 215 234, 1998. Disponível an http://citeseer.nj.nec.com/bishop98gtm.html (Acessado em $08 / 01 / 2001)$

Blackmore e Miikkulainen(1993)j Blackmore. J.; Mrkkulainen, R. Incremental Grid Growing: Encoding Iigl-J)incnsional Structure into a T'wo-I Dimensional Feature Map. In: Internationnl Confentere on Nomal Networks, San Francisco-CA: IF.HE Service Center, 1993. p. 450455.

Disponível on http://citeseer.nj.nec.com/blackmore93incremental.html (Acessiato on $(18 / 01 / 2(4) \cdot 1)$

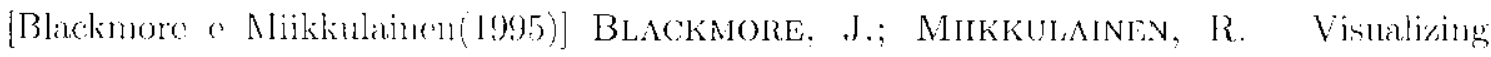
High-Dimensional Structure with Incremental Grid Growing Neural Network. fn: Prieditis, A.; Russisel, S., cds. International Conference on Machine Leaming, 19th, Sun Irancisco, CA, CSA: Morgan Kanfmann Publishers, 1995, p. $55 \cdot 63$.

lisponivel em http://citeseer.nj.nec.com/blackmore95visualizing.html

[Blackmore(1995)] BI.ACKMORE, J. M. Visualizing High-Dimensional Structure with Incremental Gird Crowing Neural Netuork. Dissertaçäo de Mestrado, University of 'lexas at Austin. Mustin. 1995.

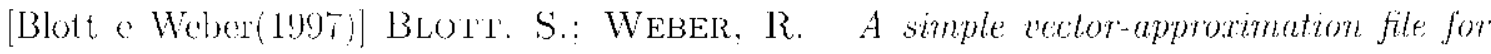
similarily scarch in himh dimensional vector spaces. Relatório Técnico. Institute for Informatics Systems - E'I'H Zentrum, Zurich, Switzerland, 1997.

[Boudjemaï ot al.(2003)] Boumjemaï, F.; Enberg, P. B.; Postairf, J.-G. Self organizing spherical mal) architecture for 3 d object modeling. 1n: Workshop on Self Organizing Maps. Jlilikino Kitakyushus. Japan, 2003, p. 197202.

[Bouton et al.(1991)] Bouron, C.; Comtrell, M.; Fort, J. C.; Pagís, G. Solf-organization and convergenee of the kohonen algorithm. In: BouleaU, N.; TALAY, D., eds. Probubilités Numónques, Paris, France: INIRIA, 1991, p. 163-180. 
[Bozkaya e Ozsoyoglu(1997)] Bozkaya, T.; Ozsoyogud, M. Distance-based indexing for high-climensional metric spaces. In: ACM SIGMOD International Conference on Managernent of Data, sigmod Record 26(2), 1997, p. 357368.

[Borkaya o Ozsoyoglu(1999)] Bozkays, T.; Ozsoyoglu, M. Indoxing large metric spaces for similarity search queries. ACM 'TRANSACTIONS ON DATABASE SYSTEMS, v. 24. n. 3. p. 361-404. 1999.

[Brin(1995)] Bris; S. Near Neightor Search in Large Metric Spaces. In: Intemational Conference on Very Large Databases, 1995, p. 574-584.

Disponível em http://citeseer.nj.nec.com/brin95near.html (Accssado em $08 /(01 / 2004)$

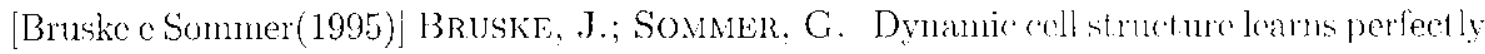
topology preserving map. Neural Computation. v. 7. 11. 4, p. 845 865. 1995.

[Bugnion at al.(1993)] Bugnion, E.; l'Hei, S.: Roos, T.: Widmayer, P.; Widmeli, F. A spatial index for approximate multiple string matching. In: BAEZA-YATES, R.: Ziviani, N., eds. South American Workshop on String Proctswing (WSP'93). 1993, p. $43-53$.

[Burkhard e Feller(1973)] Burkhakd, W.; Kéler, R. Some approaches to best-match file searching. Communications of the ACM, v. 16, n. 4. p. 230 236. 1973.

[Bulzevski e Mohan(1996)] I3urzfavsk, V.; MoHan, C. K. Iliemahical growing cell structures. Neural Nelworks, IEE'E International Conference on. v. 3. p. 1658-1663. 1996.

[Bustos et al.(2001)] Bustos, B.; Navarro, G.: Chávez. E. Pivot Selection Techniques for Proximity Searching in Metric Spaces. In: Confernee of the: Chilean. Computen Science Society (SCCC01), XX1, IEEE CS Press, 2001, p. 33.10.

Disponivel cm http://www.dcc.uchile.cl/ gnavarro/ps/sccc01.1.ps.gz (Acessado em $08 / 01 / 2004)$

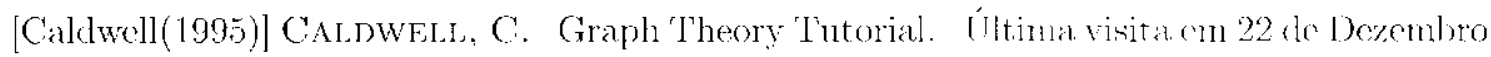
de 2004,1995 .

Disponivel en http://www utm.edu/departments/math/ graph/index.html (Acessado enos/01/2004)

[Carpenter o Grossberg(1990)] CARPEN'Eer, A.; Grossberc, S. Alt 3 hierarchical search: Chemical transmitter in self-organizing pattem rowgnition arehitertures. Nemal Networks, v. 3, p. $129152,1990$. 
Carpenter ot al.(199)2) Carplenter, G.; Grossberg, S.; Markuzon, N.; Reynolds, J. H.; Rosev. I). 13. Fuzzy Al'INAP': A neural network architecture for incremental supervised learning of malog multidimensional majs. IFFF, Transartions on Neural Netuorks, v. 3. 11. 5. p. 698 713. 1992.

Carpenter et al.(1991a)] Carpenter. G.; Grossberg, S.; Neurophystol, C.; REYNOLDS, S. ARTMAl': Supervised real-time learning and classification of nonst it tionary data by a self-organizing neural network. Neural Networks, v. 4, p. 565588 , 1991 a.

'Carpenter al. aloglb)! Carpenter, G.: Grossberg, S.; Rosen, D. Fuzy hrT: Fast Stable Leaming and Categorization of Analog Patterns by an Adaptive Resonance System. Nomal Netumbis. v. 4. 1). 759 771, 19916.

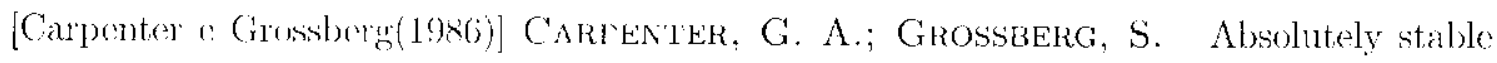
learuing of recognition codes by a self-organising neural network. AIP Conf. Proc. 151: Neural netuorks for computing, p. 77-85, new York: American Inst itute of Plysics. 1986.

Carpenter "Grossberg(1987a)] Carpenter, G. A.: Grossbero, S. ART 2 : sell-organization of stable category recognition codes for analog input patterns. Applaed Optics, v. 26(23). p. 1919 4930, $1987 \mathrm{a}$.

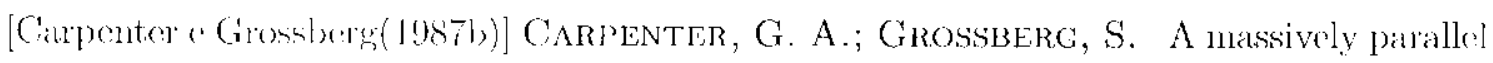
architesture for a self-organizing neural pattern recognition machine. Computer Vision, Craphics, and lmage Processing, v. 37, 11. 1, p. 24 115, 1987b.

[Carpenter et al.(19916)] Carpenter, G. A.: Grossberg, S.; Rosen, 1). B. ART 2-A: An adaptive rownane algorithn for rapjed category leaning and recognition. Neural Networks. v. 1. p. 493 no1. 1991 .

Chakrabarti o Mohrof ra(1999)] Chakrabaret, K.; Mejurotra, S. The hybrid tree: an index structure for high climensional feature spaces. Procedings, IEFE International Confertence on Bata Engineering, 15, p. 440-447, sidney, 1999.

[Chan et al.(1995)] Chav, L.-W.; Cirau, M.-W.; CHLNG, W.-C. Globalor: a parallel iuplementation of the self-organizing map. In: ZHONG, Y.; YANG, Y.; WANG, M., eds. Inlemational Conference on Neural Information Processing, Dept. of Computer Science, Chinese Univ, of Hong Long. Shatin, Hong Kong: Beijing, China: P'ublishing House of Electron. Ind., 1995. 1). 625 (j28.

[Chazele(1991)] CHAblde. B. Computational geometry: a retrospective. In: ACM Symposinm on the Themy of Computing (STOC'94), 26th, 1994, p, 7594. 
[Chiuch(1994)] Chiven, T. Content-based image indexing. In: International Conference. on Very Large Databases, Santiano, Chile, 1994, p. 582593.

[Chávez et al.(1999a)] Chávfz, E.; Marroqlín, J.; Baf\%a-Yates, R. Spaghettis: an array based algorithm for similarity queries in metric spaces. In: South American Symposium on String Processing and Information Retrintal. IEEE CS Press. ftp://garota.fismat.unich.mx/pub/user/elchavez/fqa.ps.gz. 1999ia, p. 3846.

[Chávez et al.(1999b)] Chávfz, F.; Marroquín, J.; Navarro, G. Overcoming the curse of climensionality. 1n: European Workshop on Contem-Based Multimedia Indering (CBMI'99), ftp://garota.fismat.umich.mx/pub/user/elchave/ffar.ps.g\%, 1999), p. 5764 .

[Chávez et al.(2001)] Chávez, E.; Navarro, G.; Bafza-Yates, R.; Marroquín, I. Proximity searching in metric spaces. ACM Computing Survess. ‥ 33, n. 3, p. 273 321, 2001.

[Ciaccia et al.(1999)] Chaccis, P.; Nani, A.; Phtella, M. A Query-semsitive Cost. Model for Similarity Queries with M-Tree. In: RodDick, J., al. Austrtalusun Databast: Conference (ADC'99), 10th. Auckland, Now Zealand: Springer Verlag. 1999, p. 65.76.

[Ciaccia e Patella(1998)] Ciaccia, P.; PateitaA, M. Bulk loading the M-tree. In: MoDonald, C., ed. Austrulasian Dalabase Conferenec (A1)C98), Ith. Perth. Australia: Springer Verlag, 1998, p. 15-26.

[Ciaccial e Patella(2002)] Ciacoin, P.; PATEldi, M. Searching in metrie spaces with user-defined and approximate distances. ACM Transactions on Database Systems (TOISS). v. 27: 11. 4, p. $398 \cdot 437,2002$.

[Ciaccia et al.(1997a)] Chaccia, P.; Patfida, M.; Rabitti, F.: Zrza:ta. P. Indexing metrie spaces with M-tree. In: CRISTIANI, M.: 'TANCA, L. eds. Atti del Quinto Convegno Nazionale su Sistemi Evoluti per Basi di Dati (SEBD'97), Verona, Italy, 1997a, p. 67.86.

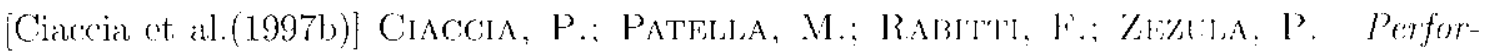
mance of M-lree, an Access Method for Similarity Search in Metrir Sparts. Technical Report 13, HERMES FSPRIT LTIR l'roject. 1997b.

Disponível em http://www.ced.tuc.gr/hermes/ (Acentarlo smo (08/01/2004)

[Chacia et al.(1997c)] Cincela, P.; PATella, M.; Zeza:LA, P. M-Trec: An efficiont access method for similarity search in motric spaces. In: International Conference on Very Large Dalabases, $1997 \mathrm{c}$, p. $426 \cdot 435$.

Disponivel om http://citeseer.nj.nec.com/ciaccia97mtree.html (Acessido cm $08 / 01 / 2004)$ 
Clarkson(1999). Cikkson. K. Nearest neighbor queries in metric spacces. Discrete Compulationat Cicometr\% v. 22. 11. 1, 1). $63.393,1999$.

[Comer(1979)] ComLik. I). The ubiquitous b-trees. ACM Compuling Surneys, v. 11, 11, 2, p. 121137.1979

[Costa a Andrake Netto(2001)] Cosia, J.; ANdrade NeTro, M. A new trecestructured self-organizing map for data analysis. In: International Joinl COnference on Neural Networks, Washington 1)(: IEEE P'ress. 2001. p. 19311936.

[Costic(1999)] Costa, I. A. F. Classificaça Aulomática a Análise de Dados por Redes

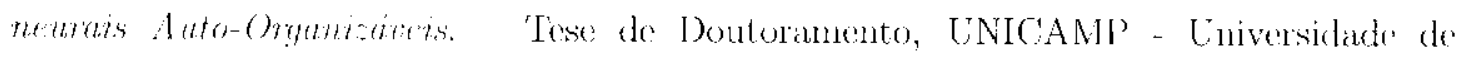
(ampinas (Faculdade de Fugenharia Elétrica e de Computaçäo), tese de Dout orado, 1999.

Cottrell(1997)j Co'rkist. M. Theoretical aspects of the SOM algorithnu. In: Workshop on Sclf-Organizing Maps. Helsinki, Finland: University of Technology. Neural Networks Research Comtre, 1997, 1. 246267.

[Cottrell et al.(1994)] Cor"rrell. M.; ForT, J. C.; PAGÈs, G. Two or three things that

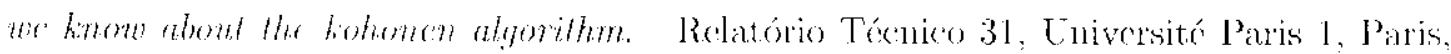
France. 1994.

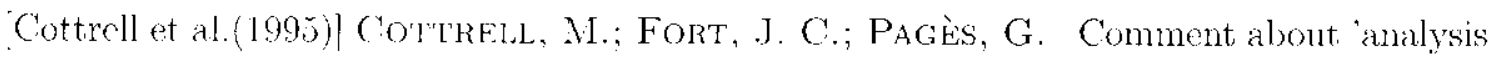
of the convergence propertics of topology preserving neural networks'. IEEE Transactions on Noural Networks, v. 6, 11, 3, 1). 797 799, 1995.

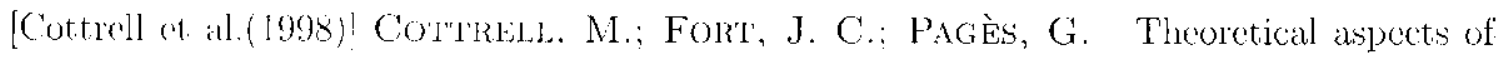
the SOM algorithm. Nomocomputing. v. 21. n. 1-3, p. $119138,1998$.

[Cuadros-Vargake Romero(2000) Cradros-Vargas, F.; Romero, R. A. F. Estudo do Modelos de Redes Netaras para Indexaçào e Recuperaçao de Dados. Relatório Técnico, ICMC - University of Sáo Paulo, Säo Carlos - SP, Brazil, notas Disláticas, N" 44, 2000.

[Cuadros-Vargas e limmero(2002)] Cuadros-Vargas, E.; Romero, R. A. F. A SAM-SON Fanily: Incorporating Spatial Access Methods into Constructive Self-Organizing Maps. In: International Joint COnference on Neural Nelworks, Hawaii, HI: IlEEE Press. 2002, 1). 1172 1177.

[Cuadros-Vargas et al.(2003a)] Cuadros-Vargas, E.; Romero, R. A. F.; Mock, M.; BrisABOA, N. R. How to teach data structures design: an increnental approach, submeticlo para o (onuputer Science Education Joumal, 2003a. 
[Cuadros-Vargas e Romero(2004)] Cuadros-Vhrgas, E.; Romero, R. F. The MAM+ Family: An novel technique to speed up similarity queries progressively. submetido para o Very Large Data Bases Jomrnal, 2001.

[Cuadros-Vargas et al.(2003b); Cundros-Vargas, E.; Romero, R. F.; Obermayfr, K. Speeding up algorithms of SOM Fannily for Jarge and High Dimensional Databases. In: Proceedings WSOM03. Workshop on Self Organizing-Mops. Hibikino-Kitakyushı, Japan, 2003b, p. 167172 .

[Cuadros-Vargas et al.(2004)] Cundros-Vargas, F.; Romero. R. F.: Obermayer, K. A SAM-SOM Family: $\Lambda$ novel idea 10 incorporate Spatial Access Methods into Self-Organizing Maps, submetido para Transactions on Nenral Networks. 2004.

[Dehne e Nolteimer(1987)] Dfhne, l'; Noldemer, H. Voronoi lrees and chustering problems. Information Systems. v. 12, n. 2, p. 171 175. 1987.

[Demian e Mignot(1993)] Demin, V.: Mignot, J. C. Optimizat ion of the self-organizing feature map on parallel computers. In: International Joint Conference on Ncural Neluorks, Nagoya, Japan: JNNS, IEEE Service Center, 1993. p. $48: 3486$.

[Demian e Mignot(1996)] Demian, V.; Mignot, J. C. Inplementation of the self-organizing feature map on parallel computers. Computers and Artificial Intelligenece, v. 15, n. 1 , p. 6380,1996 .

[Dempster et al.(1977)] Dempster, A.; Land. N.; Rubis; D. Maximm Likelihood from incomplete data via the EM algorithm. Royal Statistical Society Series B, v. 39. II. 1, p. 138,1977 .

[Dittenbach et al.(2000)] Dit'tenbach, M.; Mfrke, D.; Ravibr, A. The Growing Hicrarchical Solf-Organizing Map. In: Amari, S.; GILes. C. L.: Cort, M.; Puri, V., cds. International Joint COnference on Neural Networks, Como. Italy: IEEE Computer Seciety, 2000, p. 1519.

[Dittenbach et al.(2001a)] Dil'tenbach, M.; Merkl, D.; IRAlber, A. Hierarchical Chastering of Document. Archives with the Growing Hierarchical Solf-Organizing Map. In: International Conference on Artificial Neturl Networks, Vienna, Austria. ht tp://citescer.nj.nec.com/dittenbacho1hierarchical.html, $2001 \mathrm{a}$.

[Dittenbach et al.(2001b): Dit'Tenbach, M.; Raubeli, A.; Merkl. D. Recont Advances with the Growing Hierarchical Self-Organizing Map. In: Albivson, $X$; Yin, II.; Aldinson, L.; SLACK, J., ceds. Workshow on Sclf-Omyamzing Maps, Advances in Self-Organizing Maps, Lincoln, England: Springer, 2001h. p. 140145 (Aduances in 
Self-Oryamizing Maps.).

[jisponiva] 'm http://www ifs tuwien ac at (Acessado em $(88 / 01 / 20)(14)$

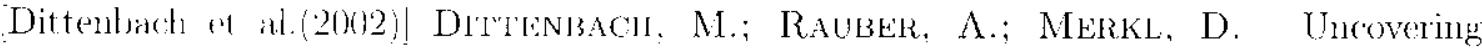
hierarchical structure in clata using the growing hierarchical self-organizing maj). Neurocomputing, v. 48, p. 199-216. 2002.

[Duch(1994)] Incm, W. Quantitative masures for self-organizing topographic maps. Open Systems of Information Dynamics, v. 2. n. 3. p. 295 302, 1994.

Disponível cm http://citeseer.nj.nec.com/duch94quantitative.html (Accssado ('m $08 / 01 / 2004)$

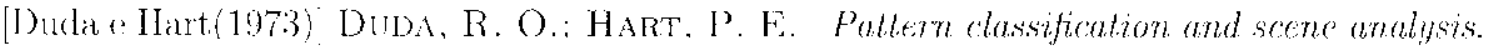
New York: Wiley, 1973.

Frwin et al.(1992a)] Erwin. E.; Obermayer, K.; Schliten, K. I Self-Organiring Maps: Stationary states, nutastability and convergence rate. Biological Cybernetics, v. 67, p. $35,45.1992 \%$

[Erwin et al.(1992h)] Frwis, E.; Obermayer, K.; Schulien, K. II Solf-Organizing Maps: Ordering, convergence properties and cnergy lunctions. Biological Cybernetios, v. $(67$, p. $17 \quad 55,19921)$

[Tahlman(1988)] FAhLMav, S. An Enpinical Study of Learning Speed in Back-Propayalion

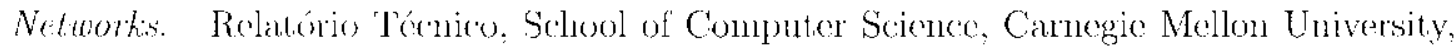
(MU-CS-88-162, 1988

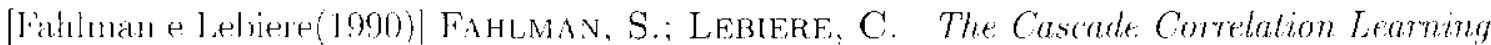
Archtecture. Rolatório Técnico CMU-CS-90-100, School of Computer Science, Carnegic Nellon University. 1 !)

[Faloutsos ot al.(1994)] Falot'rsos, C.; Barber, R.; Futckner. M.; Hafner, J.;

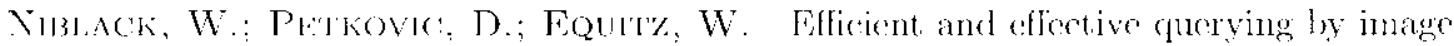
content. Journal of Intelligent Information Systems. v. 3, 11. 3/4, p. $231262,1991$. Disponivel eln http://citeseer.nj.nec.com/faloutsos94efficient.html (Acessado (en 08/01/2004)

[Faloutsos at al.(1993)] FAloutsos, C.; Equitz, W.; Fliokner, M.; NlbLaCk, W.: Pëlkovic. D.: 13arber. R. Fffficient and Effective Querying by Image Content. In: IBM Almaden Reseurch Division, San Jose, CA, 1993.

Disponível em http://citeseer.nj.nec.com/faloutsos94efficient.html (Accssado (em $08 / 01 / 2004)$ 
[Faloutsos e Lin(1994)] Faloutsos, C.: Lin, K. FastMap: A Fast Algorit lim for Indexing, Data-Mining and Visualization of Traditional and Multimedia Data. In: Int. Conf. on Management of Data ' ACM SIGMOD, San Jose: CA, 1994, p. 163174.

[Faloutsos et al.(2003)] Faioutsos, C.: Lin, K.; Cundros-Varcins. E. Multi-Threading FastMap: Automatically extracting numeric features Indexing and Visualization of Traditional and Multimedia Datasets, submetido para o Knowledge Data Discovery Joumal, 200)3.

[I'ernández-Redondo e Hernández-Espinosa(2001)] Fernánldez-Renondo, M.; HERnÁNDEZz-ESPINOSA, C. Weight initialization methods for multilayer feedforward. In: European Symposium on Artificial Neural Nelworks, Bruges (Belginm), iSBN 2-930307-01-3, 2001, p. 119121.

[Finkel e Bentlcy(1974)] Finkel, R.; Bentuey, J. Quad Trees: $A$ Data Structure for Retrieval of Composite Keys. Acta Informatica, v, 4, 1. 1, 1. 1 9. 1971.

[Flanagan(1994)] FlanAGAN, J. A. Self-organizing neural networks. Tese de Doutoramento: École Polytechnique l'édérale de Lausanne, Laulsimme, France, 1994.

[Flanagan(1996)] FlANAGAN, J. A. Self-organization in kohonen's som. Neural Netuorks, v. 9, 1. $11851197,1996$.

[Folk et al.(1998)] Fork, M.; Zoeldick, B.; Riccardi, G. File Structures, An Object Oriented Approach Using $C++.3 \mathrm{ed}$. Addison-Wesley, 1998.

[Fonsea e Jorge (2003) FOnSECA, M. J; JORGF. J. A. Indexing high-dimensional data for content-based retrieval in large databases. In: International Confenence on Databrase Systems for Advanced Applicalions (1)ASFA A 20093), 8th. Kyoto, Japan, 2003. p. 267274.

[Frean(1989)] Fren., M. The upstar algorithm: A method for constructing and training feed-foward neural networks. Technical Report, 1989.

[Fritzke(1991)] Fritzke, B. Let It Grow Self-Organizing Fature Maps with Problem Dependent Cell Structure. In: Kolionen. T.: MÄkisarA. K.; Simula, O.; Kangas, J., ads. Artificial Noural Netuorks, Amsterdam, Netherlands: Corth-Holland, 1991, p. 403-408.

Disponivel om http://citeseer.nj.nec.com/fritzke91let.html (Acessarlo om $08 / 01 / 2004)$

[Fritzke(1992)] Frutzke, B. Growing Cell Struktures a Self-()rganizing Vetwork in k. Dimensions. In: Aleksander, I.: TAYLor, J.. ceds. Artificial Neural Netuorks. Amsterdam, Netherlands: North-Holland, 1992, p. 105! 1056. 
Disponível em http://citeseer.nj.nec.com/fritzke93growing.html (Acessado cm $08 / 01 / 20(0)-1)$

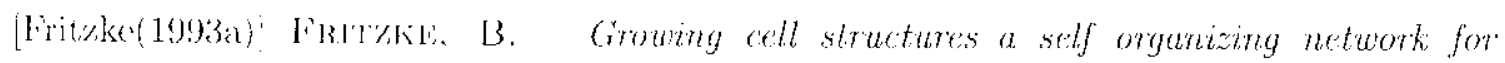
unsupervised and supertised truming. Relatório Técnico TR-93-126, ICSI Berkeley, 1993a.

[Fritzke(1993b)] FuIT\%ke, B. Kohonen feature majs and growing cell structures a performanec comparison. In: Neural Informalion Processing Systems, Morgan Kanfmann. San Matco, (A. 1993b. p. 123130.

(Frityke(1994a). Fri'zkis, B. Fast leaming with incremental rbf networks. Neural Processing latters. v. 1. 1. 1. .. 2 5. 1994a.

Fritzke(1994h)] Fral'rkik, B. Crowing cell structures - a solf-organizing networks for unsupervised and supervised learning. Neural Networks, v. 7. 11. 9, p. 1441 1460, 19941).

[Fritzke(1995a)] FriT\%kF. B. Growing grid: A solf organizing network with constint neighborhood range and adaptation strength. Neural Processing Letters, v. 2, n. 5 , p. $913.1995 \mathrm{a}$.

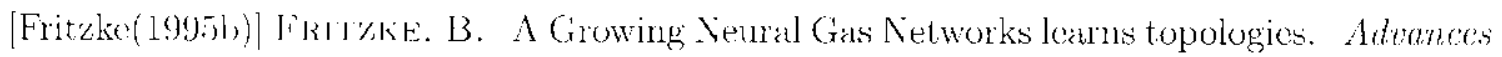
in Noural Information. Processing Systems, v. 7, p. 625 632, 19951).

Fritzke(1997)] Furm\%ki, B. Some competitive learning methods. Newal Neluorks, institute of Noural Computution, 1997.

Disponível en http://citeseer.nj.nec.com/413852.html (Acessado em 08/01/2001)

[Fukmaga(1990)] FukUNAGA. K. Introduction to Statistical Pattern Recognition. Acasemice Presis. Znd brition, 1990.

[Gadede Giinther(1998)] Gande, V.; Güv'ther, O. Multidimensional Access Methods. ACM Computing Surtigs, v. 30, 11. 2. p. $170231,1998$.

[Coldberg(1989): Golubeik, D. E. Genctic algonthms in search, optimizalion and machine leaming. Addison-Wosley Pub Co., 1989.

Grolub e Loan(1989): Golub. G. II.; LoAn, C. F. V. Matrix computations. second rd. Baltimore: 'The Johns Hopkins Lniversity Press, 1989.

[Gracpel ot al.(1998)] Grafiel, T.; Blrger, M.; Obermayer, K. Self-organizing maps: generalizations and now optimization techniques. Neurocomputing: v. 21, p. 173190 , 1998.

Disponível em http://citeseer.nj.nec.com/166762.html (Accssado em 08/01/2004) 
[Gray e Moore(2000)] Gray, A. G.; Moore. A. W. 'N-Body' problems in statistical learning. Aduances in Nenral Information Processing Systems, v. 13. p. 521 -527, 2000.

[Grimmer(1996)] Grimmer, U. Clementine: Data mining soltware. In: Classification and Multivariate Graphics: Models, Software and Applications, wIAS-Ropori No. 10, 1996.

[Grossberg(1972)] Grossberg, S. Neural expectation: Cerebellar and retinal anlalogs of cells fired by learnable or unlearned pattern (lasses. Kybermetiz: v. 10, 1). $1957,1972$.

[Grossberg(1976a)] GrossBerg, S. Adaptive pattern classilication and universal recoding: I: Parallel development and coding of neural feature detcetors. Biological Cybernetics. v. 23, p. 121-134, 1976a.

[Crossberg(1976b)] Grossbera, S. Adaptive pattcru chassilication and miversal recoding: II: Feedback, expectation, olfaction, illusions. Bological Gybentics, v. 23, p. 187-202. $1976 \mathrm{~b}$.

[Grossberg(1988)] Grossbera. S. Neural networks and natural intelligence. Cambridge, MA.: MIT Press, 1988.

[Guttman(1984)] Guttuan, $\Lambda$. R-Trees: A Dynamic Index Structure for Spatial Searching. In: ACM SIGMOD Conference. Boston. 1984, p. 4757.

'Haykin(1994)] Haykin, S. Neural networks-a comprehensive foundation. Macmillon And IEEE' P'Tess, 1994.

[Haykin(1999)] IIAYKIN, S. Nenral netuorks: a comprehensioe foundation. Prentice Ilall, 1999.

[IIebb(1949)] HebB, D. O. The organization of behavior. New York, .YY: Joln Wiley \& Sons. 1949.

[Hellerstein et al.(1995)] Hellerstein, J. M.; Nalghton, J. F.: Pffaffer, A.

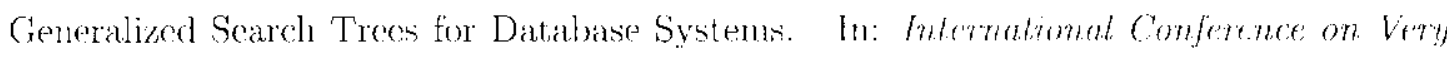
Large Databases, Morgan Kanfmann, editors Umeshwar Dayal and Peter M. D. Gray and Shojiro Nishio, isbn 1-55860-379-4, 1995, p. $562 \quad 573$

[Hämälainen(2002)] Ḧ̈MÄLAINEN, T. D. Self-organizing neural netuorks: Recent advances and applications of studies in fuzziness and sofl compuliny, v. 78, cáp. Parallel Implementations of Self-Organizing Maps Physica-Verlag Heiclelberg, p. $245278,2002$.

Hodge o Austin(2001a)] Hodge. V.: Austax. J. Hicrarchical growing cell structures: Treegcs. Knowledge and Data Engineering. IEEE Transactions on. v. 13. 11. 2. p. 207-218, 2001 a. 
[Hodge e Austin(2001b)! Hodge, V. J.; Atseris. J. An integrated neural ir system. ESANNOUn moredings - Luropean. Symposium on Artificial Neural Nelworks, p. $265270,052001-301,2001 \mathrm{~b}$.

[Holge Austin(2002)] Honge, V. J.; Avstis, J. Hierarchical word clustering-antonatie thesaurus generation. Neurocomputing, v. 48, 11, 1-4, p. 819-846, 2002.

[Hotc(1933)] Hote, H. Analysis of a Complex of Statistical Variables into Principal Componentis. Eiducational l'sychology. v. 24, p. 417‘441, 498-520, 1933.

[Hubel e Wicscl(1962)] IIUBLe, D; WIESEL, T. Receptive fields, binocular interaction

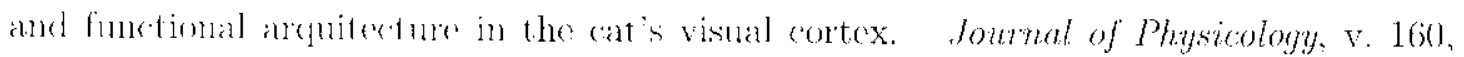
p. 104154, kondion, 1962.

¿Iubel o Wicsel(1977)| IInBEE, D.: WifsEL. T. Functional arquitecture of macaque visual cortex. In: Royul Soctety. London, 1977, p, 159.

[Huntsberger o Ajjimaranghed (1990)] Huntsberger, T. L.; A.tumarangsee, P. Parallel self-organizing [cutnure majes for unsupervised pattern recognition. Int. J. General Systems. v. 16, 11. 1, p. 357 372, 1990 .

[Jain(1999)j JaIN. A. Data Clustering: A Review. ACM Computing Surneys, v. 31, 11. 3. p. 264323,1994 .

[J.W.Sammon(1969)] .T.W.SAMMON A nonlinear mapping for data structure analysis. IFFE Transactions on Computers. v. C-18, n. 5, p. 401409, 1969.

[Kalantari e McDonald(1983)] KaLANTARI, I.; MCDOnal.1, G. A data structure and an algorithm for the nearest point problem. IEEE Transachions on Software Enginecring, v. 9. 11. 5. 1983.

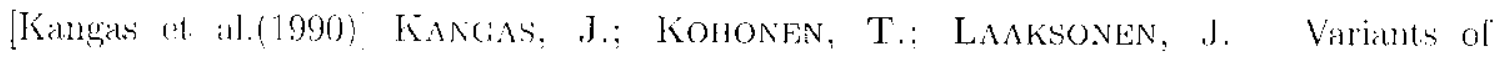
self-organizing mats. IEFE Transactions on Neural Networks. v. 1. n. 1, p. 93 99, 1990.

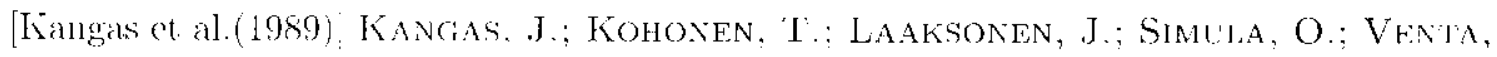
O. Variants of solf-organizing maps. In: International Joint COnference on Neural Neturorks, 1989. p. 517522.

Kanth et al.(1999)] Kav'll, K. V. R.: Ravada, S.; Silarma, J.; Banerjeg, J. Indexing modiun dimonioniality data in Oracle. In: ACM SICMOD International Conference on Manugement of Dala, Philadelphia, 1999, p. 521.522.

Lhaski(1999) Kaski. S. Fast Winner Search for SOM-based Monitoring and Retrieval of High-dineensional 1)ata. In: International Conference on Artificial Noural Networts. 
London: IEEE Conference P'ublication, 1999, p. 940-945.

Disponivel em http://citeseer.nj.nec.com/kaskig9fast.html (Accssado em $08 / 01 / 2004)$

[Kaski(20(1)] KASK1, S. Learning metrics for exploratory dattal analysis. In: Signal Processing Society Workshop, 2001, p. 5362.

[Kaski(2003)] KASKI. S. Exploration of Gene Expression. 1n: Procethings WSOM03. Workshop on Self Organizing-Mops. IHibikino-Kitakyushu. Japan, plenary Talk, 2003.

[Kaski et al.(1998)] Kaski, S.; Kancas, J.; Kohonev. T. Bibliography of Self-Organizing Map (SOM) Papers: 1981-1997. Ncural Computing S'urveys: v. 1. p. 102350,1998 .

[Kaski e Sinkkonen(2001)] KASKI, S.; SinkKonen, J. A topography-preserving latent. variable model with learning metrics. In: Workshop on Self-Organizing Maps, 2001, p. 224229.

[Kaski et al.(2001)] Kaski, S.; Sinkkones, J.; Peltonen, J. Learning metrics for self-organizing maps. In: International Joint Conference on Neural Netuorke, Washington DC: IEEE Press, 2001, p. 914-919.

[Katayama e Saloh(1997)] Katayama, N.; Saton, S. 'I'he SR-tre: An Index Structure for High-Dimensional Nearest Neighbor Queries. In: ACM SICMOD International Conference on Management of Data. Tucson, 1997, p. $369: 380$.

Disponível cm http://citeseer.nj.nec.com/katayama97srtree.html (Acessado em $08 / 01 / 20(1) 4)$

[Klinger(1971)] Kuinger, A. Pattern and search statistics. In: Restagı, S., cd. Oplimizing Methods in Statistics, 1971, p. 3033337.

[König e Michel(2003)] KönıG, A.; MıChel, T. DIPOL,SOM: A Distance Preserving Enhancement of the Solf-Organizing Maj) for Dinnensionality Reduction and Multivariate Data Visualization. In: Workshop on Self Orqanizing-Mops. Hibikino-Kitakyushu, Japan, 200:3, p. 219-214.

[Kmuth(1973)] KNUTH, D. E. The art of computer programming. vol. 1-3. Addison-Wesley, Reading, MA, 1973.

[Kohonen(1982)] KonONEN, '1'. Self-organized formation of topologically correct feature maps. Biological Cybernetics, v. 43, p. $59696,1982$.

[Kohonen(1984)] KoHonen, T. Self-organization and associative momory. Springer Serics of Information Science, v. 8, 1984. 
[Kohonen(1990)] KOHONEv, T. The self-organizing map. In: Institute of Electrical and Electronice lingineas, 1990). p. 1.4641480 .

Kohonen(1993a)! Konontev. T. Generalizations of the self-organizing map. In: International Joint Conference on Neural Networks. Nagoya, Japan, 1993a.

[Kohonen(1993h)] Kononin. T. Physiological interpretation of the self-organizing map) algorithm. Neural Neluorks, v. 6, p. 895-905, $1993 \mathrm{~b}$.

[Kohonen(1997a)] Kononfs. T. Exploration of very large databases by self-organizing nlaps. In: Intcmational Conference on Neural Networks. Houston: IEEE Scrvice Center, 1997a. p. PL1 PLG.

[Kolonen(1997b)] Kononien, T. Self-organization maps. Springer-Verlag: Berlin, 1997h.

[Kohomen(1998)] Kollonkx. T. Self-organization of very large document collections: State

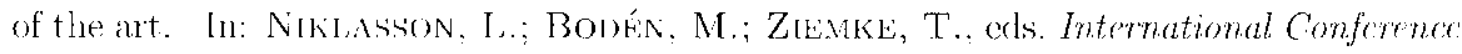
on Artificial Nrural Nelworks, London: Springer, 1998, p. 65-74.

Kohonen ot al.(1996) Komonm, 'I'; KAski, S.: Isagus, K.; HonkFi, T. Very large two-level SON for the browsing of newsgroups. In: vON DER Malsbura, C.;

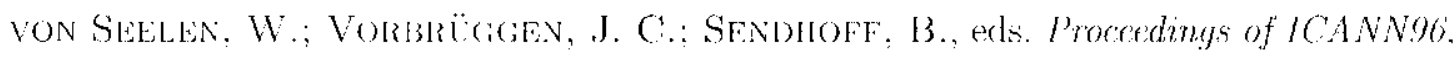
International Conforence on Artificial Noural Netuorks, Bochum, Germany: Springer. p. $269-271,1996$.

Disponivel (m http://citeseer.nj.nec.com/kohonen96very.html (Accssiado en $08 / 01 / 2004)$

[Kohonen e Somervio(1997)] KoHonfan, T.; Somervuo, P. Self-organizing maps of symbol strings with application to speech recognition. In: Workshop on Self-Organizing Maps. E'spos, Hinlank: Helsinki University of Technology. Neural Networks Researeh Centre, 1997. p. 27.

[Koikkalainen o Oja(1990)] KonkkALAINis, P.; O.A, F. Self-organizing hierarchical feature maps. In: International Joint COnference on Neural Networks, San Diego, CA. 1990, p. 279284.

Kolimumi et al.(2000) Kolinlami, P.: Plikkinen, P.; Iamalainen, 'T ; SaArinev, J. Parallel implementation of sell-organizing map on the partial tree shape neurocomputer. Noural Procsising Letters. v. 12, n. 2. p. 171 182, 2000.

Koskela(1999)] Kosken. M. Conlent-Based Image Retricual with Self-Organizing Maps. Dissertação do Mestrado. Helsinki University Of Technology Department of Enginecring 
Physics and Mathematics, Helsinki, Finland. 1999.

Disponível em http://citeseer.nj, nec.com/369758.html (Archiado em 08/01/2004)

[Laaksonen et al.(1999); LAaksonen, J.: Koskela, M.; OJA, L. Application of tree structured self-organizing maps in content-based image retrieval. In: Intemational Conforence on Artificial Neural Networks, 1999. p. 174179.

[Lampinen(1992); IAAMPINEN, .J. On clustering propertic's of hierarehical sclf-organizing majs. In: At.fosander., I.; Taylor, J., eds. Artificial Neural Notworks, 2. Anstcrdam. Netherlands: North-Holland, 1992, p. 12191222.

Disponível em http://citeseer.nj.nec.com/lampinen92clustering.html (Accssado cm $08 / 01 / 2004$ )

Lampinen e Oja(1992), LAMPlNen, J.; OJA, E. Clustering propertirs of hierarchical self-organizing maps. Journal of Mathematical Imaging and Vision. v. 2, 11. 2-3. p. 261272,1992 .

[Land e Hilton(1988)] LAND, K.; HiLton, G. The development of the time-delay neural network architecture for spech recognition. Relatório Téenico CXL-CS-88-152. Carnegie Mellon University: Pittsburgh, PA, 1988.

[Lovenshtein(1966)] Levenshteis; V. Binary codes caluable of correcting deletions: insertions, and reversals. Cybernetics and Control theory. v. 10, n. 8, p. 707 710, 1966.

Lim et al.(20)(1); Lim, J.-H.; Wu, J. K.; Singh, S.: Narasimhate, D. Leaming Similarity Matching in Multimedia Content-Based Retrieval.

IEEE Transuctions on Knomledge and Data Engineering, v. 13, n. 5, p. $846850,2001$.

[in et al.(1994)] Lin, K.; JAGnDISH, H.; FALoutsos, C. The TV-tree - An Index Structure for High-Dimensional Data. Very Large Data Basrs foumal, v. 3, n. 4 , p. 517 542, santiago de Chile, 1994.

[Lo et al.(1991)] Io, 7.; Fujlis, M.; Bavarine; B. Analysis of neighborherel interaction in Kohonen Neural networks. In: International Parallel Processing Symposium. Gth, Los Alanitos: CA, 1991, p. 247249.

[MacQueen(1967)] MACQUEEN, J. Some methods for classification and analysis of multivariate observations. Proceedings - 5th Berkcley Symposimm, v. 1, p. $281297,1967$.

[Martinetz(1993)] MarTinftz, T. Competitive hebbian learning rule forms porfectly preserving naps. In: Intemational Conference on Artificial Nearat Nemenks. Amsterdan: Springer: 1993, p. 427434. 
[Martinetz e Schulten(1994)] MAR'TINE"T'z, T.: SchuLtes, K. J. Topology representing nctworks. In: Nratal Networks. 7. Ansterdam: Springer, 1994, p. 507522.

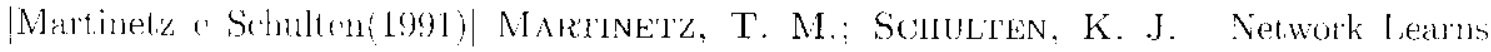
Topologics. In: T. KoHONEN. K. MAkisniza, O. S.; Kangas, .l, eds. Artificial Neural Network:s, North-Holland. Amsterdam. 1991, p. 397402.

[Merkl(1997)] MekkL, D. Exploration of Text Collections with Hierarchical Feature Maps. In: Restarch and Detelopment in Information Retrieval. 1997, p. 186195.

Disponivel "'ll http://citeseer.nj.nec.com/article/merkl97exploration.html (Acosado em 08/01/200-4)

[Merkl et al.(2003)] Wkikl. D.; He. S. H.: Dittendsach, M.; ; Rauber, A. Adaptive Hierachical Incremental Grid Growing: An architecture for high-dimensional data visualization. In: Procedings WSOM03, Workshop on Self Organizing-Maps, Hibikino-Kitakynshu, Japran. 2003. p. $293 \cdot 298$.

Micó at al.(1996)? Micó. L.; Oncina, J.; Carrasco, R. A falst branch and hound nearest neighbors classifier in metric spaces. Puttern Recognition Letters. v. 17 , p. 731739.19966.

[Micó el al.(1994) Micó. L.: Oncina, J.; Vidal, E. A new version of the nearest. neightors anproxintating and climinating scarch (acsa) with linear pre-processing and memory recuirement.s. Pallern Recognition Letlens, v. 15, p. 9-17, 1994.

[Moody o Darken(1989)]. Moody, J.; Darken, C. Fast leaming in networks of locally tunced processing units. Neural Computation, v. 1, n. 2, p. $281294,1989$.

[Morton(1960)] MorTon, G. A computer oriented geodetic data base and a new technique in file seyucneing. IB.Y Ltd, 1966 .

[Navaro(1999)] Navarko, G. Searching in metric spaces by spatial approximation. In: South Americun Sympostum on String Processing and Information Retricual. IEEE CS Press, 1999. p. 111148.

[Navarro(2002)] NAvaRRo, G. Searching in metric spaces by spatial approximation. The Very Large Databases Journal (VLDBJ), v. 11, n. 1, p. $2846,2002$.

Disponivel ('ll http://www.dcc.uchile.cl/ gnavarro/ps/vldbj02.ps.gz (Acessado cm $08 / 01 / 2004)$

[Navarro o Royes(20)(2)] Navarno, G.; Reyes, N. Fully Dynamic Spatial Approximation Trees. In: South Amcrican Symposium on String Processing and Information Retrienal. L.VCS 2476, Springer: 2002. p. 254270 (LNCS 2476.). 
Disponível em http://www.dcc.uchile.cl/ gnavarro/ps/spire02.4.ps.gz (Acessado $\mathrm{em} 08 /(01 / 2004)$

[Nene e Nayar(1997)] NFnF, S.; NAYAR, S. A simple algorithn for nearest neighbors search in high dimensions. IEEE Trans. on Pattern Analysis and Machine Intelligence. v. 19, n. 9 , p. $9891003,1997$.

[Noltcimer(1989)] Nolifimfr, II. Voronoi trees and applications. In: International Workshop on Discrele Algorithms and Complexity, Futuoka Recent. Hotcl, liukuoka, Japan, 1989, p. 69-74.

[Nolteimer et al.(1992)] Nolteimer, H.: Verbarg, K.; Zirkelbach, C. Monotonous Bisector* Trees - a tool for efficient partiotioning of complex schemes of gcometric object. In: Dato Structures and Efficient Algorithms, LNCS 594, Springer-Verlag, 1992, p. 186. 203.

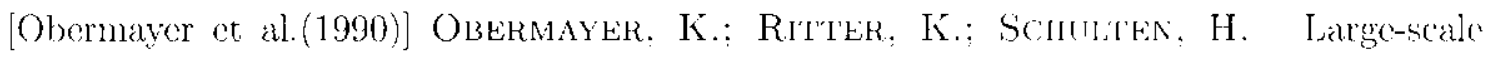
simulation of a self-organizing neural network: Formation of a somatotopic map. In: Eckmllek, R., II.; IIAuske, G., eds. Parallel Processing in Nomal S'yslems and Computers, Urbana, Illinois: Elsevier Science Publisher B.V. (North Holland), 1990, p. $71 \cdots 74$.

[Ohta e Saito(2001)] OnTA, R.; SAITo, T. A growing self-organizing algorithm for dynanice clustering. In: International Joint COnference on Neural Nefuom was, Waington DC: IELE Press, 2001, p. 469-473.

[Oja(2003)] OJA, E. Data and Image Vining with SOM. In: Procedings WSOMOrs. Workishop on Self Organizing-Maps, Hibikino-Kitakyushu, Japan, plenary Talk, 2003.

[Oja et al.(2003)] O.J, M.; KAski, S.; KOHOnen, T. Bibliography of Self-Organizing, Map (som) Papers: 1998-2001 addendum. Noural Computing Surveys, v. 3. p. 1156. 2003.

[Papadias et al.(1999)] Papadias, D.; Mamovlis, N.: 'Tmaomoridis, Y. Processing and optimization of multiway spatial joins using R-trecs. In: ACM SIGACT-SIGMOD-SIGART Symposinm on Principles of Dalabase Systcms (PODS): 1999, p. 4455.

Disponivel em http://ww.cs.ust.hk/faculty/dimitris/PAPERS/pods99.pdf (Acessado em $(08 / 01 / 2004)$

Parch et al.(1996)] PAREkH, R.; YANG. J.; Honavar. V. MTiling - a comstructive neural network learning algorithm for multi-category pattern classification. In: World Congress on Neural Netuork'96, San Diego, 1996, p. 182187. 
[Parekh et al.(1997)! PAREkH. R.; Yang, J.; Honavar, V. Constructive neural networks l'arning angerithms for multi-category real-values pattern classification. 1997.

Disponivel em http://www.cs.iastate.edu/ honavar/aigroup.html (Acessado cm $08 /(11 / 2004)$

[Parckh et al.(1995)] PAREkH, R. G.; YANG, J.; HonAVAR, V. Constructive neural network lcaming algorithms for multi-category pattern classification. Relatório Técnico, Iowa State Universily. Departunent of Computer Science, Ames, Iowa, 1995.

[Patella(1999)] PATHL, W. Similarity search in multimedia databases. Tese de Doutoramento. Dipartimenio di Eilet.ronica Informatica o Sistemistica, Lniversità degli Studi di Bologna, Bulogna. Italy; 1999.

[Pearson(1901)| Penkson, K. On lines and planes of closest fit systems of points in space. Philosophthed Magasme. v. 2, 1). $559572,1901$.

[Peltonen et al.(2003)] P'entonfon, K.; Kuami, A.; Kaski, S. Leaming Metrics for Information Visurliynlion. In: Wortshop on Self Organizing-Maps, Hibikino-Kitakyushu, Japan, 2003. p. 213--218.

[Press et al.(1988) Press. W. H.; Flannelry, B. P.: Teukolsky, S. A.; Vetterling. W. T. Numeral extes in : Cannbridge Lniversity Press, 1988.

[Rauber e Merkl(1999)| RAuBER. A.; MerkL, D. Using self-organizing maps to organize docunents collextions and to characterize subject matters: How to make a map tell the news of the workt. In: T. BENCH-CAPON, G. S.; TJOA, A., eds. Proceedings of the 10th Intemalional Confenence on Dalabase and Expert Systems Applications (DEXA99), Florenee, Italy: Springer: 1.VCS 1677 in Lecture Notes in Computcr Science, 1999, p. 302311.

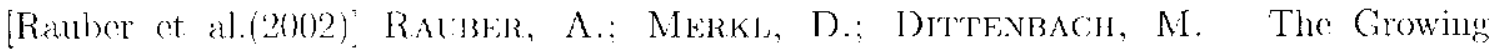
Hierarchical Sclf-(Organizing Map: Exploratory Analysis of High-Dimensional Data. IEEE Transactions on Neturl Neluorks, v. 13, 11. 6, p. 1331 1341, 2002.

[Rawtani et al.(2001). RAWTANI, L.; RANA, J.; Tiwari, A. Number of hidden nodes for shane preserving ann representation of a curve. In: International Joint COnferene on Neural Netuorks. Washington DC: IEEE Press, 2001, p. 138143.

[Recd(1993)] ReEL, 13. P'runing algorithmsa survey: IEEE Transactions on Neural Networks: v. 4, n. 5. p. 740 747. 1993.

[Riedmiller(1994)] RIEDNILLER, M. RPROP - description and implemenlalion details. Relatório 'Téenico W-76128 Kanlsruhe. Institut für Logik, University of Karlsruhe, 1994. 
[Ritter(1995)] RitTer, H. Self-organizing feature maps: Kohonen maps. In: ARBIR, M., ed. The Handbook of Brain Theory and Neural Networks, Cambriclge. MA: MIT Press, p. $846851,1995$.

[Ritter c Kohonen(1990)] RitTer. H.; Kohonex. T. Leaning 'semantotopic maps' from context. In: International Joint COnference on Neural Netuorks. IIillsdale. N.J: Lawrence Erlbaum, 1990; p. 2326.

[Ritter et al.(1992)] Rit'ter, II.; Martinetz, T. M.; SChulten, K. Nemral computation. and self-organizing maps: An introduction. Reading, MA. Addison-Wesley, 1992.

[Ritter e Schulten(1988) RITTER, H.; SCHULTEN, K. Convergence properties of Kohonen's topology conserving maps: Fluctuations, stability, and dimension selection. In: Biological Cybernetics, 1988 , p. 5971.

[Robinson(1981) Robinson, J. The K-D)-B3 Tree: a search structure for large multidimensional dynamic indexes. In: ACM SIGMOD) International Conferme on the Management of Data, Ann Arbor: Lawrence Erlbaum, 1981, p. 1018.

[Roussopoulus at al.(1995)] Roussopoulus, N.; KELlety, S.: Vincener, F. Nearest neightbor queries. Proceedings of the ACM-SIGMOD Intermational Conference On Management of Data, p. 71 79, sall Jose, 1995.

[Rumellart et al.(1986)] Rumelhak', D. E.: Hinton, G. F.; Wil.mams. R. J. Learning internal representations by crror propagation. In: Runel.HART. I). F.: M(CD.EILANI), J. L., eds. Parallel Distributed Processing: Explorations in the Microstructure of Cognition. Vol. I: Foundalions, Bradford Books/MI'T Press, Cambriclge, MA., 1986, p. $318-362$.

[Samet(1995)] SAMET, H. Spatial data structures. Modern Datahase Syatems, Kim W cd. Rcading: Addison-Wesley/ACM, 1995.

Samuel(1959)] SAMuLL, A. L. Some studies in machine learning nsing the game of checkers. IBM J. Res. Devel, v. 3, p. 210-229, 1959.

Samuel(1967)] SAMué, A. L. Some studies in maxhine lemang using the game of checkers: recent progress. IBM J. Res. Devel. v. 11, p. $601617,1967$.

[Sankoff e Kruskal(1983)] SANKOFF, D.; KneSKAL, J. Time mamps, string edits, and macromolecules: the theory and practice of sequence comparison. Addison-Wesley, 1983.

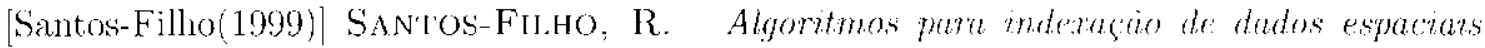
pontuais em gerenciadores de objetos. Dissertação de Mestrado. (SP' - Iniversidade de 
Sáo Paulo (IFSC: - Instituto de Fisica de São Carlos). São Carlos: tese de Mestrado -

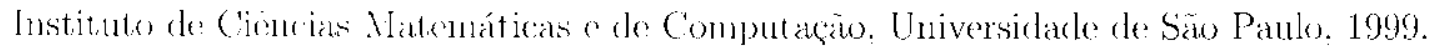

[Samtess-Fillo(20)(3)] Saveos-Filho. R. F. Métodos de Acesso Métricos para suporte a consullas por similatidude: Apresentasáo da técnica OMNI. Tese de Boutomento, ICMC- University of Sao Paulo. São Carlos-SP, Brasil, 2003.

Santos-Filho el al.(2001)] Santos-Filho, R. F.; Traina, A.; Traina Jr., C.; Fadol:Tsos, C. Sinilarity search without tears: The omni family of all-purpose aresse methods. Procerdings of the 17th International Conference on Data Enginerging. p. 623 630. heideltherg. Gormany, 2001.

[Schaefer et al(1992)] ScinefFer Fet AI. J. A World Championship caliber checters program. Artificial lintelligence, v. 53, n. 2-3, p. 273-290, 1992.

[Schroeder(1991), SCHRoEder. M. Fractals, chaos, power laws: Minutes from an infinite paradise. New York: W. II. Frecman, 1991.

[Sejnowski o Rosentherg(1987) SEJnowsk, T.; RosenberG, C. Parallel networks that learns to pronomuere English tex1. Complex Systems, v. 1, p. $145168,1987$.

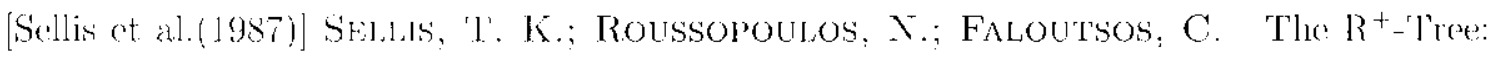
A Dynamic Index for Multi-Dimensional Objects. In: International Conference on Very Large Databases. Brighton. England, 1987. p. 507.518.

Disponível (m1 http://citeseer.nj.nec.com/sellis87tree.html (Acessardo cm $(08 / 01 / 200) 4)$

[Shapiro(1977)] SнAгIRO. M. The choice of reference points in best match file searching. Commanicalions of ACM. v. 20, n. 5, p. 339343.1977.

[Shasha e Wang(1990i] SHAshA, D.: WANG. T. New techniques for best-match retrieval. ACM Thansations on Information Systems, v. 8, n. 2, p. 140 158, 1990.

[Shiffmann et. al.(1994)] Shaffmann, W.; Joost, M.; Werner, R. Optimization of the Buckpropugation Algorthm for Training Multilayer Perecplons. Relatório 'Técnico, Institute of Physics, Luiversity of Koblenz, 1994.

Shim(2001)] SuIn, J.-Y. Solective information retrieval from lierarchical associative knowledge learning menory. In: International Joint COnference on Neural Networks, Washington DC: IEEE Press. 2001, p. 18971901.

[Sleator e Tarjan(198j)] SLEATOR. D.; TARjan, R. Self-adjusting binary search trees. Joumal of the ACM. v. 32, 11, 3, p. 652 686, 1985. 
[Somervuo(20033)] Somerveo, P. Self-Organizing Map of Symbol String with Smooth Symbol Averaging. In: Workshop on Self Organizing-Maps, Hihikino-Kitakyushu, Japan, 2003, p. 122--127.

[Strang(1980)] StRang, G. Linear algebra and its applications. Academic Press, 2nd edition, 1980 .

[Su e Basu(2001)] Su, M.; Basu, M. Inpul data clustoring to improve neural network performance. In: International Joint COnference on Netral Networks. Washington DC: IEEE Press, 2001, p. 160-165.

[Suga(1985)] SugA, N. The extent to which bisonar information is represented in the bat auditory cortex. In: Eidemann, G.: Gald, W.: Cowan, W.u ords. Dynamic Aspects of Neocortical Function, New York: Wiley Interscience: 1). 653 695. 1985.

[Suganthan(1999)] Slganthan, P. Hicrarchical overlapped SOM's for pattern classification. IEEE Transactions on Neural Networks. v. 10. Il. 1, p. 193 196. 1999.

[Sun et al.(2001)] Sun, H.; Wang, S.; JiANG, Q. A now valiclation inclex for detemining the number of clusters in a data set. In: International Jomit COnfertence on Neural Networks, Washington DC: IEEE Press, 2001, p. 18521857.

[Tino e Nabney(2002)] Tino, P.; NABNex, I. Ificrarchical GTM: constructing localized nonlinear projection manifolds in a principled way. Pottern Anolysis and Machine Intelligence. IEEE Transactions on, v. 24, n. 5. p. 639 656. 20002.

[Torgerson(1952)] I'ORGERson; W. S. Multidimensional sealing: I. theory and method. Psychometrika, v. 17. p. $401419,1952$.

[Traina Jr e Faloutsos(2000)] Traina JR, C; Faloutsos; C. Indexaçào e mineração de dados multimídia. 2000.

Disponivel em http://gbdi.icmc.usp.br/imimd/ (Acessado em 08/01/2004)

[Traina Jr et al.(2000a)] Traina JR, C.; Traina, A.; Faloutsos. C. Distance Exponent: A New Concept for Selectivity Estimation in Metric Tress. Ins: Intcmational Conference on Data Engineering (ICDE), San Diego. CA, 2000a, p. 195.

[Traina Jr et al.(2002)i Traina Jr, C.; Traina, A. J. M.; Filho, R. F. S.; Faloutsos, C. How to Innprove the Pruning Ability of Dynamic: Netric Access Methods. In: ACM Inlernational Conference on Information and Knowledge Management, 11h, 2002. p. 219226 . 


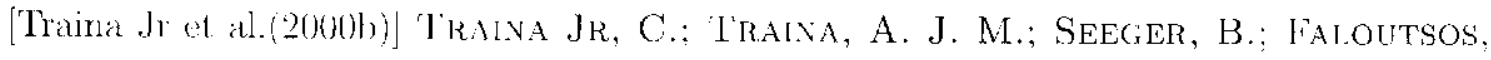
C. Slim-T'recs: High P'erformance Metric Trees Mininizing Overlap betwern Nodes. In: Adraneses in Dalabuse Technology - EDBT 20000. Gith Intermational Conferenes on Extending Database Technology. Konstanz, Germany: Springer, 20000b, p. 5165 (Lecture

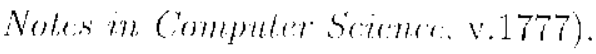

[Uhlmam(199lai)] UnImaNiv, J. Implementing metric trees to satisfy general/proximity queries. Mammincript. 1991\%.

[Uhhmam(1991b)] Umanavs. J. Satisfying General l’roximity/Similarity Queries witle Metric 'J'reess. Infonmation Processing Letter. v. 10. p. 175 179, 1991 b.

[Ultsch(1993a)] UI.TSCH, A. Knowledge Extraction from Self-Organizing Nenral Networks. In: ET AL.. O. O., ed. Information and Classification, Springer, Berlin, 1993a, p. 301306.

[Ultsch(1993b)! Ustsch. A. Sclf-Organizing Neural Networks for Visualization and Classification. In: F: AL., O. O., ed. Information and Classification, Springer, Berlin, 1993b, p. 307313.

[Ultsch(2003)| Ulwse!H, A. Maps for the Vismalizattion of high-dimensional Data Spaces. In: Work:shop on Self Oryanizing-Maps. Hibikino-Kitakyushn, Japlan, 2003, p. 225230.

[Vorbarg(1995)] VERBARG, K. The C-Tree a dinamically balanced index. Commuting Suppl., v. 10. p. 323 340. 1995.

[Vicentini(2002)] VICEN'INI, J. F. Indexação e Recuperaçăo de Informaçăo utilizando Redes Nenrais da Fimalia ART. Dissertaçăo de Mestrado, ICMC- Cniversity of Siw Panlo, Säo Carlos-sl', Brasil, 2002.

[Vicentini a Romem(2003): Vicentene, J. F.; Romero, R. A. F. Utilização de Resdes Veurais da Funnília ART para Indexação e Recuperaçăo de Informações. In: TorRs, G. L.; Abl. J. M.; Mucheroni, M. L.: Cruvinel, P. E. ods. Congress of Logic

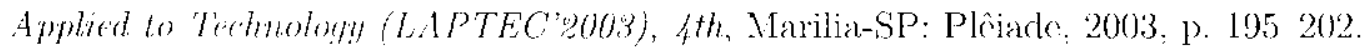

[Vidal(1986)] Vmal. di. An algorit.lm for linding nearest neighbors in (approximatrely) constant average timu. Prathenn Recognition Lelters. v. 4, p. 145-157, 1986.

[Villmimu at al.(1997)] Vildmann, T.; Der, R.; Hermane, M.: Martinétz, M. Topology preservation in sell-organizing feature maps: Exact definition and measurement. IFEW Thansactions on Nowal Networks, v. 8, 1. 1. p. 256 266, 1997.

|Voronoi(1907)| Volonol. G. F. Nonvelles applications des paramètres continus à la theorie do formes (puadratiques. I. Reine Angew, Math, v. 1, n. 133, 1). $97178,1907$. 
[Wactlar et al.(1999)] Wactlar, H. D.; Christel, M. G.; Gonci, Y.; Hauptimann, A. G. Lessons learned from building a terabyte digital video library. IEEE Computer: v. 32, n. 2, p. 6673,1999 .

[Wactlar et al.(1996)] Wactuar, H. D.; Kannde, T.; Smlth, M. A.; Stevens, S. M. Intelligent access to digital video: Informedia project. IELE Computer, v. 29, n. 5, p. $46.52,1996$.

[Waibel et al.(1989)] Waibel, A.; Hanazawa, T.; Hin'orn, G.; Shlkano, K.; Lang, K. Phoneme recognition using time-delay neural networks. IEEE Transactions on Acoustics, Speech and Signal Processing, v. ASSP-37, p. 328 339, 1989.

[Webster(1980)] WebsTek, R. B+ trees. Dissertação de Mestrado, Oklahoma State Lniversity, 1980.

[Willshaw e von der Malsburg(1976)] Willshaw, D.; von dek Malsiung, C. How pattern neural comections can be set up by self-organization. In: Royal Society of London, 1976, p. 431445 (B, v.194).

[Wilson e Martinez(2001)] Wilson, D. R.; Martinez, 'T'. R. 'l'he need for small learning rates on large problerns. Proceedings. IJCNN OI. International Joint Conference on Neural Netuorks, v. 1. 1) 115 119. 2001.

[Yamakawa(2003)] Yamakawa, 'I'. Database of Self-Organizing Maps Papers. 2003. Disponível rm http://www.brain.kyutech.ac.jp/ yamakawa/ (Arcssado cm $14 / \mathrm{sep} / 2003)$

[Yianilos(1993)] Yianilos, P. N. Data Structures and Algoritlmms for Nearest. Neighbor Search in General Motric Spaces. 4th ACM SIAM Symposium on Discrete, Algorithm.s (SODA 93), p. 311 321, austin, 1993.

[Yianilos(1998)] Yianilos, P. N. Exchded Middle Vantage Point Forests for Nearest. Neighbor Search. Relatório Técnico. NEC Research Institute. Princeton. 1998.

[Yianilos(1999)? YianiLos, P. N. Excluded middle vantage point forest for nearest neighbor scarch. In: DIMACS Implementation Challenge (ALENEX 99), Baltimore, MD, 1999)

[Yianilos(2000) Yianilos, P. N. Locally lifting the curse of dimensionality for nearest neighbor search. In: ACM-SIAM Symposium on Discrele. Algorthms (SODA'OO), 11th, 2000, p. 361370 .

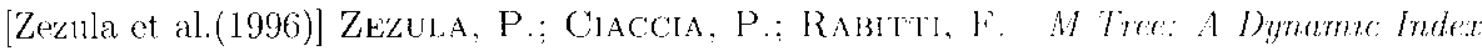
for Similarity Queries in Multimedia Databases. Technical Report 7. HERMES ESPRIT 
LTR Project. 1996.

Disponível ("ln http://www.ced.tuc.gr/hermes/ (Aressido enl 08/01/200:1)

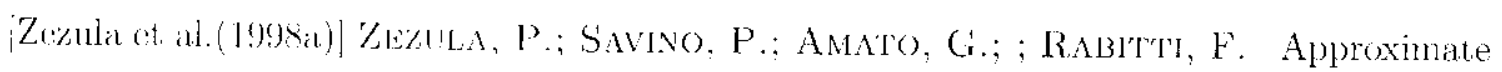
Similarity Retrienal with N-Tress. The VLDB Journal, v. 7, 11. 4, p. 275293.1998 a.

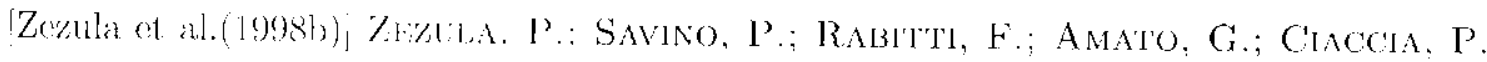
Processing M-Trees with Parallel Resources. In: International Workshop on Rescarch Issues in Data Engincering (RIDE'98), 8th. Orlando, FL, 1998b, p. 147154. 